\title{
HIGH \\ TEMPERATURES \\ MODIFIED PLANT \\ RESPONSES TO \\ ABIOTIC STRESS SITUATIONS
}

DOCTORANDO:

Damián Balfagón Sanmartín 



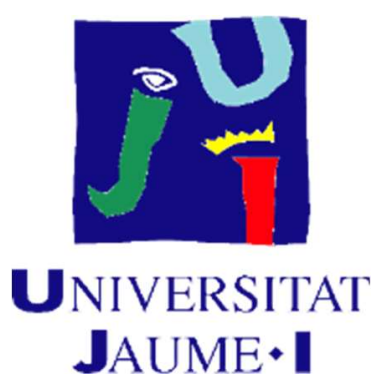

Programa de Doctorado en Ciencias

Escuela de Doctorado de la Universitat Jaume

\section{High temperatures modified plant responses to abiotic stress situations}

\section{Memoria presentada por Damián Balfagón Sanmartín para optar al grado de doctor/a por la Universitat Jaume I}

Damián Balfagón Sanmartín Aurelio Gómez Cadenas Sara Izquierdo Zandalinas
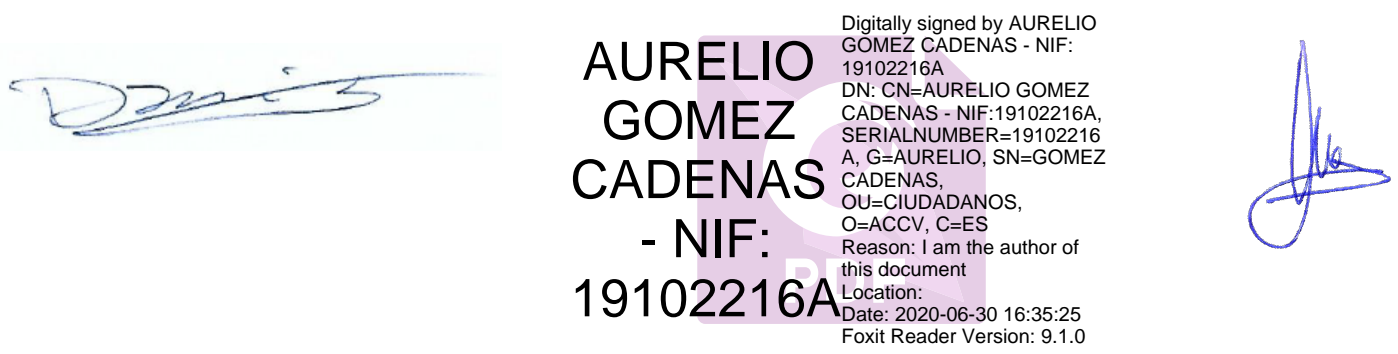



\section{Agradecimientos intitucionales}

Agencias financiadoras del doctorando.

- Generalitat Valenciana, a través de un contrato predoctoral (FDEGENT/2018/001).

- Fundación Balaguer Gonel Hermanos, a través de una ayuda para estancias predoctorales temporales en centros de investigación del extranjero.

Agencias financiadoras del proyecto de investigación o de los recursos materiales específicos del grupo de investigación.

- Ministerio de Ciencia, Innovación y Universidades, a través de la concesión del proyecto AGL2016-76574-R.

- Universitat Jaume I, a través de la concesión del proyecto UJI-B2016-23/UJIB2016-24. 



\section{Agradecimientos}

En primer lugar, quiero agradecer a mis directores de tesis, Aurelio y Sara, por todo lo que me han enseñado, el apoyo que me han dado y el tiempo que me han dedicado. A Aurelio su confianza en mí, por darme la oportunidad de iniciarme como investigador, trabajar con él y formar parte de su grupo. A Sara por su paciencia, su apoyo y haberme ayudado tanto, dentro y fuera del laboratorio.

A todos mis compañeros y amigos del laboratorio: Marta, Tico, Jorge y Ginés que tantos buenos ratos hemos compartido durante estos años y tanto me han enseñado. También, los más recientes; María, Lledó y Zara que me ayudan y alegran el laboratorio cada día. A Rosa, Vicent, Carlos, Miguel y José Luis que con su experiencia y su amabilidad siempre están dispuestos a ayudar y enseñarme.

También quisiera agradecer a tantas personas que han visitado el laboratorio o con los que he compartido buenos momentos en la universidad (y fuera) durante estos años: Alejandro, Tadeu, Clara, Raquel, Sara, Jalel... y tantos otros. Al profesor Ron Mittler por invitarme a su laboratorio y darme la oportunidad de trabajar en su grupo; a Roberto, Yosef, Amith y Maciej por su hospitalidad, por hacerme sentir como en casa y compartir buenos momentos. Gracias a Ramón por el diseño y su buen humor.

Finalmente, a mi familia que siempre me ha apoyado y ha estado conmigo, en especial a mis padres, a David, Caye y Raúl.

Para terminar, a Sara, gracias por estar mi lado durante todo este tiempo, por la ayuda, el apoyo y creer tanto en mí.

A todos vosotros, Gracias. 



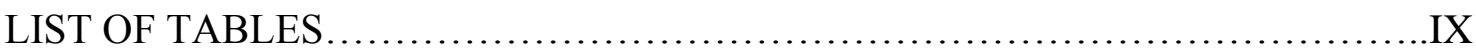

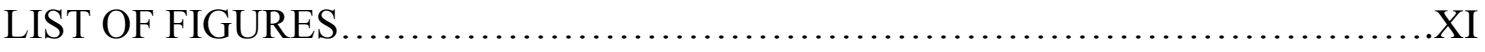

ABBREVIATIONS ..........................................................

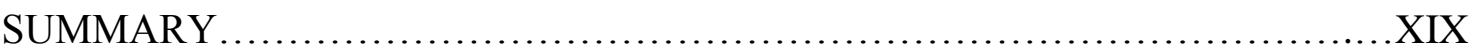

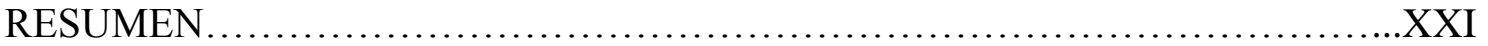

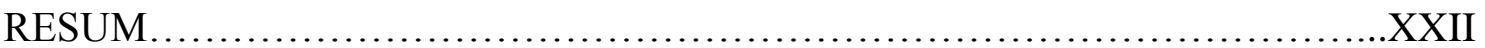

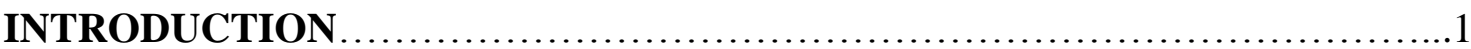

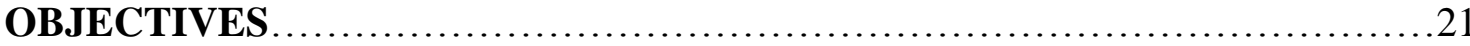

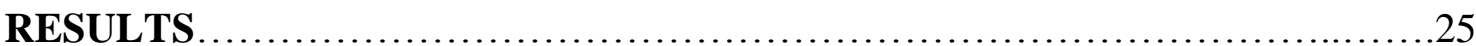

Chapter 1: Modulation of antioxidant defense system is associated with combined drought and heat stress tolerance in citrus. .25

Chapter 2: Involvement of ascorbate peroxidase and heat shock proteins on citrus tolerance to combined conditions of drought and high temperatures

Chapter 3: High temperatures change the perspective: Integrating hormonal responses in citrus plants under co-occurring abiotic stress conditions

Chapter 4: Jasmonic acid is required for plant acclimation to a combination of high light and heat stress. .95

GENERAL DISCUSSION .135

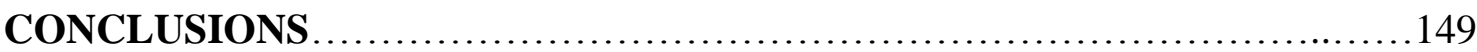

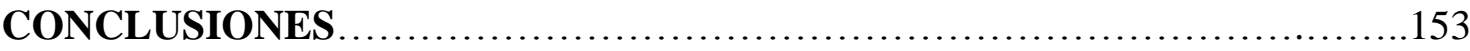

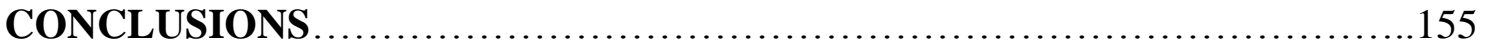

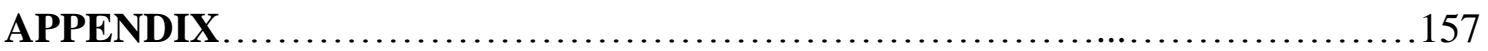





\section{Chapter 1}

Table 1. Relative water content (RWC) of Carrizo and Cleopatra leaves subjected to drought (WS), heat (HS) and their combination (WS + HS)

Table 2. Ascorbate (AsA), total ascorbate (tASA) and dehydroascorbate (DHA) content in Carrizo and Cleopatra leaves subjected to drought (WS), heat (HS) and their combination (WS + HS)

Table 3. Total glutathione (tGSH), reduced glutathione (GSH) and oxidized glutathione (GSSG) content in Carrizo and Cleopatra leaves subjected to drought (WS), heat (HS) and their combination (WS + HS).

Table S1. Designed primers for gene expression analyses by quantitative RT-PCR.....48

\section{Chapter 3}

Table S1. Designed primers for gene expression analyses by quantitative RT-PCR....92

Table S2. Run conditions and transitions used for the analysis of selected phytohormones .93

\section{Chapter 4}

Table 1. Representation of hormone- and ROS-response transcripts in the transcriptomic response of plants subjected to HL, HS, and the combination of HL+HS. 104

Table 2. Survival rate (\%), LDI (\%), and photosynthetic parameters $\left(\Phi_{\mathrm{PSII}}\right.$ and $\left.\mathrm{F}_{\mathrm{v}} / \mathrm{F}_{\mathrm{m}}\right)$ of Col, aos, sid2, and aba2 mutants subjected to combined HL+HS 112

Supplemental Table S1-S7. Transcripts significantly up or downregulated $(\mathrm{P}<0.05)$ in Col plants subjected to HL, HS and HL+HS 



\section{$\underline{\text { Introduction }}$}

Figure 1. Model for plant acclimation to conditions of abiotic stress combinations, including drought, salinity, high light or elevated $\mathrm{CO} 2$ concentration and high

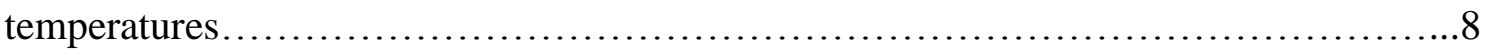

Figure 2. Effect of stress combination on the physiology and survival of different plant species .10

Figure 3. Hormonal interactions that regulate stomatal responses under individual or combined stress conditions. .14

\section{Chapter 1}

Figure 1. Experimental design used to subject Carrizo and Cleopatra plants to drought (WS), heat stress (HS) and a combination of drought and heat stress (WS + HS). .30

Figure 2. Proline accumulation in leaves $(\mathbf{A})$ and roots $(\mathbf{B})$ of Carrizo and Cleopatra plants subjected to drought (WS), heat (HS) and a combination of drought and heat stress (WS+HS)

Figure 3. Malondialdehyde (MDA) accumulation in leaves (A) and roots (B) of Carrizo and Cleopatra plants subjected to drought (WS), heat (HS) and a combination of drought and heat stress (WS + HS)

Figure 4. Effects of drought (WS), heat (HS) and a combination of drought and heat stress (WS + HS) on SOD activity (A) and transcript expression (B) in leaves of Carrizo and Cleopatra plants.

Figure 5. Effects of drought (WS), heat (HS) and a combination of drought and heat stress (WS + HS) on CAT activity (A) and transcript expression (B) in leaves of Carrizo and Cleopatra plants.

Figure 6. Effects of drought (WS), heat (HS) and a combination of drought and heat stress (WS + HS) on APX activity (A) and transcript expression (B) in leaves of Carrizo and Cleopatra plants. .38 
Figure 7. Effects of drought (WS), heat (HS) and a combination of drought and heat stress (WS + HS) on GR activity (A) and transcript expression (B) in leaves of Carrizo and Cleopatra plants.

\section{Chapter 2}

Figure 1. Stress-induced leaf damage in Carrizo citrange (A, C and E) and Cleopatra

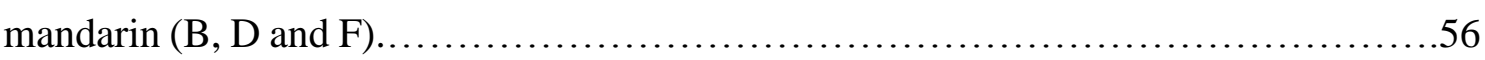

Figure 2. Leaf damage, stomatal conductance (gs) and quantum yield (ФPSII) in Carrizo and Cleopatra plants subjected to drought (WS), heat stress (HS) and the combination of

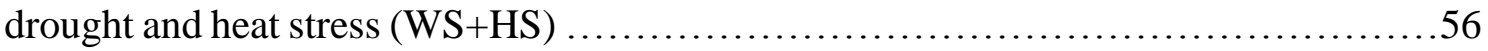

Figure 3. APX activity and APX2 gene expression in Carrizo and Cleopatra plants subjected to drought (WS), heat stress (HS) and the combination of drought and heat stress (WS+HS)

Figure 4. APX2, HSP101 and HSP17.6 levels in Carrizo and Cleopatra plants subjected to drought (WS), heat stress (HS) and the combination of drought and heat stress (WS+HS) .58

\section{Chapter 3}

Figure 1. Phenotypic traits in Carrizo plants in response to wounding (Wo), salt stress $(\mathrm{NaCl})$, heat stress (HS), combination of wounding and heat stress (Wo+HS) and combination of salt and heat stress $(\mathrm{NaCl}+\mathrm{HS})$ for 15 days

Figure 2. Leaf relative water content (RWC) of Carrizo plants subjected to wounding (Wo), salt stress $(\mathrm{NaCl})$, heat stress (HS), combination of wounding and heat stress (Wo+HS) and combination of salt and heat stress ( $\mathrm{NaCl}+\mathrm{HS})$ for 15 days .74

Figure 3. Leaf transpiration (E, panel A) and stomatal conductance (gs, panel B) of Carrizo plants subjected to wounding (Wo), salt stress $(\mathrm{NaCl})$, heat stress (HS), combination of wounding and heat stress (Wo+HS) and combination of salt and heat stress $(\mathrm{NaCl}+\mathrm{HS})$ for 15 days

Figure 4. Leaf chloride content in Carrizo plants subjected to wounding (Wo), salt stress $(\mathrm{NaCl})$, heat stress (HS), combination of wounding and heat stress (Wo+HS) and combination of salt and heat stress $(\mathrm{NaCl}+\mathrm{HS})$ for 15 days .76 
Figure 5. ABA (A), PA (B) and DPA (C) leaf content in Carrizo plants subjected to wounding (Wo), salt stress $(\mathrm{NaCl})$, heat stress (HS), combination of wounding and heat stress (Wo+HS) and combination of salt and heat stress $(\mathrm{NaCl}+\mathrm{HS})$ for 15 days

Figure 6. JA (A), JA-Ile (B) and OPDA (C) leaf content in Carrizo plants subjected to wounding (Wo), salt stress $(\mathrm{NaCl})$, heat stress (HS), combination of wounding and heat stress (Wo+HS) and combination of salt and heat stress ( $\mathrm{NaCl}+\mathrm{HS})$ for 15 days

Figure 7. SA leaf content in Carrizo plants subjected to wounding (Wo), salt stress $(\mathrm{NaCl})$, heat stress (HS), combination of wounding and heat stress (Wo+HS) and combination of salt and heat stress $(\mathrm{NaCl}+\mathrm{HS})$ for 15 days .78

Figure 8. Relative expression of genes involved in ABA biosynthesis and signaling in Carrizo plants subjected to wounding (Wo), salt stress $(\mathrm{NaCl}$ ), heat stress (HS), combination of wounding and heat stress (Wo+HS) and combination of salt and heat stress $(\mathrm{NaCl}+\mathrm{HS})$ for 15 days .80

Figure 9. Relative expression of genes involved in JAs biosynthesis and signaling in Carrizo plants subjected to wounding (Wo), salt stress $(\mathrm{NaCl}$ ), heat stress (HS), combination of wounding and heat stress (Wo+HS) and combination of salt and heat stress $(\mathrm{NaCl}+\mathrm{HS})$ for 15 days

Figure 10. Relative expression of genes involved in SA biosynthesis and signaling in Carrizo plants subjected to wounding (Wo), salt stress $(\mathrm{NaCl})$, heat stress (HS), combination of wounding and heat stress (Wo+HS) and combination of salt and heat stress $(\mathrm{NaCl}+\mathrm{HS})$ for 15 days

Figure 11. Hormonal relations in Carrizo plants to modulate an appropriate response to different stress combinations.

Figure S1. Leaf phenotypic traits in Carrizo plants subjected to different stresses.

\section{Chapter 4}

Figure 1. A combination of heat and high light stress is detrimental to plants .101 
Figure 2. Heat and light stress combination displays a heat-like stomatal response. Stomatal aperture (left), surface leaf temperature (middle) and leaf relative water content (RWC; right) of Col plants subjected to high light (HL), heat stress (HS) and a combination of high light and heat stress (HL+HS). .102

Figure 3. Heat and light stress combination is accompanied by a unique transcriptomic response 103

Figure 4. Differential expression of transcriptional regulators during the stress combination 105

Figure 5. Enhanced expression of transcripts encoding PSII and PSII repair proteins during a combination of light and heat stress is accompanied by a decrease in D1 106

Figure 6. Unique structural features of chloroplasts from plants subjected to high light (HL), heat stress (HS) and a combination of high light and heat stress (HL+HS) 108

Figure 7. Levels of $\mathrm{H}_{2} \mathrm{O}_{2}, \mathrm{ABA}, \mathrm{SA}$, JA and JA-Ile in Col plants subjected to high light (HL), heat stress (HS) and a combination of high light and heat stress (HL+HS)

Figure 8. Involvement of JA in the response of plants to a combination of high light and heat stress $(\mathrm{HL}+\mathrm{HS})$.

Supplemental Figure S1. The experimental design used for the study of HL, HS, and combined HL+HS using Arabidopsis plants

Supplemental Figure S2. GO annotation of transcripts specifically upregulated (top) and downregulated (bottom) in leaves of Col plants subjected to HL, HS, and combined HL+HS. 128

Supplemental Figure S3. Accumulation of D1 and PsaH in Col plants subjected to HL, HS, and combined HL+HS . 129

Supplemental Figure S4. Heat maps showing significantly upregulated and downregulated transcripts involved in JA biosynthesis and signaling in Col plants subjected to HL, HS, and combined HL+HS 130

Supplemental Figure S5. PSII performance and RWC of JA-deficient aos plants subjected to HL, HS, and combined HL+HS 
Supplemental Figure S6. PSII performance, survival rate, LDI, RWC, and stomatal responses rate of SA-deficient sid2 plants subjected to HL, HS, and combined HL+HS.

Supplemental Figure S7. PSII performance, survival rate, LDI, RWC, and stomatal responses rate of ABA-deficient aba2 plants subjected to $\mathrm{HL}, \mathrm{HS}$, and combined HL+HS. 133 

$\varphi$ PSII - quantum yield of photosystem II

ABA - abscisic acid

ABF - ABA binding factor

ABR- ABA repressor

AP2/EREBPs - APETALA2/ethylene-responsive

APX - ascorbate peroxidase

AREB - ABA-responsive element-binding protein

AsA - ascorbate

BHLH - basic hélix-loop-helix

CAT - catalase

DPA - dehydrophaseic acid

E - transpiration

ERF - ethylene response factor

ETR - electron transport rate

$\mathbf{F}_{\mathbf{v}} / \mathbf{F}_{\mathbf{m}}$ - maximal photochemical efficiency of photosystem II

GLO - glycolate oxidase

GR - glutathione reductase

Gs - stomatal conductance

GSH - glutathione

GSSG - oxidized glutathione

HSF - heat shock factor

HSP - heat shock protein

ICS - isochorismate synthase

IPCC - Intergovernmental Panel on Climate Change

JA - jasmonic acid

JA-Ile - JA-isoleucine

LHCII - light harvest center II

MBF1c - Multiprotein Bridging Factor 1c

Md - dry mass

MDA - malondialdehyde

Mf - fresh mass

Mt - turgid mass

OPDA - 12-oxo-phytodienoic acid

PA - phaseic acid 
PP2Cs - protein phosphatases 2C

PSII - photosystem II

RD - responsive to desiccation

REST - Relative Expression Software Tool

ROS - reactive oxygen species

RWC - relative water content

SA - salicylic acid

SOD - superoxide dismutase

TFs - transcription factors

ZAT - zinc transporter 
Plants growing in the field are affected by several adverse environmental conditions at the same time. The simultaneity of abiotic factors affecting plants creates a new stress situation different from the individual ones. Global warming is increasing earth surface temperature, and this is accompanied by other environmental changes (soil degradation, increase of drought periods, changes in precipitation pattern). All these changes will affect the arable lands around the world and crop production will be reduced unless new cultivars capable to face the environmental changes are developed.

Therefore, the main objective of this $\mathrm{PhD}$ is to study the impact of different abiotic stresses in combination with high temperatures on plant physiology. To achieve this objective, the present work is divided into four chapters. In Chapter 1, it is demonstrated that Carrizo citrange is more tolerant to drought and heat stress combination than Cleopatra mandarin. Our work reveals that the higher activation of the enzymes involved in the antioxidant ROS detoxification system of Carrizo prevents cells from the oxidative damage derived from this stress combination. It is showed that the activity of SOD in Carrizo is higher than in Cleopatra at basal levels and under stress combination. Furthermore, gene expression and enzymatic activity of APX and CAT are strongly induced under stress combination in Carrizo, while in Cleopatra this induction is much lower. In Chapter 2, it is showed that under drought and heat stress combination the accumulation of key proteins for plant acclimation to drought or heat stress, such as APX1 and the chaperone HSP101, is higher in Carrizo than in Cleopatra, which may be involved in the higher tolerance of the former to the adverse situation. Chapter 3 aims to further study the effect of abiotic stress conditions in combination with high temperatures in citrus plants. For this purpose, Carrizo citrange plants were subjected to wounding or salinity at high temperatures. Results indicate that high temperatures modify Carrizo responses to wounding and salinity. Under wounding and heat stress, stomatal aperture in plants is lower than under wounding at low temperatures. In addition, Jasmonates accumulation pattern changed. While wounding caused a higher accumulation of JA, stress combination caused a lower increase of JA levels and a significant rise of OPDA content. Salt and heat stress combination caused more severe damage on Carrizo plants than salt stress at low temperatures. Due to the stress combination, toxic chloride ions highly accumulated in Carrizo leaves. Salt and heat stress combination induced high accumulations of $\mathrm{ABA}$ and $\mathrm{JA}$ and resulted in a specific transcriptomic, stomatal and transpiration response different from that caused by individual stresses. Finally, in 
Chapter 4, to deeply investigate physiological, hormonal and molecular responses of plants to high light intensity and high temperatures, Arabidopsis thaliana plants were subjected to a combination of these stresses. JA and JA-Ile levels increased specifically under stress combination whereas no change was observed under individual high light or heat stress. This hormonal increase after stress combination together with the upregulation of JA-responsive genes and the lower tolerance of the JA-deficient mutant aos to stress combination indicated that JA is a key hormone for plant acclimation to a combination of high light and heat stress. In addition, it was observed that Arabidopsis plants affected by high light and heat stress were unable to restore PSII activity after stress, likely because damage caused in D1 protein exceeded its repairment and reassembly under the simultaneous stress conditions.

Therefore, this work has focus in studying physiological, hormonal and transcriptomic responses to different stress situations in citrus and model plants to obtain a global view of plant mechanisms to tolerate complex abiotic stress situations. 
Las plantas cultivadas se ven afectadas por numerosas condiciones ambientales adversas al mismo tiempo. Cuando dos o más factores abióticos afectan a las plantas de manera simultánea se crea una nueva condición de estrés, diferente a la provocada por los estreses individuales. Debido al calentamiento global, la temperatura de la superficie terrestre está aumentando, y esto viene acompañado por otros cambios medioambientales (degradación de suelos, incremento de sequías, cambios en los patrones de precipitaciones). Todos estos cambios afectan a las zonas de cultivos de todo el mundo y la producción agrícola se verá reducida a menos que se desarrollen nuevos cultivares capaces de soportar los cambios ambientales.

El objetivo principal de esta tesis es estudiar el impacto en la fisiología de las plantas de diversos estreses abióticos en combinación con las altas temperaturas. Para conseguir este propósito, el trabajo presente se ha dividido en cuatro capítulos. En el Capítulo 1, se ha demostrado que el patrón de cítricos Carrizo citrange es más tolerante a la combinación de sequía y calor que el patrón Cleopatra mandarin. Nuestro trabajo revela que la mayor actividad de las enzimas antioxidantes encargadas de la detoxificación de las moléculas ROS en las plantas de Carrizo previene a las células del daño oxidativo que se deriva de la combinación de estrés. En el estudio se muestra que la actividad de SOD a niveles basales y bajo estrés combinado es mayor en Carrizo que en Cleopatra. Además, la expresión genética y la actividad enzimática de APX y CAT son altamente inducidas en condiciones de stress combinado en plantas de Carrizo, mientras que en Cleopatra esta inducción es mucho menor. En el Capítulo 2, se muestra que bajo combinación de sequía y calor la acumulación de proteínas clave para la aclimatación a sequía y/o calor, como lo son APX1 y la chaperona HSP101, es mayor en Carrizo que en Cleopatra, lo que confiere al primero mayor tolerancia a la situación de estrés. En el Capítulo 3 se estudió el efecto de diferentes estreses abióticos en combinación con altas temperaturas en cítricos. Para llevar a cabo el estudio, se sometieron plantas de Carrizo citrange a estrés por herida mecánica o salinidad bajo altas temperaturas. Los resultados indicaron que las altas temperaturas modificaron las respuestas de las plantas Carrizo a la herida mecánica y a la salinidad. Las plantas sometidas a herida y calor simultáneamente mostraron una apertura estomática menor que las que se sometieron a herida en temperaturas control. Además, la acumulación de jasmonatos cambió. El daño mecánico a temperatura control causó un incremento de JA, mientras que en condiciones de altas temperaturas el aumento de JA fue menor y hubo un incremento significativo de OPDA. La combinación de 
salinidad y calor causó mayores daños en las plantas de Carrizo que la salinidad o el calor de manera individual. Debido a la combinación de estrés, los iones tóxicos de cloruro se acumularon en gran cantidad en las hojas de Carrizo. Las condiciones de salinidad y calor en combinación provocaron la alta acumulación de ABA y JA y resultó en una regulación transcriptómica y estomática específica diferente a la causada por los estreses individuales. Finalmente, en el Capítulo 4, para investigar en mayor profundidad las respuestas fisiológicas, hormonales y moleculares de las plantas a la combinación de alta intensidad de luz y altas temperaturas, se sometieron plantas de Arabidopsis thaliana a esta combinación de estrés. El contenido foliar de JA y JA-Ile se incrementó específicamente bajo condiciones de estrés, mientras que no hubo variaciones en las plantas solo bajo alta intensidad de luz o altas temperaturas. Este incremento hormonal tras la combinación de estrés junto con la sobreexpresión de genes asociados a JA y la menor tolerancia del mutante aos, deficiente en la acumulación de JA, indican que el JA es una hormona clave en la aclimatación de las plantas a la combinación de alta intensidad de luz y altas temperaturas. Además, se observó que las plantas de Arabidopsis bajo la combinación de estrés eran incapaces de recuperar la actividad del PSII tras el estrés, posiblemente debido a que el daño causado en la proteína D1 fue superior a la capacidad de reparación en la condición de estrés simultáneo.

Por lo tanto, este trabajo se ha enfocado en el estudio de las respuestas fisiológicas, hormonales y transcriptómicas de las plantas a diferentes condiciones de estrés para obtener una visión global del mecanismo de tolerancia de las plantas a situaciones complejas de estrés abiótico. 
Les plantes cultivades es veuen afectades per nombroses condicions ambientals adverses al mateix temps. Quan dos o més factors abiòtics afecten a les plantes simultàniament es crea una nova condició d'estrès, diferent a la provocada pels estressos individuals. Degut a l'escalfament global, la temperatura de la superfície terrestre està augmentant, i això ve acompanyat per altres canvis en el medi ambient (degradació de sòls, increment de sequera, canvis en el règim de precipitacions). Tots aquests canvis afecten a les zones de cultius de tot el món i la producció agrícola es veurà reduïda a menys que es desenvolupen nous cultivars capaços de suportar els canvis ambientals.

L'objectiu principal d'aquesta tesi és estudiar l'impacte de la fisiologia de les plantes de diversos estressos abiòtics en combinació amb les altes temperatures. Per a aconseguir aquest propòsit, el treball present s'ha dividit en quatre capítols. En el Capítol 1, s'ha demostrat que el patró de cítrics Carrizo citrange és més tolerant a la combinació de sequera i calor que el patró Cleopatra mandarin. El nostre treball revela que la major activitat dels enzims antioxidants encarregades de la detoxificació de les molècules ROS en les plantes de Carrizo prové a les cèlllules del dany oxidatiu que es deriva de la combinació d'estrès. A l'estudi es mostra que l'activitat basal i baix l'estrès combinat de SOD es major en Carrizo que en Cleopatra. A més a més, l'expressió genètica i l'activitat enzimàtica d'APX i CAT són altament induïdes en condicions d'estrès en plantes de Carrizo, mentre que en Cleopatra aquesta inducció és molt menor. En el Capítol 2, es mostra que baix la combinació de sequera i calor l'acumulació de proteïnes clau per a l'aclimatació a sequera i/o calor, com són APX1 i la xaperona HSP101, és major en Carrizo que en Cleopatra, fet que confereix al primer major tolerància a la situació d'estrès. En el Capítol 3 es va estudiar l'efecte de diferents estressos abiòtics en combinació amb altes temperatures en cítrics. Per dur a terme l'estudi, es van sotmetre plantes de Carrizo citrange a estrès per ferida mecànica o salinitat baix les altes temperatures. Els resultats van indicar que les altes temperatures van modificar les respostes de les plantes de Carrizo a la ferida mecànica i a la salinitat. Les plantes sotmeses a ferida i calor simultàniament mostraren una apertura estomàtica menor que les que es van sotmetre a ferida a temperatures control. A més a més, l'acumulació de jasmonats va canviar. El dany mecànic a temperatura control va causar un increment de JA, mentre que en condicions d'altes temperatures l'augment de JA va ser menor i va haver-hi un increment significatiu d'OPDA. La combinació de salinitat i calor va causar danys més grans en les plantes de Carrizo que la salinitat o el calor de manera individual. 
Degut a la combinació d'estrès, el ions tòxics de clorur es van acumular en grans quantitats en les fulles de Carrizo. Les condicions de salinitat i calor en combinació van provocar l'alta acumulació d'ABA i JA i va resultar en una regulació transcriptòmica i estomàtica específica diferent a la causada pels estressos individuals. Finalment, en el Capítol 4, per a investigar en major profunditat les respostes fisiològiques, hormonals i moleculars de les plantes a la combinació d'alta intensitat de llum i altes temperatures, es van sotmetre plantes d'Arabidopsis thaliana a la combinació d'estrès. El contingut foliar de JA i JA-Ile es va incrementar específicament baix condicions d'estrès, mentre que no va haver variacions en les plantes únicament baix alta intensitat de llum o altes temperatures. Aquest increment hormonal després de la combinació d'estrès junt amb la sobre expressió de gens associats a JA i la menor tolerància del mutant aos, deficient en l'acumulació de JA, indiquen que el JA és una hormona clau en l'aclimatació de les plantes a la combinació d'alta intensitat de llum i altes temperatures. A més a més, es va observar que les plantes d'Arabidopsis baix la combinació d'estrès van ser incapaços de recuperar l'activitat del PSS després de l'estrès, possiblement degut a que el dany causat en la proteïna D1 va ser superior a la capacitat de reparació en la condició d'estrès simultani.

Per tant, este treball s'ha enfocat en l'estudi de les respostes fisiològiques, hormonals i transcriptòmiques de les plantes a diferents condicions d'estrès per a obtindré una visió global del mecanisme de tolerància de les plantes a situacions complexes d'estrès abiòtic. 


\section{Introduction}

High temperatures modify plant responses to abiotic stress conditions

Balfagón et al. (2020) Physiologia Plantarum

doi: 10.1111/ppl.13151. 



\begin{abstract}
Climate change is altering our global environment in which plants grow and survive. We already experienced an increase in worldwide average earth surface temperatures, as well as frequency and extent of damaging heat waves. These conditions collide in the field with other abiotic stresses such as water deficit, high salinity, increased light irradiation, etc., generating complex harmful conditions that destabilize agricultural systems. The conditions generated during these episodes of stress combination greatly differ from those occurring in the field when different stress factors occur individually; conditions that have been the focus of study for decades. Fortunately, knowledge on physiological and molecular responses to stress combinations and the cost they inflict on plant growth and yield has been exponentially increasing in the past several years. Thus, it is currently accepted that plant responses to stress combinations cannot be reduced to the addition of the responses to the individual stresses that are combined. Understanding plant performance under multiple stress combinations will allow breeding crops capable of maintaining yield production under the new climatic conditions. Here, after reviewing recent data on physiological, hormonal and transcriptional responses to high temperatures, in combination with other common abiotic stress factors, we propose new approaches to investigate the response of plants to stress combinations and discuss strategies for improving crop resilience.
\end{abstract}

\title{
Introduction
}

Plants are sensitive to the changing environment and respond to any alterations in it by adjusting their gene expression and, eventually, their metabolism and physiology. Climate change is modifying our environment, causing an increase in earth average temperatures, which results in extreme heat waves and rainfalls; moreover, drought and soil contamination is reducing cropland surface. As a result, global crop production is expected to decrease unless this process could be mitigated. During the last century, temperatures have increased approximately one degree in the major cultivated areas, and is expected to keep increasing over the next years (Zhao et al., 2017)(IPCC 2019, http://www.ipcc.ch/). Heat stress is harmful for plants when occurring during different critical development stages, such as the reproductive period (Teixeira et al., 2013). In this sense, exposure to abnormal high temperatures affects pollen viability, fertilization, grain filling and fruit formation (Hatfield and Prueger, 2015). Thus, due to the increasing temperatures the staple food production is expected to decrease between 5,6\% and 18,2\% by 2100 (Zhao et al., 2017). Global areas 
affected by drought will also increase from $15.4 \%$ to $44 \%$ by 2100 (Li et al., 2009). Moreover, not only rising temperatures increase drought, but dried soils warm the atmosphere in turn by retaining less water and increasing the frequency of heat waves (Teuling, 2018).

Plant performance and crop yield under combined conditions of high temperatures and drought (or other co-occurring abiotic stress factors) have been object of recent studies (Martinez et al., 2018; Zandalinas et al., 2018a; Elferjani and Soolanayakanahally, 2018; Balfagón et al., 2019 a, b; Mahalingam and Bregitzer, 2019; Fábián et al., 2019; Jumrani and Bhatia, 2019). Plant responses to two or more stress factors simultaneously affecting it are unique and cannot be considered as the sum of responses to each of the individual stresses affecting the plant (Mittler, 2006; Zandalinas et al., 2018b).

This review summarizes recent studies on the effect of abiotic stress combinations that include high temperatures as one of their components, focusing on physiological, hormonal and molecular responses of different plants species. Based on current climate predictions for the near future, there is an urgent need to develop tolerant plants to different stress combinations. Therefore, strategies for improving crop resilience are also proposed.

\section{Plant development under abiotic stresses at high temperatures}

Temperatures above the plant optimal range cause physiological changes that alter their development (Szymańska et al., 2017). Under high temperatures, photochemical reactions and carbon metabolism are two of the most affected processes. Heat inactivates PSII electron acceptor and donor sides, disables enzymes of the Calvin cycle, reduces Rubisco activity and increases oxidative damage by enhancing ROS production. As a result, plant photosynthesis and carbon assimilation is highly compromised under heat stress (Yamamoto et al., 2008; Pospíšil, 2016; Szymańska et al., 2017). Co-occurring abiotic stress factors such as drought, salinity or light stress (that also affect electron chain transport, carbon assimilation or oxidative status) can aggravate these conditions and cause irreversible damages to the photosynthesis apparatus (Fig. 1). Therefore, improving mechanisms that avoid heat-derived damages to the photosynthetic apparatus may be essential for plant acclimation to abiotic stress factors in a warmer environment. A transcriptomic study in Arabidopsis plants under a combination of high light intensity and heat stress showed an increase of transcripts encoding photosynthetic proteins, many of them involved in degradation, repair and reassembly of PSII (Balfagón et al., 2019b). These results suggest 
that, under these conditions, de novo biosynthesis of proteins involved in the photosynthetic apparatus occurs. Under high light and heat stress combination, the steady-state level of the D1 protein (considered the most sensitive protein to stresses in the PSII complex) decreased, suggesting that under these conditions photodamage of PSII could be exceeding the rates of biosynthesis, repair and reassembly of the D1 protein. In contrast, plants subjected only to high light conditions over accumulated D1 protein. Photodamage caused by the stress combination resulted in a decline in PSII activity $\left(\varphi\right.$ PSII and $\left.F_{v} / F_{m}\right)$ and the inability of plants to recover PSII function following recovery from the adverse conditions. In contrast, plants subjected to high light showed reduced PSII activity but this process was restored following a recovery period (Balfagón et al., 2019b). Similarly, tomato plants subjected to drought and heat stress combination decreased the activity of the photosynthetic apparatus. Under drought (combined or not with heat stress), tomato plants reduced electron transport rate (ETR) and $\varphi$ PSII, compared to control conditions or heat stress alone. However, after a recovery period only plants under drought were able to restore ETR and $\varphi$ PSII while plants under stress combination were not. Therefore, stress combination caused an irreversible damage on the photosynthetic apparatus and tomato plants were unable to restore PSII performance after the combined stress period (Zhou et al., 2019).

Damage induced by abiotic stress to photosynthetic proteins, photosystems I and II, the oxygen evolving complex, and components of the electron transmission chain severely decreases photosynthetic rate and plant performance (Pospíšil, 2016; Szymańska et al., 2017; Zhou et al., 2019; Balfagón et al., 2019b). Therefore, the ability of plants to maintain a proper photosynthetic rate under stressful conditions could be critical for plant tolerance and survival. For example, it was reported that two different citrus genotypes, Carrizo citrange and Cleopatra mandarin, showed different abilities to cope with high temperatures, impacting alone or in combination with drought. Under water stress, closure of stomata along with reductions in transpiration and photosynthetic rates happened in both genotypes. On the other hand, heat stress increased transpiration, probably as a mechanism to cool leaf surface via evaporation. In Carrizo plants, this response was accompanied by a rise in stomatal conductance and photosynthetic rate. However, Cleopatra mandarin that is more sensitive to high temperatures, maintained stomatal conductance and photosynthetic rates similar to control values. Stress combination induced stomatal closure, transpiration decline, and photosynthesis reduction, and caused the most detrimental effect on both genotypes (Zandalinas et al., 2016b). Stomatal closure may be the cause of the observed reduction of the PSII efficiency whereas the decrease in photosynthetic rates could be associated to the 
impairment in the $\mathrm{CO}_{2}$ fixation. Similarly to that observed in Arabidopsis (Rizhsky et al., 2004), citrus stomatal response to drought prevailed over that to heat stress. Thus, plants closed the stomata to reduce water loss despite its potential effect on increasing leaf temperature. The impossible challenge of alleviating the effects of high temperatures and at the same time performing photosynthesis under drought stress combination caused much more severe damage than that caused by each of the different stresses applied individually (Zandalinas et al., 2016b). When heat was combined with high light stress, wheat plants reduced chlorophyll content, relative water content and total protein content. In addition, oxidative damage increased under conditions of combined stress in plants, and excess light caused damage to PSII reaction centers and reduced photosynthetic activity. High light and heat stress combination led to a rapid stomatal closure and subsequently to a decline of the photosynthetic rate due to a reduction in $\mathrm{CO}_{2}$ assimilation and Rubisco activity (Chen et al., 2017). In contrast, in Arabidopsis the combination of heat and high light stresses resulted in opening of stomata (Balfagón et al., 2019b).

The negative impact of different abiotic stress combinations on the photosynthetic apparatus, photosynthesis rate and carbon assimilation results in adverse consequences to plant development and yield. However, crop production is directly related to the development of reproductive organs. Gametogenesis, pollen formation, ovary and embryo sac differentiation, and flowering and fertilization are processes that are very sensitive to high temperatures (Prasad et al., 2017). As a result, heat stress is one of the most detrimental factors in reproductive-organ formation in natural fields and, together with other stress factors, can strongly decrease crop production (Fig. 2). For example, four barley cultivars with different tolerance to heat and drought showed a severe yield loss (over 95\%) after being subjected to a combination of both stress conditions during the heading stage, whereas the stress combination imposed during the vegetative stage only reduced yield of one cultivar (around 60\%) (Mahalingam and Bregitzer, 2019). These results suggest that the impact of this stress combination on plant yield depends on the developmental stage of the plant. In addition, seed production of barley plants under the combination of high temperatures and drought during the heading stage was almost null, whereas under individual drought or heat stress was higher (although markedly decreased compared to control) (Mahalingam and Bregitzer, 2019). In addition, wheat plants sensitive to the combination of high temperature and drought, Cappelle Desprez, showed a reduction in yield of over 55\% compared to controls as a consequence of loss of fertility following 5 days of stress combination (Fábián et al., 2019). In that work, it was suggested that spike fertility was affected because of the 
sensitivity of pollen and the damage to female reproductive organs. In canola plants, drought and heat stress combination reduced the number of siliques, which resulted in a yield reduction close to $89 \%$. Furthermore, due to the decrease of photosynthetic carbon assimilation, seed oil yield was considerably reduced in canola plants under drought and heat stress combination (Elferjani and Soolanayakanahally, 2018). Seed oil comes mostly from the photosynthetic carbon assimilation of leaves and green silique walls, afterwards carbohydrates convert into triacylglycerol (Baud and Lepiniec, 2010). Modifying sowing season and other managing techniques can prevent some of the harmful consequences of high temperatures on grain or fruit production (Fahad et al., 2017). However, breeding efforts must be directed at developing cultivars more tolerant to high temperatures and stress combination during the reproductive stage.

In addition to the damaging impacts of different stress combinations involving high temperatures on plant photosynthesis, other physiological processes can also be affected during combined stresses (Fig. 2). For example, it was reported that metabolism of carbohydrates of lentil plants subjected to drought and heat stress combination was severly affected (Sehgal et al., 2017). These adverse conditions inhibited the activity of the enzymes sucrose synthase and starch phosphorylase, causing a decrease in sucrose and starch levels in leaves and seeds. Although drought alone also caused a reduction in both compounds in leaves and seeds, levels were impacted more than those found under stress combination. Heat stress induced an increase in sucrose and starch accumulation in leaves but a reduction in seeds. Finally, plants under stress combination showed the lowest biomass and fewer and smaller seeds compared to plants subjected to individual stress conditions (Sehgal et al., 2017). 


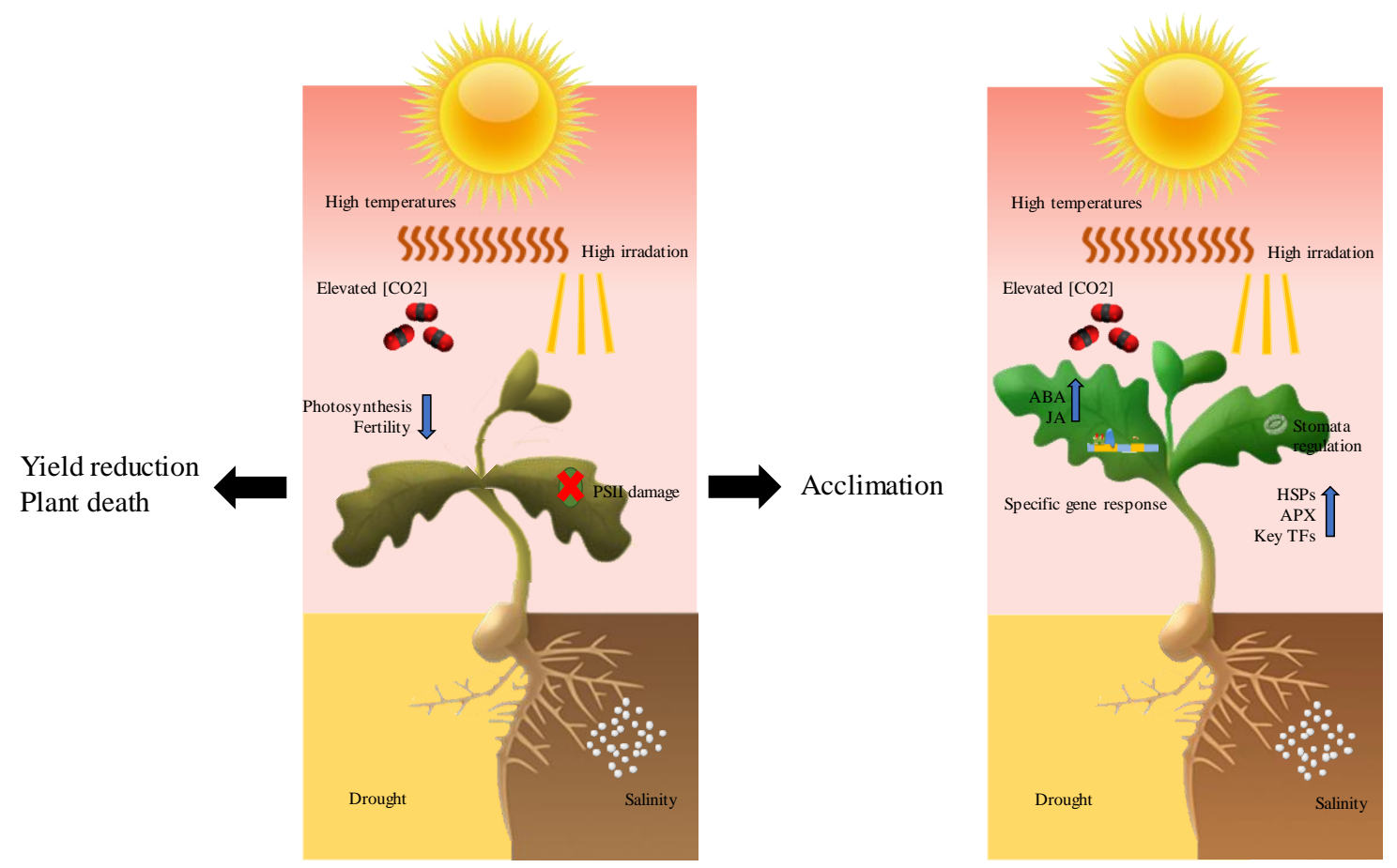

Figure 1. Model for plant acclimation to conditions of abiotic stress combinations, including drought, salinity, high light or elevated $\mathrm{CO}_{2}$ concentration and high temperatures. Abbreviations used: HSPs, heat shock proteins; APX, ascorbate peroxidase; TFs, transcription factors.

\section{Hormonal signaling, heat stress and abiotic stress combination}

Hormones are key molecules that transmit signals derived from abiotic stress conditions throughout the plant and trigger responses to cope with those adverse situations. Different stress combinations activate unique physiological and molecular responses in plants that are regulated by specific hormonal changes. Therefore, the ability of plants to modulate the hormonal balance when subjected to harmful conditions may be key for plant acclimation and survival.

Abscisic acid (ABA) is considered the main hormone in plant responses to abiotic stresses (Gómez-Cadenas et al., 2015) and it plays an important role during the acclimation of plants to different stress combinations involving high temperatures. For example, poplar plants over-accumulated $\mathrm{ABA}$ in roots and leaves when subjected to a combination of drought and high temperatures compared to their response to individual stress conditions. In addition, transcript levels of genes involved in ABA biosynthesis and signaling such as ABR family, NCED3 and ABF3, were up-regulated in leaves of poplar plants subjected to heat stress and drought. Moreover, transcription factors (TFs) induced by ABA, such as RESPONSIVE TO DESICCATION 26 (RD26) and ABA REPRESSOR1 (ABR1), were up-regulated in roots 
and leaves of poplar plants subjected to drought and heat stress (Jia et al., 2017). In agreement to these results, Arabidopsis ABA-signaling mutants (abil-1) were more sensitive to drought and heat stress combination due, at least in part, to the impaired accumulation of the ABA-dependent proteins APX1 and MBF1c (Zandalinas et al., 2016a). In addition to its key role during the combination of high temperatures and drought, $\mathrm{ABA}$ was also involved in plant responses to salt and heat stress combination. Following the application of individual salt stress conditions to citrus plants, ABA accumulated in leaves probably in order to close stomata, reduce transpiration and, therefore, decrease salt uptake from soil water absorption (Moya et al., 2003). When salt stress was combined with high temperatures, $\mathrm{ABA}$ levels were even higher than those of plants subjected to salt stress conditions. Moreover, some ABA-responsive genes such as AREB1, AREB2, RD22 and $\mathrm{RD} 29$, were up-regulated in correlation with the $\mathrm{ABA}$ increase, demonstrating the role of $\mathrm{ABA}$ as gene modulator in response to the combination of heat and salinity (Balfagón et al., 2019a). These results are in accordance with transcriptomic studies in Arabidopsis plants subjected to salt and heat stress combination (Suzuki et al., 2016), in which it was shown that in response to this stress combination, $11 \%$ of the up-regulated hormone-response transcripts were ABA-dependent (the most highly represented group). In addition, the survival rate of $\mathrm{ABA}$ deficient and signaling mutants, abal and abil, respectively, significantly decreased with respect to wild type plants (Suzuki et al., 2016).

Despite the important role of ABA for citrus acclimation to the combination of heat and salinity, ABA accumulation in plants subjected to stress combination did not correlate with stomatal closure (Balfagón et al., 2019a), as it happened under individual salt stress. A similar lack of correlation among ABA levels and stomatal closure was observed in citrus plants under the combination of drought and heat stress (Zandalinas et al., 2016b). These data suggest that other signaling molecules could play an intermediate role in stomatal closure when salt and drought occurred at high temperatures (Fig. 3). Previously, $\mathrm{H}_{2} \mathrm{O}_{2}$ and Jasmonic acid (JA) have been proposed as alternative signals (Murata et al., 2015). Balfagón et al., (2019a) showed that a notable accumulation of JA and its conjugate to isoleucine JAIle, occurred under the combined effect of salinity and high temperatures, suggesting a possible role of oxylipins in citrus responses to this stress combination. Furthermore, recent studies in Arabidopsis showed that high light intensity and heat stress combination resulted in a marked increase in JA content that was not caused by any of the individual stress conditions. In addition, the mutant aos, impaired in JA biosynthesis, was more susceptible than wild type plants to this stress combination. Moreover, the levels of 822 JA-responsive 
transcripts were uniquely up-regulated under stress combination and JA-related genes ZAT6 and ZAT10, as well as the ROS scavengers APX1 and APX2, were down-regulated in the aos mutant with respect to the wild type (Balfagón et al., 2019b). Overall, these data suggest that JA could play a key role for plant acclimation to high light and heat stress combination, and that the ability to regulate the expression of JA-dependent genes could be important to cope with the combined effect of heat and high light stress.

Therefore, different studies focused on hormonal changes during a combination of high temperatures and other abiotic stresses such as salinity or high light intensity agreed that a coordinated hormonal response to each specific stress combination is essential to trigger the proper acclimation responses (Fig. 3). Thus, more effort in developing crops with enhanced hormonal responses to specific stress combinations should be considered to improve plant performance.

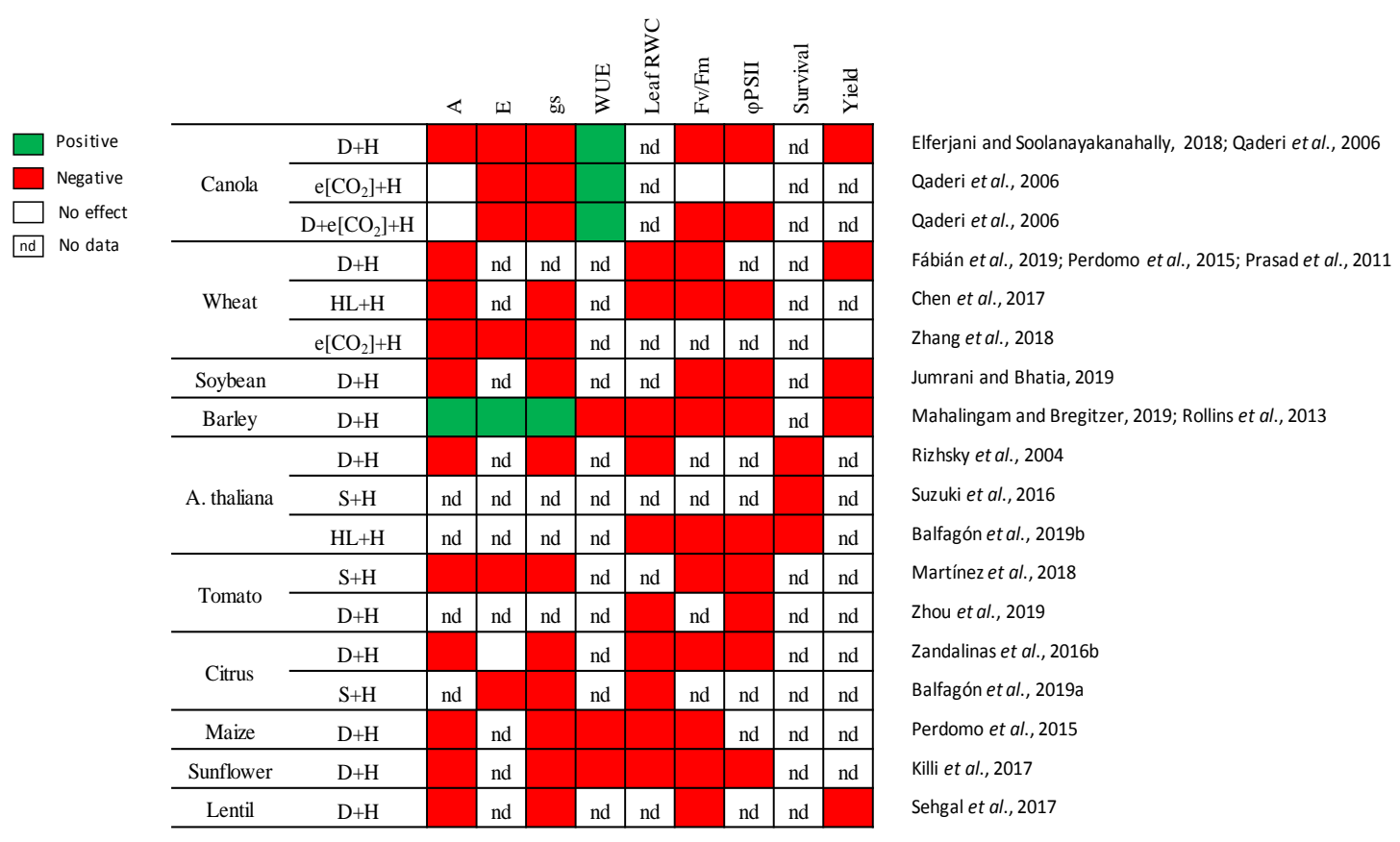

Figure 2. Effect of stress combination on the physiology and survival of different plant species. Data was obtained from the published studies on right. Abbreviations used: $\mathrm{D}$, drought; $\mathrm{H}$, heat; e[ $\left.\mathrm{CO}_{2}\right]$, elevated $\mathrm{CO}_{2}$ concentration; HL, high light; S, salinity.

\section{Transcriptomic and proteomic responses}

Previous studies focused on transcriptomic responses of plants to different stress combinations involving high temperatures, revealed some common patterns of gene regulation among different species and different stress combinations. Deciphering the most important pathways and gene families exclusively regulated during these abiotic stress combinations could provide valuable information for the development of new breeding 
programs to achieve crops more resilient under natural field conditions. For example, the transcriptomic profile of Arabidopsis plants subjected to the combination of high light and heat stress showed that 4654 genes were up-regulated specifically under this stress combination. Among those up-regulated genes, some of the more represented biological processes were oxidation-reduction processes, protein transport, protein catabolic processes and photosynthesis (Balfagón et al., 2019b). On the other hand, the simultaneous application of drought and heat stress in Wild barley (Hordeum spontaneum) resulted in a unique transcript expression profile composed of the up-regulation of 535 genes, of which 486 were not found among up-regulated genes under the individual stress conditions. The main biological processes represented by these genes were oxidation-reduction process and protein amino acid phosphorylation (Ashoub et al., 2018). Similarly, Soybean plants grown under combined drought and heat triggered the expression of genes involved in oxidationreduction, small molecule metabolic processes and protein folding, among others (Wang et al., 2018). Meta-analysis of the transcriptomic response of Arabidopsis plants to three different stress combinations involving heat stress (high temperatures together with drought, salinity or high light intensity) showed that the more represented biological processes among the up-regulated genes common to all stress combinations were: response to stress stimulus such as heat, water deprivation, salt stress or high light intensity. Also, some genes that respond to oxidative stress and hydrogen peroxide were highly up-regulated under these three stress combinations. In addition, other biological processes including protein folding and RNA splicing were also highly represented from those up-regulated genes (Zandalinas et al., 2019).

In general, transcriptomic studies have shown that changes in gene expression in response to different stress combinations, that share as a common factor high temperatures, are unique and different from the addition of responses to each of the individual stresses (Rizhsky et al., 2004; Suzuki et al., 2016; Lawas et al., 2018; Balfagón et al., 2019b). Moreover, it seems that there is not a specific response to all stress combinations but each situation induces a particular gene expression pattern. However, despite the transcriptomic variations among different stress combinations, there are common biological processes enriched by different abiotic stress combinations (Zandalinas et al., 2019). Notably, the up-regulation of many ABA-responsive genes showed the importance of this hormone in triggering acclimation responses to general abiotic stress combinations (Suzuki et al., 2016; Jia et al., 2017; Balfagón et al., 2019b). 
Reactive oxygen species (ROS) are produced during different abiotic stresses and their over accumulation in cells coupled with the lack of a powerful antioxidant systems may cause damage to proteins, DNA and lipids (Suzuki and Mittler, 2006). Genes involved in oxidation-reduction processes and genes that respond to oxidative stress or hydrogen peroxide, were up-regulated in several abiotic stress combinations and plant species (Rizhsky et al., 2004; Suzuki et al., 2016; Ashoub et al., 2018; Wang et al., 2018; Balfagón et al., 2019b). Rice lines that over expressed the enzyme glycolate oxidase (GLO), which catalyzes glycolate oxidation to produce peroxisomal $\mathrm{H}_{2} \mathrm{O}_{2}$, showed an improved photosynthetic capacity and a higher resistance to photo-oxidative stress than wild type plants under high light and heat stress combination. These results suggest that the induction of GLO, involved in photorespiratory metabolism, can confer tolerance to high light at high temperatures increasing photosynthesis rate and reducing oxidative damage (Cui et al., 2016). Therefore, the ability of plants to trigger responses to cope with oxidative damage is crucial to acclimate or survive under situations of stress combination. Other biological processes enriched by gene expression under different stress combinations were the protein folding, phosphorylation and RNA splicing ( Jia et al., 2017; Ashoub et al., 2018; Wang et al., 2018; Balfagón et al., 2019b). This could indicate that accumulation and/or activation, through phosphorylation, of proteins with protective (like chaperones) and signaling functions (like TFs) are crucial to maintain cell functioning and homeostasis against adverse conditions.

To regulate gene expression, TFs bind to specific elements in the promoters of target genes. High light and heat stress combination impacting Arabidopsis plants specifically induced the expression of several genes encoding APETALA2/ethylene-responsive (AP2/EREBPs) TFs, including ERF109, ERF88, DREB1D, ERF25, ERF57, ERF4, and ERF99 (Balfagón et al., 2019b). The AP2/EREBP family is a plant-specific TF group that includes DREBs and ERFs subfamilies, involved in plants responses to abiotic stress (Mizoi et al., 2012; Agarwal et al., 2017). In soybean plants, for example, the up-regulation of 8 AP2/EREBPs genes only occurs when drought and heat stress were combined (Wang et al., 2018). These data suggest that AP2/EREBP TF family might play an important role in coordinating gene responses to abiotic stress combinations such as high light or drought combined with high temperatures. Meta-analysis of transcriptomic studies in Arabidopsis under high temperatures in combination with other three abiotic stresses (drought, salinity and high light intensity) showed a common up-regulation of 4 AP2/EREBP TFs in all stress combinations and revealed an additive, negative and/or combinatorial manner of regulation used by 
AP2/EREBPs to control transcript expression, acclimation and development during stress combination (Zandalinas et al., 2019).

Molecular responses to stress combination have also been studied at the proteomics level. The over accumulation of proteins involved in the repair or the replacement of damaged protein complexes can confer tolerance to abiotic stresses including high temperatures. Suaeda salsa L., a tolerant plant to salinity and high temperatures, showed a different pattern of protein accumulation when plants were subjected to combined salt and heat or to any of the two stress conditions applied individually. Suaeda salsa plants showed an improved performance of PSII under salt and high temperatures as a result of a higher accumulation of chlorophyll a/b binding proteins (LHCII), considered key for the proper function of PSII (Li et al., 2011). In maize leaves, 32 proteins related to the chloroplast function were accumulated under drought and heat stress combination, such as PSI reaction center subunit V/N or the FtsH protease, involved in the turnover of the PSII reaction center-related D1 protein (Zhao et al., 2016). On the other hand, accumulation of protective proteins, such as chaperones or ROS scavenging enzymes is a common response related to the tolerance of plants to different stress combinations (Zandalinas et al., 2016a, 2017; Balfagón et al., 2018). Protein analyses in citrus under drought and heat stress combination demonstrated that accumulation of the ROS scavenger, APX, and two heat shock proteins, HSP101 and HSP17.6 conferred tolerance to these conditions (Balfagón et al., 2018).

The varying transcriptome and proteome responses to different abiotic stress conditions involving high temperatures reveal the importance of developing unique crop breeding strategies to face stress combinations at high temperatures. 
Individual stresses

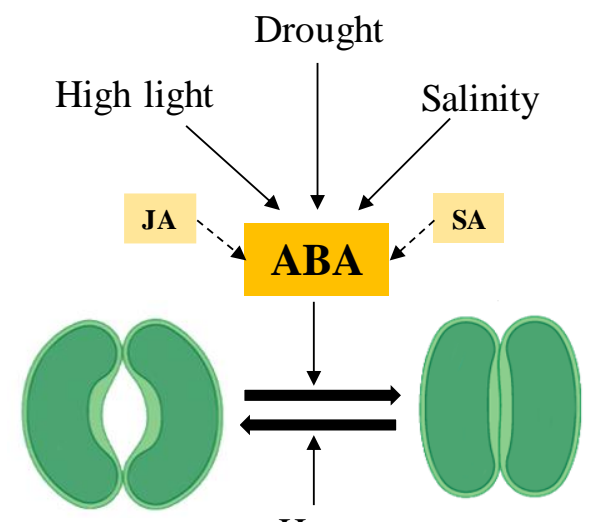

Heat

\section{Combined stresses}

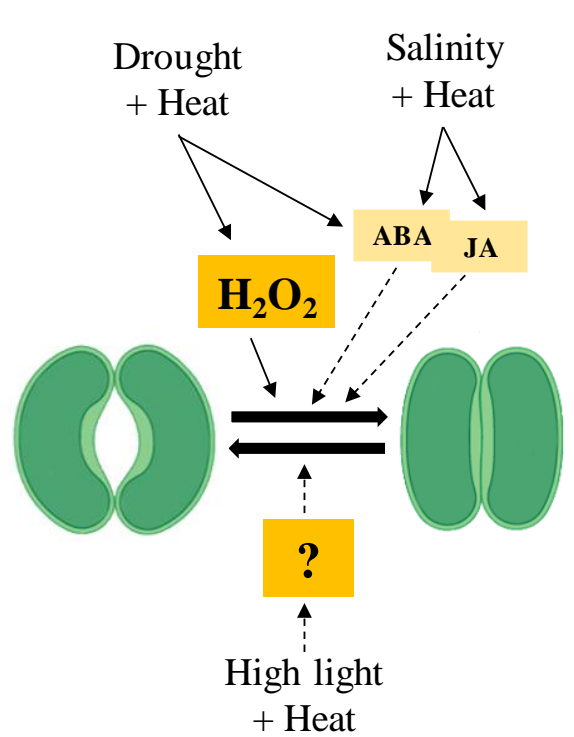

Figure 3. Hormonal interactions that regulate stomatal responses under individual or combined stress conditions. Abbreviations used: ABA, abscisic acid; JA, jasmonic acid, SA, salicylic acid.

\section{Future directions}

Climate change is a major threat to global crop yield production. The increase in average temperatures, in addition to more frequent extreme climate events or the loss of available land for agriculture, is likely to compromise crop production in the near future (Zhao et al., 2017). In light of this predicted scenario, it is essential to develop new crops capable of acclimating to these environmental changes that often impact plants in combination, in order to increase current and future plant yields. High temperatures negatively impact photosynthesis, carbon assimilation and sexual organ formation (Pospíšil, 2016; Prasad et al., 2017; Szymańska et al., 2017). Other abiotic stressors occurring in combination with heat stress exacerbate the damage to plant and affect yield (Figs. 1, 2). Breeding programs and agricultural practices must focus on avoiding the effects of these conditions, as well as on improving different crop-specific mechanisms of heat damage control and repair, considering physiological, hormonal and genetic mechanisms in an integrated manner. New cultivars must be effective in protecting and repairing their photosynthetic machinery, maintaining carbon assimilation rates and developing reproductive organs in a warmer environment. The research reviewed here indicates that high and/or fast accumulation of stress signaling hormones such as $\mathrm{ABA}$ and $\mathrm{JA}$, the induction of certain gene families and/or transcription factors involved in initiating acclimation responses and the production of 
protective proteins like HSPs, may be key factors that determine plant success to acclimate to the different stress combinations that include high temperatures.

Data reviewed here identify some of the most affected processes during plant growth under abiotic stress combinations at high temperatures. In addition, it shows common responses to different stress combinations that can be used to improve tolerance to these harmful environmental conditions. However, most of research described here was performed under laboratory conditions. It is necessary, therefore, that the conclusions obtained from these studies will be further supported by evidence obtained from field studies under real harsh climatic conditions.

Acknowledgements This work was supported by the Spanish Ministerio de Ciencia e Innovación, and Generalitat Valenciana through Grant AGL2016-76574-R and AICO/2019/150, respectively. DB was recipient of a predoctoral contract funded by Generalitat Valenciana (FEDEGENT/2018/001).

\section{References}

Agarwal PK, Gupta K, Lopato S, Agarwal P (2017) Dehydration responsive element binding transcription factors and their applications for the engineering of stress tolerance. J Exp Bot 68: 2135-2148.

Ashoub A, Müller N, Jiménez-Gómez JM, Brüggemann W (2018) Prominent alterations of wild barley leaf transcriptome in response to individual and combined drought acclimation and heat shock conditions. Physiol Plant 163: 18-29.

Balfagón D, Zandalinas SI, Baliño P, Muriach M, Gómez-Cadenas A (2018) Involvement of ascorbate peroxidase and heat shock proteins on citrus tolerance to combined conditions of drought and high temperatures. Plant Physiol Bioch 127: 194-199.

Balfagón D, Zandalinas SI, Gómez-Cadenas A (2019a) High temperatures change the perspective: Integrating hormonal responses in citrus plants under co-occurring abiotic stress conditions. Physiol Plant 165: 183-197.

Balfagón D, Sengupta S, Gómez-Cadenas A, Fritschi FB, Azad R, Mittler R, Zandalinas SI (2019b) Jasmonic acid is required for plant acclimation to a combination of high light and heat stress. Plant Phys 181: 1668-1682. 
Baud S, Lepiniec L (2010) Physiological and developmental regulation of seed oil production. Prog Lipid Res 49: 235-249.

Chen Y-E, Zhang C-M, Su Y-Q, Ma J, Zhang Z-W, Yuan M, Zang H-Y, Yuan S (2017) Responses of photosystem II and antioxidative systems to high light and high temperature co-stress in wheat. Environ Exp Bot 135: 45-55.

Cui L-L, Lu Y, Li Y, Yang C, Peng X-X (2016) Overexpression of Glycolate Oxidase Confers Improved Photosynthesis under High Light and High Temperature in Rice. Front Plant Sci 7: 1165.

Elferjani R, Soolanayakanahally R (2018) Canola responses to drought, heat, and combined stress: shared and specific effects on carbon assimilation, seed yield, and oil composition. Front Plant Sci 9: 1224.

Fábián A, Sáfrán E, Szabó-Eitel G, Barnabás B, Jäger K (2019) Stigma functionality and fertility are reduced by heat and drought co-stress in wheat. Front Plant Sci 10: 244.

Fahad S, Bajwa AA, Nazir U, Anjum SA, Farooq A, Zohaib A, Sadia S, Nasim W, Adkins S, Saud S, Ihsan MZ, Alharby H, Wu C, Wang D, HUag J (2017) Crop production under drought and heat stress: Plant responses and management options. Front Plant Sci 8: 1147.

Gómez-Cadenas A, Vives V, Zandalinas SI, Manzi M, Sánchez-Pérez AM, Pérez-Clemente RM, Arbona V (2015) Abscisic acid: a versatile phytohormone in plant signaling and beyond. Curr Protein Pept Sc 16: 413-434.

Hatfield JL, Prueger JH (2015) Temperature extremes: Effect on plant growth and development. Weather Clim 10: 4-10.

Jia J, Zhou J, Shi W, Cao X, Luo J, Polle A, Luo ZB (2017) Comparative transcriptomic analysis reveals the roles of overlapping heat-/drought-responsive genes in poplars exposed to high temperature and drought. Sci Rep 7, 43215.

Jumrani K, Bhatia VS (2019) Interactive effect of temperature and water stress on physiological and biochemical processes in soybean. Physiol Mol Biol Pla 25: 667-681.

Killi D, Bussotti F, Raschi A, Haworth M (2017) Adaptation to high temperature mitigates the impact of water deficit during combined heat and drought stress in $\mathrm{C} 3$ sunflower and C4 maize varieties with contrasting drought tolerance. Physiol Plant 159: 130-147. 
Lawas LMF, Zuther E, Jagadish SK, Hincha DK (2018) Molecular mechanisms of combined heat and drought stress resilience in cereals. Curr Opin Plant Biol 45: 212-217.

Li Y, Ye W, Wang M, Yan X (2009) Climate change and drought: a risk assessment of cropyield impacts. Clim Res 39: 31-46.

Li W, Zhang C, Lu Q, Wen X, Lu C (2011) The combined effect of salt stress and heat shock on proteome profiling in Suaeda salsa. J Plant Physiol 168: 1743-1752.

Mahalingam R, Bregitzer P (2019) Impact on physiology and malting quality of barley exposed to heat, drought and their combination during different growth stages under controlled environment. Physiol Plant 165: 277-289.

Martinez V, Nieves-Cordones M, Lopez-Delacalle M, Rodenas R, Mestre TC, GarciaSanchez F, Rubio F, Nortes PA, Mittler R, Rivero RM (2018) Tolerance to stress combination in tomato plants: New insights in the protective role of melatonin. Molecules 23: 535 .

Mittler R (2006) Abiotic stress, the field environment and stress combination. Trends Plant Sci 11: 15-19.

Mizoi J, Shinozaki K, Yamaguchi-Shinozaki K (2012) AP2/ERF family transcription factors in plant abiotic stress responses. BBA-GENE Regul Mech 1819: 86-96.

Moya JL, Gómez-Cadenas A, Primo-Millo E, Talon M (2003) Chloride absorption in saltsensitive Carrizo citrange and salt-tolerant Cleopatra mandarin citrus rootstocks is linked to water use. J Exp Bot 54: 825-833.

Murata Y, Mori IC, Munemasa S (2015) Diverse stomatal signaling and the signal integration mechanism. Annu Rev Plant Biol 66: 369-392.

Perdomo JA, Conesa M, Medrano H, Ribas-Carbó M, Galmés J (2015) Effects of long-term individual and combined water and temperature stress on the growth of rice, wheat and maize: Relationship with morphological and physiological acclimation. Physiol Plant 155: $149-165$.

Pospíšil P (2016) Production of Reactive Oxygen Species by Photosystem II as a Response to Light and Temperature Stress. Front Plant Sci 7: 1950.

Prasad PVV, Bheemanahalli R, Jagadish SVK (2017) Field crops and the fear of heat stress-Opportunities, challenges and future directions. Field Crops Res 200: 114-121. 
Prasad PVV, Pisipati SR, Momčilović I, Ristic Z (2011) Independent and Combined Effects of High Temperature and Drought Stress During Grain Filling on Plant Yield and Chloroplast EF-Tu Expression in Spring Wheat. J Agron Crop Sci 197: 430-441.

Qaderi MM, Kurepin LV, Reid DM (2006) Growth and physiological responses of canola (Brassica napus) to three components of global climate change: Temperature, carbon dioxide and drought. Physiol Plant 128: 710-721.

Rizhsky L, Liang H, Shuman J, Shulaev V, Davletova S, Mittler R (2004) When defense pathways collide. The response of Arabidopsis to a combination of drought and heat stress. Plant Phys 134: 1683-1696.

Rollins JA, Habte E, Templer SE, Colby T, Schmidt J, Von Korff M (2013) Leaf proteome alterations in the context of physiological and morphological responses to drought and heat stress in barley (Hordeum vulgare L.). J Exp Bot 64: 3201-3212.

Sehgal A, Sita K, Kumar J, Kumar S, Singh S, Siddique KHM, Nayyar H (2017) Effects of drought, heat and their interaction on the growth, yield and photosynthetic function of lentil (Lens culinaris medikus) genotypes varying in heat and drought sensitivity. Front Plant Sci 8: 1776.

Suzuki N., Basil E., Hamilton J.S., Inupakutika, Madhuri A Zandalinas S.I., Tripathy D, Yuting L, Dion E, Fukui G, Kumazaki A, Nakano R, Rivero R, Azad RK, Blumwald E, Mittler R (2016) ABA is required for plant acclimation to a combination of salt and heat stress. PloS One 11: e0147625.

Suzuki N, Mittler R (2006) Reactive oxygen species and temperature stresses: A delicate balance between signaling and destruction. Physiol Plant 126: 45-51.

Szymańska R, Ślesak I, Orzechowska A, Kruk J (2017) Physiological and biochemical responses to high light and temperature stress in plants. Environ Exp Bot 139: 165-177.

Teixeira EI, Fischer G, van Velthuizen H, Walter C, Ewert F (2013) Global hot-spots of heat stress on agricultural crops due to climate change. Agr Forest Meteorol 170: 206-215.

Teuling AJ (2018) A hot future for European droughts. Nat Clim Chang 8: 364-365.

Wang L, Liu L, Ma Y, Li S, Dong S, Zu W (2018) Transcriptome profilling analysis characterized the gene expression patterns responded to combined drought and heat stresses in soybean. Comput Biol Chem 77: 413-429. 
Yamamoto Y., Aminaka R., Yoshioka M., Khatoon M., Komayama K., Takenaka D., Yamashita A., Nijo N., Inagawa K., Morita N., Sasaki T., Yamamoto Y (2008) Quality control of photosystem II: Impact of light and heat stresses. Photosynth Res 98: 589-608.

Zandalinas SI, Balfagón D, Arbona V, Gómez-Cadenas A, Inupakutika MA, Mittler R (2016a) ABA is required for the accumulation of APX1 and MBF1c during a combination of water deficit and heat stress. J Exp Bot 67: 5381-5390.

Zandalinas SI, Rivero RM, Martínez V, Gómez-Cadenas A, Arbona V (2016b) Tolerance of citrus plants to the combination of high temperatures and drought is associated to the increase in transpiration modulated by a reduction in abscisic acid levels. BMC Plant Biol 16: 105.

Zandalinas SI, Balfagón D, Arbona V, Gómez-Cadenas A (2017) Modulation of Antioxidant Defense System Is Associated with Combined Drought and Heat Stress Tolerance in Citrus. Front Plant Sci 8: 953.

Zandalinas SI, Balfagón D, Arbona V, Gómez-Cadenas A (2018a) Regulation of citrus responses to the combined action of drought and high temperatures depends on the severity of water deprivation. Physiol Plant 162: 427-438.

Zandalinas SI, Mittler R, Balfagón D, Arbona V, Gómez-Cadenas A (2018b) Plant adaptations to the combination of drought and high temperatures. Physiol Plant 162: 2-12.

Zandalinas SI, Fritschi FB, Mittler R (2020) Signal transduction networks during stress combination. J Exp Bot, 71:1734-1741.

Zhang X, Högy P, Wu X, Schimd I, Wang X, Schulze WX, Jiang D, Fangmeier A (2018) Physiological and Proteomic Evidence for the Interactive Effects of Post-Anthesis Heat Stress and Elevated CO2 on Wheat. Proteomics 18: 1800262.

Zhao C., Liu B., Piao S., Wang X., Lobell D.B., Huang Y., Huang M., Yao Y., Bassu S., Ciais P., Durand J.L., Elliot J., Ewert F., Janssens I.A., Li T., Lin E., Liu Q., Martre P., Müller C., Peng S., Peñuelas J., Ruane A.C., Wallach D., Wang T., Wu D., Liu Z., Zhu Y., Asseng S (2017) Temperature increase reduces global yields of major crops in four independent estimates. Proc Natl Acad Sci USA 114: 9326-9331.

Zhao F, Zhang D, Zhao Y, Wang W, Yang H, Ta F, Li C, Hu X (2016) The difference of physiological and proteomic changes in maize leaves adaptation to drought, heat, and combined both stresses. Front Plant Sci 7: 1471. 
Zhou R, Kong L, Wu Z, Rosenqvist E, Wang Y, Zhao L, Zhao T, Ottosen C-O (2019) Physiological response of tomatoes at drought, heat and their combination followed by recovery. Physiol Plant 165: 144-154. 
Objectives 

The main objective of this work consists in the study of the impact of different abiotic stresses in combination with high temperatures on plant physiology.

To achieve this aim, the following partial objectives were established:

1. Determine the physiological and molecular responses of two citrus genotypes (Carrizo citrange and Cleopatra mandarin) to the combination of drought and high temperatures (Chapter 1).

2. Study the relationship between the antioxidant activity and the tolerance of these citrus genotypes to drought and heat stress combination (Chapter 2).

3. Analyze the physiological and hormonal responses of the citrus genotype Carrizo citrange to mechanical wounding and salinity in combination with high temperatures. (Chapter 3).

4. Evaluate the physiological, hormonal and transcriptomic responses to high light and heat stress combination in the model plant Arabidopsis thaliana (Chapter 4). 


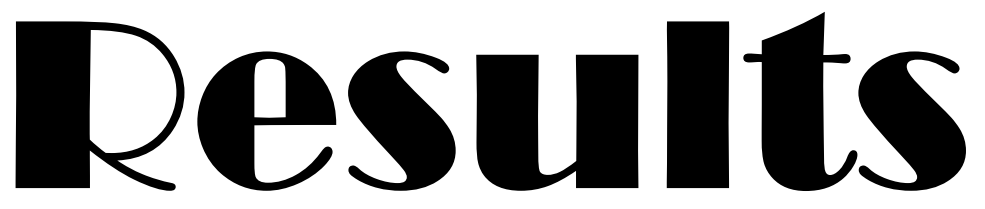

\section{Chapter 1}

Modulation of antioxidant defense system is associated with combined drought and heat stress tolerance in citrus

Zandalinas \& Balfagón et al. (2017) Frontiers in Plant Science 8:953 



\begin{abstract}
Drought and high temperatures are two major abiotic stress factors that often occur simultaneously in nature, affecting negatively crop performance and yield. Moreover, these environmental challenges induce oxidative stress in plants through the production of reactive oxygen species (ROS). Carrizo citrange and Cleopatra mandarin are two citrus genotypes with contrasting ability to cope with the combination of drought and heat stress. In this work, a direct relationship between an increased antioxidant activity and stress tolerance is reported. According to our results, the ability of Carrizo plants to efficiently coordinate superoxide dismutase (SOD), ascorbate peroxidase (APX), catalase (CAT), and glutathione reductase (GR) activities involved in ROS detoxification along with the maintenance of a favorable GSH/GSSG ratio could be related to their relative tolerance to this stress combination. On the other hand, the increment of SOD activity and the inefficient GR activation along with the lack of CAT and APX activities in Cleopatra plants in response to the combination of drought and heat stress, could contribute to an increased oxidative stress and the higher sensibility of this citrus genotype to this stress combination.
\end{abstract}

\title{
Introduction
}

Environmental stresses cause large economic losses in agriculture every year, constraining crop yield and production. Owing to the consequences of the climate change, different combinations of abiotic stress conditions are severely impacting on plants in the natural field. Although research on plants is traditionally based on the study of the responses to single abiotic factors, further effort has been made over the last years to analyze plant responses to different combined stresses, either abiotic or biotic (Suzuki et al., 2014; Zandalinas et al., 2017a). Particularly, drought and heat are considered one of the most frequent abiotic stress combinations that drastically affect global agricultural systems (International Panel of Climate Change, IPCC 2014).

In general, abiotic stresses that limit $\mathrm{CO}_{2}$ availability due to stomatal closure enhance the accumulation of reactive oxygen species (ROS). Interestingly, while ROS, such as $\mathrm{H}_{2} \mathrm{O}_{2}$, are considered important signal transduction molecules (Baxter et al., 2014; Mittler, 2016), they are also toxic, causing extensive cellular damage and inhibition of photosynthesis (Choudhury et al., 2016). To prevent damage, ROS accumulation is mitigated by the antioxidant machinery including ROS-scavenging enzymes and 


\section{Chapter 1}

increased levels of antioxidants such as ascorbate (AsA) and glutathione (GSH), components of the so-called Halliwell-Asada cycle (Mittler et al., 2004). One of the key enzymes of the antioxidant defense system is the superoxide dismutase (SOD), which constitutes the first level of defense against superoxide radicals. SOD-catalyzed $\mathrm{O}_{2}{ }^{\bullet-}$ dismutation renders $\mathrm{H}_{2} \mathrm{O}_{2}$ as a reaction product, which in turn is removed by ascorbate peroxidase (APX) and catalase (CAT) activities (Mittler et al., 2004). APX reduces $\mathrm{H}_{2} \mathrm{O}_{2}$ using AsA as the electron donor and the balance between GSH and oxidized glutathione (GSSG) is critical for maintaining a favorable redox status for the detoxification of $\mathrm{H}_{2} \mathrm{O}_{2}$. In addition, glutathione reductase (GR), the rate-limiting enzyme of AsA-GSH cycle, keeps the GSH/GSSG ratio favorable for ascorbate reduction (Foyer and Noctor, 2005).

Several studies have reported that the ability of plants to balance ROS production and scavenging is associated to a higher tolerance to different environmental stresses (Arbona et al., 2008; Hernandez et al., 2000; Lin et al., 2004; Martinez et al., 2016). The accumulation of high amount of ROS-response transcripts in plants subjected to different combinations of stress factors, reflects the relevance of ROS as an important component of acclimation pathways during combined stresses (reviewed in Suzuki et al. 2014). For example, it has been suggested the key role of cytosolic APX1 for the acclimation of plants to a combination of drought and heat (Koussevitzky et al., 2008). In that work, Arabidopsis mutants deficient in this enzyme (apxl), were found to be highly sensitive to this stress combination. Furthermore, ROS-ABA interactions are very important for plant acclimation to stress combination. In this way, previous reports have shown that mutants impaired in the function of the ABA and ROS-regulated PP2Cs (abi-1) were sensitive to the combined impact of drought and heat, as well as salinity and heat (Suzuki et al., 2016; Zandalinas et al., 2016a). Furthermore, several studies have reported that the expression of different ROS-scavenging enzymes and the accumulation of different antioxidants exhibit a unique mechanism of response during stress combination that is different than that found in response to each individual stress (Giraud et al., 2008; Jin et al., 2016; Keles and Oncel, 2002; Martinez et al., 2016; Pandey et al., 2015; Prasch and Sonnewald, 2013; Rasmussen et al., 2013; Rivero et al., 2013; Rizhsky et al., 2002, 2004; Vile et al., 2012).

Metabolite profiling of leaves of both citrus genotypes in response to combined drought and heat revealed that the accumulation of secondary metabolites with antioxidant function is associated to sensitivity to this stress combination (Zandalinas et al., 2017b). 
Therefore, the higher sensitivity of Cleopatra plants required a higher accumulation of protective metabolites oriented to mitigate the damaging effects of stress, including flavonols, flavones and limonoids (Zandalinas et al., 2017b). However, the role of the antioxidant defense involving ROS-scavenging enzymes in the tolerance of citrus plants to combined drought and heat is currently unknown. Previous reports have associated the ability to modulate the antioxidant system with the tolerance of citrus plants to waterlogging (Arbona et al., 2008; Hossain et al., 2009), salinity (Arbona et al., 2003) or water stress (Wu et al., 2006). In general, these investigations concluded that coordinated antioxidant activity associated to increased activities of SOD and CAT, along with a modulation of the AsA-GSH cycle, allowed citrus plants to reduce stress-induced oxidative damage. In addition, a recent study demonstrated that the antioxidant response of different citrus plants subjected to $\mathrm{Cu}$ stress was dependent on the signaling regulated by the rootstocks, suggesting that the use of appropriate rootstocks contributes to alleviate the effects of $\mathrm{Cu}$ stress (Hippler et al., 2016).

The aim of the present work was to investigate how oxidative metabolism and related antioxidants were modified during the combination of drought and high temperatures in two citrus genotypes (Carrizo citrange and Cleopatra mandarin) with different ability to cope with combined stresses (Zandalinas et al., 2016b) and to correlate the modulation of the antioxidant system with the different tolerance to this stress combination.

\section{Materials and methods}

\section{Plant material and growth conditions}

Carrizo citrange (Poncirus trifoliata L. Raf. x Citrus sinensis L. Osb.) and Cleopatra mandarin (Citrus reshni Hort. Ex Tan.) plants were purchased from a commercial nursery (Beniplant S.L., Penyíscola, Spain). One-year-old seedlings of both citrus genotypes were grown in plastic pots filled with perlite and watered three times a week with a halfstrength Hoagland solution under greenhouse conditions, with natural photoperiod and day and night temperature averaging $25.0 \pm 3.0^{\circ} \mathrm{C}$ and $18.0 \pm 3.0^{\circ} \mathrm{C}$, respectively. Then, plants were maintained for two weeks in growth chambers to acclimate to a 16-h photoperiod at $25{ }^{\circ} \mathrm{C}$ and relative moisture at approximately $80 \%$. Temperature and relative moisture were recorded regularly with a portable USB datalogger (OM-EL-WINUSB, Omega, New Jersey, USA). 


\section{Stress treatments and experimental designs}

A 24-h experiment of combined drought and heat was performed with both types of plants (Figure 1). High temperatures $\left(40^{\circ} \mathrm{C}\right)$ were firstly imposed for 7 days to a group of plants, maintaining another group at $25^{\circ} \mathrm{C}$ as control. After imposing the temperature treatment, severe water stress conditions were applied by transplanting a group of plants grown at $25{ }^{\circ} \mathrm{C}$ or at $40{ }^{\circ} \mathrm{C}$ to dry perlite. Therefore, four experimental groups for each citrus genotype were established: well-watered plants at $25{ }^{\circ} \mathrm{C}(\mathrm{CT})$ and at $40{ }^{\circ} \mathrm{C}$ (HS) and plants subjected to water stress at $25{ }^{\circ} \mathrm{C}$ (WS) and at $40{ }^{\circ} \mathrm{C}$ (WS $+\mathrm{HS}$ ). Leaves with an intermediate position in the canopy were harvested and immediately submerged in liquid $\mathrm{N}_{2}$.

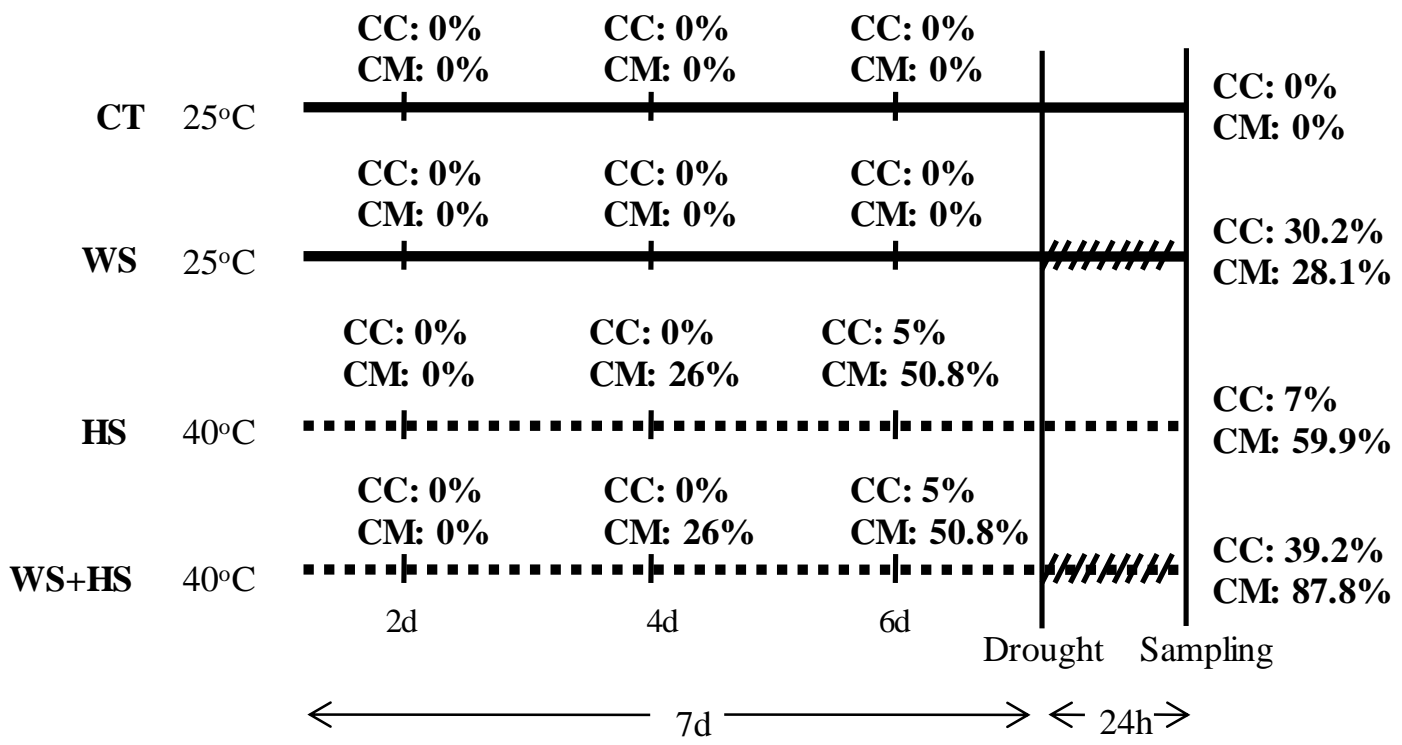

Figure 1. Experimental design used to subject Carrizo and Cleopatra plants to drought (WS), heat stress (HS) and a combination of drought and heat stress (WS + HS) with details of period times for each stress treatment. Percentages of affected leaves in Carrizo (CC) and Cleopatra (CM) subjected to WS, HS and WS+HS are also indicated.

\section{Proline concentration}

Proline analysis was performed as described by Bates et al. (1973) with some modifications. Briefly, $50 \mathrm{mg}$ of ground leaf tissue was extracted in $5 \mathrm{ml}$ of $3 \%$ sulfosalicylic acid (Panreac, Barcelona, Spain) by sonication for 30 min. After centrifuging at $4000 \mathrm{~g}$ for $20 \mathrm{~min}$ at $4{ }^{\circ} \mathrm{C}, 1 \mathrm{ml}$ of the supernatant was mixed with $1 \mathrm{ml}$ of glacial acetic acid and ninhydrin reagent (Panreac) in a 1:1 (v:v) ratio. The reaction mixture was incubated in a water bath at $100{ }^{\circ} \mathrm{C}$ for $1 \mathrm{~h}$ and subsequently centrifuged at $2000 \mathrm{~g}$ for $5 \mathrm{~min}$ at $4{ }^{\circ} \mathrm{C}$. Finally, absorbance was read at $520 \mathrm{~nm}$. A standard curve was assayed with pure proline (Sigma-Aldrich, St. Louis, MO, USA). 


\section{Leaf water status}

Relative water content (RWC) of citrus leaves was calculated using adjacent leaves, which were weighed to obtain a leaf fresh mass $\left(\mathrm{M}_{\mathrm{f}}\right)$. Leaves were allowed to rehydrate overnight in an opaque beaker filled with water. Therefore, they were reweighed to obtain turgid mass $\left(\mathrm{M}_{\mathrm{t}}\right)$. Finally, leaves were dried at $80{ }^{\circ} \mathrm{C}$ for $48 \mathrm{~h}$ to obtain dry mass $\left(\mathrm{M}_{\mathrm{d}}\right)$. RWC was calculated as $\left[\left(\mathrm{M}_{\mathrm{f}}-\mathrm{M}_{\mathrm{d}}\right) \times\left(\mathrm{M}_{\mathrm{t}}-\mathrm{M}_{\mathrm{d}}\right)^{-1}\right] \times 100$ according to Morgan (1984).

\section{Malondialdehyde concentration}

Malondialdehyde (MDA) content was measured following the procedure of Hodges et al. (1999) with modifications. Ground leaf tissue ( $0.2 \mathrm{~g})$ were extracted in $2 \mathrm{~mL} 80 \%$ ethanol by sonication for $30 \mathrm{~min}$ and, after that, centrifuged at $12000 \mathrm{~g}$ for $10 \mathrm{~min}$. Different aliquots of the supernatant were mixed either with $20 \%$ trichloroacetic acid or with a mixture of $20 \%$ trichloroacetic acid and $0.5 \%$ thiobarbituric acid. Both mixtures were incubated in a water bath at $90{ }^{\circ} \mathrm{C}$ for $1 \mathrm{~h}$. After cooling samples in ice, homogenates were centrifuged at $2000 \mathrm{~g}$ for $10 \mathrm{~min}$ at $4{ }^{\circ} \mathrm{C}$. Lastly, the absorbance at 440,534 and 600 nm of supernatants was read.

\section{Gene expression}

The specific primers used for the amplification of each gene are included in Table S1. qRT-PCR analyses were performed in a StepOne Real-Time PCR system (Applied Biosystems, CA, USA). The reaction mixture contained $1 \mu \mathrm{L}$ of cDNA, $5 \mu \mathrm{L}$ of SYBRGreen (Applied Biosystems) and $1 \mu \mathrm{M}$ of each gene-specific primer pair in a final volume of $10 \mu \mathrm{L}$. The thermal profile used to analyze the relative gene expression consisted of $10 \mathrm{~min}$ at $95{ }^{\circ} \mathrm{C}$ for pre-incubation, followed by 40 cycles of $10 \mathrm{~s}$ at $95{ }^{\circ} \mathrm{C}$ for denaturation, $10 \mathrm{~s}$ at $60{ }^{\circ} \mathrm{C}$ for annealing and $20 \mathrm{~s}$ at $72{ }^{\circ} \mathrm{C}$ for extension. Amplicon specificity of the PCR reaction was evaluated by the presence of a single peak in the dissociation curve after the amplification steps. The expression levels of all genes was normalized against the expression of two endogenous control genes (tubulin and actin) based on previous housekeeping selection for citrus tissues (Mafra et al., 2012) and the relative expression were calculated by using Relative Expression Software Tool (REST; Pfaffl et al. 2002). For all genes studied, the reference sample was the expression value obtained at the non-stressed samples and set at zero. 


\section{Antioxidant enzyme activities}

About $100 \mathrm{mg}$ of frozen ground leaf tissue were extracted in $2 \mathrm{~mL}$ of phosphate buffer in a ball mill (MillMix20, Domel, Železniki, Slovenija). After centrifugation $14000 \mathrm{~g}$ at 4 ${ }^{\circ} \mathrm{C}$ for $10 \mathrm{~min}$, supernatant were recovered. Different buffers were used for enzyme extractions as follows: for APX, $50 \mathrm{mM}$ phosphate buffer ( $\mathrm{pH} 7.8$ ) supplemented with 1 $\mathrm{mM}$ sodium ascorbate and $1 \mathrm{mM}$ EDTA; for SOD, $50 \mathrm{mM}$ phosphate buffer ( $\mathrm{pH}$ 6.8) with $1.33 \mathrm{mM}$ diethyl-diamino-pentaacetic acid; finally, CAT and GR were extracted in $50 \mathrm{mM}$ phosphate buffer ( $\mathrm{pH} 6.8$ and $\mathrm{pH} 7.5$, respectively). The APX activity was assayed following the depletion in absorbance at $290 \mathrm{~nm}$ due to AsA consumption. The SOD activity was determined following the $\mathrm{O}_{2}{ }^{\bullet-}$-induced reduction of nitroblue tetrazolium using the xanthine-xanthine oxidase system. CAT was determined using the hydrogen peroxide-dependent reduction of titanium chloride. The GR activity was studied following the increase in absorbance at $412 \mathrm{~nm}$ during 2 min as result of the production of the adduct DTNB-GSH after GSSG reduction. The reaction was initiated by adding a suitable aliquot of enzyme extract and the increment in absorbance was recorded during $3 \mathrm{~min}$ at $265 \mathrm{~nm}$. Soluble protein content was determined according to Bradford (1976) using BSA as a standard. Enzyme activity was expressed as $\mathrm{U} \mathrm{mg}^{-1}$ protein. Further details on enzyme assays are provided in Hossain et al. (2009).

\section{Ascorbate and glutathione levels}

Procedures for ascorbate and glutathione determinations are described in Hossain et al. (2009). In short, ascorbate assay is derived from the reduction of $\mathrm{Fe}^{3+}$ to $\mathrm{Fe}^{2+}$ in acidic solution by ascorbate. $\mathrm{Fe}^{2+}$ forms a red chelate with bipyridyl that absorbs at $525 \mathrm{~nm}$. DHA was calculated by subtracting AsA from total ascorbate. The DTNB-GSSG reductase recycling process was used to calculate both total (GSH+GSSG) and GSSG levels.

\section{Statistical analyses}

Data are means of three independent determinations and were subjected to analysis of variance (ANOVA) using a two-way ANOVA with the interaction genotype $\mathrm{x}$ stress followed by Tukey posthoc test $(\mathrm{P}<0.05)$ when a significant difference was detected. 


\section{Results}

Leaf damage induced by drought, heat and combined stresses

As shown in Figure 1, 24-hour of drought applied individually induced visible leaf damage in both citrus genotypes $(30.2 \%$ and $28.1 \%$ of Carrizo and Cleopatra leaves, respectively, were injured). Carrizo plants subjected to continuous heat stress $\left(40^{\circ} \mathrm{C}\right)$ were slightly affected, showing only $5 \%$ and $7 \%$ of total leaves damaged at 6 days and at the end of the experiment, respectively. On the contrary, after 4 days of heat regime, $26 \%$ of Cleopatra leaves were damaged, reaching about 59.9\% at the end of the experiment. Plants subjected to a combination of drought and heat stress showed the highest percentage of leaf damage in both citrus genotypes. Hence, $39.2 \%$ and $87.8 \%$ of leaves were affected by the combined stresses in Carrizo and Cleopatra, respectively (Figure 1). Impact of drought, heat and combined stresses on water status

Leaf RWC of Carrizo and Cleopatra plants subjected to drought, heat stress and a combination of drought and heat stress was measured (Table 1). Drought and heat stress conditions similarly decreased leaf RWC in Carrizo and Cleopatra: in Carrizo plants subjected to WS and HS, RWC reached $60.32 \%$ and $75.32 \%$ respect to control values, respectively. In Cleopatra plants, RWC decreased to $59.66 \%$ and $69.01 \%$ (with respect to controls) in response to WS and HS, respectively. Interestingly, stress combination had an additive impact on this parameter, showing the greatest decrease $(43.38 \%$ and $39.41 \%$ with respect to control values in Carrizo and Cleopatra, respectively; Table 1). 
Table 1. Relative water content (RWC) of Carrizo and Cleopatra leaves subjected to drought (WS), heat (HS) and their combination (WS + HS). Data are presented as mean value of three different replicates \pm SD. Different letters denote statistical significance at $p \leq 0.05$. G: genotype; $\mathrm{S}$ : stress treatment; GxS: interaction genotype $\mathrm{x}$ stress treatment. $* \mathrm{P}<0.05 ; * * \mathrm{P}<0.01$; $* * * \mathrm{P}<$ 0.001; ns: no statistical differences.

\begin{tabular}{crc}
\hline Genotype & & RWC (\%) \\
\hline Carrizo & CT & $92.96 \pm 0.75 \mathrm{a}$ \\
& WS & $60.32 \pm 3.01 \mathrm{bc}$ \\
& HS & $75.32 \pm 4.73 \mathrm{~b}$ \\
& WS + HS & $43.38 \pm 5.17 \mathrm{de}$ \\
Cleopatra & CT & $93.72 \pm 3.01 \mathrm{a}$ \\
& WS & $59.66 \pm 4.31 \mathrm{~cd}$ \\
& HS & $69.01 \pm 3.92 \mathrm{bcd}$ \\
& WS + HS & $39.41 \pm 6.07 \mathrm{e}$ \\
\hline G: $* *$ & & \\
S: $* * *$ & & \\
GxS: ns & \\
\hline
\end{tabular}

\section{Proline concentration}

Endogenous proline levels were examined in leaves and roots of both citrus genotypes in response to individual and combined stresses (Figure 2). In general, basal proline content of both Cleopatra leaves and roots almost doubled the levels observed in Carrizo. Furthermore, proline concentration in Carrizo leaves significantly increased respect to control values in response to individual stresses. In addition, stress combination induced the highest proline concentration in this genotype $\left(52.6 \mathrm{nmol} \mathrm{g}^{-1} \mathrm{FW}\right)$. Proline content only increased in response to WS and WS+HS in Cleopatra leaves (Figure 2A). On the other hand, significant increments of proline levels were observed in Carrizo roots subjected to WS (2.2-fold) and especially to WS+HS (3.1-fold), whereas HS did not impact on proline build-up. Finally, proline levels increased similarly in Cleopatra roots in response to WS and WS+HS (about 2-fold) and HS caused a reduction of its levels below control values (Figure 2B).

\section{MDA concentration}

Oxidative damage in terms of malondialdehyde (MDA) concentration in response to drought, heat stress and the combination of drought and heat stress was studied in leaves and roots of both citrus genotypes (Figure 3). MDA accumulated in Carrizo leaves in response to WS and more prominently in response to WS+HS, reaching $170.02 \mathrm{nmol} \mathrm{g}^{-1}$ FW. On the contrary, Cleopatra leaves increased MDA content in response to HS and 
especially during WS+HS (234.21 $\mathrm{nmol} \mathrm{g}^{-1} \mathrm{FW}$, Figure 3A). MDA accumulation pattern in roots was different between both citrus genotypes. Whereas WS induced MDA accumulation only in Cleopatra, HS slightly increased its accumulation in both citrus plants. Strikingly, stress combination resulted in a minor MDA accumulation in Carrizo roots $\left(133.83 \mathrm{nmol} \mathrm{g}^{-1} \mathrm{FW}\right)$ whereas in Cleopatra roots, it resulted in a strong MDA accumulation, reaching $250.24 \mathrm{nmol} \mathrm{g}^{-1} \mathrm{FW}$ (Figure 3B).
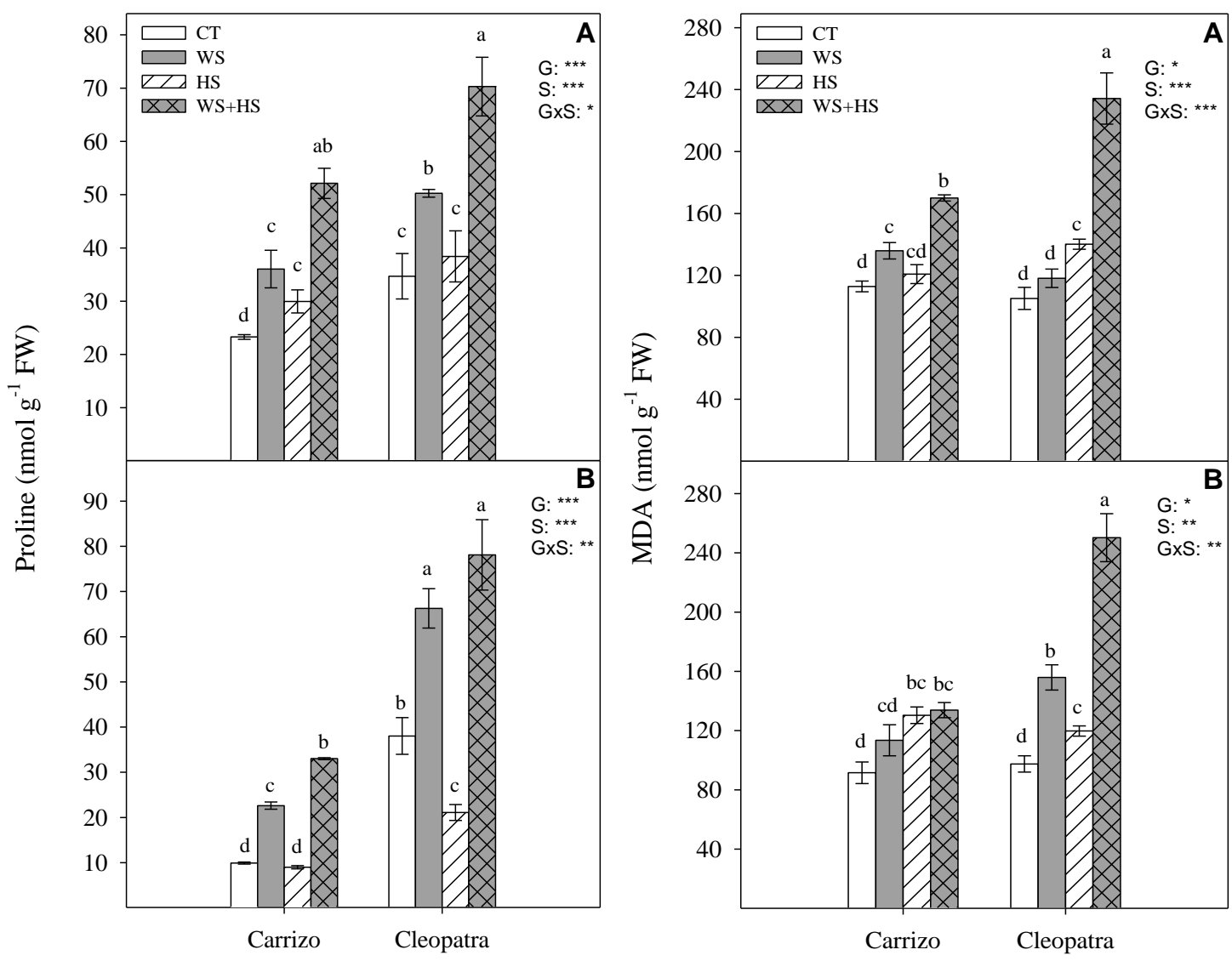

Figure 2. Proline accumulation in leaves (A) and roots $(\mathbf{B})$ of Carrizo and Cleopatra plants subjected to drought (WS), heat (HS) and a combination of drought and heat stress (WS + HS). Different letters denote statistical significance at $\mathrm{p} \leq 0.05$. G: genotypes; $\mathrm{S}$ : stress treatment; GxS: interaction genotype $\mathrm{x}$ stress treatment. $* \mathrm{P}<0.05 ; * * \mathrm{P}<0.01 ; * * * \mathrm{P}$ $<0.001$; ns: no statistical differences.

Figure 3. Malondialdehyde (MDA) accumulation in leaves $(\mathbf{A})$ and roots $(\mathbf{B})$ of Carrizo and Cleopatra plants subjected to drought (WS), heat (HS) and a combination of drought and heat stress (WS + HS). Different letters denote statistical significance at $\mathrm{p} \leq$ 0.05 . G: genotypes; $\mathrm{S}$ : stress treatment; GxS: interaction genotype $\mathrm{x}$ stress treatment. $* \mathrm{P}<$ $0.05 ; * * \mathrm{P}<0.01 ; * * * \mathrm{P}<0.001 ;$ ns: no statistical differences. 
Antioxidant enzymatic activity

To find out the importance of the antioxidant enzymatic machinery in coping with the oxidative stress induced by abiotic stress, the activity of antioxidant enzymes (SOD, CAT, APX, GR) in Carrizo and Cleopatra leaves in response to drought, heat and their combination was studied. Additionally, the transcript levels of genes encoding for those enzymes were analyzed in both citrus genotypes under each stress condition.

Under all conditions (control or stress), the SOD activity was significantly higher in Carrizo (5-fold) compared to Cleopatra plants. Imposition of individual and combined stresses had no significant impact on SOD activity in Carrizo leaves, whereas Cleopatra plants showed a 2-fold and 3-fold increment of this enzymatic activity in response to individual (WS and HS) and combined stresses (WS+HS), respectively (Figure 4A). Furthermore, the relative expression of the gene encoding SOD-CuZn in Carrizo was upregulated under individual stress conditions. In Cleopatra leaves, an accumulation of SOD-CuZn transcripts was observed in response to HS and WS+HS treatments. In addition, SOD-Fe transcripts slightly accumulated in response to HS in Carrizo and in response to WS and WS+HS in Cleopatra (Figure 4B).

Similar to SOD, CAT activity was more than 3-fold higher in Carrizo than in Cleopatra in all conditions studied. In response to individual drought and heat stress, CAT activity did not change with respect to control values in leaves of both citrus genotypes. Interestingly, under stress combination, CAT activity increased in Carrizo and decreased in Cleopatra compared to control levels (Figure 5A). Analysis of the relative accumulation of CAT transcripts in Carrizo revealed a remarkable up-regulation under individual and especially under combined stress conditions. Contrarily, CAT was downregulated in Cleopatra leaves, particularly under WS and WS+HS (Figure 5B).

APX activity significantly increased in response to heat stress and the combination of drought and heat stress with respect to control conditions in Carrizo leaves, whereas in Cleopatra a significant increment in APX activity was observed only in response to heat stress (Figure 6A). Moreover, the relative expression of APX was up-regulated under heat stress and especially under WS and WS+HS in Carrizo, whereas only HS and WS+HS induced the accumulation of APX transcripts in Cleopatra (Figure 6B).

In Carrizo plants, WS significantly increased the GR activity whereas neither HS nor WS+HS had effect on it. In contrast, in Cleopatra plants, WS and WS+HS increased GR 
activity and HS did not change this enzymatic activity respect to control levels (Figure 7A). Nevertheless, GR transcript number increased under all stress conditions studied in both genotypes, mainly in Carrizo leaves under stress combination (Figure 7B).
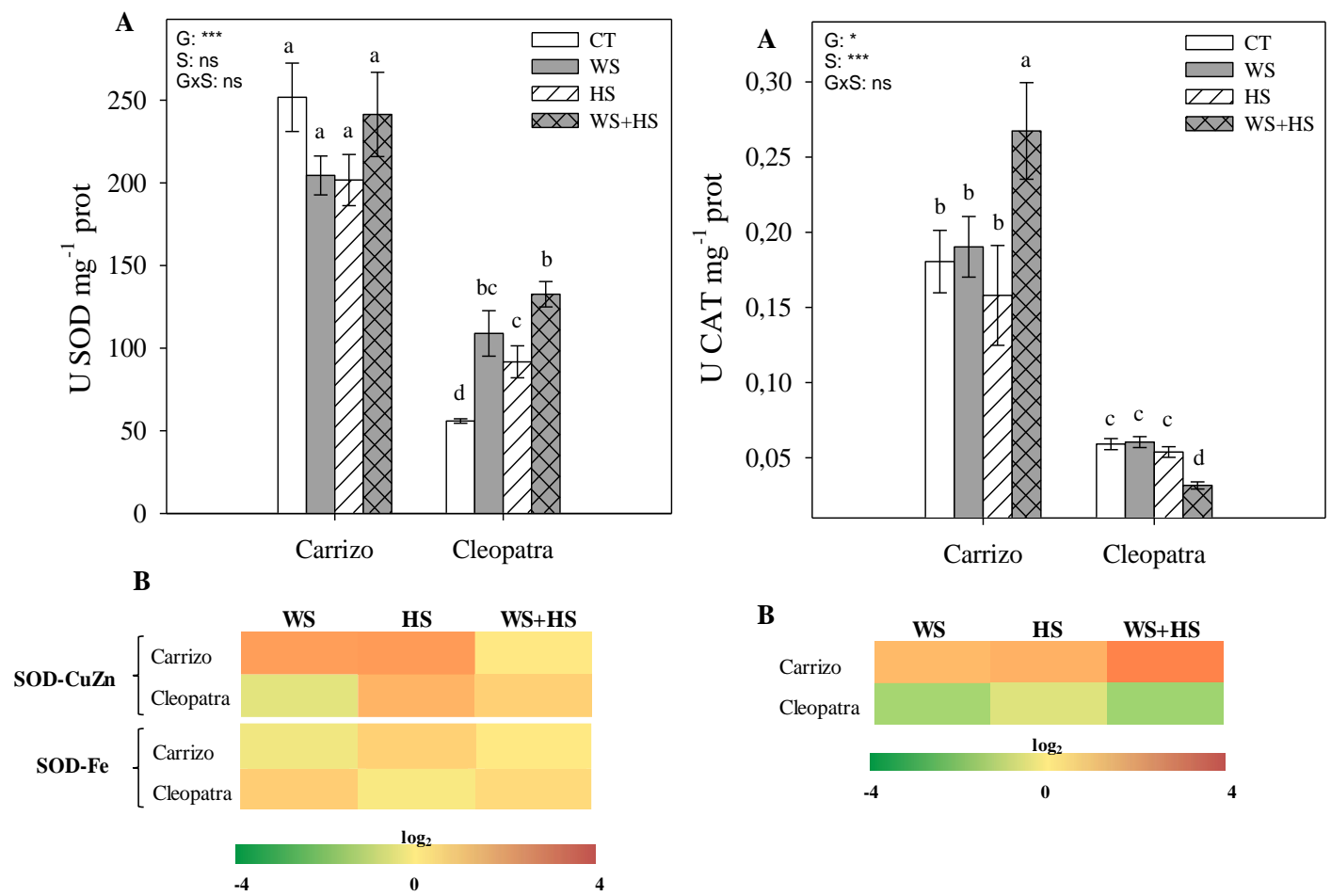

Figure 4. Effects of drought (WS), heat (HS) and a combination of drought and heat stress (WS + HS) on SOD activity (A) and transcript expression (B) in leaves of Carrizo and Cleopatra plants. Different letters denote statistical significance at $\mathrm{p} \leq 0.05$. G: genotypes; S: stress treatment; GxS: interaction genotype $\mathrm{x}$ stress treatment. $* \mathrm{P}<$ $0.05 ; * * \mathrm{P}<0.01 ; * * * \mathrm{P}<0.001$; ns: no statistical differences. Scale for gene expression is $\log _{2}$ of the mean values after normalization against control plants.

Figure 5. Effects of drought (WS), heat (HS) and a combination of drought and heat stress (WS + HS) on CAT activity (A) and transcript expression (B) in leaves of Carrizo and Cleopatra plants. Different letters denote statistical significance at $\mathrm{p} \leq 0.05$. G: genotypes; S: stress treatment; GxS: interaction genotype $\mathrm{x}$ stress treatment. $* \mathrm{P}<$ $0.05 ; * * \mathrm{P}<0.01 ; * * * \mathrm{P}<0.001$; ns: no statistical differences. Scale for gene expression is $\log _{2}$ of the mean values after normalization against control plants. 


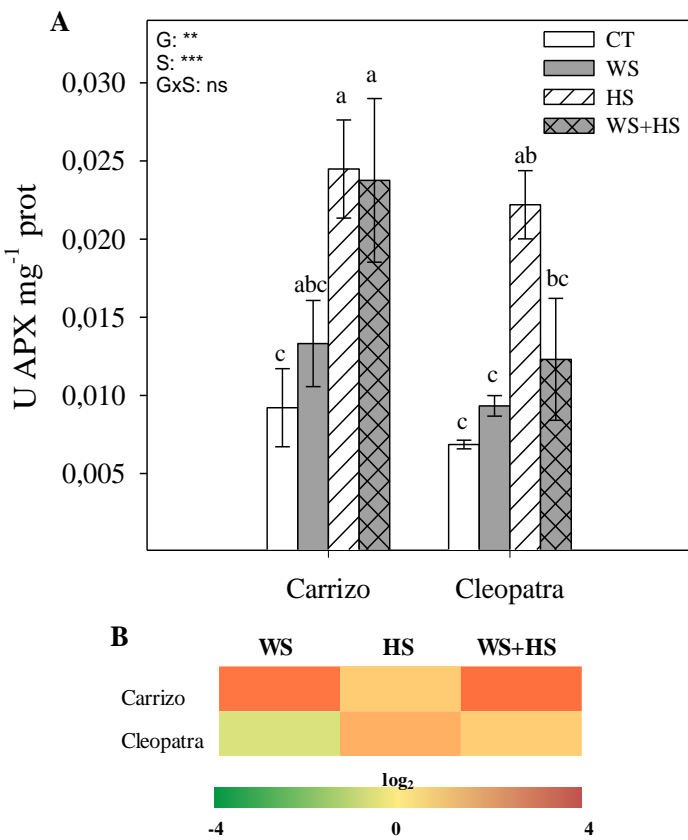

Figure 6. Effects of drought (WS), heat (HS) and a combination of drought and heat stress (WS + HS) on APX activity (A) and transcript expression (B) in leaves of Carrizo and Cleopatra plants. Different letters denote statistical significance at $\mathrm{p} \leq 0.05$. G: genotypes; $\mathrm{S}$ : stress treatment; GxS: interaction genotype $\mathrm{x}$ stress treatment. $* \mathrm{P}<$ $0.05 ; * * \mathrm{P}<0.01 ; * * * \mathrm{P}<0.001 ; \mathrm{ns}:$ no statistical differences. Scale for gene expression is $\log 2$ of the mean values after normalization against control plants.

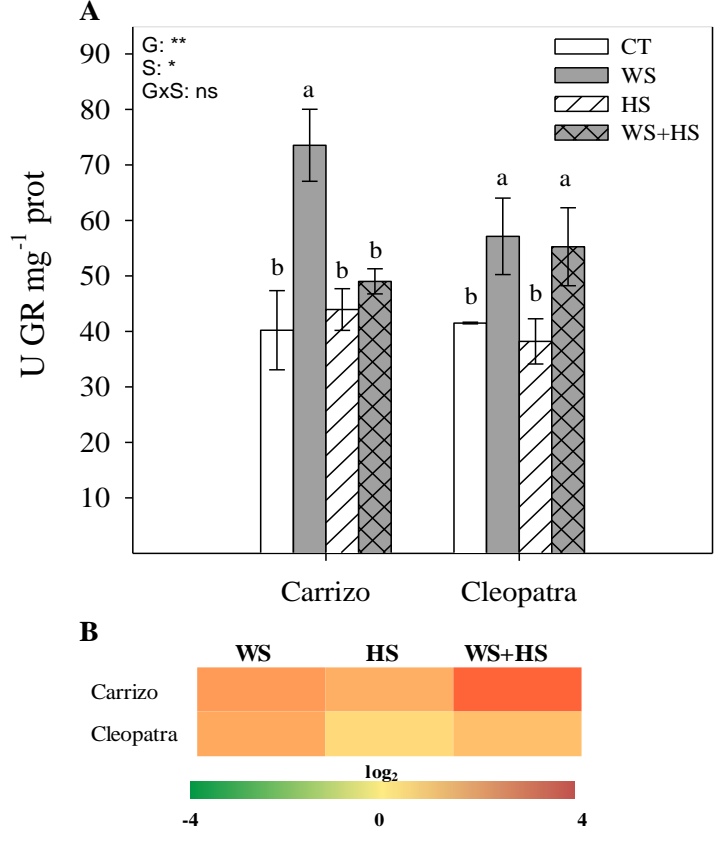

Figure 7. Effects of drought (WS), heat (HS) and a combination of drought and heat stress (WS + HS) on GR activity (A) and transcript expression (B) in leaves of Carrizo and Cleopatra plants. Different letters denote statistical significance at $\mathrm{p} \leq 0.05$. G: genotypes; S: stress treatment; GxS: interaction genotype $\mathrm{x}$ stress treatment. $* \mathrm{P}<$ $0.05 ; * * \mathrm{P}<0.01 ; * * * \mathrm{P}<0.001 ; \mathrm{ns}:$ no statistical differences. Scale for gene expression is $\log 2$ of the mean values after normalization against control plants.

\section{Antioxidant metabolites}

Under combined stress, tAsA and AsA levels increased in Carrizo and Cleopatra leaves with respect to control values (Table 2). Moreover, Cleopatra showed a higher tAsA content than Carrizo under combined stress conditions. However, DHA content only increased in Cleopatra leaves in response to stress combination. Due to the concomitant changes in AsA and DHA levels in response to each stress condition, no significant alteration in leaf redox AsA/DHA ratio was observed within each citrus genotype (Table 2). Additionally, in response to stress combination, Carrizo and Cleopatra leaves accumulated significant higher levels of tGSH, GSH and GSSG respect to control values (Table 3). Furthermore, HS induced an accumulation of tGSH, GSH and GSSG compared to control conditions only in Carrizo leaves. GSH/GSSG ratio increased in 
Cleopatra leaves upon imposition of WS with respect to control values and higher values in this ratio were found in CT and WS conditions respect to Carrizo values (Table 3).

Table 2. Ascorbate (AsA), total ascorbate (tASA) and dehydroascorbate (DHA) content in Carrizo and Cleopatra leaves subjected to drought (WS), heat (HS) and their combination (WS + HS). Data are presented as mean value of three different replicates \pm SD. Different letters denote statistical significance at $\mathrm{p} \leq 0.05$. G: genotype; $\mathrm{S}$ : stress treatment; GxS: interaction genotype $\mathrm{x}$ stress treatment. $* \mathrm{P}<0.05 ; * * \mathrm{P}<0.01 ; * * * \mathrm{P}<0.001$; ns: no statistical differences.

\begin{tabular}{|c|c|c|c|c|}
\hline Genotype & $\begin{array}{c}\text { tAsA } \\
\left(\mu \mathrm{mol} \mathrm{g}{ }^{-1} \mathbf{F W}\right)\end{array}$ & $\begin{array}{c}\text { AsA } \\
\left(\mu \mathrm{mol} \mathrm{g}{ }^{-1} \mathbf{F W}\right)\end{array}$ & $\begin{array}{c}\text { DHA } \\
\left(\mu \mathrm{mol} \mathrm{g}{ }^{-1} \mathbf{F W}\right)\end{array}$ & AsA/DHA \\
\hline \multicolumn{5}{|l|}{ Carrizo } \\
\hline CT & $4.68 \pm 0.2 \mathrm{e}$ & $4.26 \pm 0.09 \mathrm{~b}$ & $0.42 \pm 0.11 \mathrm{bc}$ & $11.58 \pm 2.79 \mathrm{ab}$ \\
\hline WS & $3.87 \pm 0.31 \quad \mathrm{e}$ & $3.58 \pm 0.26 \mathrm{~b}$ & $0.29 \pm 0.05 \quad \mathrm{c}$ & $13.11 \pm 1.59 \quad \mathrm{a}$ \\
\hline HS & $7.24 \pm 0.55 \mathrm{bc}$ & $6.0 \pm 0.35 \mathrm{ab}$ & $1.24 \pm 0.33 \mathrm{bc}$ & $5.04 \pm 2.3 \mathrm{bc}$ \\
\hline WS+HS & $9.35 \pm 0.32 \quad b$ & $8.53 \pm 0.33 \quad \mathrm{a}$ & $0.81 \pm 0.16 \mathrm{bc}$ & $10.51 \pm 1.76 \mathrm{ab}$ \\
\hline \multicolumn{5}{|l|}{ Cleopatra } \\
\hline CT & $4.75 \pm 0.74 \mathrm{de}$ & $3.91 \pm 0.52 \quad b$ & $0.84 \pm 0.39 \mathrm{bc}$ & $6.52 \pm 1.99 a b c$ \\
\hline WS & $7.02 \pm 0.72 \mathrm{~cd}$ & $4.82 \pm 0.48 \quad b$ & $2.2 \pm 0.39 \quad \mathrm{~b}$ & $2.40 \pm 0.47 \quad \mathrm{c}$ \\
\hline HS & $6.12 \pm 0.21 \mathrm{cde}$ & $4.13 \pm 0.25 \quad b$ & $1.99 \pm 0.18 \mathrm{bc}$ & $2.10 \pm 0.23$ \\
\hline WS+HS & $13.84 \pm 0.41 \quad \mathrm{a}$ & $8.4 \pm 1.18 \quad \mathrm{a}$ & $5.44 \pm 1.17 \quad \mathrm{a}$ & $1.68 \pm 0.35$ \\
\hline & $\mathrm{G}: * * *$ & G: *** & $\mathrm{G}: * * *$ & G: $\mathrm{ns}$ \\
\hline & $\mathrm{S}: * *$ & S: ns & $\mathrm{S}: * * *$ & $\mathrm{~S}: * * *$ \\
\hline & GxS: ns & GxS: ns & GxS: $* * *$ & GxS: ns \\
\hline
\end{tabular}

Table 3. Total glutathione (tGSH), reduced glutathione (GSH) and oxidized glutathione (GSSG) content in Carrizo and Cleopatra leaves subjected to drought (WS), heat (HS) and their combination (WS + HS). Data are presented as mean value of three different replicates \pm SD. Different letters denote statistical significance at $\mathrm{p} \leq 0.05$. G: genotype; S: stress treatment; GxS: interaction genotype $\mathrm{x}$ stress treatment. $* \mathrm{P}<0.05 ; * * \mathrm{P}<0.01$; $* * * \mathrm{P}<0.001$; ns: no statistical differences.

\begin{tabular}{|c|c|c|c|c|}
\hline Genotype & $\begin{array}{c}\text { tGSH } \\
\left(\mathrm{nmol} \mathrm{g}^{-1} \mathrm{FW}\right)\end{array}$ & $\begin{array}{c}\text { GSH } \\
\left(\mathrm{nmol} \mathrm{g}^{-1} \mathbf{F W}\right)\end{array}$ & $\begin{array}{c}\text { GSSG } \\
\left(\mathrm{nmol} \mathrm{g}^{-1} \mathbf{F W}\right)\end{array}$ & GSH/GSSG \\
\hline \multicolumn{5}{|l|}{ Carrizo } \\
\hline CT & $96.5 \pm 3.2 \mathrm{~cd}$ & $81.2 \pm 5.8 \mathrm{~cd}$ & $15.4 \pm 7.3 \mathrm{bc}$ & $4.5 \pm 2.0 \mathrm{c}$ \\
\hline WS & $83.4 \pm 7.7 \mathrm{~cd}$ & $75.7 \pm 7.2 \mathrm{~cd}$ & $7.7 \pm 3.5 \quad \mathrm{c}$ & $6.6 \pm 0.4 \mathrm{c}$ \\
\hline HS & $147.8 \pm 5.5 \quad \mathrm{a}$ & $118.3 \pm 12.6 \mathrm{ab}$ & $29.4 \pm 8.2 \quad \mathrm{a}$ & $4.8 \pm 1.5 \mathrm{c}$ \\
\hline WS+HS & $153.5 \pm 22.6$ & $129.4 \pm 22.7 \quad \mathrm{a}$ & $24.1 \pm 0.4 \mathrm{ab}$ & $5.4 \pm 1.0 \quad \mathrm{c}$ \\
\hline \multicolumn{5}{|l|}{ Cleopatra } \\
\hline CT & $77.8 \pm 6.8 \mathrm{~cd}$ & $73.5 \pm 6.8$ & $4.3 \pm 0.1$ & $17.0 \pm 1.3 \mathrm{~b}$ \\
\hline WS & $75.5 \pm 5.3 \quad \mathrm{~d}$ & $68.4 \pm 8.2 \quad \mathrm{~d}$ & $7.1 \pm 3.4 \quad c$ & $20.9 \pm 1.8 \quad \mathrm{a}$ \\
\hline HS & $107.9 \pm 5.5 \mathrm{bc}$ & $92.8 \pm 4.8 \mathrm{bcd}$ & $15.1 \pm 0.7 \mathrm{bc}$ & $6.1 \pm 0.1 \mathrm{c}$ \\
\hline \multirow[t]{4}{*}{$\mathrm{WS}+\mathrm{HS}$} & $132.6 \pm 4.2 \mathrm{ab}$ & $109.9 \pm 3.7 \mathrm{abc}$ & $22.7 \pm 1.3 \mathrm{ab}$ & $4.9 \pm 0.3 \quad \mathrm{c}$ \\
\hline & $\mathrm{G}: * * *$ & $\mathrm{G}: * *$ & $\mathrm{G}: * * *$ & $\mathrm{G}: * * *$ \\
\hline & $\mathrm{S}: * *$ & S: ns & $\mathrm{S}: *$ & $\mathrm{~S}: * * *$ \\
\hline & GxS: ns & GxS: ns & GxS: ns & GxS: *** \\
\hline
\end{tabular}




\section{Chapter 1}

\section{Discussion}

In general, abiotic stresses including high temperatures, drought or different combinations of environmental challenges, induce in plants metabolic imbalances that can cause an oxidative stress in cells. This effect results in the generation and accumulation of ROS, promoting oxidation of cellular components, hindering metabolic activities and affecting organelle integrity (Suzuki et al., 2012). Particularly in citrus plants, it has been proposed that environmental cues such as waterlogging, $\mathrm{Cu}$ toxicity, salinity or drought induce oxidative damage (Arbona et al., 2003, 2008; Hippler et al., 2016; Hossain et al., 2009; $\mathrm{Wu}$ et al., 2006), highlighting the importance of modulating the antioxidant system efficiently to cope with these abiotic stresses. In the present work, the antioxidant machinery of two citrus genotypes, Carrizo citrange and Cleopatra mandarin, with contrasting ability to tolerate the combination of drought and heat (Zandalinas et al., 2016b) was investigated to correlate differences in the modulation of the antioxidant system with tolerance to this stress combination. In this sense, Cleopatra constitutes a genotype more sensitive than Carrizo to drought combined with heat according to data presented in Figure 1 and also reported in Zandalinas et al. (2016c). Therefore, the percentage of damaged leaves in response to heat or a combination of drought and heat was significantly higher in Cleopatra than in Carrizo (Figure 1), demonstrating the higher ability of Carrizo to deal with stresses that involve high temperatures. Moreover, a positive correlation between stress sensitivity and proline accumulation was observed. Hence, Cleopatra accumulated higher amounts of proline in leaves and roots in response to the combination of drought and heat compared to Carrizo. Additionally, both citrus genotypes accumulated higher levels of this metabolite in response to combined stress factors, a more damaging situation with respect to individual stresses. This result matches other works in which a higher stress pressure exerts a major proline accumulation (Arbona et al., 2008; Claussen, 2005) due to its protective roles, including maintenance of redox balance and radical scavenging, maintenance of protein structure and contribution to reduce cell membrane damage (Shao et al., 2008; Szabados and Savouré, 2010).

In addition, the accumulation of MDA as an estimation of oxidative damage was also higher in leaves and roots of Cleopatra in response to combined stresses (Figure 3), suggesting that the extent of oxidative damage is directly linked to susceptibility of citrus plants to the combination of drought and heat stress. The increased SOD and CAT activities of Carrizo in basal and stress conditions compared to Cleopatra (Figure 4A and 
5A) could be related to an active and efficient antioxidant response that might be involved in maintaining a lower MDA content (and oxidative stress) especially under the combination of drought and heat, and therefore helping citrus plants to cope with the combined stresses. On the contrary, whereas SOD activity of Cleopatra leaves increased in response to stress imposition, CAT activity did not change in response to individual stresses and even decreased under WS+HS compared to control levels. In addition to CAT, APX removes $\mathrm{H}_{2} \mathrm{O}_{2}$ and this reaction has been previously reported to be a crucial process for the tolerance of plants to combined drought and heat (Koussevitzky et al., 2008). In our work, APX activity was significantly induced by HS and WS+HS in Carrizo leaves (Figure 6A), suggesting an efficient $\mathrm{H}_{2} \mathrm{O}_{2}$ scavenging ability under these stress conditions. However, in Cleopatra, only HS significantly induced an increased APX activity (Figure 6A). However, under high temperatures, this enzyme activity could be insufficient to scavenge the excess of $\mathrm{H}_{2} \mathrm{O}_{2}$ when CAT activity is not activated (Figure 5A), rendering an increased oxidative damage. Additionally, APX dismutes $\mathrm{H}_{2} \mathrm{O}_{2}$ using AsA as the electron donor. Both citrus genotypes showed increases in leaf AsA and tAsA contents in response to WS+HS, suggesting that the accumulation of AsA could be related with a strong stress pressure. In addition, Cleopatra showed higher tAsA and DHA levels as well as a lower AsA/DHA ratio with respect to Carrizo during this stress combination

(Table 2), which are according to the lower APX activity observed during WS+HS in this citrus genotype (Figure 6A).

Accurate modulation of the glutathione cycle is involved in maintaining a favorable GSH/GSSG ratio required for cellular redox regulation. In this way, GR activity could effectively recycle GSH at the expense of NADPH. The pattern observed for GR activity in Figure 7 indicates that Carrizo, despite increasing tGSH, GSH and GSSG levels in response to HS and WS+HS (Table 3), preserved the GR activity as well as the GSH/GSSG ratio around control values, probably as a result of a lower incidence of oxidative damage. In contrast, in Cleopatra leaves, the reduction in GSH/GSSG ratio with respect to control values, especially under WS+HS (Table 3), suggests an impairment of GSH recycling. This result points to a better ROS non-enzymatic detoxification system and to an efficient GSH recycling in Carrizo plants compared to Cleopatra, with no apparent NADPH limitation. In this sense, it has been previously reported that maintenance of a more oxidized glutathione status could be a consequence of an enhanced ROS accumulation (Foyer and Noctor, 2011). Our results are in accordance with this 
statement since MDA specially accumulated in Cleopatra in response to WS+HS (Figure 3). Furthermore, the activation of GR activity observed in Cleopatra under this stress combination (Figure 7A) might be insufficient to keep a proper GSH/GSSH ratio, leading to a lower ability for ROS detoxification (Arbona et al., 2008) and, as a result, to a higher sensitivity of this citrus genotype to WS+HS. These results also demonstrated the previous hypothesis suggesting that a deficient antioxidant system in Cleopatra plants under the combination of drought and heat would lead to an enhanced activation of secondary metabolites with antioxidant properties including flavonols, flavones and limonoids to supplement the antioxidant deficiency and mitigate the damaging effects of stress (Zandalinas et al., 2017b). However, all these metabolic strategies, including proline accumulation (Figure 2), do not seem to be effective as Cleopatra mandarin suffered important damage under WS+HS conditions.

Drought and heat stress are two major abiotic stresses occurring simultaneously in natural environments that cause oxidative stress in plants through the production of ROS. According to our data, the combination of drought and heat negatively impacted both citrus genotypes (Figure 1) but the effective activation of the antioxidant machinery was associated to the ability to tolerate this stress combination. Accordingly, the increment of SOD activity (Figure 4A) along with the decline in CAT activity (Figure 5A) and the lack of APX activity increase (Figure 6A) compared to control values in Cleopatra plants in response to WS+HS could be partially responsible of the increased oxidative damage and sensitivity of this citrus genotype to the combination of drought and high temperatures. In contrast, the ability of Carrizo plants to efficiently activate antioxidant enzymes involved in ROS detoxification along with preserving a favorable GSH/GSSG ratio would be partially related to genotype tolerance to combined stresses. This work provides physiological basis for directing future genetic programs to improve the antioxidant system of Cleopatra mandarin, a genotype that has been very useful as a rootstock for plants cultivated under conditions of water scarcity. However, its future use can be seriously compromised in a scenario of climatic change due to the high sensibility to combined conditions of heat and drought.

\section{Conflict of interest statement}

The authors declare that the research was conducted in the absence of any commercial or financial relationships that could be construed as a potential conflict of interest. 


\section{Author and contributors}

SZ and DB performed the research. AGC and VA supervised the project and provided funding. SZ, DB and AG wrote the manuscript and prepared figures. SZ, DB, VA and $A G$ revised the final version. All authors have read and approved the final version of the manuscript.

\section{Funding}

This work was supported by the Ministerio de Economía (MINECO) and Universitat Jaume I through grants $\mathrm{n}^{\circ}$ AGL2016-76574-R and UJI-B2016-23/UJI-B2016-24, respectively. SIZ was supported by a predoctoral fellowship from Universitat Jaume I.

\section{References}

Arbona, V., Flors, V., Jacas, J., García-Agustín, P., and Gómez-Cadenas, A. (2003). Enzymatic and non-enzymatic antioxidant responses of Carrizo citrange, a salt-sensitive citrus rootstock, to different levels of salinity. Plant Cell Physiol. 44, 388-394. doi:10.1093/pcp/pcg059.

Arbona, V., Hossain, Z., López-Climent, M. F., Pérez-Clemente, R. M., and GómezCadenas, A. (2008). Antioxidant enzymatic activity is linked to waterlogging stress tolerance in citrus. Physiol. Plant. 132, 452-466. doi:10.1111/j.1399-3054.2007.01029.x.

Bates, L. S., Waldren, R. P., and Teare, I. D. (1973). Rapid determination of free proline for water-stress studies. Plant Soil 39, 205-207. doi:10.1007/BF00018060.

Baxter, A., Mittler, R., and Suzuki, N. (2014). ROS as key players in plant stress signalling. J. Exp. Bot. 65, 1229-1240. doi:10.1093/jxb/ert375.

Bradford, M. M. (1976). A rapid and sensitive method for the quantitation of microgram quantities of protein utilizing the principle of protein-dye binding. Anal. Biochem. 72, $248-254$.

Choudhury, F. K., Rivero, R. M., Blumwald, E., and Mittler, R. (2016). Reactive oxygen species, abiotic stress and stress combination. Plant J. doi:10.1111/tpj.13299.

Claussen, W. (2005). Proline as a measure of stress in tomato plants. Plant Sci. 168, 241248. doi:10.1016/j.plantsci.2004.07.039. 
Foyer, C. H., and Noctor, G. (2005). Redox homeostasis and antioxidant signaling: a metabolic interface between stress perception and physiological responses. Plant Cell 17, 1866-1875. doi:10.1105/tpc.105.033589.

Foyer, C. H., and Noctor, G. (2011). Ascorbate and glutathione: the heart of the redox hub. Plant Physiol. 155, 2-18. doi:10.1104/pp.110.167569.

Giraud, E., Ho, L. H. M., Clifton, R., Carroll, A., Estavillo, G., Tan, Y.-F., et al. (2008). The absence of ALTERNATIVE OXIDASE1a in Arabidopsis results in acute sensitivity to combined light and drought stress. Plant Physiol. 147, 595-610. doi:10.1104/pp.107.115121.

Hernandez, J. A., Jimenez, A., Mullineaux, P., and Sevilia, F. (2000). Tolerance of pea (Pisum sativum L.) to long-term salt stress is associated with induction of antioxidant defences. Plant, Cell Environ. 23, 853-862. doi:10.1046/j.1365-3040.2000.00602.x.

Hippler, F. W. R., Cipriano, D. O., Boaretto, R. M., Quaggio, J. A., Gaziola, S. A., Azevedo, R. A., et al. (2016). Citrus rootstocks regulate the nutritional status and antioxidant system of trees under copper stress. Environ. Exp. Bot. 130, 42-52. doi:10.1016/j.envexpbot.2016.05.007.

Hodges, D. M., DeLong, J. M., Forney, C. F., and Prange, R. K. (1999). Improving the thiobarbituric acid-reactive-substances assay for estimating lipid peroxidation in plant tissues containing anthocyanin and other interfering compounds. Planta 207, 604-611. doi:10.1007/s004250050524.

Hossain, Z., López-Climent, M. F., Arbona, V., Pérez-Clemente, R. M., and GómezCadenas, A. (2009). Modulation of the antioxidant system in citrus under waterlogging and subsequent drainage. J. Plant Physiol. 166, 1391-1404. doi:10.1016/j.jplph.2009.02.012.

Jin, R., Wang, Y., Liu, R., Gou, J., and Chan, Z. (2016). Physiological and metabolic changes of purslane (Portulaca oleracea L.) in response to drought, heat, and combined stresses. Front. Plant Sci. 6, 1123. doi:10.3389/fpls.2015.01123.

Keles, Y., and Oncel, I. (2002). Response of antioxidative defence system to temperature and water stress combinations in wheat seedlings. Plant Sci. 163, 783-790. 
Koussevitzky, S., Suzuki, N., Huntington, S., Armijo, L., Sha, W., Cortes, D., et al. (2008). Ascorbate peroxidase 1 plays a key role in the response of Arabidopsis thaliana to stress combination. J. Biol. Chem. 283, 34197-34203. doi:10.1074/jbc.M806337200.

Lin, K.-H. R., Weng, C.-C., Lo, H.-F., and Chen, J.-T. (2004). Study of the root antioxidative system of tomatoes and eggplants under waterlogged conditions. Plant Sci. 167, 355-365. doi:10.1016/j.plantsci.2004.04.004.

Mafra, V., Kubo, K. S., Alves-Ferreira, M., Ribeiro-Alves, M., Stuart, R. M., Boava, L. P., et al. (2012). Reference genes for accurate transcript normalization in citrus genotypes under different experimental conditions. PLoS One 7, e31263. doi:10.1371/journal.pone.0031263.

Martinez, V., Mestre, T. C., Rubio, F., Girones-vilaplana, A., Moreno, D. A., Mittler, R., et al. (2016). Accumulation of flavonols over hydroxycinnamic acids favors oxidative damage protection under abiotic stress. Front. Plant Sci. 7, 1-17. doi:10.3389/fpls.2016.00838.

Mittler, R. (2016). ROS are good. Trends Plant Sci. 22, 11-19. doi:10.1016/j.tplants.2016.08.002.

Mittler, R., Vanderauwera, S., Gollery, M., and Van Breusegem, F. (2004). Reactive oxygen gene network of plants. Trends Plant Sci. 9, 490-498. doi:10.1016/j.tplants.2004.08.009.

Morgan, J. A. (1984). Interaction of water supply and N in wheat. Plant Physiol. 76, 112117.

Pandey, P., Ramegowda, V., and Senthil-Kumar, M. (2015). Shared and unique responses of plants to multiple individual stresses and stress combinations: physiological and molecular mechanisms. Front. Plant Sci. 6, 1-14. doi:10.3389/fpls.2015.00723.

Pfaffl, M. W., Horgan, G. W., and Dempfle, L. (2002). Relative expression software tool (REST) for group-wise comparison and statistical analysis of relative expression results in real-time PCR. Nucleic Acids Res. 30, e36.

Prasch, C. M., and Sonnewald, U. (2013). Simultaneous application of heat, drought, and virus to Arabidopsis plants reveals significant shifts in signaling networks. Plant Physiol. 162, 1849-1866. doi:10.1104/pp.113.221044. 
Rasmussen, S., Barah, P., Suarez-Rodriguez, M. C., Bressendorff, S., Friis, P., Costantino, P., et al. (2013). Transcriptome responses to combinations of stresses in Arabidopsis. Plant Physiol. 161, 1783-1794. doi:10.1104/pp.112.210773.

Rivero, R. M., Mestre, T. C., Mittler, R., Rubio, F., Garcia-Sanchez, F., and Martinez, V. (2013). The combined effect of salinity and heat reveals a specific physiological, biochemical and molecular response in tomato plants. Plant, Cell Environ. 37, 10591073. doi:10.1111/pce.12199.

Rizhsky, L., Liang, H., and Mittler, R. (2002). The combined effect of drought stress and heat shock on gene expression in tobacco. Plant Physiol. 130, 1143-1151. doi:10.1104/pp.006858.then.

Rizhsky, L., Liang, H., Shuman, J., Shulaev, V., Davletova, S., and Mittler, R. (2004). When defense pathways collide. The response of Arabidopsis to a combination of drought and heat stress. Plant Physiol. 134, 1683-1696. doi:10.1104/pp.103.033431.1.

Shao, H., Chu, L., Shao, M., Jaleel, C. A., and Mi, H. (2008). Higher plant antioxidants and redox signaling under environmental stresses. C. R. Biol. 331, 433-441. doi:10.1016/j.crvi.2008.03.011.

Suzuki, N., Basil, E., Hamilton, J. S., Inupakutika, Madhuri A Zandalinas, S. I., Tripathy, D., Yuting, L., et al. (2016). ABA is required for plant acclimation to a combination of salt and heat stress. PLoS One 11, e0147625.

Suzuki, N., Koussevitzky, S., Mittler, R., and Miller, G. (2012). ROS and redox signalling in the response of plants to abiotic stress. Plant, Cell Environ. 35, 259-270. doi:10.1111/j.1365-3040.2011.02336.x.

Suzuki, N., Rivero, R. M., Shulaev, V., Blumwald, E., and Mittler, R. (2014). Abiotic and biotic stress combinations. New Phytol. 203, 32-43.

Szabados, L., and Savouré, A. (2010). Proline: a multifunctional amino acid. Trends Plant Sci. 15, 89-97. doi:10.1016/j.tplants.2009.11.009.

Vile, D., Pervent, M., Belluau, M., Vasseur, F., Bresson, J., Muller, B., et al. (2012). Arabidopsis growth under prolonged high temperature and water deficit: independent or interactive effects? Plant, Cell Environ. 35, 702-718. doi:10.1111/j.13653040.2011.02445.x. 
Wu, Q. S., Xia, R. X., and Zou, Y. N. (2006). Reactive oxygen metabolism in mycorrhizal and non-mycorrhizal citrus (Poncirus trifoliata) seedlings subjected to water stress. $J$. Plant Physiol. 163, 1101-1110. doi:10.1016/j.jplph.2005.09.001.

Zandalinas, S. I., Balfagón, D., Arbona, V., Gómez-Cadenas, A., and Inupakutika, Madhuri A Mittler, R. (2016a). ABA is required for the accumulation of APX1 and MBF1c during a combination of water deficit and heat stress. J. Exp. Bot. 67, 5381-5390. doi:10.1093/jxb/erw299.

Zandalinas, S. I., Mittler, R., Balfagón, D., Arbona, V., and Gómez-Cadenas, A. (2017a). Plant adaptations to the combination of drought and high temperatures. Physiol. Plant., doi: 10.1111/ppl.12540. doi:10.1111/ppl.12540.

Zandalinas, S. I., Rivero, R. M., Martínez, V., Gómez-Cadenas, A., and Arbona, V. (2016b). Tolerance of citrus plants to the combination of high temperatures and drought is associated to the increase in transpiration modulated by a reduction in abscisic acid levels. BMC Plant Biol. 16, 105. doi:10.1186/s12870-016-0791-7.

Zandalinas, S. I., Sales, C., Beltran, J., Gómez-Cadenas, A., and Arbona, V. (2017b). Activation of secondary metabolism in citrus plants is associated to sensitivity to combined drought and high temperatures. Front. Plant Sci., doi: 10.3389/fpls.2016.01954. 


\section{Supplementary material}

Table S1. Designed primers for gene expression analyses by quantitative RT-PCR.

\begin{tabular}{|c|c|c|c|c|}
\hline Citrus gene & Locus & $\begin{array}{c}\text { Forward / } \\
\text { Reverse }\end{array}$ & Sequence $\left(5^{\prime} \rightarrow 3^{\prime}\right)$ & $\begin{array}{c}\text { Amplicon } \\
\text { size (bp) }\end{array}$ \\
\hline \multirow{2}{*}{ SOD-CuZn } & \multirow{2}{*}{ orange $1.1 \mathrm{~g} 031837 \mathrm{~m}$} & $\mathrm{~F}$ & CTTGGTGGAACTGAGGGTGT & \multirow{2}{*}{173} \\
\hline & & $\mathrm{R}$ & GGGTTAAAGTGGGGTCCAGT & \\
\hline \multirow{2}{*}{ SOD-Fe } & \multirow{2}{*}{ orange $1.1 \mathrm{~g} 026199 \mathrm{~m}$} & $\mathrm{~F}$ & CAGCTTCATCTGCTCCAACA & \multirow{2}{*}{148} \\
\hline & & $\mathrm{R}$ & GGTGGAGGCTTCAAATCAAA & \\
\hline \multirow{2}{*}{ CAT } & \multirow{2}{*}{ orange $1.1 \mathrm{~g} 042356 \mathrm{~m}$} & $\mathrm{~F}$ & GTAACCAAGACCTGGCCTGA & \multirow{2}{*}{134} \\
\hline & & $\mathrm{R}$ & ATGCCAGGAACCACAATAGC & \\
\hline \multirow{2}{*}{ APX } & \multirow{2}{*}{ orange $1.1 \mathrm{~g} 024615 \mathrm{~m}$} & $\mathrm{~F}$ & CCATTCGGAACCATGAGGCT & \multirow{2}{*}{153} \\
\hline & & $\mathrm{R}$ & CTCAACGCCAACAACACCAG & \\
\hline \multirow{2}{*}{ GR } & \multirow{2}{*}{ orange $1.1 \mathrm{~g} 042564 \mathrm{~m}$} & $\mathrm{~F}$ & CTTGGAGCATCAATGTGTGG & \multirow{2}{*}{165} \\
\hline & & $\mathrm{R}$ & AGCAACACGTCTCGTCACAG & \\
\hline \multirow{2}{*}{ ACT } & \multirow{2}{*}{ orange $1.1 \mathrm{~g} 037845 \mathrm{~m}$} & $\mathrm{~F}$ & СССТТССТCATGCCATTCTTC & \multirow{2}{*}{105} \\
\hline & & $\mathrm{R}$ & CGGCTGTGGTGGTAAACATG & \\
\hline \multirow{2}{*}{ TUB } & \multirow{2}{*}{ orange1.1g013335m } & $\mathrm{F}$ & GGGGCAAAATGAGCACTAAA & \multirow{2}{*}{187} \\
\hline & & $\mathrm{R}$ & CGCCTGAACATCTCCTGAAT & \\
\hline
\end{tabular}




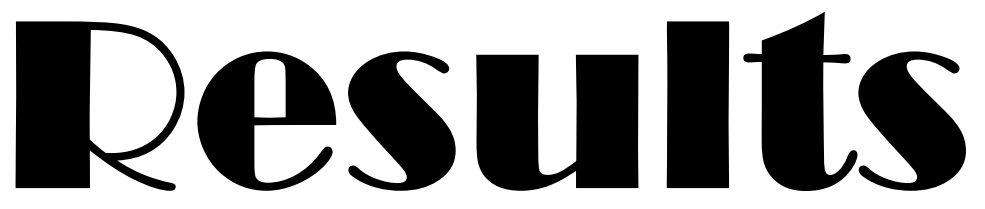

\section{Chapter 2}

Involvement of ascorbate peroxidase and heat shock proteins on citrus tolerance to combined conditions of drought and high temperatures

Balfagón et al. (2018) Plant Physiology and Biochemistry 127: 194-199 



\begin{abstract}
Usually several environmental stresses occur in nature simultaneously causing a unique plant response. However, most of the studies until now have focused in individuallyapplied abiotic stress conditions. Carrizo citrange (Poncirus trifoliata L. Raf. X Citrus sinensis L. Osb.) and Cleopatra mandarin (Citrus reshni Hort. ex Tan.) are two citrus rootstocks with contrasting tolerance to drought and heat stress and have been used in this work as a model for the study of plant tolerance to the combination of drought and high temperatures. According to our results, leaf integrity and photosynthetic machinery are less affected in Carrizo than in Cleopatra under combined conditions of drought and heat stress. The pattern of accumulation of three proteins (APX, HSP101 and HSP17.6) involved in abiotic stress tolerance shows that they do not accumulate under water stress conditions individually applied. However, contents of APX and HSP101 are higher in Carrizo than in Cleopatra under stress combination whereas HSP17.6 has a similar behavior in both types of plants. This, together with a better stomatal control and a higher APX activity of Carrizo, contributes to the higher tolerance of Carrizo plants to the combination of stresses and point to it as a better rootstock than Cleopatra (traditionally used in areas with scare water supplies) under the predictable future climatic conditions with frequent periods of drought combined with high temperatures. This work also provides the basis for testing the tolerance of different citrus varieties grafted on these rootstocks and growing under different field conditions.
\end{abstract}

\title{
1. Introduction
}

Environmental stresses cause molecular and physiological changes in plants. Through these changes, plants respond to adverse conditions to reduce damage and acclimate to the unfavorable situations. In the field, the major crop losses are recently caused by the action of combined stresses, that converge in a new unique adverse situation with different consequences to plants with respect to those caused by the stresses applied individually (Mittler 2006, Mittler and Blumwald 2010, Zandalinas et al. 2018). Although the consequences of abiotic stress applied individually have been deeply studied in many plant species, the effects of combined stresses on citrus plants are barely understood (Zandalinas et al. 2016b). A deeper knowledge could be important for genetic 
improvement and/or agronomical practices oriented to avoid yield losses derived from the climatic change.

One of the plant mechanisms to cope with abiotic stress conditions is the accumulation of key proteins with a protective role. Among them, heat shock proteins (HSP) are molecular chaperones that have been detected in almost all type of organisms. They are characterized by a carboxylic termination called heat-shock domain. In plants, HSPs are classified according to their approximate molecular weight: HSP100, HSP90, HSP70, HSP60, and small HSPs. They protect other proteins from denaturalization during stress situations regulating refolding, localization and accumulation as well as preventing agglomeration and degradation (Nakamoto and Vígh 2007). Although it has been demonstrated the key role of HSPs on plant responses to heat stress, they are induced by different types of biotic and abiotic stress conditions. As an example, they play an important role on plant tolerance to oxidative stress (Wang et al. 2003; Rizhsky et al. 2004). Moreover, recent work showed that specific HSPs are involved plant responses to stress combination (Rizhsky et al. 2004, Zandalinas et al. 2016a). In addition, it has been shown that APX plays a central role under drought and heat stress combination in Citrus and Arabidopsis thaliana (Koussevitzky et al. 2008, Zandalinas et al. 2017).

Recently, we have demonstrated that two citrus genotypes, Carrizo citrange and Cleopatra mandarin, have different abilities to tolerate drought, heat stress and the combination of both adverse situations. Thus, Carrizo is more tolerant to heat stress (HS) and combined drought and heat stress (WS+HS) whereas Cleopatra is more tolerant to drought (WS) (Argamasilla et al. 2014; Zandalinas et al. 2016b). This different tolerance can be explained partially by their distinct stomatal response that allows a better leaf cooling in Carrizo plants under heat. Antioxidant machinery in Carrizo is also more efficient and contributes to the acclimation of this genotype to the stress combination.

In this work, we aimed to further understand the mechanism of citrus tolerance to simultaneous abiotic stress conditions by studying the accumulation of ascorbate peroxidase (APX), HSP101 and HSP17.6 (three proteins considered key in plant tolerance to abiotic stress conditions) in two citrus genotypes with contrasting tolerance to water stress and high temperatures.

\section{Materials and methods}

\subsection{Plant material and growth conditions}


One-year-old seedlings of two citrus genotypes, Carrizo citrange (Poncirus trifoliata L. Raf. X Citrus sinensis L. Osb.) and Cleopatra mandarin (Citrus reshni Hort. ex Tan.) purchased from a commercial nursery (Beniplant S.L., Penyíscola, Spain), were grown as described in Zandalinas et al. 2017. Briefly, plants were grown in 0,6 1 plastic pots with perlite as substrate and were watered three times a week with a half-strength Hoagland solution under greenhouse conditions. Then, plants were transferred to growth chambers with $16 \mathrm{~h}$ photoperiod at $25{ }^{\circ} \mathrm{C}$ and relative moisture fixed at $80 \%$ approximately and keep there for 2 weeks.

\subsection{Stress treatments and experimental design}

An experiment of drought stress, heat stress and combined drought and heat was performed in Carrizo and Cleopatra plants as described in Zandalinas et al. (2017). Severe drought conditions were imposed to plants by transplanting them to dry perlite during 24 hours. Prior to imposition of drought regime, heat stress was applied for 7 days. Therefore, we established four experimental groups for each genotype: well-watered plants at a) $25{ }^{\circ} \mathrm{C}(\mathrm{CT})$ and b) $40{ }^{\circ} \mathrm{C}$ (HS) and plants subjected to drought at c) $25{ }^{\circ} \mathrm{C}$ (WS) and d) $40{ }^{\circ} \mathrm{C}$ (WS+HS). Leaf tissue was sampled $24 \mathrm{~h}$ after the stress imposition.

\subsection{Quantum yield of photosystem II ( $\left.\Phi_{P S I}\right)$ and stomatal conductance (gs)}

$\Phi_{\text {PSII }}$ was analyzed using a portable fluorometer (FluorPen FP-MAX 100, Photon Systems Instruments, Czech Republic). Stomatal conductance (gs) was measured by using an LCpro+ portable infrared gas analyzer (ADC BioScientific Ltd., Hoddesdon, UK) under ambient $\mathrm{CO}_{2}$ and moisture. Supplemental light was provided by a PAR lamp at 1000 $\mu \mathrm{mol} \mathrm{m} \mathrm{m}^{-2} \mathrm{~s}^{-1}$ photon flux density, and air flow was set at $150 \mu \mathrm{mol} \mathrm{mol}{ }^{-1}$.

\subsection{APX enzyme activity}

APX (EC 1.11.1.11) enzymatic activity was quantified as described previously (Hossain et al. 2009) . Briefly, frozen ground leaf tissue was extracted in phosphate buffer and after centrifugation, enzymatic activity was assayed following the depletion in absorbance at $290 \mathrm{~nm}$ due to ascorbate (AsA) consumption.

\subsection{Gene expression}

The amplification of cytoplasmic APX2 gene (orange1.1g024615m) was performed by using the following primers: 5'-CCATTCGGAACCATGAGGCT-3' and 5'CTCAACGCCAACAACACCAG-3'. qRT-PCR analyses were performed in a StepOne 
Real-Time PCR system (Applied Biosystems, CA, USA). The reaction mixture contained $1 \mu \mathrm{L}$ of cDNA, $5 \mu \mathrm{L}$ of SYBRGreen (Applied Biosystems) and $1 \mu \mathrm{M}$ of each genespecific primer pair in a final volume of $10 \mu \mathrm{L}$. The thermal profile used to analyze the relative gene expression consisted of $10 \mathrm{~min}$ at $95{ }^{\circ} \mathrm{C}$ for pre-incubation, followed by 40 cycles of $10 \mathrm{~s}$ at $95{ }^{\circ} \mathrm{C}$ for denaturation, $10 \mathrm{~s}$ at $60{ }^{\circ} \mathrm{C}$ for annealing and $20 \mathrm{~s}$ at $72{ }^{\circ} \mathrm{C}$ for extension. Gene expression levels was normalized against the expression of two endogenous control genes based on previous housekeeping selection for citrus tissues (Mafra et al. 2012): tubulin (5'-GGGGCAAAATGAGCACTAAA-3' and 5'CGCCTGAACATCTCCTGAAT-3') and actin (5'-CCCTTCCTCATGCCATTCTTC-3' and 5'-CGGCTGTGGTGGTAAACATG-3'). The relative expression were calculated by using Relative Expression Software Tool (REST; Pfaffl et al. 2002).

\subsection{Protein extraction and Western Blot analysis}

For protein extraction, $100 \mathrm{mg}$ of frozen ground leaf tissue were extracted in $500 \mu \mathrm{L}$ of Laemli buffer 2x (Bio-Rad, Hercules, CA, USA) supplemented with $\beta$-mercaptoethanol (9:1) and heated during 10 minutes in a thermoblock at $85{ }^{\circ} \mathrm{C}$. After centrifugation at $14000 \mathrm{~g}$ and $4{ }^{\circ} \mathrm{C}$ for $10 \mathrm{~min}$, supernatant was recovered. Protein concentration was calculated by measuring the absorbance at $660 \mathrm{~nm}$ using the Pierce reactive (Thermo Scientific, Rockford, IL, USA). A standard curve was performed with BSA. $20 \mu \mathrm{g}$ of protein samples were fractionated by SDS-PAGE on 7,5\% to $12 \%$ Tris gel with Tris running buffer and transferred to a PVDF membrane according to the manufacturer's protocol (Bio-Rad). Membranes were blocked for 1h with 3\% BSA and, then, were incubated with primaries antibodies against APX2 (orange1.1g024615m, L-Ascorcorbate peroxidase 2, cytosolic) (1:10000), HSP101 (orange1.1g046258m, ATP dependent CLP Protease) (1:1000), HSP17.6 (orange1.1g031266m, Small heat-shock protein HSP20 family) (1:1000) and actin (1:5000) from Agrisera (Vännäs, Sweden) at $4{ }^{\circ} \mathrm{C}$ overnight. After washing, membranes were incubated with goat anti-rabbit IgG (H\&L), HRP conjugated antibodies with a dilution 1:25000 for $1 \mathrm{~h}$. Blots were washed again three times for 10-15 minutes and incubated with the Pierce ECL 2 Western Blotting Substrate (Thermo Scientific, Rockford, IL, USA) according to the manufacturer's protocol. The band signals were detected by using the ImageQuant LAS 500 imager (GE Healthcare Bio-Sciences AB, Uppsala, Sweden). BlastP analysis were performed between the proteins sequences in Citrus sinensis and Arabidopsis thaliana with the following results: 
APX2 (Qc 99\%; E value 1 e-153; Identity 78\%), HSP101 (Qc 98\%; E value 0.0; Identity 88\%), HSP17.6 (Qc 99\%; E value 7e-82; identity 72\%).

\subsection{Statistical analyses}

For $\Phi_{P S I I}$ and gs, at least 10 measurements were taken on three leaves in three replicate plants from each genotype and stress treatment. For the rest of parameters, data are means of three independent determinations. One-way analysis of variance (ANOVA) was performed followed by Tukey posthoc test $(\mathrm{p}<0.05)$ when a significant difference was detected.

\section{Results}

\subsection{Effect of WS, HS and WS+HS on Carrizo and Cleopatra plants}

Stress treatments (drought, heat and their combination) were imposed to Carrizo and Cleopatra plants and the impact of these conditions was found to be genotype-specific. Figure 1 shows typical symptoms of visible damage caused by abiotic stress. This damage was quantified by the ability of plants to maintain healthy sprouts (as in panels A and B in Figure 1). As shown in Figure 2, leaf damage caused by drought was higher in Carrizo than in Cleopatra. However, whereas Cleopatra plants were highly affected by heat stress (63.4\% of affected leaves), only $5.9 \%$ of Carrizo leaves were damaged under the same conditions. When both stresses were combined, the percentage of damaged leaves increased in both genotypes but especially in Cleopatra, showing Carrizo plants greater performance (Figure 2).

When plants were subjected to WS, stomatal aperture decreased respect to control conditions in both genotypes although in Cleopatra the stomatal closure was more pronounced. Under HS conditions, Cleopatra plants showed a slight increase in gs values, whereas values of this parameter in Carrizo leaves increased to a large degree (almost 3fold higher than control values). Similar to WS, combined stress conditions reduced gs values in both Cleopatra and Carrizo plants, having a more pronounced effect in Cleopatra than in Carrizo (Figure 2). 
Chlorophyll fluorescence parameters were also measured in response to individual and combined stresses (Figure 2). In leaves of both citrus genotypes, quantum efficiency of PSII ( $\left.\Phi_{\text {PSII }}\right)$ was slightly affected by WS. On the contrary, HS did not have significative consequences on this parameter in Carrizo but it significantly decreased $\Phi_{\text {PSII values in }}$ Cleopatra plants. Moreover, WS+HS had the most detrimental effect on quantum efficiency in both kind of citrus leaves, but especially in Cleopatra plants (Figure 2).

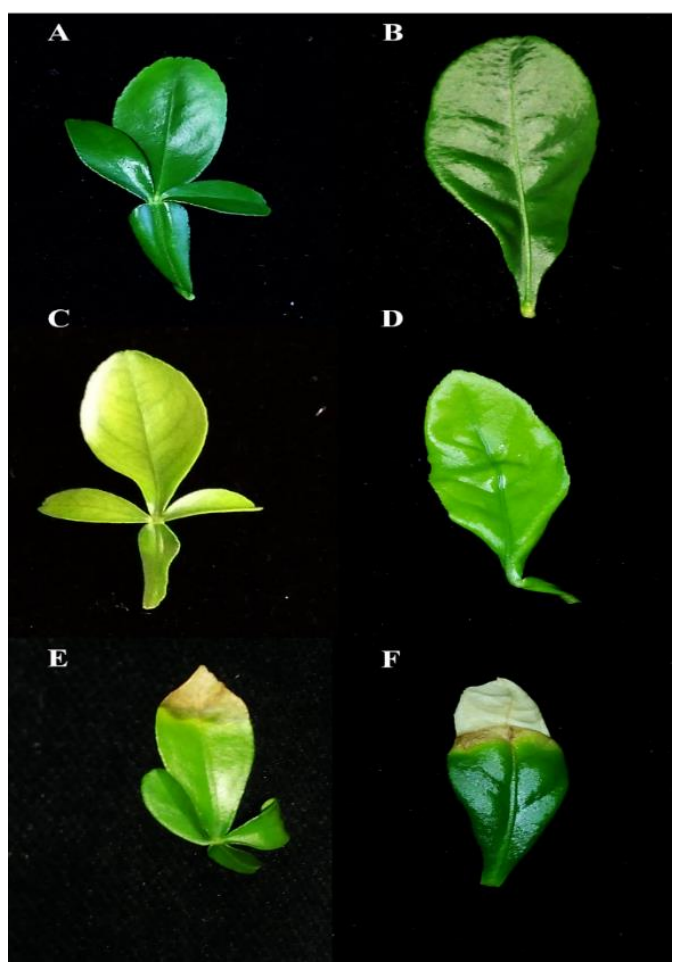

Figure 1. Stress-induced leaf damage in Carrizo citrange (A, C and E) and Cleopatra mandarin (B, $\mathrm{D}$ and F). A and B: intact leaves; C and D: Chlorotic leaves; E and F: partially necrotic leaves.
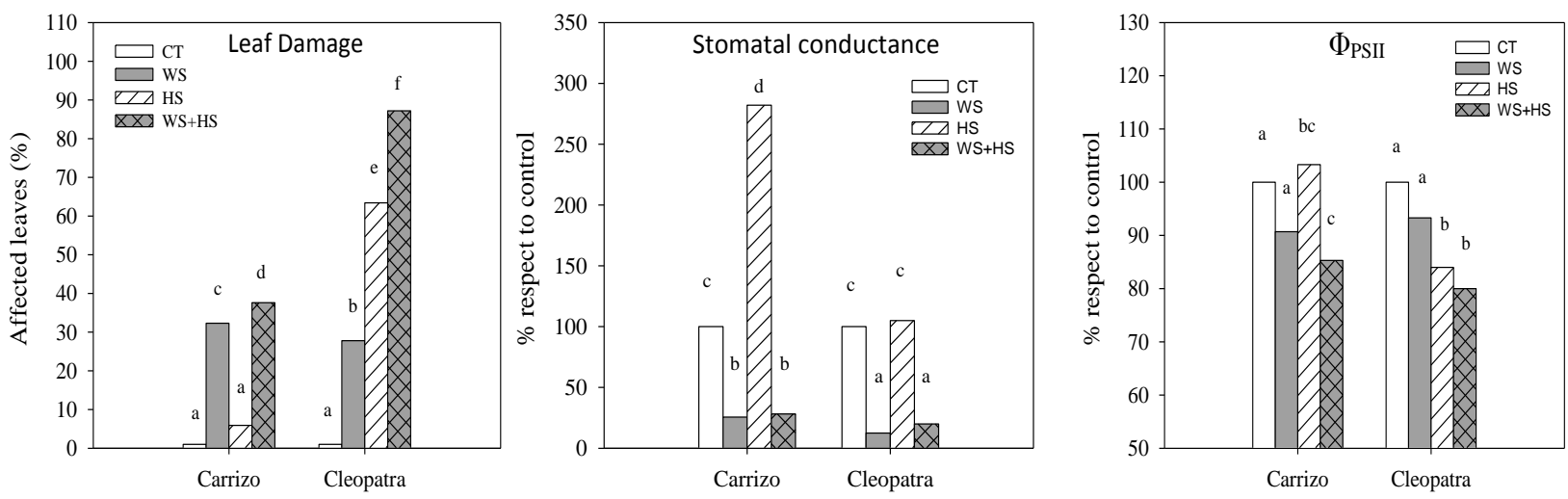

Figure 2. Leaf damage, stomatal conductance (gs) and quantum yield ( $\left.\Phi_{\mathrm{PSII}}\right)$ in Carrizo and Cleopatra plants subjected to drought (WS), heat stress (HS) and the combination of drought and heat stress (WS+HS). Different letters denote statistical significance at $p \leq 0.05$ within each parameter. 
3.2 APX activity and expression of Carrizo and Cleopatra plants subjected to WS, HS and $W S+H S$

Figure 3 shows APX enzymatic activity and transcript accumulation in Carrizo and Cleopatra plants in response to WS, HS and WS+HS conditions. Drought similarly enhanced the APX activity in both genotypes whereas transcript expression increased only in Carrizo plants. Heat stress induced the highest APX activity in both genotypes, having Cleopatra a more pronounced response. APX gene was upregulated under HS, following the same pattern than the enzymatic activity in both Carrizo and Cleopatra plants. Finally, under stress combination Carrizo plants showed an APX activity similar to that observed under heat stress. In contrast, in Cleopatra plants, APX activity was significantly lower under stress combination with respect to heat stress. APX expression achieved the highest rate under WS+HS in Carrizo whereas in Cleopatra, it slightly increased with respect to control plants, correlating with the enzymatic activity.
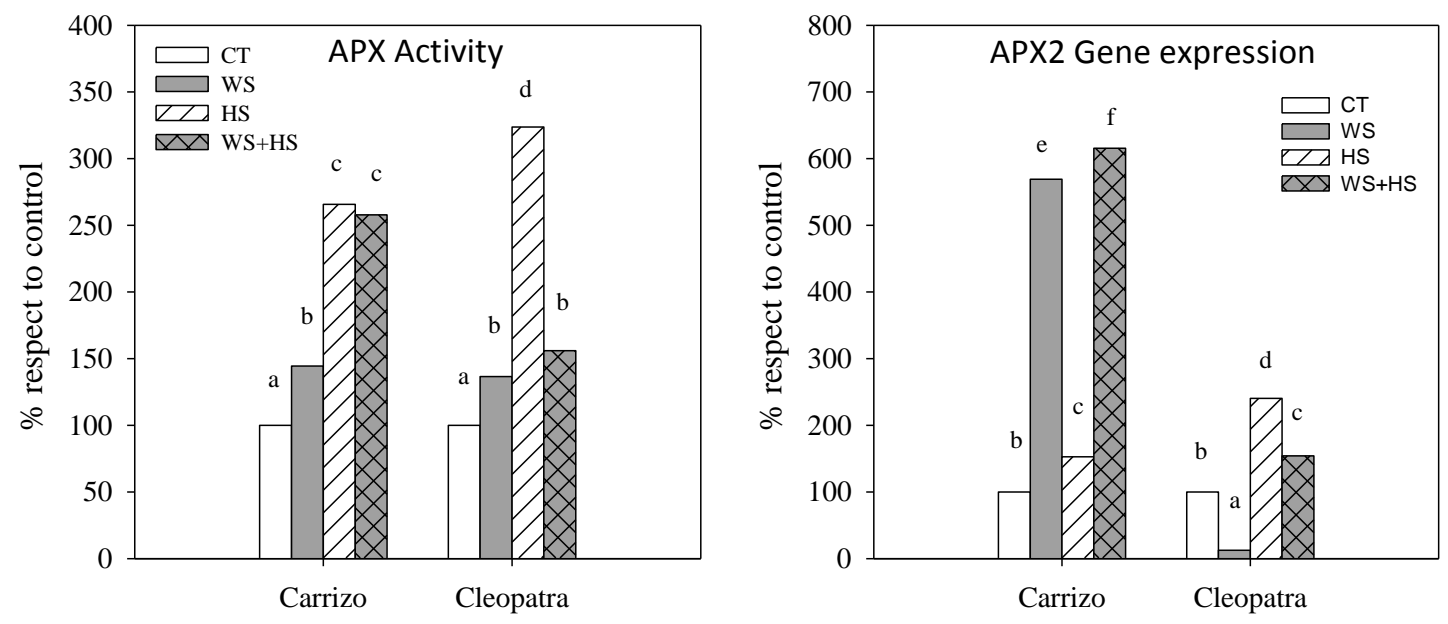

Figure 3. APX activity and APX2 gene expression in Carrizo and Cleopatra plants subjected to drought (WS), heat stress (HS) and the combination of drought and heat stress (WS+HS). Different letters denote statistical significance at $\mathrm{p} \leq 0.05$ within each parameter.

\subsection{Accumulation of APX, HSP101 and HSP17.6 proteins in Carrizo and Cleopatra} plants subjected to WS, HS and WS+HS

The accumulation of three proteins (HSP101, HSP17.6 and APX2) was studied in Carrizo and Cleopatra plants subjected to drought, heat stress and their combination. As shown in Figure 4, Drought did not have significant effects on APX, HSP101 and HSP17.6 accumulations respect to control plants in any of the two studied genotypes. Heat stress induced the accumulation of APX and HSP101 in both citrus leaves, but especially in 
Carrizo. HSP17.6 accumulation increased considerably under heat stress in Carrizo and Cleopatra, finding similar levels in both genotypes. WS+HS induced a marked accumulation of these three proteins in Carrizo leaves and it also caused significant accumulation in Cleopatra ones. However, for APX and HSP101, the extent of this increase was clearly lower.
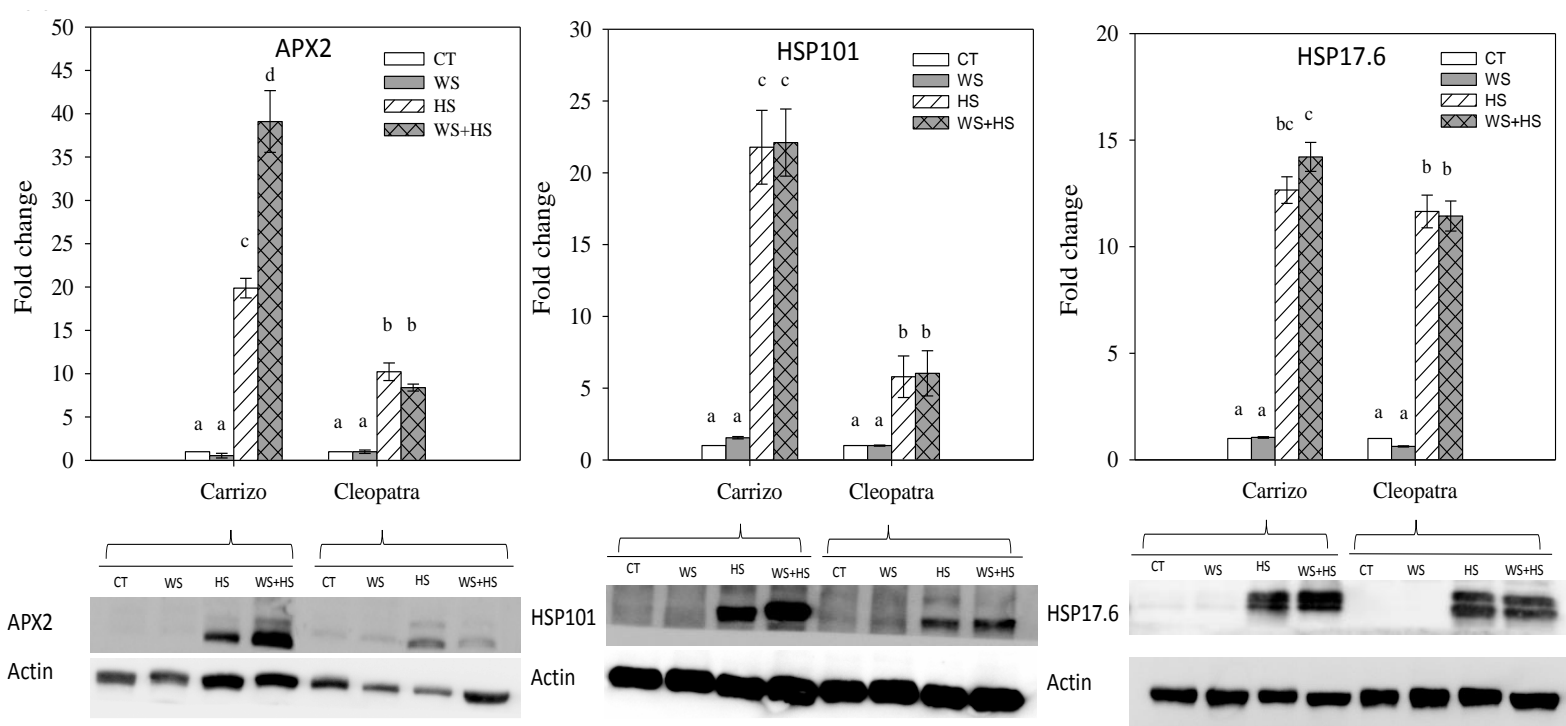

Figure 4. APX2, HSP101 and HSP17.6 levels in Carrizo and Cleopatra plants subjected to drought (WS), heat stress (HS) and the combination of drought and heat stress (WS+HS). Top: Quantification graphs. Bottom: Representative protein blots and loading controls. Different letters denote statistical significance at $\mathrm{p} \leq 0.05$.

\section{Discussion}

Tolerance of Carrizo citrange and Cleopatra mandarin plants to drought, heat stress and the combination of both conditions has been previously studied, concluding that Carrizo plants are more tolerant to HS and WS+HS than Cleopatra. This enhanced tolerance can be explained, at least in part, by a higher stomata opening and transpiration rate that allow cooling the leaf surface (Zandalinas et al. 2016b). In this sense, data presented in Figure 2 confirmed that Cleopatra is more sensitive to the heat stress and the combination of drought and high temperatures assayed in this work since the percentage of affected leaves is higher in Cleopatra plants. This difference in tolerance is due, at least in part, to the reduced ability of Cleopatra stomata to open under high temperatures (Figure 2) together with a worse performance of the antioxidant enzyme APX (Figure 3, Zandalinas et al. 2017). 
The enzyme APX reduces the $\mathrm{H}_{2} \mathrm{O}_{2}$, resulting from $\mathrm{O}_{2}{ }^{-}$- scavenging by superoxide dismutase (SOD), using AsA as the electron donor and rendering water and monodehydroascorbate. The role of APX, together with other antioxidant enzymes like SOD or catalase (CAT), is key for the protection of the photosynthetic machinery from the oxidative damage produced by environmental stresses (Silva et al. 2010). APX has a pivotal role in the acclimation of plants to stress combination, as drought and high temperatures (Rizhsky et al. 2002; Koussevitzky et al. 2008). Although APX activity increased slightly in both genotypes under WS conditions (Figure 3), there was not APX2 accumulation (the main isoform involved in antioxidant activity under stress conditions in both, citrus and Arabidopsis thaliana, Hossain et al. 2009, Zandalinas et al. 2016a). This suggests that other APX isoforms (thylakoidal or stromal APX) could have a minor role in the enzymatic increase observed under this condition. The higher accumulation of APX protein observed in Carrizo plants under HS and, particularly, under WS+HS with respect to Cleopatra (Figure 4), indicates that the antioxidant machinery in Carrizo was more activated under these stress conditions, since not only APX gene expression was higher in this genotype but also functional protein strongly accumulated. These results suggest that the accumulation of APX is a specific response of Carrizo plants to combined conditions of water stress and high temperatures and that the antioxidant system is probably involved in citrus tolerance to this stress combination. In addition, it is remarkable that it is a differentiated response from the responses to the individual stresses. Furthermore, from this study it seems clear the importance of studying the accumulation of a protein and its activity and not only its gene expression. The role of a protein in cells cannot be estimated only by measuring gene expression, considering that posttranscriptional regulation can be determinant for the final production of the protein and its functionality. Different example can be found elsewhere with transcript accumulations that result in no final phenotype. As an example, in Manzi et al. (2017), an up-regulation of genes coding for the enzymes involved in the abscisic acid (ABA) biosynthesis pathway was reported under drought stress conditions. However, there was not accumulation of $\mathrm{ABA}$ in this tissue under that particular experimental design.

In addition to APX, the HSP is a family of proteins characterized by its role as molecular chaperones during stress conditions. They prevent protein misfolding or aggregation and promote the reactivation of proteins already aggregated. There are numerous subgroups of HSP regarding its molecular mass. HSP101, which belongs to HSP100 subgroup, could 
form molecular complexes with others HSPs to correct protein folding. HSP101 is a pivotal protein in establishing thermotolerance and stress combination resistance (Queitsch et al. 2000, Wu et al. 2013, Suzuki et al. 2016). HSP17.6 belongs to the subgroup of small heat shock proteins (smHSP) which accumulate rapidly under stress situations, principally heat stress. It was shown that plants overexpressing HSP17.6 had increased osmotolerance (Sun et al. 2001). Furthermore, in Arabidopsis thaliana, an increase of HSP17.6 levels in response to exogenous treatment of $\mathrm{H}_{2} \mathrm{O}_{2}$ has been reported, suggesting its role in coping with oxidative stress (Sun et al. 2001, Volkov et al. 2006).

The higher accumulation of HSP101 in Carrizo plants with respect to Cleopatra under HS and WS+HS suggests that this protein regulates plant acclimation to conditions involving high temperatures. Since no differences were found in the accumulation of HSP101 under high temperatures individually applied and combined stresses, it seems that HSP101 is a heat stress-specific protein. This result correlates with the up-regulation of HSP101 in Arabidopsis thaliana plants subjected to different stress situations involving heat (Rizhsky et al. 2004, Suzuki et al. 2016). The fact that HSP17.6 remarkably accumulated in both genotypes under heat stress applied individually or in combination with drought suggests that the accumulation of this protein is heat-dependent and do not respond to additional stress conditions. Furthermore, in contrast to the other proteins studied in this work, the sensitive genotype to high temperatures (Cleopatra) accumulated similar protein levels than the tolerant one (Carrizo). Thus, HSP17.6 does not seem to be central for the acclimation of citrus plants to situations involving high temperatures.

In this work, we have studied the accumulation of three important proteins under drought, high temperatures and their combination in Carrizo citrange and Cleopatra mandarin, two citrus genotypes with contrasting ability to tolerate these stress conditions. Our results extend the knowledge on the basis for the higher tolerance of Carrizo to combined stress conditions. It has been shown that three different proteins putatively involved in plant tolerance to heat stress (APX, HSP101 and HSP17.6) have distinct accumulation patterns in citrus under high temperatures or combined conditions of heat and water stress. APX would be crucial for the acclimation of citrus to stress combinations whereas HSP101 accumulation would be determinant for thermotolerance. However, HSP17.6 might have a residual role on tolerance to these conditions. Carrizo citrange has different characteristics (a suitable stomatal behavior under high temperatures together with an efficient antioxidant machinery and an ability to specifically accumulate key proteins) 
that appoint it as a predictable better rootstock than Cleopatra (traditionally employed in areas with scare water supplies) to be used under the present (and future) changing climatic conditions, in which periods of drought and high temperatures will be more frequent and of greater intensity. Further agronomic studies will be needed to test the tolerance of different citrus varieties grafted on these rootstocks growing under different field conditions.

\section{Contribution}

DB and SIZ designed, performed the experiments and harvested plant material and analyzed samples. DB, PB and MM performed Western blot analysis. AGC supervised the project and provided funding. DB, SIZ, PB; MM and AGC wrote the manuscript and prepared figures. All authors have read and approved the final version of the manuscript.

\section{Acknowledgements}

This work was supported by Ministerio de Economía y Competitividad (MINECO) and Universitat Jaume I through grants No. AGL2016-76574-R and UJI-B2016-23, respectively.

\section{References}

Al-Whaibi MH (2011) Plant heat-shock proteins: A mini review. Journal of King Saud University - Science 23: 139-150.

Argamasilla R, Gómez-Cadenas A, Arbona V (2014) Metabolic and regulatory responses in citrus rootstocks in response to adverse environmental conditions. Journal of Plant Growth Regulation 33: 169-180.

Hossain Z, López-Climent MF, Arbona V, Pérez-Clemente RM, Gómez-Cadenas A (2009) Modulation of the antioxidant system in citrus under waterlogging and subsequent drainage. Journal of Plant Physiology 166: 1391-1404.

Koussevitzky S, Suzuki N, Huntington S, Armijo L, Sha W, Cortes D, Shulaev V, Mittler R (2008) Ascorbate peroxidase 1 plays a key role in the response of Arabidopsis thaliana to stress combination. Journal of Biological Chemistry 283: 34197-34203. 
Mafra V, Kubo KS, Alves-Ferreira M, Ribeiro-Alves M, Stuart RM, Boava LP, Rodrigues CM, Machado MA (2012) Reference genes for accurate transcript normalization in citrus genotypes under different experimental conditions. PloS one 7: e31263.

Manzi M, Pitarch-Bielsa M, Arbona V, Gómez-Cadenas A (2017) Leaf dehydration is needed to induce abscisic acid accumulation in roots of citrus plants. Environmental and Experimental Botany 139: 116-126.

Mittler R (2006) Abiotic stress, the field environment and stress combination. Trends in Plant Science 11: 15-19.

Mittler R, Blumwald E (2010) Genetic engineering for modern agriculture: challenges and perspectives. Annual Review of Plant Biology 61: 443-462.

Nakamoto H, Vígh L (2007) The small heat shock proteins and their clients. Cellular and Molecular Life Sciences 64: 294-306.

Pfaffl MW, Horgan GW, Dempfle L (2002) Relative expression software tool (REST) for group-wise comparison and statistical analysis of relative expression results in realtime PCR. Nucleic Acids Research 30: e36.

Queitsch C, Hong SW, Vierling E, Lindquist S (2000) Heat shock protein 101 plays a crucial role in thermotolerance in Arabidopsis. Plant Cell 12: 479-92.

Rizhsky L, Liang H, Mittler R (2002) The combined effect of drought stress and heat shock on gene expression in tobacco. Plant Phisiology 130: 1143-1151.

Rizhsky L, Liang H, Shuman J, Shulaev V, Davletova S, Mittler R (2004) When defense pathways collide. The response of Arabidopsis to a combination of drought and heat stress. Plant Physiology 134: 1683-1696.

Silva EN, Ferreira-Silva SL, Fontenele A de V, Ribeiro RV, Viégas RA, Silveira JAG (2010) Photosynthetic changes and protective mechanisms against oxidative damage subjected to isolated and combined drought and heat stresses in Jatropha curcas plants. Journal of Plant Physiology 167: 1157-1164.

Sun W, Bernard C, van de Cotte B, Van Montagu M, Verbruggen N (2001) AtHSP17.6A, encoding a small heat-shock protein in Arabidopsis, can enhance osmotolerance upon overexpression. Plant Journal 27: 407-15. 
Suzuki N, Basil E, Hamilton JS, Inupakutika, Madhuri A Zandalinas SI, Tripathy D, Yuting L, Dion E, Fukui G, Kumazaki A, Nakano R, Rivero R, Azad RK, Blumwald E, Mittler R (2016) ABA is required for plant acclimation to a combination of salt and heat stress. PloS One 11: e0147625.

Volkov RA, Panchuk II, Mullineaux PM, Schöffl F (2006) Heat stress-induced H2O2 is required for effective expression of heat shock genes in Arabidopsis. Plant Molecular Biology 61: 733-746.

Wang W, Vinocur B, Altman A (2003) Plant responses to drought, salinity and extreme temperatures: towards genetic engineering for stress tolerance. Planta 218: 1-14.

Wu T, Juan Y, Hsu Y, Wu S, Liao H, Fung RWM, Charng Y (2013) Interplay between heat shock proteins HSP101 and HSA32 prolongs heat acclimation memory posttranscriptionally in Arabidopsis. Plant Physiology 161: 2075-2084.

Zandalinas SI, Balfagón D, Arbona V, Gómez-Cadenas A (2017) Modulation of antioxidant defense system is associated with combined drought and heat stress tolerance in citrus. Frontiers in Plant Science 8: Art. 953.

Zandalinas SI, Balfagón D, Arbona V, Gómez-Cadenas A, Inupakutika MA, Mittler R (2016a) ABA is required for the accumulation of APX1 and MBF1c during a combination of water deficit and heat stress. Journal of Experimental Botany 6: 5381-5390.

Zandalinas SI, Mittler R, Balfagón D, Arbona V, Gómez-Cadenas A (2018) Plant adaptations to the combination of drought and high temperatures. Physiologia Plantarum 162: $2-12$.

Zandalinas SI, Rivero RM, Martínez V, Gómez-Cadenas A, Arbona V (2016b) Tolerance of citrus plants to the combination of high temperatures and drought is associated to the increase in transpiration modulated by a reduction in abscisic acid levels. BMC Plant Biology 16: Art. 105. 


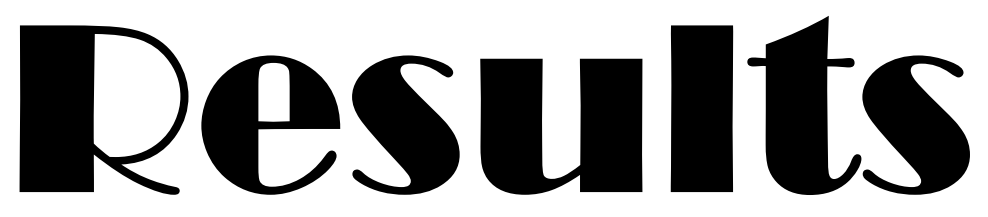

\section{Chapter 3}

High temperatures change the perspective: Integrating hormonal responses in citrus plants under co-occurring abiotic stress conditions

Balfagón et al. (2019) Physiologia Plantarum 165: 183-197 



\section{Abstract}

Plants growing in the field are subjected to multiple stress factors acting simultaneously. Abnormally high temperatures are expecting to affect wild plants and crops in the next years due to global warming. In this work, we have studied physiological, hormonal and molecular responses of the citrus rootstock, Carrizo citrange (Poncirus trifoliata L. Raf. X Citrus sinensis L.Osb.) subjected to wounding or high salinity individually occurring or in combination with heat stress. According to our results, combination of high salinity and heat stress aggravated the negative effects of salt intoxication in Carrizo. The high transpiration rate caused by high temperatures counteracted physiological responses of plants to salt stress and increased $\mathrm{Cl}^{-}$intake in leaves. In addition, 12-oxo-phytodienoic acid (OPDA) accumulated specifically under combination of wounding and heat stress, whereas at low temperatures, wounded plants accumulated jasmonic acid (JA) and JAisoleucine (JA-Ile). Moreover, an antagonism between salicylic acid (SA) and JA was observed, and wounded plants subjected to high temperatures did not accumulate JA nor JA-Ile whereas SA levels increased (via ICS biosynthetic pathway). Wounded plants did not accumulate abscisic acid (ABA) but its catabolite phaseic acid (PA). This could act as a signal for the upregulation of (ABA)-RESPONSIVE ELEMENT (ABRE)-BINDING TRANSCRIPTION FACTOR 2 CSAREB2 and RESPONSIVE TO DISSECATION 22 $(C s R D 22)$ in an ABA-independent way. This work uncovers some mechanisms that explain Carrizo citrange tolerance to high temperatures together with different hormonal signals in response to specific stresses. It is suggested that co-occurring abiotic stress conditions can modify (either enhance or reduce) the hormonal response to modulate specific responses.

\section{Introduction}

Abiotic stress is an important detrimental factor for crop yield and productivity. Environmental adverse conditions such as drought, heat, salinity, soil toxicity, flooding or high light intensity among others, negatively impact on plants compromising growth, yield and even plant survival. These unfavorable situations lead to adaptive responses in plants, including morphological, physiological, biochemical and molecular changes (Zhang and Sonnewald 2017, Vives-Peris et al. 2017, Devireddy et al. 2018, De Ollas et al. 2018). Although the effects of individually-applied abiotic stresses on plants have been widely studied, extensive efforts to study plant responses to different stress combinations 


\section{Chapter 3}

are just recently emerging. Recent studies have demonstrated that the biochemical and molecular responses of plants to stress combinations are different from those changes caused by the same stresses applied individually (Mittler 2006, Suzuki et al. 2014, Zandalinas et al. 2018, Balfagón et al. 2018).

Increased temperatures associated to the climate change are predicted to have a negative effect on crops leading to important losses in yields (Lobell et al. 2011). Due to the global warming, heat waves are increasing in frequency and intensity and worldwide surface temperature is expected to rise considerably in the coming years (IPCC 2014; http://www.ipcc.ch/). Moreover, under field conditions, high temperatures usually appear together with drought and/or low-quality water supplies and also can be combined with other stress factors like high light intensity, flooding, nutrient deficiencies, mechanical wounding or increased concentrations of heavy metals, among others. For example, it has been reported that the combination of high temperatures and increased $\mathrm{CO}_{2}$ concentration enhances the accumulation of $\mathrm{Cd}$ and reduces $\mathrm{Zn}$ levels in shoots and roots of Triticum aestivum leading to reduced seedlings growth (Wang et al. 2016). Combination of drought and high temperatures has been deeply studied in citrus plants. It has been reported that stomatal regulation, efficiency in reactive oxygen species (ROS) scavenging and accumulation of key proteins are crucial plant responses to survive this stress combination (Zandalinas et al. 2016b, 2017, Balfagón et al. 2018). Furthermore, combination of high temperatures and ozone stress had a negative effect on Betula pendula growth and leaf biomass production because allocation of carbon is partly altered by ozone stress (Kasurinen et al. 2012). Also, it has been described that aldehyde dehydrogenase (ALDH) enzymes, which contribute to redox balance by producing NADPH and NADH, are key in Arabidopsis thaliana (Arabidopsis) survival under combination of wounding and heat stress (Zhao et al. 2017).

Phytohormones are demonstrated to play a pivotal role in the response of plants to abiotic stress applied individually or in combination (Peleg and Blumwald 2011, GómezCadenas et al. 2015, Suzuki 2016a). Among them, abscisic acid (ABA) is key to activate plant responses to water deficit, salinity and heat. ABA induces the accumulation of different proteins involved in acclimation and regulates stomatal closure under osmotic stress or heat stress situations (Finkelstein 2013, Gómez-Cadenas et al. 2015). In Arabidopsis, it has been demonstrated that ABA is crucial for the accumulation of essential proteins during a combination of water deficit and heat stress (Zandalinas et al. 2016a). Furthermore, Suzuki et al. (2016b) demonstrated that mutants deficient in ABA 
metabolism and signaling were more susceptible than wild type plants to a combination of salt and heat stress. Apart from ABA, its catabolite phaseic acid (PA) has been demonstrated to act as a signaling molecule that fine-tunes environmental adaptation and development. In particularly, PA selectively alters the expression of ABA-responsive and non-responsive genes (Weng et al. 2016).

Jasmonates (JAs) and salicylic acid (SA), although being widely studied for its role under biotic stress conditions, are also involved in plant tolerance to abiotic stress. Thus, jasmonic acid (JA) was reported to accumulate in Arabidopsis plants exposed to cold, and mutants deficient in JA biosynthesis or signaling have an increased sensitivity to freezing stress relative to wild type plants ( $\mathrm{Hu}$ et al. 2013). Moreover, in wheat, the ALLENE OXIDE SYNTHASE (AOC)-catalyzed branch of the JA biosynthesis pathway provides salt resistance in a MYC2-dependent way (Zhao et al. 2014). In addition, the JA precursor, 12-oxo-phytodienoic acid (OPDA), causes stomatal closure and enhances plant tolerance under drought stress (Kazan 2015). SA has been reported to be an important signal in plants under abiotic stress, particularly under high temperatures. SA may protect the photosystem II complex (PSII) from an increase of ROS and improve photosynthetic capacity under salt, drought or heat stress (Wang et al. 2010). Also, SA acting together with JAs was demonstrated to confer thermotolerance in Arabidopsis (Clarke et al. 2009). Citrus is an economically important fruit tree worldwide. The Mediterranean and subtropical areas where citrus are usually cultivated are especially vulnerable to global warming, which threatens crop production. This scenario rises awareness about the study of genotypes acclimated to high temperatures that could deal with other predicted stress conditions. Hence, the aim of this work was to evaluate the tolerance of Carrizo citrange, a citrus rootstock acclimated to high temperatures, to different stress combinations (wounding or salt stress combined with heat stress). To achieve this, physiological, hormonal and molecular responses of plants to individual and combined stress conditions were studied.

\section{Materials and methods}

\section{Plant material and growth conditions}

Carrizo citrange (Poncirus trifoliata L. Raf. X Citrus sinensis L.Osb.) plants were purchased from a commercial nursery (Beniplant S.L., Penyíscola, Spain). One-year-old seedlings of Carrizo were grown in 0.6-1 plastic pots filled with perlite and watered three times a week with 0.51 of a half-strength Hoagland solution (Lopez-Climent et al. 2008) 
in greenhouse conditions, with natural photoperiod and day and night temperature averaging $25.0 \pm 3.0^{\circ} \mathrm{C}$ and $18.0 \pm 3.0^{\circ} \mathrm{C}$, respectively. Then, plants were transferred for 2 weeks to growth chambers to acclimate to a $16-\mathrm{h}$ photoperiod at $300 \mu \mathrm{mol} \mathrm{m}^{-2} \mathrm{~s}^{-1}$ at $25^{\circ} \mathrm{C}$ and relative moisture was fixed approximately at $80 \%$.

\section{Experimental designs and stress treatments}

An experimental system was designed in which wounding and high salinity in the watering solution were applied individually or in combination with high temperatures $\left(40^{\circ} \mathrm{C}\right)$. Therefore, 6 experimental groups were established: (1) intact plants growing at $25^{\circ} \mathrm{C}$ (control, CT), (2) or at $40^{\circ} \mathrm{C}$ (heat shock, HS), (3) wounded plants growing at $25^{\circ} \mathrm{C}$ (wounded, Wo) (4) or at $40^{\circ} \mathrm{C}$ (wounded + heat shock, Wo+HS), (5) salinized plants growing at $25^{\circ} \mathrm{C}(\mathrm{NaCl})(6)$ or at $40^{\circ} \mathrm{C}(\mathrm{NaCl}+\mathrm{HS})$. All the conditions were applied at the same time for 15 days. Wounding was performed by drilling $50 \%$ of the leaves with a paper puncher (three times per leaf). Only not wounded leaves were collected and used for further analyses. High salinity in the water solution was achieved by adding $60 \mathrm{mM}$ $\mathrm{NaCl}$ to the nutrient solution. Each experiment was repeated twice.

\section{Plant status and water-plant relations}

To analyze the phenotypical effect of the different stresses studied in this work, damaged leaves and new sprouts were quantified at day 15 on each group of plants.

Relative water content of citrus leaves was calculated at day 15 by using adjacent leaves, which were weighed to obtain a leaf fresh mass (Mf). Leaves were allowed to rehydrate overnight in an opaque beaker filled with water. Therefore, they were reweighed to obtain turgid mass (Mt). Finally, leaves were dried at $80^{\circ} \mathrm{C}$ for $48 \mathrm{~h}$ to obtain dry mass $(\mathrm{Md})$. RWC was calculated as $\left[(\mathrm{Mf}-\mathrm{Md}) \times(\mathrm{Mt}-\mathrm{Md})^{-1}\right] \times 100$ according to Morgan (1984).

\section{Physiological parameters}

Transpiration (E) and stomatal conductance (gs) were measured using a LCpro+ portable infrared gas analyzer (ADC BioScientific Ltd., Hoddesdon, UK) under ambient $\mathrm{CO}_{2}$ and moisture. Supplemental light was provided by a PAR lamp at $1000 \mu \mathrm{mol} \mathrm{m}{ }^{-2} \mathrm{~s}^{-1}$ photon flux density, and air flow was set at $150 \mu \mathrm{mol} \mathrm{mol}{ }^{-1}$. After instrument stabilization, at least 10 measurements were taken on three leaves in three replicate plants from each stress treatment. 


\section{Chloride analysis}

Chloride content in shoot tissues was measured by automatic titration as described in López-Climent et al. (2008). Briefly, approximately $250 \mathrm{mg}$ of frozen grind plant tissue was incubated for $12 \mathrm{~h}$ with $0.1 \mathrm{~N} \mathrm{HNO}_{3}$ (Panreac, Barcelona, Spain) and $10 \%$ glacial acetic acid (Sigma-Aldrich, St. Louis, MO). Finally, the chloride concentration was obtained by measuring $0.5 \mathrm{ml}$ of the solution with a chloride meter (Model 926; Sherwood Scientific Ltd., Cambridge, UK).

\section{Hormone analyses}

Hormone extraction and analysis were carried out as described in Durgbanshi et al. (2005) with few modifications. Briefly, $0.1 \mathrm{~g}$ of fresh tissue (FW) was extracted in $2 \mathrm{ml}$ of ultrapure water after spiking with $50 \mathrm{ng}$ of $\left[{ }^{2} \mathrm{H}_{6}\right]-\mathrm{ABA},\left[{ }^{2} \mathrm{H}_{3}\right]-\mathrm{PA},\left[{ }^{13} \mathrm{C}\right]-\mathrm{SA}$, and dihydrojasmonic acid in a ball mill (MillMix20, Domel, Železniki, Slovenia). $\left[{ }^{2} \mathrm{H}_{6}\right]-\mathrm{ABA}$ was used to determine ABA, $\left[{ }^{2} \mathrm{H}_{3}\right]-\mathrm{PA}$ was used to determine PA and DPA, $\left[{ }^{13} \mathrm{C}\right]-\mathrm{SA}$ was used to determine SA and dihydrojasmonic acid to determine JA, OPDA and JA-Ile. After centrifugation at $4000 \mathrm{~g}$ at $4^{\circ} \mathrm{C}$ for $10 \mathrm{~min}$, supernatants were recovered and $\mathrm{pH}$ adjusted to 3 with $30 \%$ acetic acid. The water extract was partitioned twice against $2 \mathrm{ml}$ of diethyl ether and the organic layer recovered and evaporated under vacuum in a centrifuge concentrator (Speed Vac; Jouan, Saint Herblain Cedex, France). Once dried, the residue was resuspended in a 10:90 MeOH: $\mathrm{H}_{2} \mathrm{O}$ solution by gentle sonication. The resulting solution was filtered through $0.22 \mu \mathrm{m}$ polytetrafluoroethylene membrane syringe filters (Albet S.A., Barcelona, Spain) and directly injected into an ultra-performance LC system (Acquity SDS; Waters Corp., Milford, MA). Chromatographic separations were carried out on a reversed-phase C18 column (Gravity, $50 \times 2.1 \mathrm{~mm}, 1.8-\mu \mathrm{m}$ particle size; Macherey-Nagel GmbH, Düren, Germany) using a $\mathrm{MeOH}: \mathrm{H}_{2} \mathrm{O}$ (both supplemented with $0.1 \%$ acetic acid) gradient at a flow rate of $300 \mu \mathrm{min}^{-1}$. Hormones were quantified with a TQS triple quadrupole mass spectrometer (Micromass, Manchester, UK) connected online to the output of the column though an orthogonal Z-spray electrospray ion source. Measurements were carried out in mode MRM negative (run conditions and transitions used are described in Table S2).

\section{RNA isolation, cDNA synthesis and qRT-PCR analyses}

RNA was extracted from frozen plant tissues using a RNeasy Mini kit (Qiagen, Hilden, Germany) following the manufacturer's instructions. Total RNA concentration and purity 
was determined using a Nanodrop 2000 spectrophotometer (Thermo Scientific, Wilmington, DE) from the ratio of absorbance readings at 260 and $280 \mathrm{~nm}$. Reverse transcription was carried out from $1 \mu \mathrm{g}$ of total RNA using Primerscript RT reagent with oligo(dT) primer (Takara Bio Inc., Kusatsu, Japan).

The specific primers used for the amplification of each gene are included in Table S1. qRT-PCR analyses were performed in a StepOne Real-Time PCR system (Applied Biosystems, Foster City, CA). The reaction mixture contained $1 \mu 1$ of cDNA, $5 \mu 1$ of SYBRGreen (Applied Biosystems) and $1 \mu \mathrm{M}$ of each gene-specific primer pair in a final volume of $10 \mu \mathrm{l}$. The thermal profile used to analyze the relative gene expression consisted of $10 \mathrm{~min}$ at $95^{\circ} \mathrm{C}$ for pre-incubation, followed by 40 cycles of $10 \mathrm{~s}$ at $95^{\circ} \mathrm{C}$ for denaturation, $10 \mathrm{~s}$ at $60^{\circ} \mathrm{C}$ for annealing and $20 \mathrm{~s}$ at $72^{\circ} \mathrm{C}$ for extension. Amplicon specificity of the PCR reaction was evaluated by the presence of a single peak in the dissociation curve after the amplification steps. The expression levels of all genes were normalized against the expression of two endogenous control genes (TUBULIN and ACTIN) based on previous housekeeping selection for citrus tissues (Mafra et al. 2012) and the relative expression were calculated using REST software (Pfaffl et al. 2002). For all genes studied, the reference sample was the expression value obtained at the nonstressed samples and set at one. Three technical replicates were analyzed on each biological replicate.

\section{Statistical analyses}

One-way analysis of variance (ANOVA) was performed followed by Tukey posthoc test $(\mathrm{p}<0.01)$ when a significant difference was detected.

\section{Results}

\section{Vegetative growth and leaf damage}

Carrizo plants were exposed for 15 days to two abiotic stress conditions (wounding and salt stress) applied individually or combined with high temperatures. To evaluate plant tolerance to these adverse situations, number of new sprouts and leaf damage were recorded at the end of the experimental period (Fig. 1). Emission of new sprouts was lower in plants subjected to salt stress than in controls. Heat stress (HS) increased significantly the vegetative growth of Carrizo plants. However, plants cultivated under high temperatures in combination with high salinity reduced the number of new sprouts in comparison with those under HS, recording values similar to control plants. Wounding 
(Wo) applied individually or in combination with heat stress did not alter vegetative growth (Fig. 1A). Leaf damage in plants under Wo, HS and Wo+HS was very low and similar to controls. However, plants under $\mathrm{NaCl}$ and $\mathrm{NaCl}+\mathrm{HS}$ conditions had an increased number of damaged leaves. The combination of high salinity and heat was the most harmful condition for citrus plants, with $29.7 \%$ of leaves affected (Fig. 1B).

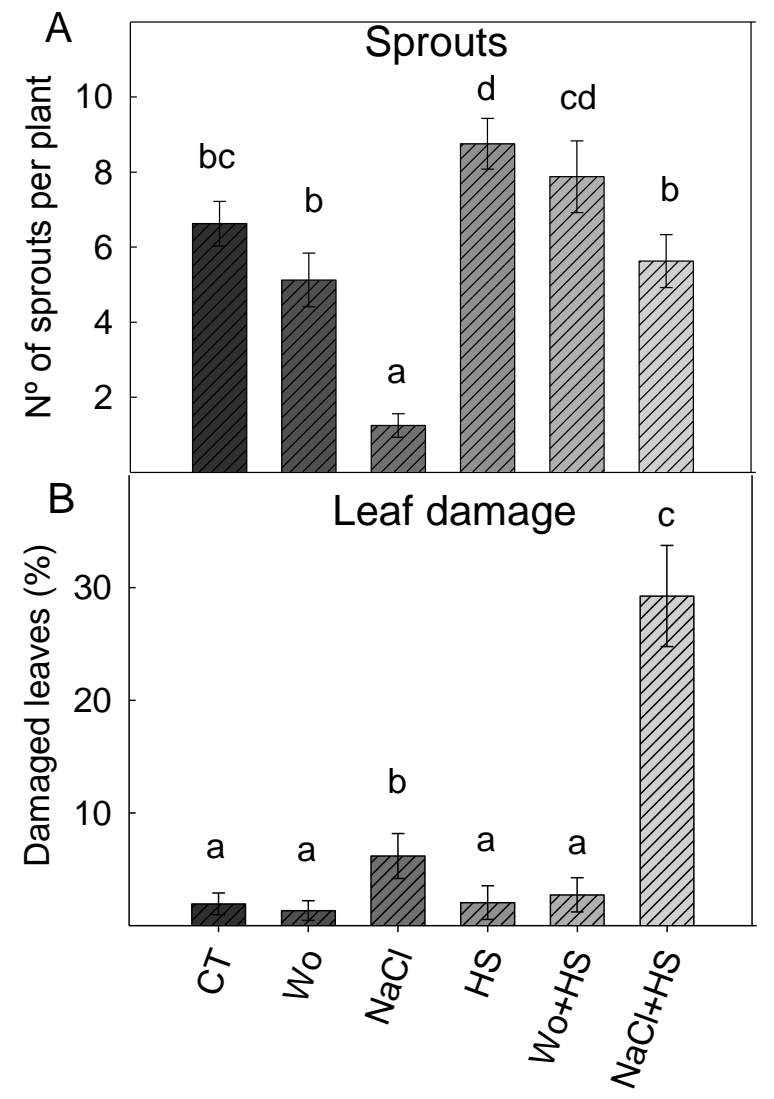

Fig. 1. Phenotypic traits: New sprouts per plant (A) and damaged leaves (B), in Carrizo plants in response to wounding (Wo), salt stress $(\mathrm{NaCl})$, heat stress (HS), combination of wounding and heat stress (Wo+HS) and combination of salt and heat stress $(\mathrm{NaCl}+\mathrm{HS})$ for 15 days. Different letters denote statistical significance among treatments at $P \leq 0.01$.

\section{Leaf water status}

Leaf relative water content of Carrizo plants subjected to wounding and salt stress applied individually or in combination with heat stress was measured (Fig. 2). $\mathrm{NaCl}+\mathrm{HS}$ was the only stress condition that caused a significant decrease of leaf RWC (values were 52.9\% of those registered in control plants). The rest of adverse situations did not affect leaf RWC. 


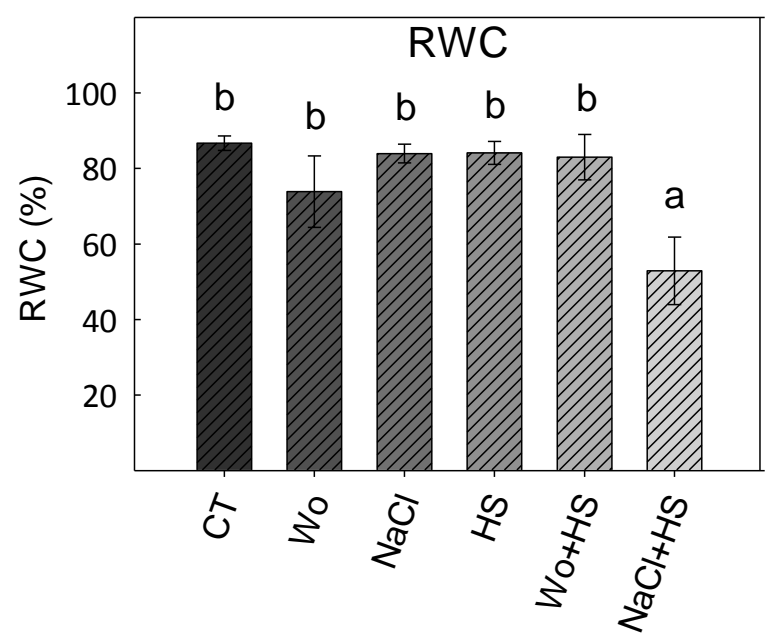

Fig. 2. Leaf relative water content (RWC) of Carrizo plants subjected to wounding (Wo), salt stress $(\mathrm{NaCl})$, heat stress (HS), combination of wounding and heat stress (Wo+HS) and combination of salt and heat stress $(\mathrm{NaCl}+\mathrm{HS})$ for 15 days. Different letters denote statistical significance among treatments at $P \leq 0.01$.

\section{Leaf transpiration and stomatal conductance parameters}

Leaf transpiration (E) and stomatal conductance (gs) were measured in citrus plants in response to each stress (Fig. 3). Wounded plants did not increase leaf transpiration nor stomatal conductance values respect to controls. Plants under salt stress strongly reduced $\mathrm{E}$ and gs to values that were $37.1 \%$ and $26.6 \%$ of those found in control plants. Heat stress caused the highest increase of E and gs in Carrizo plants (3.1-fold and 2.0-fold increases with respect to controls, respectively). Transpiration levels in Wo+HS plants increased significantly with respect to CT plants, although they were similar to Wo ones (Fig. 3A). In opposition, stomatal conductance considerably decreased in Wo+HS plants. Similarly, $\mathrm{NaCl}+\mathrm{HS}$ plants increased transpiration compared to CT plants and especially to $\mathrm{NaCl}$ plants but transpiration in $\mathrm{NaCl}+\mathrm{HS}$ plants was not as high as in HS ones. Stomatal conductance in $\mathrm{NaCl}$ plants were the lowest registered followed by levels in $\mathrm{NaCl}+\mathrm{HS}$ plants (Fig. 3B). 


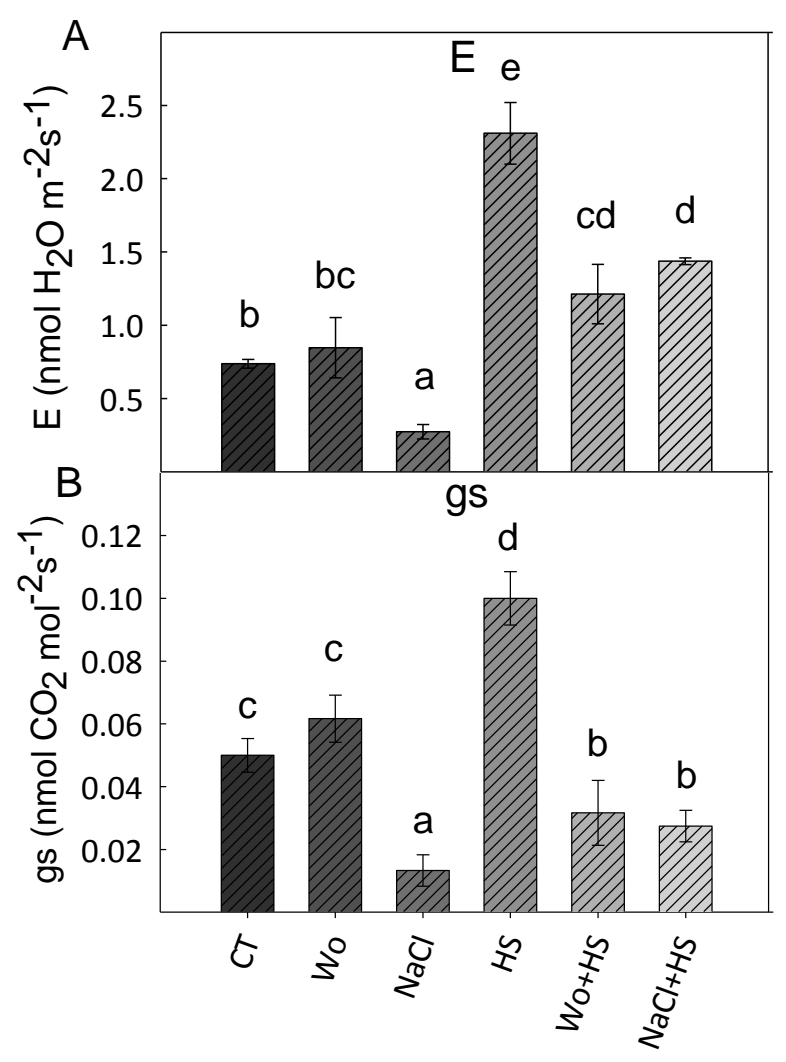

Fig. 3. Leaf transpiration (E, panel A) and stomatal conductance (gs, panel B) of Carrizo plants subjected to wounding (Wo), salt stress $(\mathrm{NaCl})$, heat stress (HS), combination of wounding and heat stress (Wo+HS) and combination of salt and heat stress ( $\mathrm{NaCl}+\mathrm{HS})$ for 15 days. Different letters denote statistical significance among treatments at $P \leq 0.01$.

\section{$\mathrm{Cl}^{-}$intake}

Leaf $\mathrm{Cl}^{-}$levels were measured in Carrizo plants after 15 days of stress treatments (Fig. 4). Adverse conditions not involving $\mathrm{NaCl}$ (Wo, $\mathrm{HS}, \mathrm{Wo}+\mathrm{HS}$,) did not cause leaf $\mathrm{Cl}^{-}$ accumulation with respect to control plants. However, leaf concentration of this toxic ion considerably increased in plants treated with $\mathrm{NaCl}$, either at $25^{\circ} \mathrm{C}$ (1.9-fold increase with respect control plants) or at $40^{\circ} \mathrm{C}$ (3.7-fold increase). 


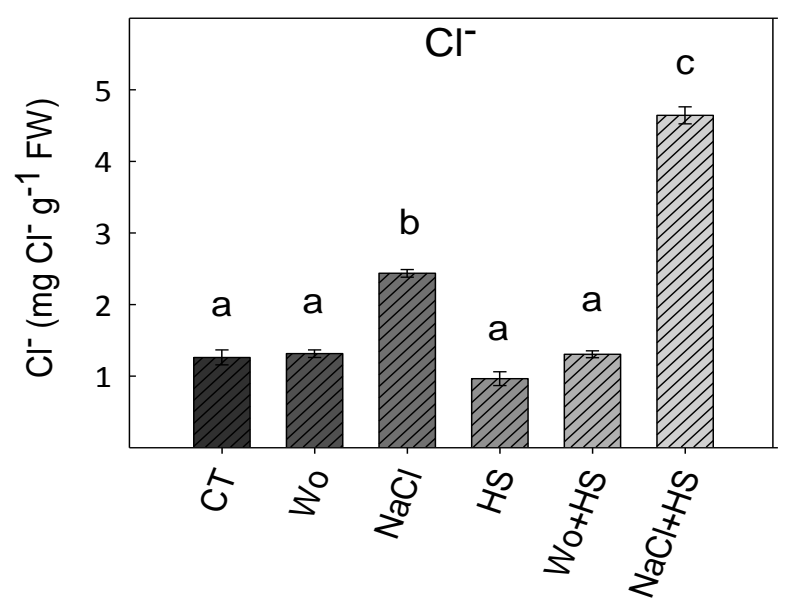

Fig. 4. Leaf chloride content in Carrizo plants subjected to wounding (Wo), salt stress ( $\mathrm{NaCl}$ ), heat stress (HS), combination of wounding and heat stress (Wo+HS) and combination of salt and heat stress $(\mathrm{NaCl}+\mathrm{HS})$ for 15 days. Different letters denote statistical significance among treatments at $P \leq 0.01$.

\section{ABA metabolism}

Leaf concentration of ABA and the two main products of its catabolism, PA and DPA (dehydrophaseic acid), were analyzed in Carrizo plants subjected to the different stress conditions (Fig. 5A-C). Wounded plants did not accumulate ABA at any of the two temperatures studied. At $25^{\circ} \mathrm{C}$, PA levels in Wo plants were higher than in CT conditions although DPA levels were similar to basal levels. However, Wo+HS plants had higher levels of PA and DPA than Wo and CT plants. Salt stress caused a significant accumulation of ABA in Carrizo plants, whereas PA levels did not change and DPA concentration decreased with respect to CT plants. When salt stress was combined with high temperatures, ABA content reached the highest levels. In addition, PA and DPA strongly accumulated under this combined stress conditions. Finally, ABA content did not significantly increase under heat stress with respect to control values although both PA and DPA concentrations were higher under this condition.

\section{Jasmonate metabolism}

Leaf concentrations of JA, its conjugate JA-isoleucine (JA-Ile) and its precursor OPDA were measured in Carrizo plants subjected to the different abiotic stress conditions (Fig. 6A-C). Jasmonic acid levels increased in Wo+HS plants (4.4-fold with respect to CT) and especially in Wo and $\mathrm{NaCl}+\mathrm{HS}$ plants (37.1- and 39.4-fold, respectively). $\mathrm{NaCl}$ and $\mathrm{HS}$ 
did not change JA levels compared to controls (Fig. 6A). JA-Ile concentration slightly increased in plants subjected to wounding stress, alone or combined with heat stress. However, $\mathrm{NaCl}+\mathrm{HS}$ caused the strongest increase in JA-Ile leaf concentration (9.4-fold, Fig. 6B). Finally, OPDA concentration pattern was different from that of JA or JA-Ile. Wo and HS plants did not show significant differences with respect to control plants but Wo+HS plants had the highest OPDA levels. Whereas salt stress caused a decreased in OPDA concentration with respect to $\mathrm{CT}, \mathrm{NaCl}+\mathrm{HS}$ reverted this phenotype and induced an OPDA accumulation (Fig. 6C).

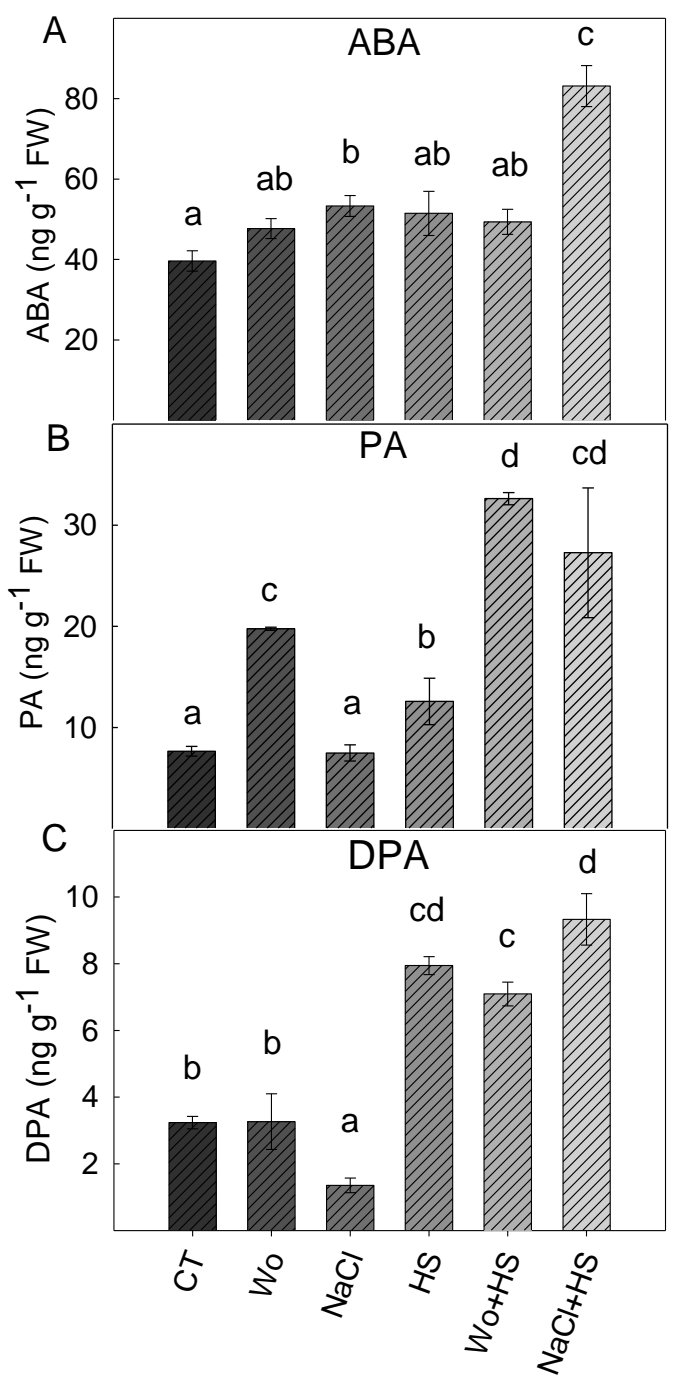

Fig. 5. ABA (A), PA (B) and DPA (C) leaf content in Carrizo plants subjected to wounding (Wo), salt stress $(\mathrm{NaCl})$, heat stress (HS), combination of wounding and heat stress (Wo+HS) and combination of salt and heat stress $(\mathrm{NaCl}+\mathrm{HS})$ for 15 days. Different letters denote statistical among treatments at $P$ $\leq 0.01$.

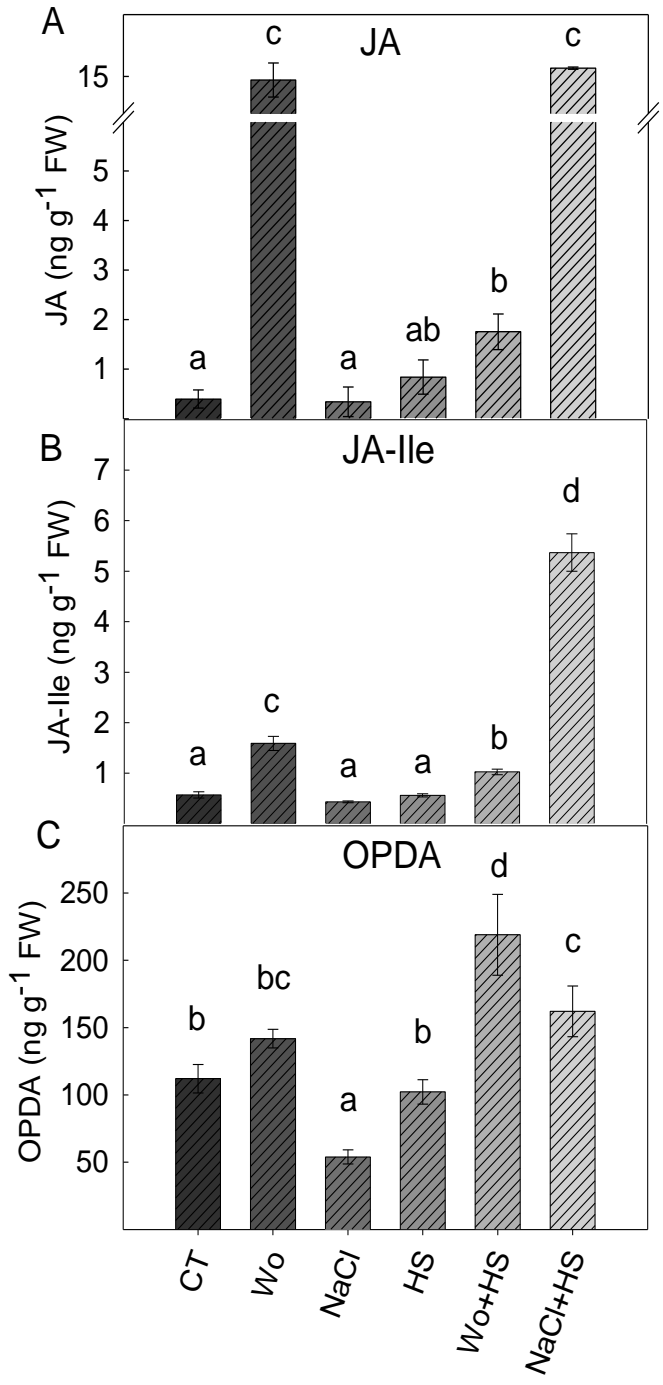

Fig. 6. JA (A), JA-Ile (B) and OPDA (C) leaf content in Carrizo plants subjected to wounding (Wo), salt stress $(\mathrm{NaCl})$, heat stress (HS), combination of wounding and heat stress (Wo+HS) and combination of salt and heat stress $(\mathrm{NaCl}+\mathrm{HS})$ for 15 days. Different letters denote statistical significance among treatments at $P \leq 0.01$. 


\section{SA metabolism}

SA leaf concentration did not vary significantly with respect to CT in wounded or salinized plants (Fig. 7). In contrast, when these adverse conditions were combined with high temperatures, SA concentration increased significantly. In Wo+HS plants, SA reached levels 2.2 times higher than controls, whereas in $\mathrm{NaCl}+\mathrm{HS}$ plants concentration SA level was 5.6 times superior compared to unstressed plants. Heat stress individually applied also caused a slightly increased in SA content in Carrizo plants.

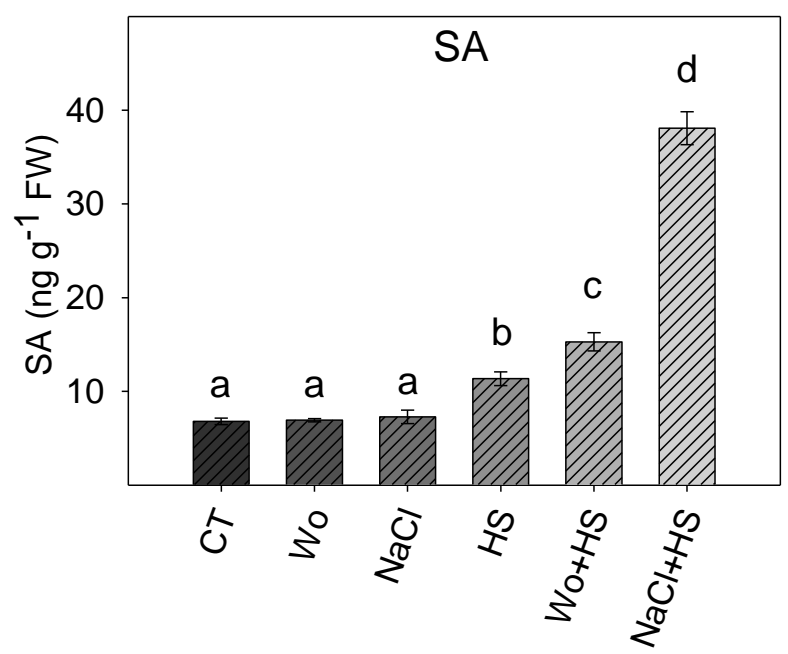

Fig. 7. SA leaf content in Carrizo plants subjected to wounding (Wo), salt stress ( $\mathrm{NaCl}$ ), heat stress (HS), combination of wounding and heat stress (Wo+HS) and combination of salt and heat stress $(\mathrm{NaCl}+\mathrm{HS})$ for 15 days. Different letters denote statistical significance among treatments at $P \leq 0.01$.

\section{Changes on hormone-related gene expression}

Relative expression of genes involved in ABA biosynthesis and signaling pathways was measured in leaves after all stress treatments (Fig. 8A-F). Salt stress did not affect the expression of 9-NEOXANTHIN CIS-EPOXICAROTENOID DIOXYGENASE (CsNCED1, the AtNCED3 homologous) gene involved in ABA biosynthesis (Cutler and Krochko 1999) in Carrizo leaves. However, salt stress combined with heat stress caused a strong upregulation (108-fold increase with respect to controls). Both heat stress and wounding increased the relative expression of CSNCED1 (4.7- and up to 15.4-fold, respectively) but levels were even higher when wounding and heat stress were combined (42.9-fold, Fig. 8A). ALDEHYDE OXIDASE 3 (CSAAO3), also involved in ABA biosynthesis (Cutler and Krochko 1999), had a different expression pattern: it was downregulated under Wo+HS and $\mathrm{NaCl}+\mathrm{HS}$ conditions (opposite to CsNCED1). On the 
other hand, $\mathrm{NaCl}$ induced the highest $C s A A O 3$ upregulation (up to 7.9-fold) contrasting again with $C S N C E D 1$. Finally, wounding and heat stress applied individually did not change CsAAO3 expression respect to controls (Fig. 8B). Expression of (ABA)RESPONSIVE ELEMENT (ABRE)-BINDING TRANSCRIPTION FACTOR1 (CSAREB1), CSAREB2, CsRD22 and RESPONSIVE TO DISSECATION29 (CsRD29), involved in the ABA signaling pathway (Narusaka et al. 2003, Yoshida et al. 2010), were also studied. CSAREB1 expression did not increase in Wo plants compared to controls and decreased in Wo+HS plants. In salt-stressed plants, the expression of this gene increased significantly and when salt stress was combined with heat stress, CsAREB1 expression strongly increased (up to 61.7-fold). Heat stress also induced a significant increase of CSAREB1 expression (3.3-fold increase, Fig. 8C). CsAREB2 was upregulated in Wo plants whereas in Wo+HS plants the expression of this gene did not change compared to control values. Salt stress, applied alone or combined with heat stress, caused an important accumulation of CsAREB2 transcripts (6.5- and 7.5-fold, Fig. 8D). Expressions of $C s R D 22$ and $C s R D 29$ genes were similar under all stress conditions (Fig. 8E-F). Both genes were strongly upregulated in $\mathrm{NaCl}$ and $\mathrm{NaCl}+\mathrm{HS}$ plants. Heat stress did not affect the expression of $C s R D 22$ in Carrizo leaves compared to control level but it induced a slight downregulation of CsRD29. Wounding did not change the pattern of expression of these genes at any of the two temperatures assayed (Fig. 8E-F). 

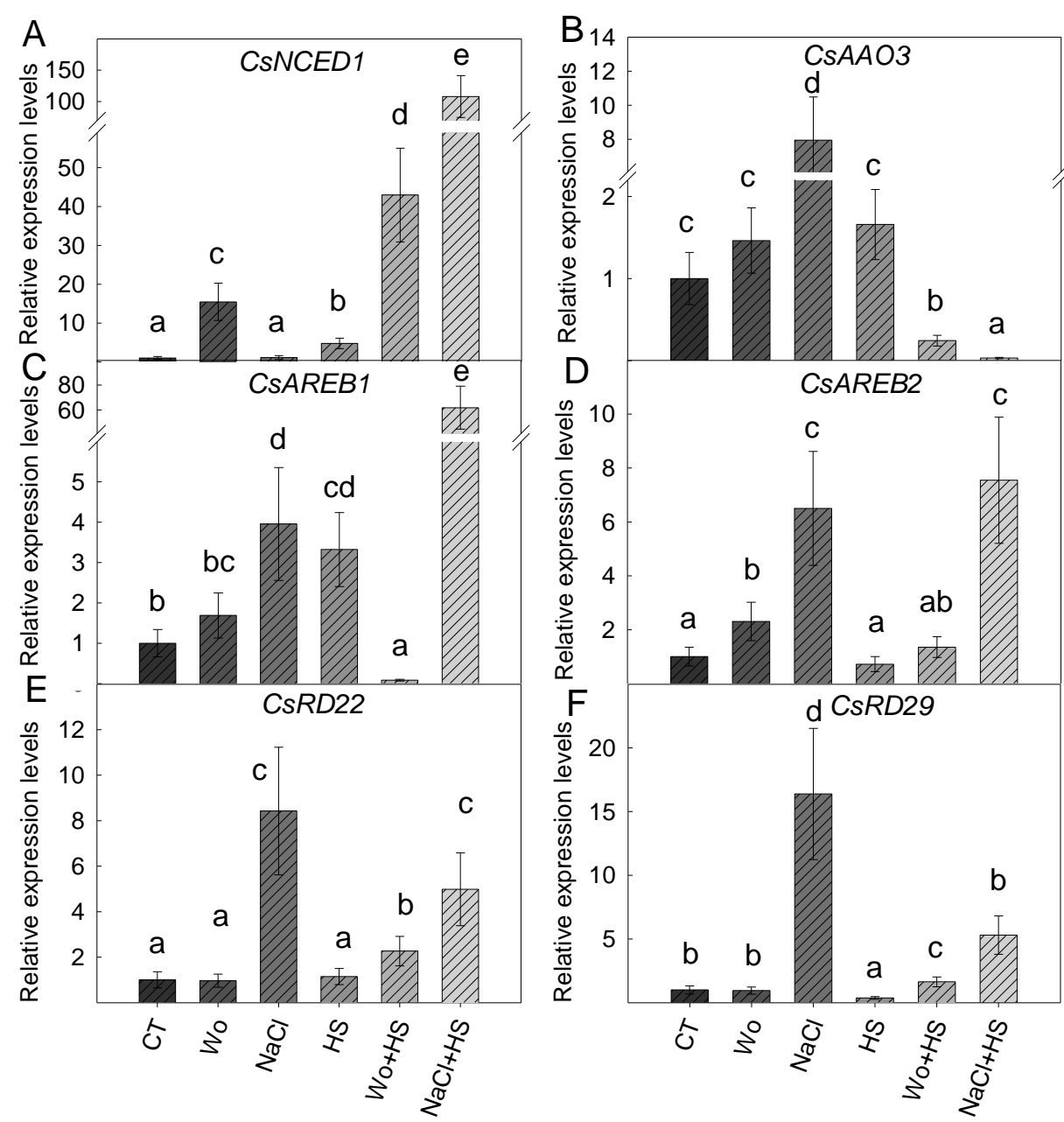

Fig. 8. Relative expression of genes involved in ABA biosynthesis (CsNCED1, panel A and CSAAO3, panel B) and signaling (CsAREB1, panel C; CsAREB2, panel D; CsRD22, panel E and CsRD29, panel F) in Carrizo plants subjected to wounding (Wo), salt stress ( $\mathrm{NaCl}$ ), heat stress (HS), combination of wounding and heat stress (Wo+HS) and combination of salt and heat stress $(\mathrm{NaCl}+\mathrm{HS})$ for 15 days. Different letters denote statistical significance among treatments at $P \leq$ 0.01 .

Relative expression of genes involved in jasmonate biosynthesis and signaling pathways were measured in leaves after all stress conditions (Fig. 9A-D). Despite that LIPOXYGENASE (CSLOX), ALLENE OXIDE SYNTHASE (CSAOS) and JASMONIC ACID RESISTANT 1 (CSJARl) are involved in the JA biosynthesis pathway, they showed different patterns of expression under each stress condition. CsLOX was strongly upregulated in wounded and salinized plants. In addition, $\mathrm{HS}$, Wo+HS and $\mathrm{NaCl}+\mathrm{HS}$ conditions induced increases in CsLOX transcription but to a lower extent (Fig. 9A). $C S A O S$ was upregulated by wounding at the two temperatures assayed in this work. Moreover, CsAOS expression did not change under high salinity at control temperature but it strongly increased when $\mathrm{NaCl}$ was combined with $\mathrm{HS}$ (up to 192.7-fold, Fig. 9B). 
All the stress conditions enhanced the expression of CSJARl with respect to controls, especially in response to wounding and salt stress applied alone or in combination with HS (Fig. 9C). Moreover, VEGETATIVE STORAGE PROTEIN 2 (CsVSP2), involved in jasmonate signaling pathway (Caarls et al. 2015), was upregulated in Carrizo leaves in response to wounding (80.2-fold increase with respect to controls). When Wo was applied at high temperatures, CsVSP2 transcripts increased but to a lower extent (4.9-fold). Finally, $\mathrm{NaCl}$ and $\mathrm{NaCl}+\mathrm{HS}$ conditions caused similar CsVSP2 upregulation (8.5-fold and 13.5-fold respectively, Fig. 9D).
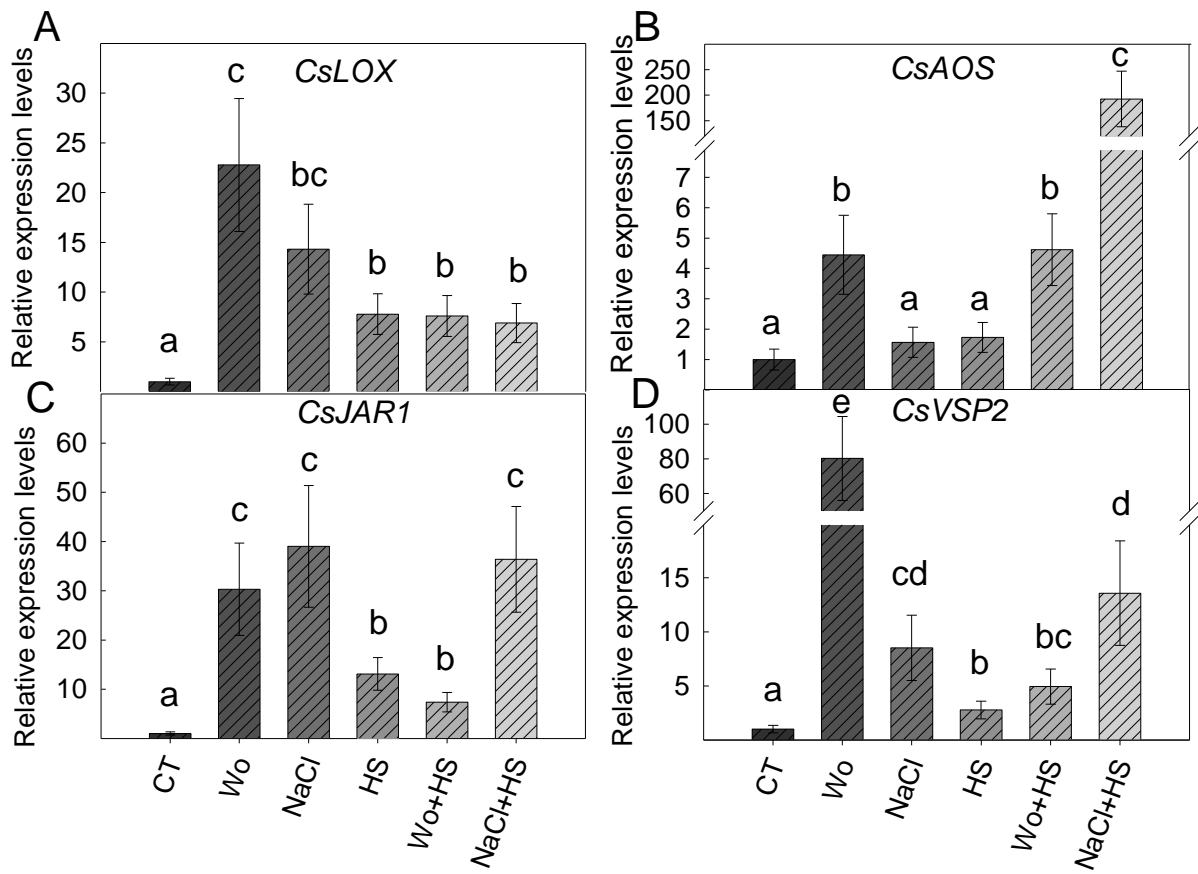

Fig. 9. Relative expression of genes involved in JAs biosynthesis (CsLOX, panel A; CsAOS, panel $\mathrm{B}$ and $C s J A R 1$, panel C) and signaling (CsVSP2, panel D) in Carrizo plants subjected to wounding (Wo), salt stress $(\mathrm{NaCl})$, heat stress (HS), combination of wounding and heat stress (Wo+HS) and combination of salt and heat stress $(\mathrm{NaCl}+\mathrm{HS})$ for 15 days. Different letters denote statistical significance among treatments at $P \leq 0.01$.

Relative expressions of ISOCHORISMATE SYNTHASE 1 (CSICS1) and PHENYLALANINE AMMONIA-LYASE (CSPAL), considered crucial in the two differentiated SA biosynthesis pathways (Dempsey et al. 2011), were studied (Fig. 10AC). Whereas Wo did not affect CSICS1 expression whereas plants under salt stress had 9.6-fold higher CsICS1 transcripts number with respect to control plants. Plants under all the different heat stress conditions upregulated CsICS1. Heat stress applied alone raised the expression up to 9.8-fold compared to control. In addition, when combining high temperatures and other stress condition CsICS1 expression raised considerably (22.1-fold 
increase for $\mathrm{Wo}+\mathrm{HS}$ plants and 651.2-fold for $\mathrm{NaCl}+\mathrm{HS}$ plants, Fig. 10A). None of the stress conditions assayed modified CsPAL expression with respect to control (Fig. 10B). PATHOGENESIS-RELATED GENE 2 (CSPR2) was upregulated in plants under stress conditions involving heat stress, similarly to CsICS1 gene expression. In contrast, Wo and $\mathrm{NaCl}$ did not change CsPR2 expression respect to CT. However, this gene was strongly upregulated in Wo+HS and $\mathrm{NaCl}+\mathrm{HS}$ plants (51.2-fold and 31.9-fold, respectively, Fig. 10C).

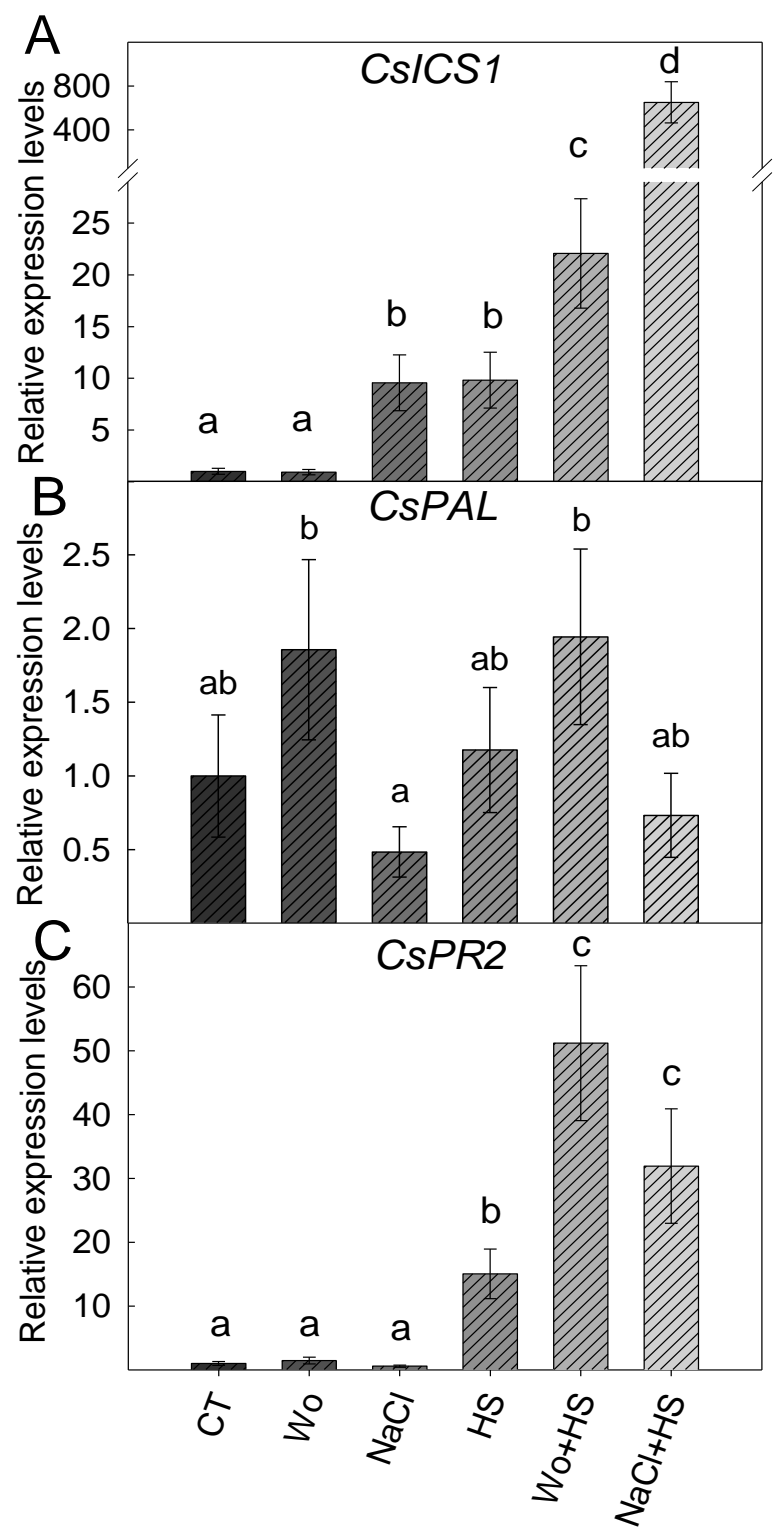

Fig. 10. Relative expression of genes involved in SA biosynthesis (CsICS1, panel A and CsPAL, panel B) and signaling (CsPR2, panel C) in Carrizo plants subjected to wounding (Wo), salt stress $(\mathrm{NaCl})$, heat stress (HS), combination of wounding and heat stress (Wo+HS) and combination of salt and heat stress $(\mathrm{NaCl}+\mathrm{HS})$ for 15 days. Different letters denote statistical significance among treatments at $P \leq 0.01$. 


\section{Discussion}

Plants cultivated in the field are exposed to adverse environmental conditions that often occur simultaneously. Recent studies have focused on plant responses to specific stress combinations demonstrating that those responses are unique and not only the sum of responses to each individual stress (Mittler 2006, Suzuki et al. 2014, Zandalinas et al. 2018). However, the knowledge about the effects of different stress combinations on crops needs to be deeply addressed due to the changing climate conditions that lead to important economic losses. In citrus plants, the combination of drought and high temperatures has been recently studied in two genotypes: Carrizo citrange (Poncirus trifoliata L. Raf. X Citrus sinensis L.Osb.) and Cleopatra mandarin (Citrus reshni Hort. ex Tan.) (Zandalinas et al. 2016b, 2017, Balfagón et al. 2018). These studies demonstrated that Carrizo was more tolerant than Cleopatra to the combined action of drought and high temperature. Thus, a better performance in stomatal responses, that allowed a better leaf cooling under heat (Zandalinas et al. 2016b), along with an efficient antioxidant machinery (Zandalinas et al. 2017) and a significant accumulation of key acclimation proteins (Balfagón et al. 2018) contributed to the best performance of Carrizo under this stress combination.

In this work, the acclimation responses of Carrizo citrange to mechanical wounding and salt stress, applied individually or in combination with heat stress, were evaluated. Firstly, the phenotypical response of plants to the different individual and combined stresses was assessed. Salt stress negatively affected plant growth (Fig. 1A), showing a greater impact on leaves when combined with high temperatures (Fig. 1B). On the contrary wounding, either at low or at high temperatures, did not visually affect leaves (Fig 1B). These results highlight the sensibility of Carrizo to salt stress, as previously reported (Gómez-Cadenas et al. 1998, Moya et al. 2002).

Data in this work also show that the specific stress combinations caused different physiological responses compared to isolated adverse conditions (Figs 2 and 3). Strikingly, although combinations of high temperatures with salt stress or with wounding resulted in similar physiological responses (Fig. 3), these stress combinations differently affected plant performance (Figs 1 and 2). Whereas Wo+HS had no phenotypical impact (Fig. 1) and did no alter the leaf water status (RWC; Fig. 2), $\mathrm{NaCl}+\mathrm{HS}$ strongly induced leaf damage (Fig. 1B) and caused a decrease in RWC (Fig. 2), as well as a significant increment in leaf $\mathrm{Cl}^{-}$levels (Fig. 4). This indicates that the combination of high salinity and heat stress was the most harmful condition for Carrizo plants. It has been previously 
reported that the absorption of chloride (the most toxic ion in citrus plants) under salinization is mostly driven by passive forces from water uptake (Moya et al. 2003). In our work, salt-stressed plants reduced transpiration (Fig. 3A) and stomatal conductance (Fig. 3B), probably to prevent further $\mathrm{Cl}^{-}$intoxication by reducing water uptake and flow through the plant. Although $\mathrm{NaCl}+\mathrm{HS}$ plants had reduced $\mathrm{E}$ and gs with respect to $\mathrm{HS}$ plants, levels of these two parameters were still higher than those of $\mathrm{NaCl}$ plants due to the effect of high temperatures (Fig. 3). Consequently, the intake of $\mathrm{Cl}^{-}$considerably increased together with the water uptake under $\mathrm{NaCl}+\mathrm{HS}$ conditions (Fig. 4), causing a very damaging situation to Carrizo plants.

The pattern of hormonal changes (ABA, JA and SA) in Carrizo leaves in response to the individual and combined stresses and their possible involvement in the physiological and molecular responses to each stress was also addressed. ABA has been previously suggested to be key in the adaptation of plants to salt stress (Gómez-Cadenas et al. 2015). In addition, in Arabidopsis plants, ABA was demonstrated to have a pivotal role for plant acclimation to the combination of salt and heat stress (Suzuki et al. 2016b). In this work, ABA levels only increased in response to high salinity (Fig. 5A). Therefore, ABA accumulation seems to be responsible, at least in part, for the observed stomatal closure, oriented to limit $\mathrm{Cl}^{-}$intoxication. Furthermore, when salt stress was combined with high temperatures, the highest ABA levels were observed. This response was probably oriented to counteract the aperture of the stomata caused by the high temperatures (Fig. 3A). Under salt stress, applied individually or in combination with heat, ABA biosynthetic pathway was activated as demonstrated by the upregulation of CSNCEDI in $\mathrm{NaCl}$ and $\mathrm{NaCl}+\mathrm{HS}$ plants (Fig. 8A) as well as CsAAO3 in $\mathrm{NaCl}$ plants (Fig. 8B). To further confirm ABA signaling in these stress situations, expression of other genes was followed (Fig. 8C-F). Among them, AREB1 and AREB2 are transcription factors activated in an ABA-dependent manner that regulate, together with ABF3 and ABF1, most of downstream gene expression of three subclass III SNF1 RELATED KINASE 2 (SnRK2s) (Yoshida et al. 2014); RD22 and RD29 are induced in response to osmotic stress situations through AREB TFs in an ABA-dependent manner (Narusaka et al. 2003, Yamaguchi-Shinozaki and Shinozaki 2006). In this work, CsRD22 and CsRD29 expression (Fig. 8E-F) in Carrizo plants subjected to salt stress (applied alone or in combination with heat stress) increased probably through the action of the TFs CSAREBI and CsAREB2 (Fig. 8C-D), confirming thus the activation of ABA signaling under these stress conditions. 
Although Wo and Wo+HS plants did not accumulate significant levels of ABA (Fig. 5A), upregulations of $C S N C E D 1$ and $C S A A O 3$ (Fig. 8A-B), along with an upregulation of CsAREB2 in Wo plants (Fig. 8D) and CsRD22 in Wo+HS plants (Fig. 8E) were observed. This could indicate an ABA signaling activation in these stress situations in an ABAindependent manner. A possible explanation could be that PA is recognized by a subset of ABA-receptors of the PYRABACTIN RESISTANCE (PYL/PYR/RCAR) family in a way that partially overlaps with ABA-mediated regulation (Weng et al. 2016). Therefore, the enhanced expression of CsAREB2 in Wo plants (Fig. 8D) and CsRD22 in Wo+HS plants (Fig. 8E) could be a response caused by the observed PA accumulation (Fig. 5B). Jasmonic acid is a hormone widely related to biotic stress responses in plants (Kazan and Manners 2008). In the present work, an accumulation of JA and JA-Ile (Fig. 6A-B), as well as an upregulation of JA-related genes involved in biosynthesis and signaling (CsLOX, CsAOS, CsJARI and CsVSP2; Fig. 9) were observed in Wo plants, highlighting the importance of this hormone in plant adaptations to wounding as previously reported (Wasternack and Song 2016). Interestingly, whereas JA and JA-Ile levels in Wo plants were significantly higher than in Wo+HS plants (Fig. 6A-B), OPDA content had the opposite behavior (Fig. 6C). It has been previously reported than OPDA can induce stomatal closure and trigger a signal, independently from JA, in guard cells (Murata et al. 2015). Thus, OPDA accumulation under Wo+HS conditions (Fig. 6C) could be a response to reduce stomatal opening and consequently water loss. Therefore, the pattern of jasmonate accumulation in plants under wounding was different from those under wounding combined with heat stress. This result suggests that OPDA has a specific role to adjust stomatal aperture in Carrizo plants under this stress combination. Similarly, combination of high salinity and heat stress induced JA, JA-Ile and OPDA accumulation (Fig. 6) as well as an upregulation of jasmonate biosynthetic and signaling pathways (Fig. 9A). This response could be an additional mechanism to the ABA signal that further counteracts heat effects by closing stomata, reducing transpiration and, thus, avoiding salt intoxication.

SA has been previously proposed to protect the PSII complex and membrane integrity under heat stress conditions (Clarke et al. 2004, Wang et al. 2010, 2014). Accordingly, SA significantly accumulated in response to heat stress applied alone, and especially in response to heat stress combined with salinity or wounding, showing an additive output (Fig. 7). A similar SA additive response was previously observed in citrus plants in response to the combined action of drought and heat (Zandalinas et al. 2016b), indicating 


\section{Chapter 3}

that SA accumulation parallels the physiological impact of the individual and combined stresses. Furthermore, the SA accumulation pattern of Carrizo plants subjected to each stress condition correlated with CsICS1 gene expression (Fig. 10A), whereas CsPAL expression had a marginal change under these stress conditions (Fig. 10B). To further analyzed SA signaling, the upregulation of CsPR2 (SA signaling marker; Zandalinas et al. 2016b) confirmed the activation of SA-dependent molecular responses in response to both stress combinations studied in this work (Fig. 10C). Cross-communication between SA and JA signaling pathways has been extendedly reported in response to different biotic stresses to fine tune transcriptional programs that determine resistance to invaders (Thaler et al. 2012, Caarls et al. 2015). In this work, a possible antagonistic interaction between SA and JA could emerge in wounded plants (Figs. 6A-7). Thus, wounded plants at control temperature strongly accumulated JA (Fig. 6A) with no variation in SA levels (Fig. 7). However, when SA was accumulated in response to heat stress (Fig. 7), levels of JA considerably decreased (Figs. 6A).

Results obtained in this work indicate that physiological, hormonal and molecular responses of Carrizo plants are different when wounding and salt stress are applied individually or in combination with heat stress. Combination of high salinity and heat stress resulted in the most harmful conditions. Transpiration and stomatal conductance increment caused by high temperatures counteracted the plant adaptative responses to salt stress resulting in a negative interaction and a serious salt intoxication of the plants (Fig. 3). Different hormonal accumulation and signaling in response to specific stresses could lead to unique responses, allowing plants to mount proper acclimation mechanisms. Therefore, adding a new stress can modify (either enhance or reduce) the plant hormonal response which modulate the response to a specific stress (Fig. 11). It has been shown that PA could have a signaling role activating the expression of ABA-related genes in wounded Carrizo plants, enhancing its accumulation when HS was added (Fig. 5B). In addition, differential pattern of jasmonate accumulation was observed in response to Wo and Wo+HS plants (Fig. 6). OPDA accumulated specially in wounded plants under heat stress whereas JA and JA-Ile seemed to have a more important role when wounding was applied at control temperatures (Fig. 6). As a response to high temperatures, SA levels increased in Carrizo plants (Fig. 7), via ICS biosynthetic pathway (Fig. 10A). Furthermore, a putative antagonism between SA and JA was observed in wounded plants. The response to mechanical wounding seemed to be mediated by jasmonates although at high temperatures SA signal could be more determinant (Fig. 11). 


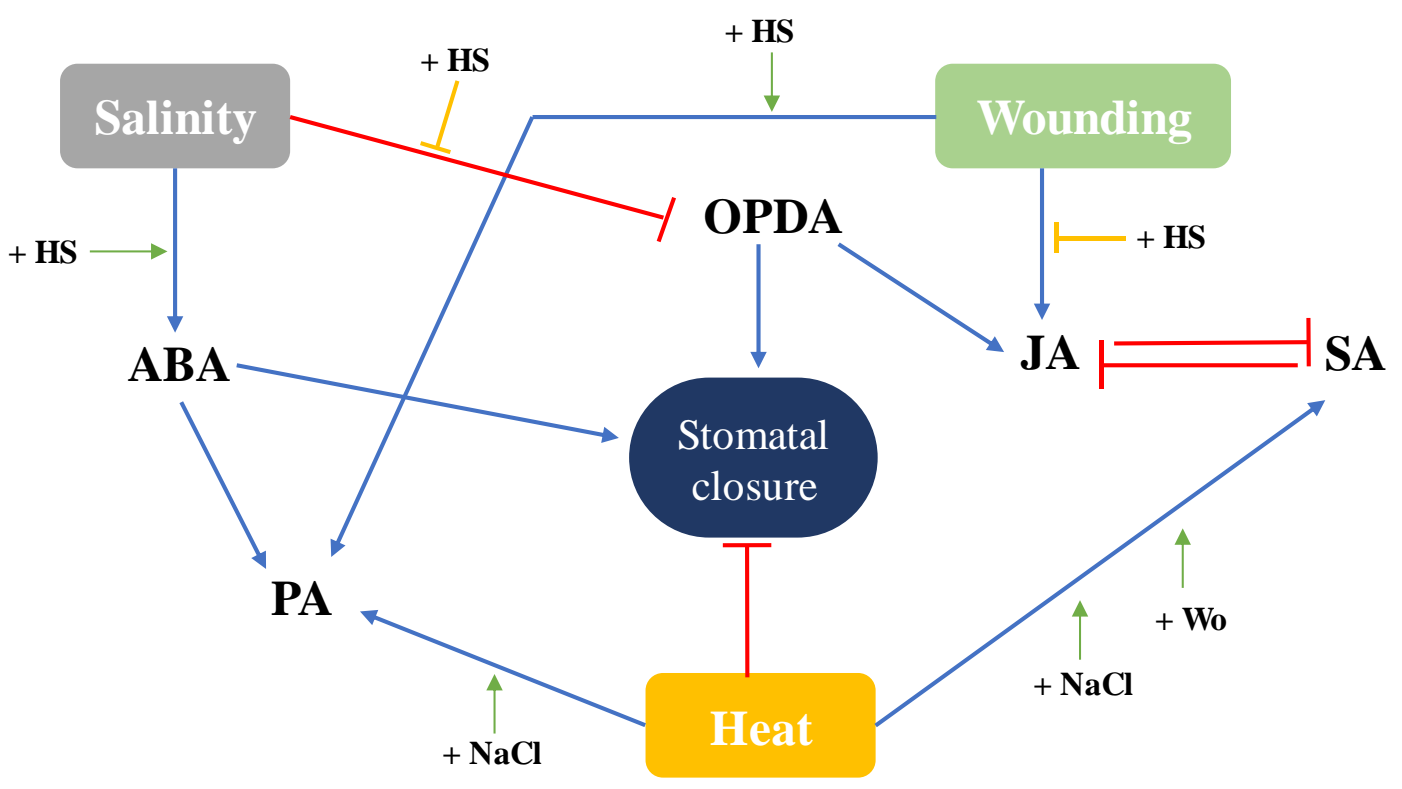

Fig. 11. Hormonal relations in Carrizo plants to modulate an appropriate response to different stress combinations. Green arrows indicate an increase in the hormone accumulation by the addition of a new stress condition to an existing one whereas yellow lines indicate a reduction in hormonal content.

Due to global warming, temperatures will increase in coming years and it is important for the citriculture to find rootstocks not only tolerant to high temperatures, but also capable of withstanding other co-occurring stress conditions such as soil toxicity or mechanical wounding. Our work extends the knowledge about the performance of Carrizo citrange to different stress combinations in which heat stress is involved and provides information for the improvement of citrus rootstocks adapted to the environmental conditions to come.

\section{Author contributions}

D.B., S.I.Z. and A.G.C. designed the experiments. D.B. performed the experiments, harvested plant material and analyzed samples. A.G.C. supervised the project and provided funding. D.B., S.I.Z. and A.G.C. wrote the manuscript and prepared figures. All authors have read and approved the final version of the manuscript.

Acknowledgements - This work was supported by the Spanish Ministerio de Economía y Competitividad and Universitat Jaume I through grants No. AGL2016-76574-R and UJIB2016-23, respectively. 


\section{Chapter 3}

\section{References}

Balfagón D, Zandalinas SI, Baliño P, Muriach M, Gómez-Cadenas A (2018) Involvement of ascorbate peroxidase and heat shock proteins on citrus tolerance to combined conditions of drought and high temperatures. Plant Physiol Biochem 127: 194-199

Caarls L, Pieterse CMJ, Van Wees SCM (2015) How salicylic acid takes transcriptional control over jasmonic acid signaling. Front Plant Sci 6: 170

Clarke SM, Cristescu SM, Miersch O, Harren FJM, Wasternack C, Mur LAJ (2009) Jasmonates act with salicylic acid to confer basal thermotolerance in Arabidopsis thaliana. New Phytol 182: 175-187

Clarke SM, Mur LAJ, Wood JE, Scott IM (2004) Salicylic acid dependent signaling promotes basal thermotolerance but is not essential for acquired thermotolerance in Arabidopsis thaliana. Plant J 38: 432-447

Cutler AJ, Krochko J (1999) Formation and breakdown of ABA. Trends Plant Sci 4: 472478

Dempsey DA, Vlot AC, Wildermuth MC, Klessig DF (2011) Salicylic Acid biosynthesis and metabolism. The arabidopsis book 9: e0156

De Ollas C, Arbona V, Gómez-Cadenas A, Dodd IC (2018) Attenuated accumulation of jasmonates modifies stomatal responses to water deficit. J Exp Bot 69: 2103-2116

Devireddy AR, Zandalinas SI, Gómez-Cadenas A, Blumwald E, Mittler R (2018) Coordinating the overall stomatal response of plants: Rapid leaf-to-leaf communication during light stress. Sci Signal 11: eaam9514

Durgbanshi A, Arbona V, Pozo O, Miersch O, Sancho J V, Gómez-Cadenas A (2005) Simultaneous determination of multiple phytohormones in plant extracts by liquid chromatography-electrospray tandem mass spectrometry. J Agric Food Chem 53: 84378442

Finkelstein R (2013) Abscisic acid synthesis and response. The Arabidopsis Book 11: 136

Gómez-Cadenas A, Tadeo FR, Primo-Millo E, Talon M (1998) Involvement of abscisic acid and ethylene in the responses of citrus seedlings to salt shock. Physiol Plant 103: $475-484$

Gómez-Cadenas A, Vives V, Zandalinas SI, Manzi M, Sánchez-Pérez AM, PérezClemente RM, Arbona V (2015) Abscisic acid: a versatile phytohormone in plant signaling and beyond. Curr Protein Pept Sci 16: 413-434 
Hu Y, Jiang L, Wang F, Yu D (2013) Jasmonate regulates the inducer of cbf expressionC-repeat binding factor/DRE binding factor1 cascade and freezing tolerance in Arabidopsis. Plant Cell 25: 2907-2924

Kasurinen A, Biasi C, Holopainen T, Rousi M, Maenpaa M, Oksanen E (2012) Interactive effects of elevated ozone and temperature on carbon allocation of silver birch (Betula pendula) genotypes in an open-air field exposure. Tree Physiol 32: 737-751

Kazan K (2015) Diverse roles of jasmonates and ethylene in abiotic stress tolerance. Trends Plant Sci 20: 219-229

Kazan K, Manners JM (2008) Jasmonate signaling: toward an integrated view. Plant Physiol 146: 1459-1468

Lobell DB, Schlenker W, Costa-Roberts J (2011) Climate trends and global crop production since 1980. Science 333: 616-620

López-Climent MF, Arbona V, Pérez-Clemente RM, Gómez-Cadenas A (2008) Relationship between salt tolerance and photosynthetic machinery performance in citrus. Environ Exp Bot 62: 176-184

Mafra V, Kubo KS, Alves-Ferreira M, Ribeiro-Alves M, Stuart RM, Boava LP, Rodrigues CM, Machado MA (2012). Reference genes for accurate transcript normalization in citrus genotypes under different experimental conditions. PloS one 7: e31263

Mittler R (2006) Abiotic stress, the field environment and stress combination. Trends Plant Sci 11: 15-19

Morgan JA (1984) Interaction of water supply and N in wheat. Plant Physiol 76: 112-117 Moya JL, Gómez-Cadenas A, Primo-Millo E, Talon M (2003) Chloride absorption in salt-sensitive Carrizo citrange and salt-tolerant Cleopatra mandarin citrus rootstocks is linked to water use. J Exp Bot 54: 825-833

Moya JL, Tadeo FR, Gómez-Cadenas A, Primo-Millo E, Talón M (2002) Transmissible salt tolerance traits identified through reciprocal grafts between sensitive Carrizo and tolerant Cleopatra citrus genotypes. J Plant Physiol 159: 991-998

Murata Y, Mori IC, Munemasa S (2015) Diverse stomatal signaling and the signal integration mechanism. Annu Rev Plant Biol 66: 369-392

Narusaka Y, Nakashima K, Shinwari ZK, Sakuma Y, Furihata T, Abe H, Narusaka M, Shinozaki K, Yamaguchi-Shinozaki K (2003) Interaction between two cis-acting elements, ABRE and DRE, in ABA-dependent expression of Arabidopsis rd29A gene in response to dehydration and high-salinity stresses. Plant Journa 34: 137-148 
Peleg Z, Blumwald E (2011) Hormone balance and abiotic stress tolerance in crop plants. Curr Opin Plant Biol 14: 290-295

Pfaffl MW, Horgan GW, Dempfle L (2002) Relative expression software tool (REST) for group-wise comparison and statistical analysis of relative expression results in realtime PCR. Nucleic Acids Res 30: e36

Suzuki N (2016a) Hormone signaling pathways under stress combinations. Plant Signal Behav 11: e1247139

Suzuki N, Basil E, Hamilton JS, Inupakutika Madhuri A, Zandalinas SI, Tripathy D, Yuting L, Dion E, Fukui G, Kumazaki A, Nakano R, Rivero R, Azad RK, Blumwald E, Mittler R, (2016b) ABA is required for plant acclimation to a combinationof salt and heat stress. PloS One 11 e0147625

Suzuki N, Rivero RM, Shulaev V, Blumwald E, Mittler R (2014) Abiotic and biotic stress combinations. New Phytol 203: 32-43

Thaler JS, Humphrey PT, Whiteman NK (2012) Evolution of jasmonate and salicylate signal crosstalk. Trends Plant Sci 17: 260-270

Vives-Peris V, Gómez-Cadenas A, Pérez-Clemente RM (2017) Citrus plants exude proline and phytohormones under abiotic stress conditions. Plant Cell Rep 36: 1971-1984 Wang L-J, Fan L, Loescher W, Duan W, Liu G-J, Cheng J-S, Luo H-B, Li S-H (2010) Salicylic acid alleviates decreases in photosynthesis under heat stress and accelerates recovery in grapevine leaves. BMC Plant Biol 10: 34

Wang X, Li Y, Lu H, Wang S (2016) Combined effects of elevated temperature and CO2 concentration on $\mathrm{Cd}$ and $\mathrm{Zn}$ accumulation dynamics in Triticum aestivum L. J Environ Sci 47: 109-119

Wang Y, Zhang H, Hou P, Su X, Zhao P, Zhao H, Liu S (2014) Foliar-applied salicylic acid alleviates heat and high light stress induced photoinhibition in wheat (Triticum aestivum) during the grain filling stage by modulating the psbA gene transcription and antioxidant defense. Plant Growth Regul 73: 289-297

Wasternack C, Song S (2016) Jasmonates: biosynthesis, metabolism, and signaling by proteins activating and repressing transciption. J Exp Bot 68: erw443

Weng J-K, Ye M, Li B, Noel JP (2016) Co-evolution of Hormone Metabolism and Signaling Networks Expands Plant Adaptive Plasticity. Cell 166: 881-893

Yamaguchi-Shinozaki K, Shinozaki K (2006) Transcriptional regulatory networks in cellular responses and tolerance to dehydration and cold stresses. Annu Rev Plant Biol 57: $781-803$ 
Yoshida T, Fujita Y, Sayama H, Kidokoro S, Maruyama K, Mizoi J, Shinozaki K, Yamaguchi-Shinozaki K (2010) AREB1, AREB2, and ABF3 are master transcription factors that cooperatively regulate $\mathrm{ABRE}-$ dependent $\mathrm{ABA}$ signaling involved in drought stress tolerance and require ABA for full activation. Plant J 61: 672-685

Yoshida T, Mogami J, Yamaguchi-Shinozaki K (2014) ABA-dependent and ABAindependent signaling in response to osmotic stress in plants. Curr Opin Plant Biol 21: $133-139$

Zandalinas SI, Balfagón D, Arbona V, Gómez-Cadenas A (2017) Modulation of Antioxidant Defense System Is Associated with Combined Drought and Heat Stress Tolerance in Citrus. Front Plant Sci 8: 953

Zandalinas SI, Balfagón D, Arbona V, Gómez-Cadenas A, Inupakutika MA, Mittler R (2016a) ABA is required for the accumulation of APX1 and MBF1c during a combination of water deficit and heat stress. J Exp Bot: 6: 5381-5390

Zandalinas SI, Mittler R, Balfagón D, Arbona V, Gómez-Cadenas A (2018) Plant adaptations to the combination of drought and high temperatures. Physiol Plant 162: 212

Zandalinas SI, Rivero RM, Martínez V, Gómez-Cadenas A, Arbona V (2016b) Tolerance of citrus plants to the combination of high temperatures and drought is associated to the increase in transpiration modulated by a reduction in abscisic acid levels. BMC Plant Biol 16: 105

Zhang H, Sonnewald U (2017) Differences and commonalities of plant responses to single and combined stresses. Plant J 90: 839-855

Zhao Y, Dong W, Zhang N, Xinghui A, Wang M, Huang Z, Xiao L, Xia G (2014) A wheat allene oxide cyclase gene enhances salinity tolerance via jasmonate signaling. Plant Physiol 164: 1068-1076

Zhao J, Missihoun TD, Bartels D (2017) The role of Arabidopsis aldehyde dehydrogenase genes in response to high temperature and stress combinations. J Exp Bot 68: 4295-4308 


\section{Supporting information}

Additional supporting information may be found in the online version of this article:

Table S1. Designed primers for gene expression analyses by quantitative RT-PCR.

\begin{tabular}{|c|c|c|c|c|}
\hline Citrus gene & Locus & $\begin{array}{c}\text { Forward / } \\
\text { Reverse }\end{array}$ & Sequence $\left(5^{\prime} \rightarrow 3^{\prime}\right)$ & $\begin{array}{c}\text { Amplicon } \\
\text { size (bp) }\end{array}$ \\
\hline \multirow{2}{*}{ CsNCED1 } & \multirow{2}{*}{ orange1.1g007379m } & $\mathrm{F}$ & GTCCCCAAAATACCCTCCAT & \multirow{2}{*}{151} \\
\hline & & $\mathrm{R}$ & GACTGCGTCCAAGGCTAAAG & \\
\hline \multirow{2}{*}{ CsAAO3 } & \multirow{2}{*}{ orange1.1g000629m } & $\mathrm{F}$ & CACTTAGGTCAACCCCTGGA & \multirow{2}{*}{174} \\
\hline & & $\mathrm{R}$ & CCCGAACTTTTTCCAACAGA & \\
\hline \multirow{2}{*}{ CsAREB1 } & \multirow{2}{*}{ orange1.1g021624m } & $\mathrm{F}$ & GTTGGTGGCAAGGTTAATGG & \multirow{2}{*}{214} \\
\hline & & $\mathrm{R}$ & GAGCTAGGGGATGCTGATTC & \\
\hline \multirow{2}{*}{ CsAREB2 } & \multirow{2}{*}{ orange1.1g013197m } & $\bar{F}$ & GTGGACTGGGGAAGGATTTT & \multirow{2}{*}{201} \\
\hline & & $\mathrm{R}$ & CССТCCAAACTTCATCGACT & \\
\hline \multirow{2}{*}{ CsRD22 } & \multirow{2}{*}{ orange1.1g000107m } & $\bar{F}$ & GTGCATTGTGTCGTGGATTC & \multirow{2}{*}{142} \\
\hline & & $\mathrm{R}$ & TCTCCGCATCTGATTTTTCC & \\
\hline \multirow{2}{*}{ CsRD29 } & \multirow{2}{*}{ orange1.1g007806m } & $\mathrm{F}$ & GCTCTATGCCAGCATCAACA & \multirow{2}{*}{150} \\
\hline & & $\mathrm{R}$ & CCTTCTCGCTGCCTGTATTA & \\
\hline \multirow{2}{*}{ CsLOX } & \multirow{2}{*}{ orange1.1g002617m } & $\bar{F}$ & GCAACATTGCCACTGAAGATCCATC & \multirow{2}{*}{103} \\
\hline & & $\mathrm{R}$ & GTAGCTTGAATCTGGGAAGGGAAGG & \\
\hline \multirow{2}{*}{ CsAOS } & \multirow{2}{*}{ orange1.1g039030m } & $\mathrm{F}$ & GTTTCAGCTCGCTCCGTTAC & \multirow{2}{*}{209} \\
\hline & & $\mathrm{R}$ & TGGCAAATACGAGGTTGTGA & \\
\hline \multirow{2}{*}{ CsJARI } & \multirow{2}{*}{ orange1.1g007464m } & $\mathrm{F}$ & TTCTTCTGAGGGGTGGAT & \multirow{2}{*}{217} \\
\hline & & $\mathrm{R}$ & ACCTGCAACATTGGTGACAA & \\
\hline \multirow{2}{*}{ CsVSP2 } & \multirow{2}{*}{ orange1.1g023352m } & F & CATCCGCCATCTTTTTCTGG & \multirow{2}{*}{195} \\
\hline & & $\mathrm{R}$ & CATTTTTCGGGAACAGTCGC & \\
\hline \multirow{2}{*}{ CsICS1 } & & $\mathrm{F}$ & GTTGAATGTGGTGCGTCATC & \\
\hline & orangel.lg044177m & $\mathrm{R}$ & CCATGTGGACATTGGTGTGT & 150 \\
\hline$C_{\mathrm{c}} \boldsymbol{P A T}$ & orance1 1 $1037382 \mathrm{~m}$ & $\mathrm{~F}$ & GAGGCACAATCACTGCTTCA & 125 \\
\hline CSTAL & orange $1.1 g 0 s / 382 \mathrm{~m}$ & $\mathrm{R}$ & AGAGGCTTCCTGAGCATCAA & 125 \\
\hline CSPR? & oranoe1 1 o019014m & $\mathrm{F}$ & GGGCAGTTTGGTTACAGGAA & 104 \\
\hline CSPR 2 & orangel.1g019014m & $\mathrm{R}$ & CTCTCCGACACCACAATCCT & 104 \\
\hline & & $\mathrm{F}$ & СССТTССТCATGCCATTCTTC & 105 \\
\hline $\operatorname{CsACT}$ & orange1.1g03/845m & $\mathrm{R}$ & CGGCTGTGGTGGTAAACATG & 105 \\
\hline$C T U D$ & $100012225 \mathrm{~m}$ & $\mathrm{~F}$ & GGGGCAAAATGAGCACTAAA & 107 \\
\hline CSTEB & orange1.1g013535m & $\mathrm{R}$ & CGCCTGAACATCTCCTGAAT & 181 \\
\hline
\end{tabular}


Chapter 3

\begin{tabular}{|cccccc|}
\hline Compound & $\begin{array}{c}\text { Dwell } \\
\text { (secs) }\end{array}$ & $\begin{array}{c}\text { Cone } \\
\text { voltaje }(\mathbf{V})\end{array}$ & $\begin{array}{c}\text { Collision } \\
\text { energy }(\mathbf{e V})\end{array}$ & $\begin{array}{c}\text { Precursor } \\
\text { ion }(\mathbf{m} / \mathbf{z})\end{array}$ & $\begin{array}{c}\text { Diagnostic } \\
\text { transition }(\mathbf{m} / \mathbf{z})\end{array}$ \\
\hline ABA & 0.050 & 25 & 12 & 263 & $263 \rightarrow 153$ \\
\hline$\left[{ }^{\mathbf{2}} \mathbf{H} 6\right]-A B A$ & 0.050 & 25 & 12 & 269 & $269 \rightarrow 159$ \\
\hline PA & 0.025 & 25 & 20 & 279 & $279 \rightarrow 139$ \\
\hline$\left[{ }^{2} \mathbf{H}_{3}\right]-\mathbf{P A}$ & 0.025 & 25 & 20 & 282 & $282 \rightarrow 142$ \\
\hline SA & 0.050 & 20 & 20 & 137 & $137 \rightarrow 93$ \\
\hline$[\mathbf{1 3 C}]-S A$ & 0.050 & 25 & 15 & 143 & $143 \rightarrow 99$ \\
\hline JA & 0.050 & 25 & 15 & 209 & $209 \rightarrow 59$ \\
\hline JA-ile & 0.050 & 25 & 12 & 322 & $322 \rightarrow 130$ \\
\hline OPDA & 0.050 & 40 & 25 & 291 & $291 \rightarrow 165$ \\
\hline DHJA & 0.050 & 25 & 15 & 211 & $211 \rightarrow 59$ \\
\hline
\end{tabular}

Table S2. Run conditions and transitions used for the analysis of selected phytohormones.

Figure S1. Leaf phenotypic traits in Carrizo plants subjected to different stresses.

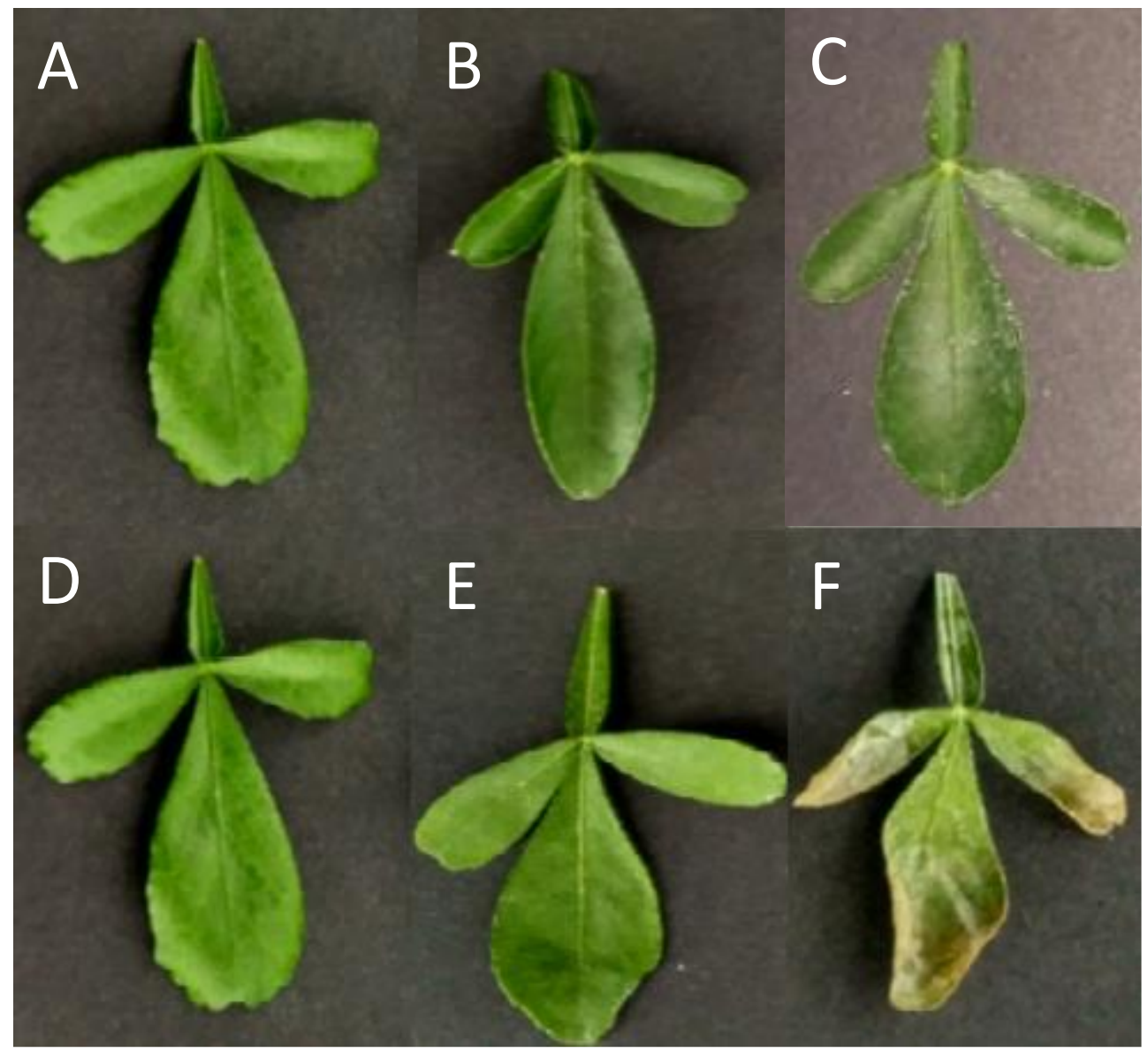




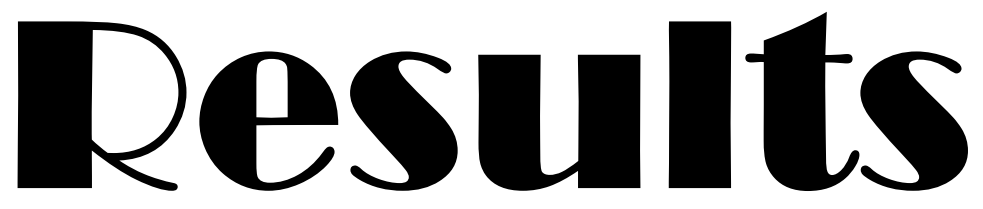

\section{Chapter 4}

Jasmonic acid is required for plant acclimation to a combination of high light and heat stress

Balfagón et al. (2019) Plant Physiology 181: 1668-1682 



\begin{abstract}
In the field, plants experience high light intensities that are often accompanied by elevated temperatures. Such conditions are a serious threat to agriculture production, since photosynthesis is highly sensitive to both high light intensities and high temperature stress. One of the potential cellular targets of high light and heat stress combination is photosystem II (PSII) because its degree of photoinhibition depends on the balance between the rate of PSII damage (induced by light stress), and the rate of PSII repair (impaired under heat stress). Here, we studied the response of Arabidopsis thaliana plants to a combination of high light and heat stress conditions. High light and heat stress combination was accompanied by an irreversible damage to PSII, a decrease in D1 (PsbA) protein levels, and an enhanced transcriptional response indicative of PSII repair activation. We further identified several unique aspects of this stress combination that included enhanced accumulation of jasmonic acid (JA) and JA-isoleucine (JA-Ile), elevated expression of over 2200 different transcripts that are unique to the stress combination (including many that are JA-associated), and distinctive structural changes to chloroplasts. Further analysis of a mutant deficient in JA biosynthesis (allene oxide synthase; aos) subjected to a combination of light and heat stress, revealed that JA is required for regulating several transcriptional responses unique to the stress combination. This mutant also displayed enhanced sensitivity to the stress combination. Our study reveals that JA plays an important role in the acclimation of plants to a combination of high light and heat stress.
\end{abstract}

\title{
Introduction
}

The majority of plants growing under direct sunlight routinely encounter light intensities that exceed their photosynthetic capacity (Ort, 2001). An additional environmental parameter that may accompany high light intensities is heat stress. In the past several years, the frequency of extreme weather events combining high light and high temperature conditions have been increasing dramatically, especially in the summer during midday, in which temperatures often rise to $30-40^{\circ} \mathrm{C}$ and light intensity reaches $2000 \mu \mathrm{mol} \mathrm{m} \mathrm{m}^{-2}$ (Yamamoto et al., 2008; Suzuki et al., 2014). High light intensity or high temperatures are both abiotic conditions that can drastically impact the photosynthetic machinery and limit the growth and development of plants. During high 


\section{Chapter 4}

light stress, the reaction centers become saturated and the excess excitation energy can become harmful since it can irreversibly damage photosystem II (PSII; Murata et al., 2007; Ruban, 2009; Ruban, 2015). This damaging scenario leads to photoinhibition, a sustained decline in photosynthetic efficiency caused by the imbalance between the rate of photodamage to PSII and the rate of PSII repair (Nishiyama et al., 2006; Murata et al., 2007). In addition to high light stress, heat stress can compromise PSII electron transport due to the increase in fluidity of the thylakoid membranes which causes dislodging of PSII light harvesting complexes (LHC) and decreased integrity of PSII (Mathur et al., 2014). Heat stress can also impair the repair process of PSII, exacerbating the effects of high light stress (Takahashi and Murata, 2008; Dogra et al., 2019). On top of that, high light intensities and heat stress may each induce the production of reactive oxygen species (ROS) via different mechanisms (Murata et al., 2007; Pospíšil, 2016), potentially leading to a distinct ROS signature when the two stresses are combined (Choudhury et al., 2017).

In plants, PSII contains more than 20 subunits including four major core subunits termed D1 (PsbA), D2 (PsbD), CP43 (PsbC), and CP47 (PsbB) (Allen et al., 2011). Among them, the D1 protein is the main site susceptible to damage by heat stress or high light (Murata et al., 2007; Yamamoto et al., 2008; Su et al., 2014). Plants evolved several different protective systems to survive under unfavorable light conditions (Szymańska et al., 2017). Following PSII inactivation by light, its activity can be restored by a highly coordinated multistep repair system that involves degradation of damaged D1, new D1 synthesis and PSII reassembly (Lu, 2016). This repair cycle includes the disassembly of the PSII-LHCII supercomplex and the PSII core dimer in grana stacks, followed by lateral migration of the PSII core monomer to stroma-exposed thylakoid membranes, dephosphorylation, partial disassembly of the PSII core monomer, and degradation of photodamaged D1. Finally, synthesis and reassembly of new D1, re-incorporation of CP43, migration of the PSII core monomer back to grana stacks, dimerization into PSII core dimers and reformation of PSII-LHCII supercomplexes occur (reviewed in Lu, 2016). More than 60 auxiliary proteins, enzymes or components of thylakoid protein trafficking/targeting systems are directly or indirectly involved in the PSII repair cycle (Baena-González and Aro, 2002; Lu, 2016). For example, FtsH proteases are involved in the degradation of photodamaged D1. It has been reported that var2-2 plants, deficient in FtsH, are much more susceptible to light-induced PSII photoinhibition than wild-type plants (Bailey et 
al., 2002), suggesting that impaired PSII repair could lead to failure in acclimation to high light intensity.

Plant hormones play important roles in regulating responses to a wide variety of biotic and abiotic stresses. Among them, jasmonates have been traditionally associated with defense responses against herbivores, necrotrophic pathogens, nematodes and other biotic threats. In addition, jasmonic acid (JA) and its conjugate form, JA-isoleucine (JA-Ile), have been implicated in responses to abiotic challenges such as UV, osmotic stress, salinity, cold, heat, and heavy metal stresses (reviewed in Wasternack and Hause, 2013; Dar et al., 2015; Kazan, 2015). A study of the ultra-fast transcriptomic response of Arabidopsis to light stress revealed that approximately $12 \%$ of transcripts that accumulated within seconds of light stress application were JA-response transcripts (Suzuki et al., 2015), suggesting a possible role for this phytohormone in rapid responses to high light intensity stress.

Because in the field, light and heat stress combination occurs during the summer season in many of the areas used for crop production worldwide, we studied the effect of this stress combination on the model plant Arabidopsis thaliana. Here, we uncover the unique transcriptomic, physiological, and hormonal responses of Arabidopsis plants to a combination of high light and heat stress. Because both stresses impact PSII performance, albeit in different ways, we hypothesized that the stress combination would have a severe effect on PSII performance, higher than each of the individual stresses would have. Here we show that a combination of heat and high light stress has a detrimental effect on plants and that this combination displays unique physiological and molecular characteristics, including a decreased ability to repair PSII. We further reveal that JA plays a key role in the response of plants to this stress combination. In contrast, abscisic acid (ABA) and salicylic acid (SA) play a much lesser role. Our findings reveal that the response of Arabidopsis plants to a combination of light and heat stress is unique and might require dedicated breeding efforts to overcome under field conditions. 


\section{Results}

\section{Acclimation of Arabidopsis plants to high light (HL), heat stress (HS) and a combination of high light and heat stress $(\mathrm{HL}+\mathrm{HS})$}

To study high light, heat stress and their combination, we subjected wild-type Arabidopsis plants (Col) to a light intensity of $600 \mu \mathrm{mol} \mathrm{m} \mathrm{m}^{-2}$ (HL), a temperature of $42^{\circ} \mathrm{C}(\mathrm{HS})$, or to a light intensity of $600 \mu \mathrm{mol} \mathrm{m} \mathrm{m}^{-2} \mathrm{~s}^{-1}$ combined with a temperature of $42^{\circ} \mathrm{C}$ (HL+HS) for 7 hours (Fig. 1A; Supplemental Fig. S1). In contrast, control (CT) plants were maintained at $50 \mu \mathrm{mol} \mathrm{m} \mathrm{m}^{-2} \mathrm{~s}^{-1}, 23^{\circ} \mathrm{C}$. PSII performance in terms of quantum yield of PSII (ФPSI) and maximal efficiency of PSII (Fv/Fm) were determined in Col plants subjected to HL, HS and HL+HS (Fig. 1B and 1C). $\Phi_{\mathrm{PSII}}$ and Fv/Fm values significantly decreased following the application of HL and more dramatically following the application of HL+HS, compared to CT values. In contrast, HS did not significantly affect PSII activity (Fig. 1B and 1C, top panels). To examine the ability of plants to recover from stress, we measured $\Phi_{\mathrm{PSII}}$ and Fv/Fm 24 hours following the stress treatments (Fig. 1B and 1C, bottom panels; Supplemental Fig. S1). As shown in Figure 1B and 1C, $\Phi_{\text {PSII }}$ and Fv/Fm values of plants subjected to HL returned to control values whereas those of plants subjected to the stress combination remained significantly lower compared to CT plants. These findings suggest that PSII function cannot be completely recovered following exposure to HL+HS conditions. Leaf Damage Index (LDI) demonstrated that approximately $6 \%$ of leaves showed damage in response to HL, whereas all leaves looked healthy in plants subjected to HS (Fig. 1A and 1D). In contrast, Col plants subjected to the stress combination showed a higher number of affected leaves (35\% dead and $38 \%$ damaged; Fig. 1A and 1D). In addition, whereas all plants survived the application of HL or HS, the combination of HL and HS significantly decreased survival rate to $75 \%$ (Fig. $1 \mathrm{~A}$ and 1D). 


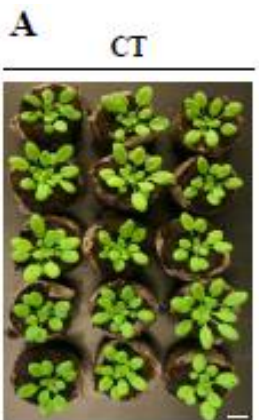

HS

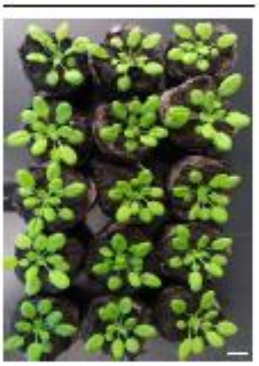

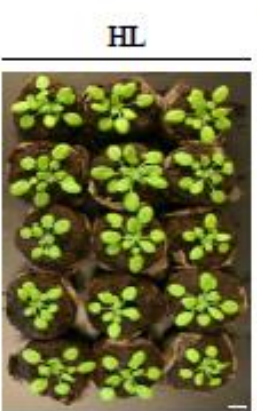

$\mathrm{HL}+\mathrm{HS}$

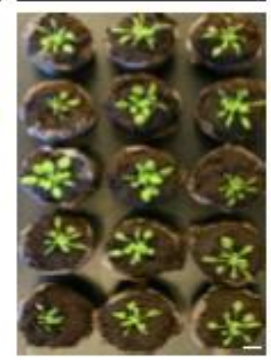

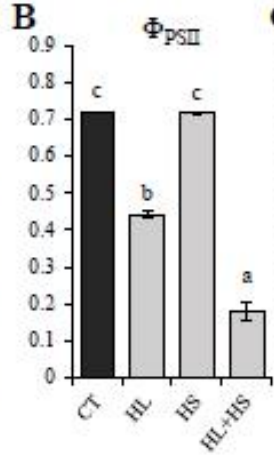
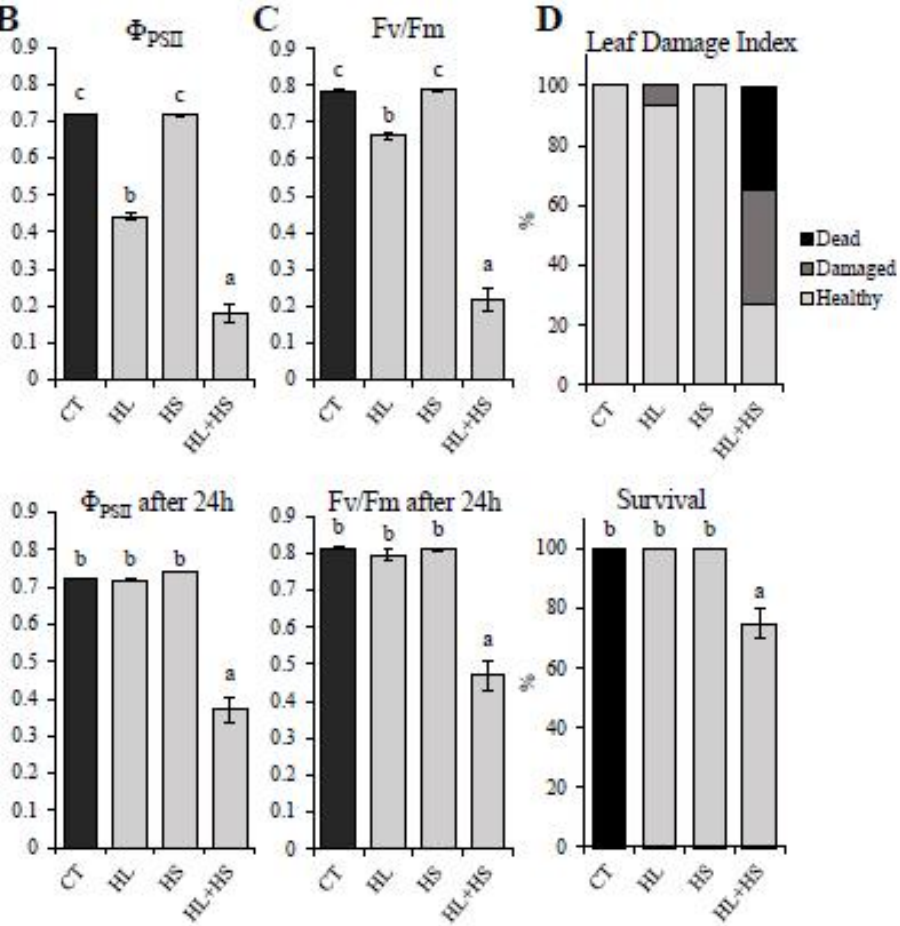

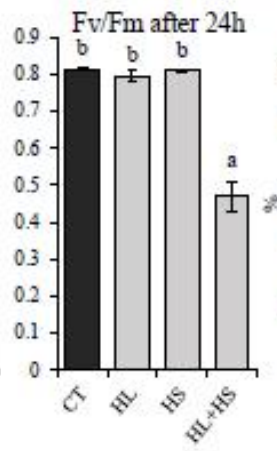

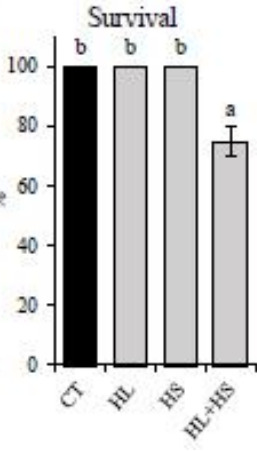

Fig. 1. A combination of heat and high light stress is detrimental to plants. (A) Representative images of Col plants subjected high light (HL), heat stress (HS) and a combination of high light and heat stress (HL $+\mathrm{HS})$. (B) Quantum yield of PSII $\left(\Phi_{\mathrm{PSII}}\right)$ immediately after the application of each stress (top) and $24 \mathrm{~h}$ following recovery from the stress treatments (bottom). (C) Maximum efficiency of PSII (Fv/Fm) immediately after the application of each stress (top) and $24 \mathrm{~h}$ following recovery from the stress treatments (bottom). (D) Leaf Damage Index of Col plants following the stress treatments (top) and survival of plants subjected to the different stresses (bottom). Different letters denote statistical significance at $\mathrm{P}<0.05$. Scale bar in A indicates 1 $\mathrm{cm}$. CT, control.

\section{Stomatal responses of Arabidopsis plants to HL, HS, and HL+HS stress combination}

Because stomata were previously shown to close during light stress (Devireddy et al., 2018), but open during heat (Rizhsky et al., 2004; Teskey et al., 2015; Zandalinas et al., 2016a; Urban et al., 2017), suggesting a potential conflict in the response of plants to HL+HS, we tested the effect of HL+HS on stomatal aperture (Fig. 2). Whereas HL induced a decrease in stomatal aperture (23\% compared to CT), both HS and HL+HS induced stomatal opening. Leaf temperature increased in plants subjected to HL by about $4^{\circ} \mathrm{C}$ compared to leaves of CT plants. In contrast, the leaf temperature of HS plants was higher, reaching about $10^{\circ} \mathrm{C}$ more than $\mathrm{CT}$, while combined $\mathrm{HL}+\mathrm{HS}$ caused leaf temperature to be about $10-12^{\circ} \mathrm{C}$ more than CT. Consequently, leaf relative water content (RWC) significantly decreased primarily in plants subjected to HS or HL+HS compared 
to control values (Fig. 2). These results demonstrate that from the standpoint of signal transduction mechanisms regulating stomatal conductance, the combination of HL+HS is more similar to HS than to HL.

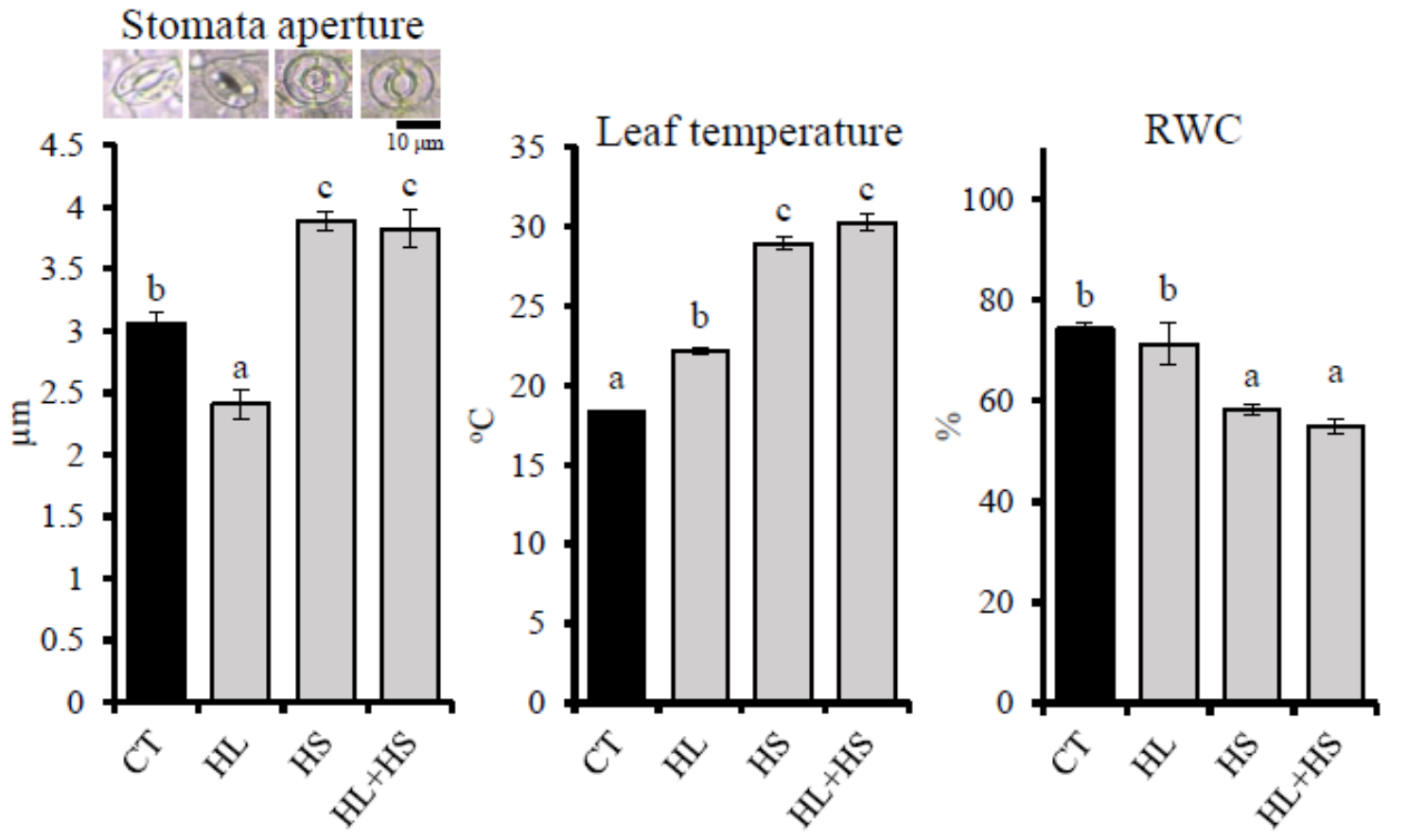

Fig. 2. Heat and light stress combination displays a heat-like stomatal response. Stomatal aperture (left), surface leaf temperature (middle) and leaf relative water content (RWC; right) of Col plants subjected to high light (HL), heat stress (HS) and a combination of high light and heat stress $(\mathrm{HL}+\mathrm{HS})$. Different letters denote statistical significance at $\mathrm{P}<0.05$. Representative stomatal images are shown on left. Scale bar in stomatal images indicates $10 \mu \mathrm{m}$. CT, control.

Transcriptomic responses of Arabidopsis plants to HL, HS, and HL+HS stress combination

A transcriptomic (RNA-Seq) analysis of Col plants subjected to HL, HS and HL+HS conditions revealed that the steady-state level of 3942, 5304 and 6314 transcripts was significantly enhanced in response to $\mathrm{HL}, \mathrm{HS}$ and $\mathrm{HL}+\mathrm{HS}$, respectively (Fig. 3A; Supplemental Tables S1-S6), and a high proportion of these transcripts was associated with hormone and ROS responses (Supplemental Table S7; Suzuki et al., 2015; Zandalinas et al., 2019a). In addition, the steady-state level of 3670, 4994 and 5678 transcripts was significantly decreased in response to HL, HS and HL+HS, respectively (Fig. 3A; Supplemental Tables S4-S6). Of the 6314 transcripts significantly elevated in response to HL+HS, 2125 transcripts (34\%) were common with HL-induced transcripts, 3166 transcripts (50\%) were common with HS-induced transcripts, and 2239 transcripts 
(36\%) were found to be specifically upregulated by the stress combination. These results suggest that a considerable proportion of the transcriptomic changes in plants subjected to HL+HS is specific for the stress combination. According to Gene Ontology (GO) term enrichment analysis (Fig. 3B; Supplemental Fig. S2), HL+HS-specific transcripts were involved in different biological processes including oxidation-reduction processes, protein transport, protein catabolic processes or photosynthesis, as well as related to responses to cadmium, salt stress or involved in the tricarboxylic acid cycle (Fig. 3B).

A

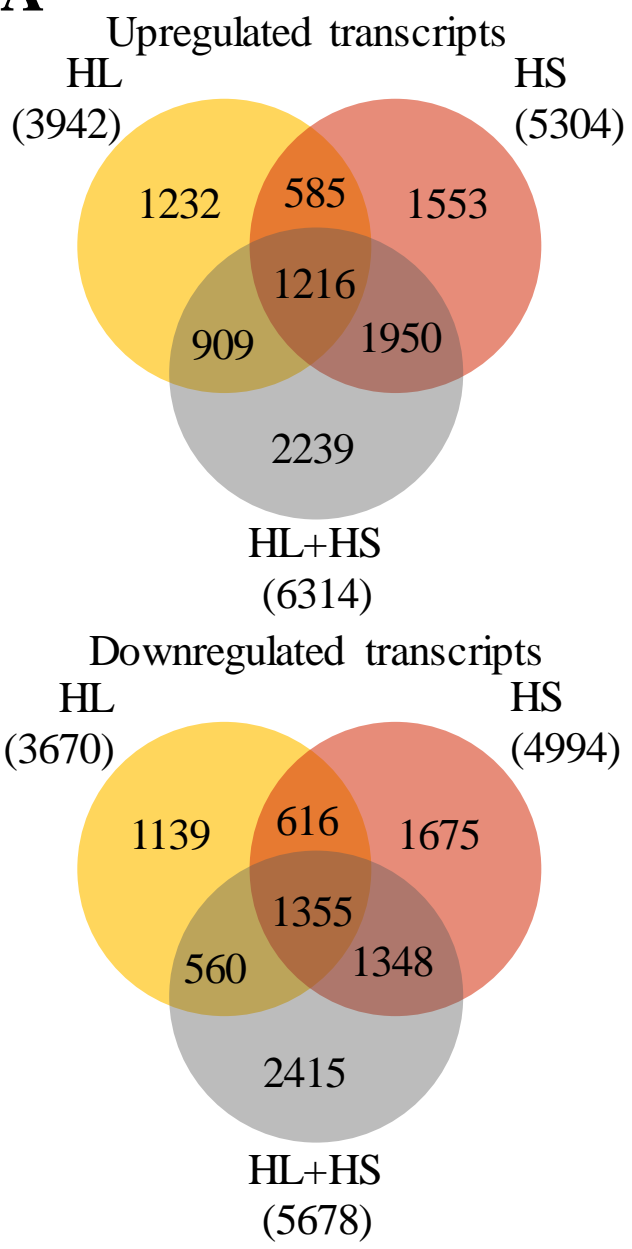

B

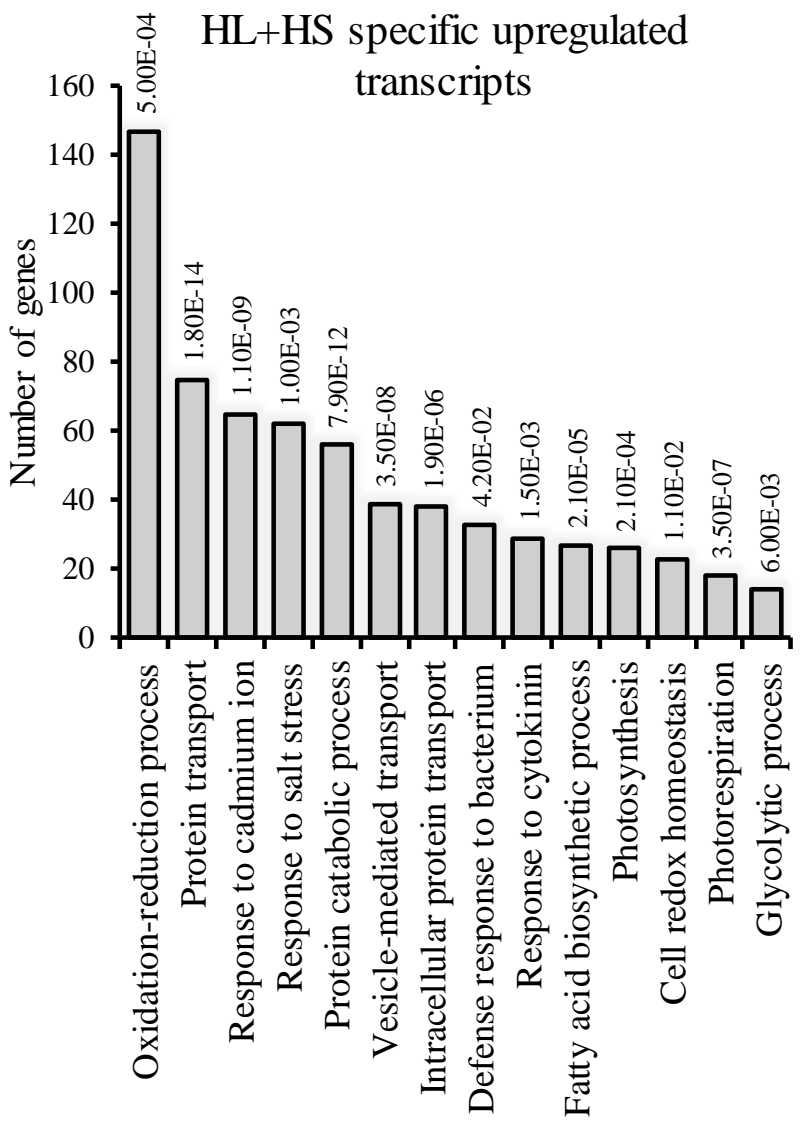

Fig. 3. Heat and light stress combination is accompanied by a unique transcriptomic response. (A) Venn diagrams showing the overlap among the upregulated (top) or downregulated (bottom) transcripts in each of the different stress treatments [high light (HL), heat stress (HS) and a combination of high light and heat stress (HL+HS)]. (B) Gene Ontology (GO) annotation of transcripts specifically upregulated in leaves of Arabidopsis in response to the combination of high light and heat stress (HL+HS; numbers above each bar represent $\mathrm{P}$ value for statistical significance). 
Table 1. Representation of hormone- and ROS-response transcripts in the transcriptomic response of plants subjected to $H L, H S$, and the combination of $H L+H S$

\begin{tabular}{lcrr}
\hline \multicolumn{1}{c}{ Hormone/ROS } & $\mathrm{HL}$ & $\mathrm{HS}$ & $\mathrm{HL}+\mathrm{HS}$ \\
\hline Abscisic acid $(1,460)$ & $220(15.07 \%)$ & $472(32.33 \%)$ & $554(37.94 \%)$ \\
1-Aminocyclopropane-1-carboxylic acid (175) & $19(10.86 \%)$ & $30(17.14 \%)$ & $36(20.57 \%)$ \\
Brassinolide (276) & $19(6.88 \%)$ & $31(11.23 \%)$ & $60(21.74 \%)$ \\
Cytokinin (355) & $154(43.38 \%)$ & $121(34.08 \%)$ & $110(30.98 \%)$ \\
Gibberellin (43) & $6(13.95 \%)$ & $9(20.93 \%)$ & $8(18.60 \%)$ \\
Indole-3-acetic acid (436) & $43(9.86 \%)$ & $70(16.05 \%)$ & $90(20.64 \%)$ \\
Methyl jasmonate (3,877) & $611(15.76 \%)$ & $689(17.77 \%)$ & $829(21.38 \%)$ \\
Salicylic acid (217) & $21(9.67 \%)$ & $23(10.60 \%)$ & $37(17.05 \%)$ \\
$\mathrm{H}_{2} \mathrm{O}_{2}(956)$ & $166(17.36 \%)$ & $229(23.95 \%)$ & $354(37.03 \%)$ \\
$\mathrm{O}_{2}{ }^{-}(287)$ & $1(0.35 \%)$ & $2(0.69 \%)$ & $3(1.04 \%)$ \\
${ }^{1} \mathrm{O}_{2}(297)$ & $47(15.82 \%)$ & $70(23.57 \%)$ & $80(26.94 \%)$ \\
\hline
\end{tabular}

The expression of selected transcriptional regulators involved in plant responses to different stresses, such as Heat Shock Factors (HSFs), APETALA2/ethylene-responsive element binding proteins (AP2/EREBPs), or MYBs revealed a differential expression pattern in plants subjected to HL, HS and HL+HS, compared to CT (Fig. 4). As shown in Figure 4, some HSFs displayed an additive manner of expression, with HSFA2, HSFA7A, HSFB1, HSFB2A and HSFB2B showing the highest expression values in response to HL+HS. In contrast, other HSFs were specifically upregulated in response to HS (HSFA6B) or HL (HSFA1D; Fig. 4A). Interestingly, no HSF was found to be uniquely expressed during the HL+HS response. In contrast to HSFs, several AP2/EREBP transcription factors were upregulated specifically in response to HL+HS (Fig. 4B). These included ERF109, ERF88, DREB1D, ERF25, ERF57, ERF4 and ERF99 (Fig. 4B). A similar pattern with the steady-state level of several transcriptional regulator enhanced specifically during HL+HS was also found in the MYB family (Fig. 4C). For instance, MYB50, MYB15, MYB35, MYB62, MYB86, MYB77, MYB17 and MYB23 were specifically upregulated in response to HL+HS, whereas MYB90, MYB11, MYB114, MYB113 and MYB97, were specifically upregulated in response to HL or HS (Fig. 4C). These findings highlight particular transcriptional regulators and their related families as potential breeding targets for future efforts to develop plants with enhanced tolerance to HL+HS combination. In addition, they reveal the complexity underlying plant acclimation to stress combination. 
$\mathbf{A}$

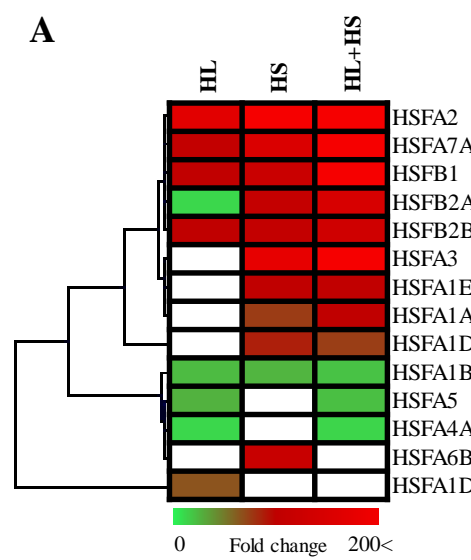

B

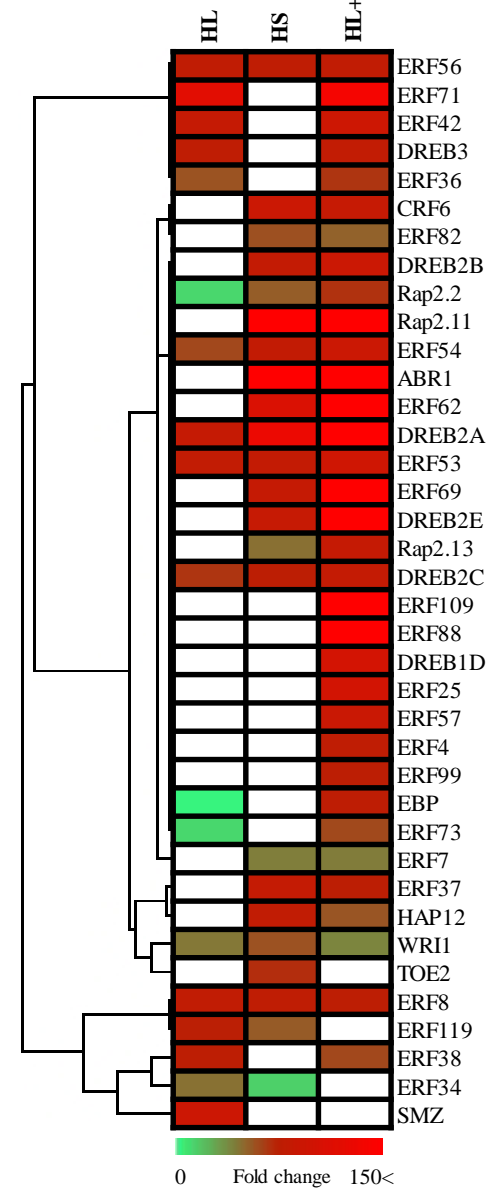

C
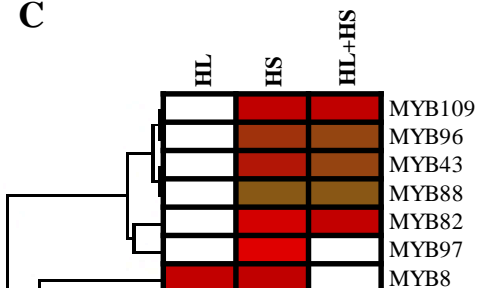

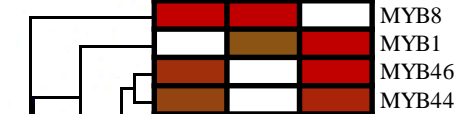

\begin{tabular}{|l|l|l|l|}
\hline MYB44 \\
\hline
\end{tabular}

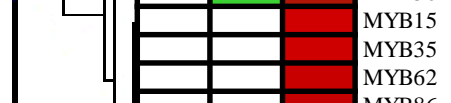

\begin{tabular}{|l|l|l|l|l|}
\hline & & & MYB86 \\
\hline & & & \\
\hline
\end{tabular}
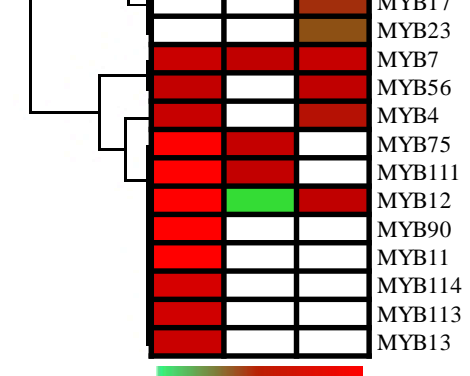

0 Fold change $100<$

Fig. 4. Differential expression of transcriptional regulators during the stress combination. Heat maps showing the response of different transcriptional regulators in each stress condition (relative to control) are shown. (A) Heat Shock Factor (HSF) family. (B) APETALA2/ethylene-responsive element binding protein (AP2/EREBP) family. (C) MYB family. 

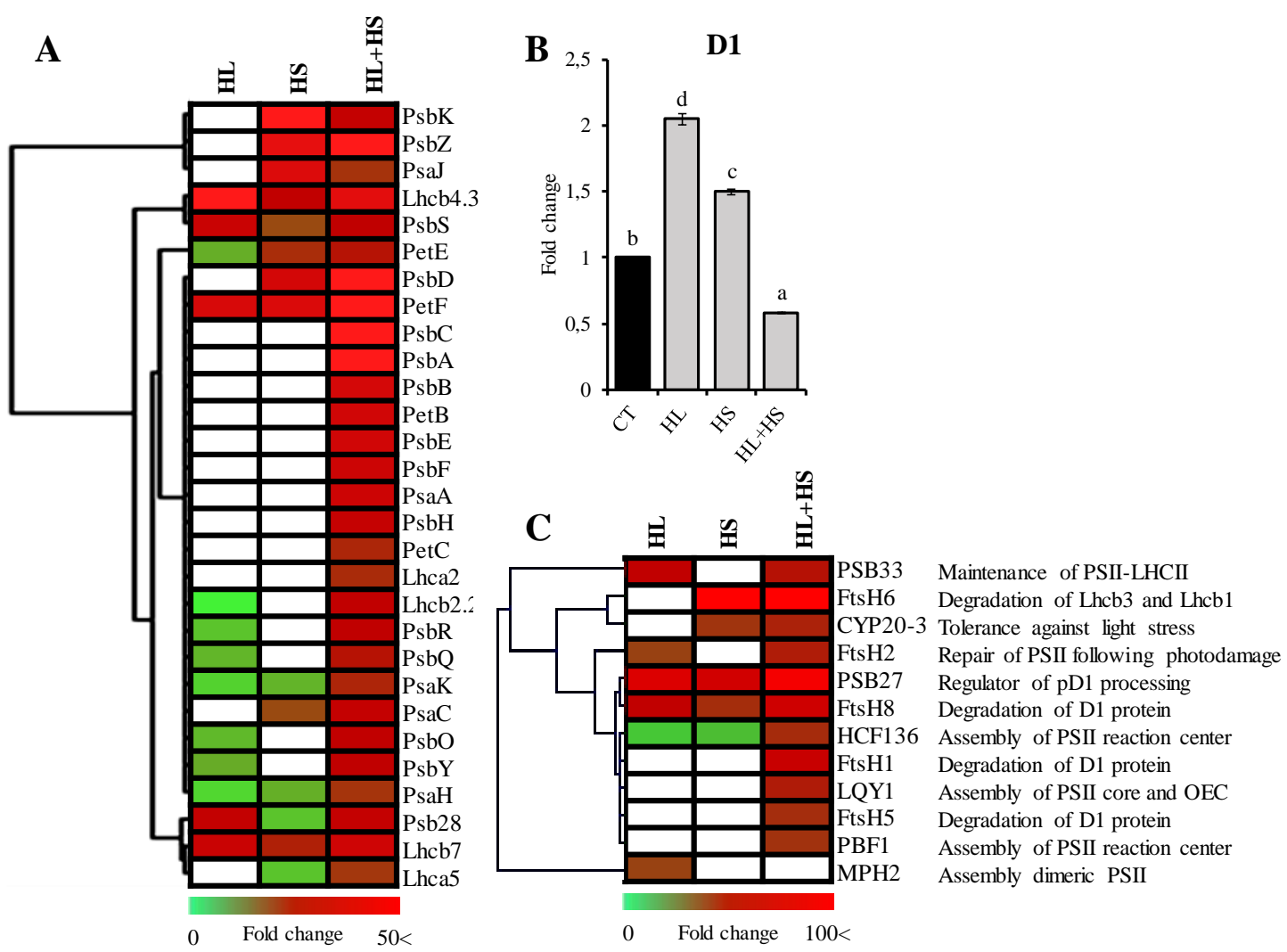

Fig. 5. Enhanced expression of transcripts encoding PSII and PSII repair proteins during a combination of light and heat stress is accompanied by a decrease in D1. (A) Heat map showing changes in expression of transcripts encoding proteins of the photosynthetic apparatus in Col leaves in response to high light (HL), heat stress (HS) and the combination of high light and heat stress (HL+HS). (B) Accumulation of D1 proteins in response to each stress condition. Different letters denote statistical significance at $\mathrm{P}<0.05$. CT, control. (C) Heat map showing changes in the expression of transcripts encoding proteins involved in the D1 turnover in Col leaves in response to each stress.

\section{Impact of HL+HS combination on PSII and different chloroplast structures}

Because HL intensity and HS negatively impact the photosynthetic machinery (Mathur et al., 2014; Ruban, 2015), and one of the major impacts of HL+HS appears to be PSII (Fig. 1), we analyzed the expression of transcripts encoding photosynthetic proteins in our RNA-Seq data set (Fig. 3). As shown in Figure 5A, transcripts encoding PSII (PsbC, PsbA, PsbB, PsbE, PsbF, PsbH or PsbZ), PSI (PsaA, PsaK, PsaC or PsaH) proteins, proteins of the cytochrome b6f complex (PetB, PetC), and proteins involved in photosynthetic electron transport (PetE and PetF) were upregulated in response to HL+HS (with some upregulated in response to HL or HS as well). In addition, HL or HL+HS combination enhanced the expression of several transcripts encoding antenna proteins such as Lhcb4.3, Lhcb7 or Lhca5 (Fig. 5A). Since the D1 protein of PSII (encoded by PsbA) is considered to be highly sensitive to photodamage (Edelman and 
Mattoo, 2008), we further analyzed the levels of D1 under the different stresses (Fig. 5B), as well as the expression of transcripts that encode proteins involved in the PSII repair cycle (Lu, 2016; Fig. 5C). Whereas HS and HL significantly increased the accumulation of D1 with respect to CT plants, plants subjected to HL+HS displayed reduced levels of this protein (Fig. 5B). In addition, many transcripts encoding proteins involved in D1 degradation (FtsH1, FtsH5, FtsH6, FtsH8), its repair (CYP20-3, PSB27), and the reassembly of PSII (CYP20-3, LQY1, PBF1, HCF136, PSB33) (Järvi et al., 2015; Lu, 2016), were upregulated in response to HL+HS, suggesting that the PSII repair cycle is activated under this stress combination (Fig. 5C). Our findings suggest that the D1 protein of PSII is particularly sensitive to the combination of HL+HS, and that plants subjected to this stress combination are attempting to repair this protein. Nevertheless, as shown in Figure 1, the combination of HL+HS results in an overall decline in PSII activity during the stress combination.

To determine the degree of structural changes to chloroplasts resulting from the stress combination, we conducted transmission electron microscopy (TEM) analysis of leaf samples from plants subjected to the different treatments. As shown in Figure 6, HLinduced structural changes to chloroplasts included a decrease in the number of starch granules and enhanced stacking of thylakoids (number of thylakoid membranes per $\mu \mathrm{m}$; Fig. 6B). In contrast, chloroplasts of HS-treated plants appeared to contain a higher number of starch granules, as well as reduced granal stacking (Fig. 6B). Interestingly, compared to controls, HL+HS-induced structural changes included an increased number of starch granules, of which about $75 \%$ appeared highly distorted, as well as fewer thylakoids per $\mu \mathrm{m}$ (Fig. 6). Plant subjected to HL+HS displayed therefore unique structural features of distorted starch granules, as well as reduced granal stacking. These features suggest that the impact of HL+HS on chloroplast structure and metabolism is unique and should be addressed in future studies. 
A

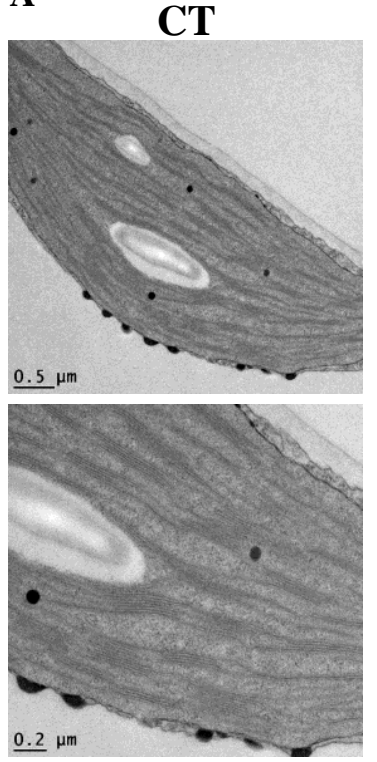

B

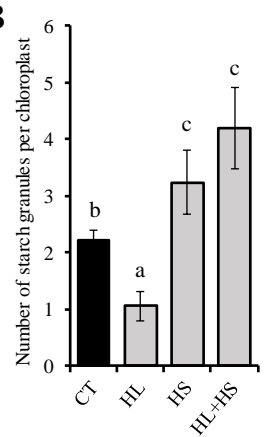

HL
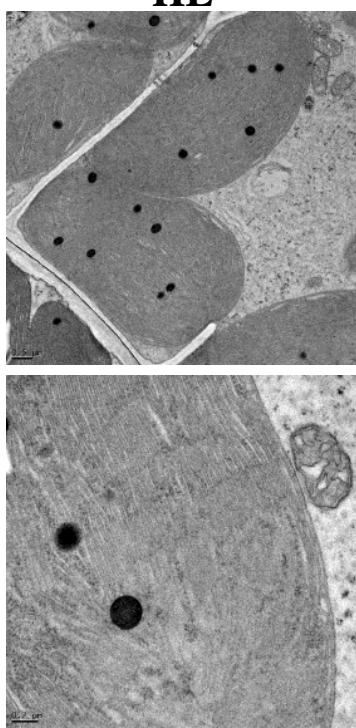

HS
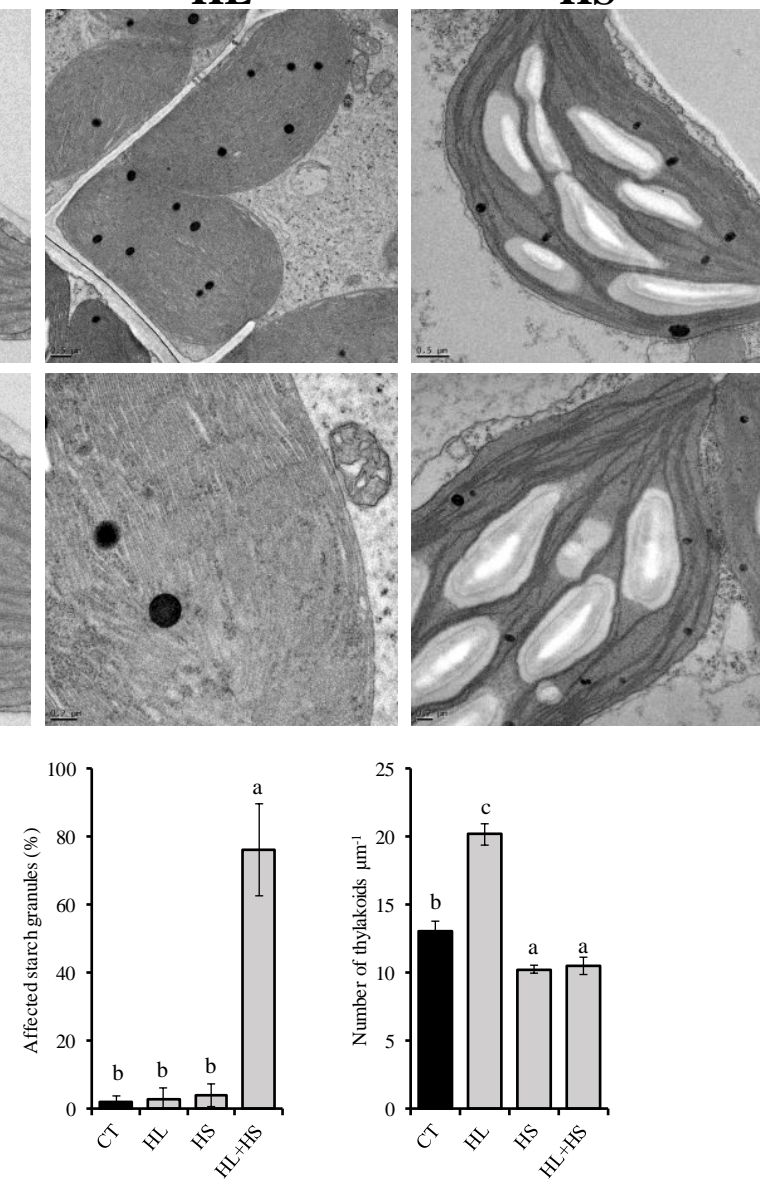

HL+HS
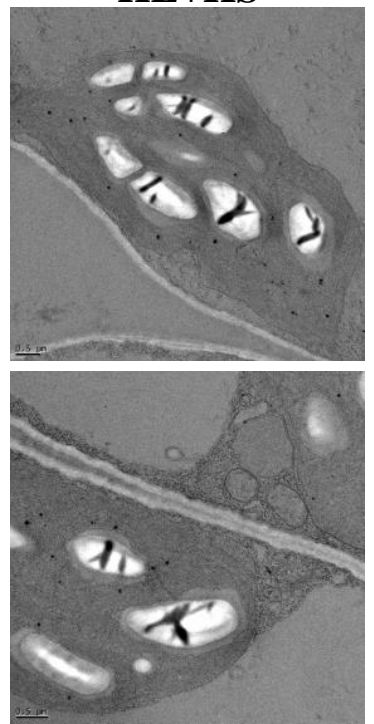

Fig. 6. Unique structural features of chloroplasts from plants subjected to high light (HL), heat stress (HS) and a combination of high light and heat stress (HL+HS). (A) Representative transmission electron microscope images of chloroplasts of Col plants subjected to the different stresses. (B) Quantification bar graphs showing structural changes to chloroplasts of plants subjected to the different stresses. At least 100 images, each containing 2-4 chloroplasts from at least three plants from each treatment were analyzed. Different letters denote statistical significance at $\mathrm{P}<0.05$. Scale bar in $\mathrm{A}$ indicates 0.5 or $0.2 \mu \mathrm{m}$. CT, control.

\section{Accumulation of $\mathrm{H}_{2} \mathrm{O}_{2}$, ABA, SA, JA and JA-Ile in Arabidopsis plants subjected to HL+HS combination}

A large number of plant hormones and ROS are involved in the response of plants to different abiotic stresses and their combination (Peleg and Blumwald, 2011; Choudhury et al., 2017). To further dissect the response of plants to a combination of HL+HS, we measured the levels of $\mathrm{H}_{2} \mathrm{O}_{2}, \mathrm{ABA}, \mathrm{SA}$, JA and JA-Ile in all treatments. As shown in Figure 7, $\mathrm{H}_{2} \mathrm{O}_{2}$ and $\mathrm{ABA}$ content significantly increased in Col leaves in response to HS and the combination of HL and HS (Fig. 7A and B). In contrast, SA levels decreased in response to all stress treatments (Fig. 7C). Interestingly, compared to CT, HL and HS 
treatments, the levels of JA and its conjugate JA-Ile dramatically increased in response to the stress combination (Fig. 7D). These results suggest that jasmonates could be playing an important role in the acclimation of plants to this stress combination.

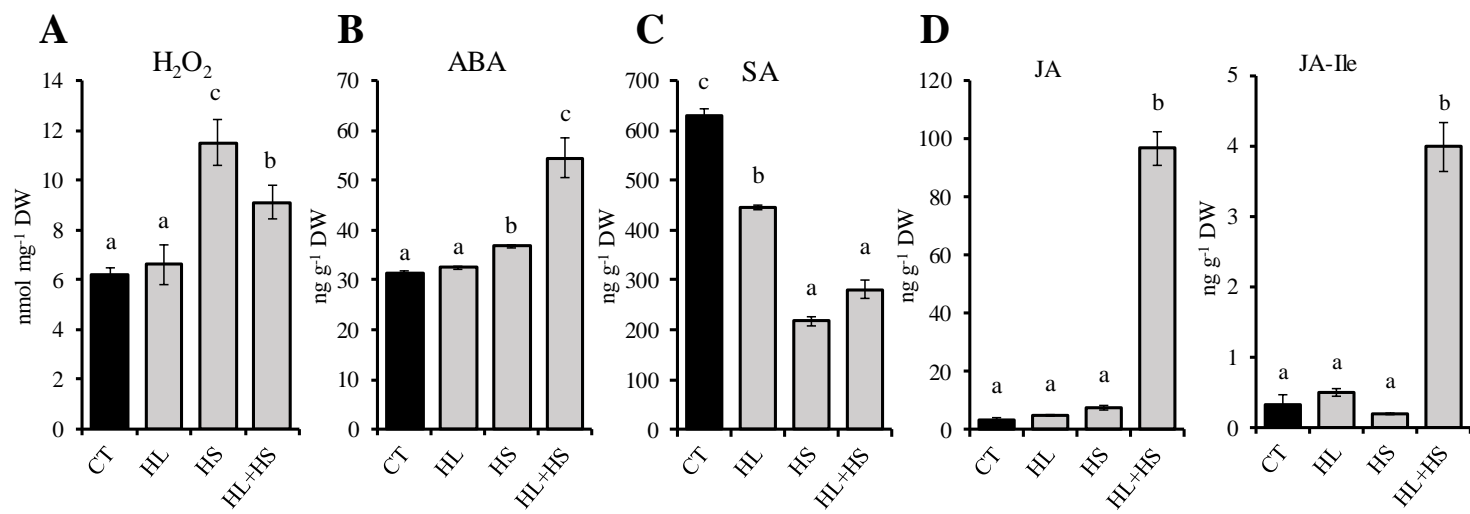

Fig. 7. Levels of $\mathrm{H}_{2} \mathrm{O}_{2}$, ABA, SA, JA and JA-Ile in Col plants subjected to high light (HL), heat stress (HS) and a combination of high light and heat stress (HL+HS). (A) $\mathrm{H}_{2} \mathrm{O}_{2}$. (B) ABA. (C) SA. (D) JA and JA-Ile accumulation. Different letters denote statistical significance at $\mathrm{P}<0.05$. CT, control.

\section{Characterizing the response of JA-deficient (allene oxide synthase; aos) plants to HL+HS stress combination}

To further dissect the role of JA in the response of plants to HL+HS combination, we compared our transcriptomic data with previous reports that identified JA-associated transcripts (Suzuki et al., 2015; Hickman et al., 2017). We found that out of the 6314 transcripts that were upregulated in response to HL+HS, 822 transcripts (13\%) were JAresponsive transcripts (Fig. 8A; Supplemental Fig. S3). In addition, as shown in Figure $8 \mathrm{~A}$, the expression of many JA-response transcriptional regulators was upregulated in response to HL+HS and some of these were specific for the stress combination (including bZIP3, BHLH114, BHLH137, WRKY8, WRKY57 and WRKY18). In addition, the expression of many transcripts involved in JA biosynthesis was upregulated in plants subjected to the stress combination (Supplemental Fig. S3). These findings suggest that JA could be mediating some of the HL+HS-specific transcriptional responses identified in Figure 3.

To further study the role of JA in the response of plants to HL+HS combination, we analyzed the response of the highly studied JA-deficient mutant aos (Park et al., 2002; Chehab et al., 2012; Hu et al., 2013; Gasperini et al., 2015) to HL, HS and HL+HS (Fig. 
8B-8D; Supplemental Fig. S4). As shown in Figure 8C, compared to CT, $\Phi_{\text {PSII }}$ and Fv/Fm values of aos mutants significantly decreased in response to HL and more markedly in response to HL+HS. In addition, whereas all aos plants survived the individual HL or HS stresses, the survival rate of aos plants subjected to a combination of HL and HS decreased to about $49 \%$ (Fig. 8D, top panel). Furthermore, when analyzing leaf damage (LDI) in aos plants subjected to the different stresses, we found that about $33 \%$ of leaves were damaged by HL whereas signs of stress were not apparent in aos plants subjected to HS. In contrast, HL+HS negatively influenced leaf appearance, with $60 \%$ of leaves dead, $30 \%$ of leaves damaged and only $10 \%$ of leaves healthy (Fig. 8D, bottom panel). Compared to Col plants, aos mutants were therefore more sensitive to the stress combination [displaying a significantly reduced survival rate and LDI; Fig. 8B and 8D, Supplemental Table S8)]. In contrast, to the aos mutant, mutants deficient in ABA (aba2) or SA (sid2) did not display higher sensitivity to the HL+HS stress combination compare to wild type Col plants (Supplemental Figs. S5 and S6; Supplemental Table S8).

To determine whether the differences in survival of $\mathrm{Col}$ and aos plants subjected to the stress combination (Supplemental Table S8) were related to JA-dependent changes in transcript expression, we analyzed the expression of different JA-responsive transcriptional regulators (ZAT6, ZAT10 and MYB15), as well as the ROS-scavengers APX1 and APX2, in Col and aos plants subjected to the different stress treatments (Fig. 8E). Compared to wild-type plants, the expression of ZAT6, ZAT10, APX1 and APX2 was significantly reduced in aos plants in response to the combination of HL+HS (Fig. $8 \mathrm{E}$ ), suggesting the JA-dependent responses could be key for plant tolerance to the combination of high light and heat stress. 
A

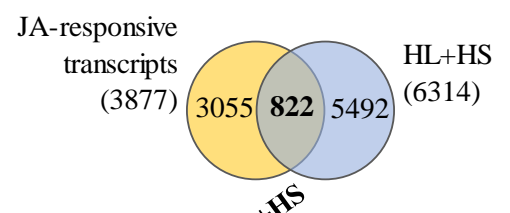

B

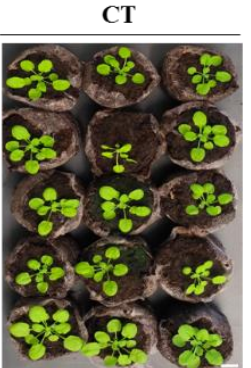

HS

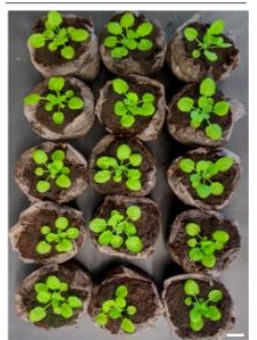

E
C

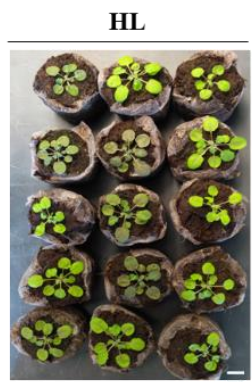

HL+HS

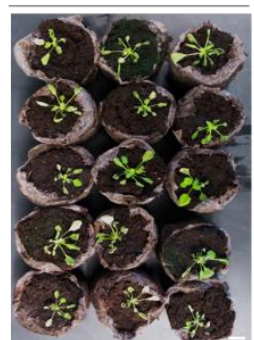

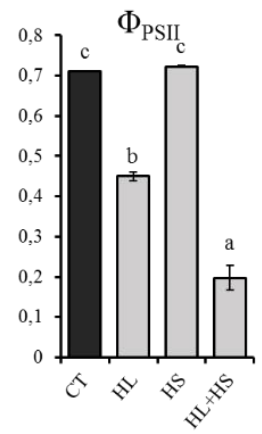

D
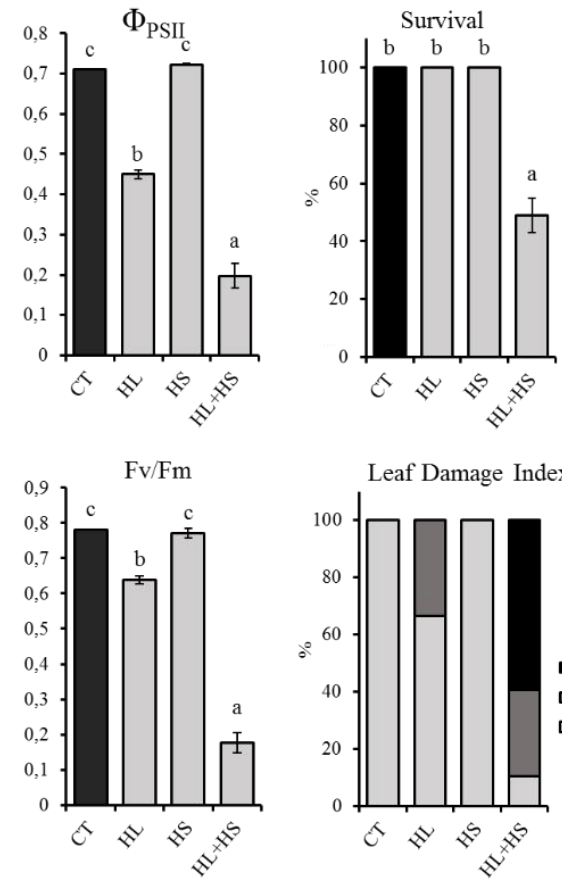
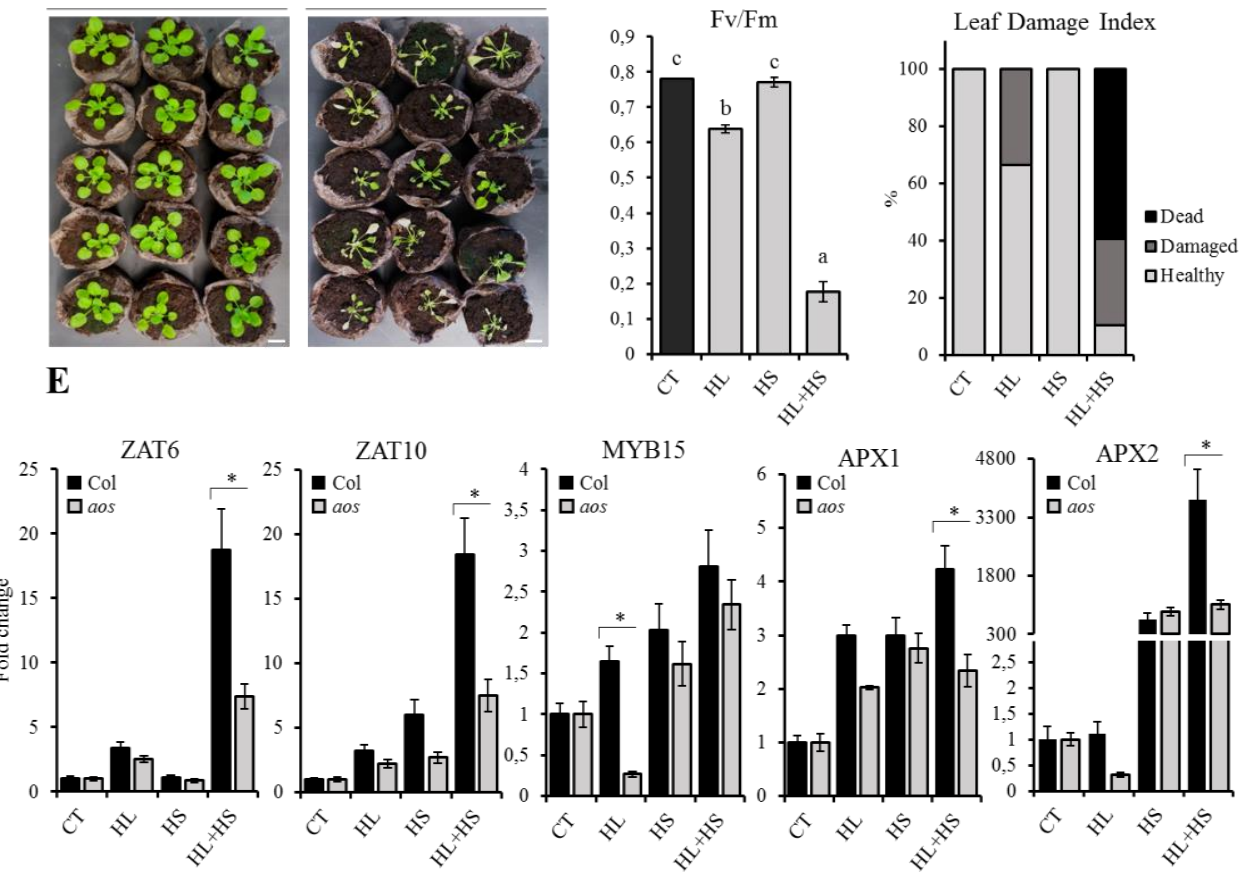

Fig. 8. Involvement of JA in the response of plants to a combination of high light and heat stress (HL+HS). (A) Venn diagram showing the overlap between JA-responsive transcripts and transcripts upregulated in response to a combination of high light and heat stress (HL+HS, top), and heat map showing changes in the expression of JA-response transcriptional regulators during high light (HL), heat stress (HS) and HL+HS (bottom). (B) Representative images of aos plants subjected to the different stresses and their combination. (C) Quantum yield of PSII ( $\Phi_{\text {PSII }}$, top) and maximum efficiency of PSII (Fv/Fm, bottom) immediately following the application of each stress in aos plants. (D) Leaf Damage Index showing the appearance of aos plants in response to each stress (top) and survival of aos plants subjected to the different stresses (bottom). (E) Relative expression of the transcriptional regulators ZAT6, ZAT10 and MYB15 and the ROS-scavengers APX1 and APX2 in Col and aos plants in response to the different stresses. Different letters denote statistical significance at $\mathrm{P}<$ 0.05. Asterisks denote Student's t-test significance at $\mathrm{P}<0.05$. Bar in B indicates $1 \mathrm{~cm}$. CT, control. 
Table 2. Survival rate (\%), LDI (\%), and photosynthetic parameters $\left(\Phi_{P S / l}\right.$ and $\left.\mathrm{F}_{\sqrt{ }} / \mathrm{F}_{\mathrm{m}}\right)$ of $\mathrm{Col}$, aos, sid2, and aba2 mutants subjected to combined $\mathrm{HL}+\mathrm{HS}$

Data were taken from Figures 1 and 8 , and Supplemental Figs. S6 and S7. Values are means \pm SD. Asterisks denote statistical significance at $P<0.05$ (ANONA) with respect to that in Col.

\begin{tabular}{lcccc}
\hline \multicolumn{1}{c}{ Parameter } & Col & aos & sid2 & aba2 \\
\hline Survival (\%) & $75.0 \pm 5.0$ & $48.9 \pm 5.8^{*}$ & $75.5 \pm 5.9$ & $77.7 \pm 4.4$ \\
Leaf damage index $(\%)$ & $34.9 \pm 7.8$ & $60.1 \pm 6.5^{*}$ & $41.8 \pm 13.3$ & $37.6 \pm 8.9$ \\
Dead & $38.2 \pm 7.6$ & $30.0 \pm 4.1$ & $33.3 \pm 6.8$ & $35.7 \pm 2.5$ \\
Damaged & $26.9 \pm 5.9$ & $9.9 \pm 3.0^{*}$ & $24.9 \pm 9.1$ & $26.7 \pm 8.1$ \\
Healthy & $0.19 \pm 0.05$ & $0.20 \pm 0.03$ & $0.11 \pm 0.03$ & $0.19 \pm 0.04$ \\
$\Phi_{\text {PSII }}$ & $0.22 \pm 0.04$ & $0.18 \pm 0.02$ & $0.14 \pm 0.02$ & $0.18 \pm 0.04$ \\
$F_{v} / F_{m}$ & & & & \\
\hline
\end{tabular}

\section{Discussion}

Plants growing within their natural habitat are routinely subjected to a combination of different environmental stresses that could adversely impact their growth and productivity (Mittler, 2006). The ability to sense and respond to these adverse conditions is therefore crucial for plants. Of particular importance for this study is the ability of plants to acclimate to a combination of HL and HS. The frequency of this stress combination has been increasing during the last several years, affecting the photosynthetic performance of plants (Yamamoto et al., 2008; Suzuki et al., 2014). Previous reports analyzed some aspects of the response of different plant species to a combination of HL and HS. Lipidomics analysis in tomato identified lipophilic antioxidant molecules that could potentially contribute to the protection of PSII against photodamage and enhance tolerance to a combined high-temperature and high-light stress (Spicher et al., 2017). In addition, studies in sunflower identified HL+HS-specific responses involving the upregulation of transcripts associated with energy metabolism, protein synthesis, cell wall activity and signal transduction components (Hewezi et al., 2008). However, to our knowledge, a comprehensive physiological, hormonal and transcriptomic analysis of this stress combination has not been conducted in the model plant Arabidopsis thaliana to date.

Our study of the stomatal responses of plants subjected to HL, HS and HL+HS combination (Fig. 2) suggest that during the stress combination the effect of high temperature, i.e., opening of stomata to increase transpiration and cool the leaf (Rizhsky et al., 2004; Zandalinas et al., 2016a), prevailed over the effect of HL, i.e., reducing stomatal aperture (Devireddy et al., 2018). Light stress-induced stomatal closure, 
potentially to prevent water loss (Fig. 2), could limit $\mathrm{CO}_{2}$ uptake and therefore energy supply (Flexas et al., 2002), possibly leading to a decreased number of starch granules in chloroplasts (Fig. 6). In contrast, HS and HL+HS enhanced stomatal aperture, to decrease leaf temperature via transpiration (Rizhsky et al., 2002; Rizhsky et al., 2004; Zandalinas et al., 2016a), potentially leading to a reduced RWC in these plants (Fig. 2). The appearance of more starch granules in the chloroplasts of HS- and HL+HS-treated plants (Fig. 6) could indicate an increased rate of $\mathrm{CO}_{2}$ fixation due to stomatal opening (Fig. 2). Interestingly, under the combined HL+HS stress, starch granules appeared highly distorted (Fig. 6). The reason for this distortion could be attributed to an altered amylose/amylopectin ratio during the stress combination, and/or a possible rupture of the plastidial envelope during stress combination, allowing access for starch-degrading enzyme (Bondada and Syvertsen, 2005). Further studies are needed to unravel the role of different metabolic pathways during a combination of HL and HS and their effect on chloroplast structures. It is nevertheless important to note that, in contrast to a combination of drought and heat stress, in which the effect of drought prevailed over the effect of heat on stomatal conductance (i.e., stomata remained closed during the stress combination; Rizhsky et al., 2002; Rizhsky et al., 2004), in the current study the effect of HS prevailed over HL (i.e., stomata remained open; Fig. 2). Further studies addressing the different mechanisms modulating stomatal conductance during different types of stress combination may reveal the exact molecular mechanisms that control such interesting interactions.

Expression analysis of transcripts encoding different photosynthetic proteins, as well as proteins involved in the degradation, repair and reassembly of PSII (Lu, 2016; Fig. 5A and $5 \mathrm{C}$ ), suggested that during $\mathrm{HL}+\mathrm{HS}$ combination the de novo biosynthesis of many proteins comprising the photosynthetic apparatus [e.g., PsbA (D1), PsbD (D2), PsbC (CP43) and PsbB (CP47); Fig. 5A], is enhanced. Nevertheless, the steady-state level of the D1 protein declined during HL+HS stress combination (Fig. 5B), suggesting that the rate of photodamage to PSII occurring during this stress combination (Fig. 1B and 1C) exceeds the active biosynthesis, repair and reassembly of D1 proteins (Fig. 5A and 5C). As a possible consequence, PSII activity and survival of plants declined during the stress combination (Fig. 1). Further studies directly measuring the rate of D1 turnover are of course needed to address this possibility. Because HS and HL+HS result in enhanced accumulation of ROS (Fig. 7A), and ROS were proposed to directly or indirectly affect 


\section{Chapter 4}

the rate of D1 turnover (Murata et al., 2007; Yamamoto et al., 2008), the role of ROS in affecting PSII function during HL+HS combination should also be addressed in future studies. In contrast to HL+HS, D1 protein markedly accumulated during HL (Fig. 5B) and the HL-induced decrease in PSII activity could be restored $24 \mathrm{~h}$ following the stress period (Fig. 1), probably due to the induction of D1 turnover, repair and assembly of PSII (Bailey et al., 2002; Fig. 5C). In this respect it should be noted that only HL specifically induced the expression of transcripts encoding MPH2, a chloroplast thylakoid lumen protein that is required for proper photosynthetic acclimation of plants under fluctuating light environments (Liu and Last, 2017; Fig. 5C).

While we could not find a significant change in the acclimation response of ABA- and SA-deficient mutants (aba2, sid2, respectively) to the combination of HL+HS (compared to wild type Col; Supplemental Figs. S5 and S6; Supplemental Table S8), we found a significant decline in the ability of the JA biosynthesis mutant (aos) to acclimate to a combination of HL+HS (Fig. 8; Supplemental Table S8). The AOS protein produces most of the non-volatile oxylipins in plants and is a focus of attention in large part due to its key role in the biosynthesis of JA and biologically active JA-Ile (Farmer and Goossens, 2019). Although JA and JA-Ile have been widely associated with the defense response of plants against pathogens and insect attack (Wasternack, 2015), many of the roles of jasmonates in nature are still unknown (Hickman et al., 2017; Farmer and Goossens, 2019). Our findings suggest that JA-dependent gene expression could be important for the acclimation of plants to HL and HS acclimation (Fig. 8). For instance, expression of the JA-regulated ZAT6 and ZAT10 (Suzuki et al., 2015; Hickman et al., 2017), or the ROS-scavengers APX1 and APX2 (all important transcripts involved in the acclimation of plants to different abiotic stresses) was significantly reduced in response to HL+HS in aos plants compared to Col (Fig. 8E). ZAT6 was proposed to positively modulate biotic and abiotic stress tolerance (Shi et al., 2014), and ZAT10 is involved in APX2 induction in response to excess light (Li et al., 2009). Moreover, overexpression of ZAT10 resulted in enhanced tolerance to photoinhibitory light (Rossel et al., 2007), as well as enhanced tolerance to salinity, heat and osmotic stresses in Arabidopsis plants (Mittler et al., 2006). APX1 plays an important role in Arabidopsis tolerance to the combination of drought and heat stress (Koussevitzky et al., 2008; Zandalinas et al., 2016a). In addition, it has been reported that APX2 is induced by high light intensities and HS (Panchuk et al., 2002; Mullineaux et al., 2006), and that the induction of APX2 by excess light involved $\mathrm{H}_{2} \mathrm{O}_{2}$ 
(accumulated in response to HS and HL+HS; Fig. 7; Fryer et al., 2003; Rossel et al., 2006; Bechtold et al., 2008). The JA-dependent modulation of these transcripts in response to the combination of HL and HS could therefore be important for plant acclimation to a combination of HL+HS. Further studies are needed to shed more light on the role of each of these genes in the JA-dependent response of plants to HL+HS stress combination.

In nature, photosynthetic organisms may experience extreme changes in light intensity that are often accompanied by high temperatures. Taken together, our study reveals that a combination of HL and HS could dramatically compromise the photosynthetic capacity of plants, and that the plant hormone JA positively regulates plant responses to this stress combination.

\section{Materials and Methods}

\section{Plant material and growth conditions}

Arabidopsis thaliana Col-0 (var. Columbia-0), aos (Salk_01775C), sid2 (Salk_093400C) and aba2 (CS3835) plants were grown in peat pellets (Jiffy-7, http://www.jiffygroup.com/) at $23^{\circ} \mathrm{C}$ under long day growth conditions (12-hour light from $7 \mathrm{AM}$ to $7 \mathrm{PM} ; 50 \mu \mathrm{mol} \mathrm{m} \mathrm{m}^{-2} \mathrm{~s}^{-1} / 12$-hour dark from $7 \mathrm{PM}$ to $7 \mathrm{AM}$ ).

\section{Stress treatments}

Three different stress treatments were performed in parallel: high light, heat stresses and a combination of high light and heat stress (Supplemental Fig. S1). High light stress was applied by exposing 30-day-old plants to $600 \mu \mathrm{mol} \mathrm{m}^{-2} \mathrm{~s}^{-1}$ (Philips, F54T5/TL84/HO/ALTO) at $23^{\circ} \mathrm{C}$ for 7 hours. Heat stress was imposed by transferring 30-day-old plants to $42^{\circ} \mathrm{C}, 50 \mu \mathrm{mol} \mathrm{m} \mathrm{m}^{-2} \mathrm{~s}^{-1}$, for 7 hours. The high light stress and heat stress combination was performed by simultaneously subjecting plants to $600 \mu \mathrm{mol} \mathrm{m}{ }^{-2}$ $\mathrm{s}^{-1}$ light stress and $42^{\circ} \mathrm{C}$ for 7 hours (Supplemental Fig. S1). Control plants were maintained at $50 \mu \mathrm{mol} \mathrm{m} \mathrm{m}^{-2} \mathrm{~s}^{-1}, 23^{\circ} \mathrm{C}$. Following the stresses, plants of each treatment were divided into plants sampled for analysis as described below, or plants allowed to recover under controlled conditions until flowering time to score for survival (Supplemental Fig. S1). Twenty four hours following the stress treatments, Leaf Damage Index (LDI; Gallas 
and Waters, 2015), and PSII activity ( $\left.\Phi_{\mathrm{PSII}}, \mathrm{Fv} / \mathrm{Fm}\right)$ were also determined (Supplemental Fig. S1). All experiments were carried out at the same time of the light cycle (from 9 AM to $4 \mathrm{PM}$ ) and were repeated at least three times.

\section{Photosynthetic parameters}

Quantum yield of Photosystem II ( $\left.\Phi_{\mathrm{PSII}}\right)$ and maximum efficiency of Photosystem II (Fv/Fm) were measured using a portable fluorometer (FluorPen FP 110/S, Photon Systems Instruments, Czech Republic). Photosynthetic parameters were analyzed at two time points: immediately after the 7 hours of individual and combined stress treatments, and 24 hours following the stress treatments (recovery; Supplemental Fig. S1). Photosynthetic measurements were taken for at least 15 plants using two fully-expanded young leaves per plant for each stress treatment, and each experiment was repeated at least three times.

\section{Stomatal aperture measurements and leaf temperatures}

Stomatal aperture analyses were performed as described in (Morillon and Chrispeels, 2001; Zandalinas et al., 2016a). Briefly, two leaves per plant were cut and their lower surface was immediately stuck to a microspore slide with a medical adhesive (Hollister, Libertyville, IL, USA). The leaf was removed and the slides were washed with distilled water. The lower epidermis of the leaf stuck to the slide was visualized under the microscope and stomatal images acquired. Measurements of stomatal aperture were performed with the imaging software ImageJ. At least 600 stomata were measured in 15 plants for each treatment. Surface leaf temperature was measured using an infrared thermal camera (FLIR C2; Flir Systems Inc, Sweden; https://www.flir.com/). Leaf temperature was measured on two expanded young leaves per plant using at least 15 plants for each stress treatment.

\section{RWC}

Rosette relative water content (RWC) was calculated at the end of the stress treatments. Rosettes were weighed to obtain a fresh mass (Mf) immediately after the individual and 
combined stresses. Rosettes were allowed to rehydrate overnight in an opaque beaker filled with distilled water. Then, they were reweighed to obtain turgid mass (Mt). Finally, rosettes were dried at $80^{\circ} \mathrm{C}$ for $48 \mathrm{~h}$ to obtain dry mass (Md). RWC was calculated as $[(\mathrm{Mf}-\mathrm{Md}) \times(\mathrm{Mt}-\mathrm{Md})-1] \times 100$ according to (Morgan, 1984)

\section{RNA-seq analysis}

Three true leaves pooled from at least 30 different plants subjected to each of the control and stress treatments were used for each biological repeat for RNA-Seq analysis, and three biological repeats were performed. Total RNA was isolated using TRIzol reagent (Invitrogen Life Technologies) according to the manufacturer's instructions and purified using a NucleoSpin RNA Clean-up kit (Macherey-Nagel). Initial RNA sample quality, RNA quantification, preparation of RNA libraries and sequencing were performed as previously described (Zandalinas et al., 2019a). RNA library construction and sequencing were performed by the DNA Core Facility at the University of Missouri, Columbia, Missouri (USA). Single-end sequenced reads obtained from the Illumina Next-Seq 500 platform were quality-tested using FastQC v0.11.7 (Andrews, 2010) and aligned to the reference genome of Arabidopsis (genome build 10) obtained from TAIR (https://www.arab idopsis.org/) using STAR aligner v2.4.0.1 (Dobin et al., 2013). Default mapping parameters (10 mismatches/read; nine multi- mapping locations/read) were used as described in (Zandalinas et al., 2019a). The genome index was generated using the gene annotation file (gff file) obtained from TAIR (https://www.arabidopsis.org/) for the genome build 10. Differential gene expression analysis was carried out using R-based package DESeq2 v1.20.0 available in Bioconductor (Love et al., 2014). Transcripts differentially expressed compared to controls were identified by examining the difference in their abundance under the different conditions. The difference in expression was quantified in terms of the logarithm of the ratio of mean normalized counts between two conditions (log fold change) and differentially expressed transcripts were defined as those with an adjusted P-value $<0.05$ in their fold change (negative binomial Wald test followed by a Benjamini-Hochberg correction). Functional annotations and overrepresentation of GO terms $(\mathrm{P}<0.05)$ were performed using DAVID Bioinformatics Resources 6.8 (https://david.ncifcrf.gov/; Huang et al., 2009). Heat maps were generated using MeV v. 4.9.0 software (Saeed et al., 2006). 


\section{Transmission electron microscopy}

Leaves of Col plants subjected to the different stresses were analyzed by transmission electron microscopy as described in (Zandalinas et al., 2019b). Briefly, leaves were fixed in $2 \%$ paraformaldehyde, $2 \%$ glutaraldehyde in $100 \mathrm{mM}$ sodium cacodylate buffer $\mathrm{pH}=7.35$. Fixed tissues were rinsed with $100 \mathrm{mM}$ sodium cacodylate buffer, $\mathrm{pH} 7.35$ containing $130 \mathrm{mM}$ sucrose. Secondary fixation was performed using $1 \%$ osmium tetroxide (Ted Pella, Inc. Redding, California) in cacodylate buffer using a Pelco Biowave (Ted Pella, Inc. Redding, California) operated at 100 Watts for 1 min. Tissues were incubated at $4^{\circ} \mathrm{C}$ for $1 \mathrm{~h}$, then rinsed with cacodylate buffer followed by washes with distilled water. En bloc staining was performed using $1 \%$ aqueous uranyl acetate, incubated at $4^{\circ} \mathrm{C}$ overnight and then rinsed with distilled water. A graded dehydration series was performed using ethanol, transitioned into acetone, and dehydrated tissues were then infiltrated with a $1 \mathrm{v} / 1 \mathrm{v}$ of Epon and Spurr resin for $24 \mathrm{~h}$ at room temperature and polymerized at $60{ }^{\circ} \mathrm{C}$ overnight. Sections were cut to a thickness of $80 \mathrm{~nm}$ using an ultramicrotome (Ultracut UCT, Leica Microsystems, Germany) and a diamond knife (Diatome, Hatfield PA). Images were acquired with a JEOL JEM 1400 transmission electron microscope (JEOL, Peabody, MA) at $80 \mathrm{kV}$ on a Gatan Ultrascan $1000 \mathrm{CCD}$ (Gatan, Inc, Pleasanton, CA) at the Electron Microscopy Core Facility, University of Missouri. At least 100 images, each containing 2-4 chloroplasts from at least three different plants from each treatment were analyzed. Affected starch granules were defined as those containing black spots/lines and the number of thylakoids was recorded per $1 \mu \mathrm{m}$ perpendicular to thylakoid orientation in at least 50 chloroplasts per stress treatment.

\section{$\mathrm{H}_{2} \mathrm{O}_{2}$ and hormonal analysis}

Hormone extraction and analysis were carried out as described in (Durgbanshi et al., 2005) with few modifications. Briefly, $0.1 \mathrm{~g}$ of dry tissue was extracted in $2 \mathrm{~mL}$ of ultrapure water after spiking with $50 \mathrm{ng}$ of $\left[{ }^{2} \mathrm{H}_{6}\right]-\mathrm{ABA},\left[\mathrm{C}_{13}\right]-\mathrm{SA}$ and dihydrojasmonic acid in a ball mill (MillMix20, Domel, Železniki, Slovenija). Following centrifugation at $4000 \mathrm{~g}, 4^{\circ} \mathrm{C}$, for $10 \mathrm{~min}$, supernatants were recovered and $\mathrm{pH}$ adjusted to 3 with $30 \%$ acetic acid. The water extract was partitioned twice against $2 \mathrm{~mL}$ of diethyl ether and the organic layer recovered and evaporated under vacuum in a centrifuge concentrator (Speed 
Vac, Jouan, Saint Herblain Cedex, France). Once dried, the residue was resuspended in a 10:90 MeOH: $\mathrm{H}_{2} \mathrm{O}$ solution by gentle sonication. The resulting solution was filtered through $0.22 \mu \mathrm{m}$ polytetrafluoroethylene membrane syringe filters (Albet S.A., Barcelona, Spain) and directly injected into an ultra performance LC system (Acquity SDS, Waters Corp., Milford, MA, USA). Chromatographic separations were carried out on a reversed-phase $\mathrm{C} 18$ column (Gravity, $50 \times 2.1 \mathrm{~mm}, 1.8-\mu \mathrm{m}$ particle size, MachereyNagel GmbH, Germany) using a $\mathrm{MeOH}: \mathrm{H}_{2} \mathrm{O}$ (both supplemented with $0.1 \%$ acetic acid) gradient at a flow rate of $300 \mu \mathrm{L} \mathrm{min}{ }^{-1}$. Hormones were quantified with a TQS triple quadrupole mass spectrometer (Micromass, Manchester, UK).

$\mathrm{H}_{2} \mathrm{O}_{2}$ accumulation in leaves was measured using the Amplex Red Hydrogen PeroxidePeroxidase Assay kit (Molecular Probes, Invitrogen, Carlsbad, CA, USA) as described in (Suzuki et al., 2015; Zandalinas et al., 2016a). Briefly, $500 \mu \mathrm{L}$ of $50 \mathrm{mM}$ sodium phosphate buffer (pH 7.4) containing $50 \mu \mathrm{M}$ Amplex Red and $0.05 \mathrm{U} \mathrm{mL}^{-1}$ horseradish peroxidase was added to ground, frozen tissues. Samples were centrifuged at $12000 \mathrm{~g}$ for 12 min at $4^{\circ} \mathrm{C} .450 \mu \mathrm{L}$ of supernatant was transferred into fresh tubes and incubated for $30 \mathrm{~min}$ at room temperature in the dark. Absorbance at $560 \mathrm{~nm}$ was measured using a NanoDrop spectrophotometer (Thermo Scientific, Wilmington, DE, USA). The concentration of $\mathrm{H}_{2} \mathrm{O}_{2}$ in each sample was determined from a standard curve consisting of $0,0.5,1,3,6$, and $9 \mu \mathrm{M}$ of $\mathrm{H}_{2} \mathrm{O}_{2}$. Following absorbance measurement, tissue samples were dried using a speed vacuum concentrator for 90 min and $\mathrm{H}_{2} \mathrm{O}_{2}$ accumulation per gram of dry weight was calculated.

\section{Protein blot and qRT-PCR analysis}

Protein was isolated, quantified and analyzed by protein blot as previously described (Zandalinas et al., 2016a). Relative expression analysis by qRT-PCR was performed according to (Zandalinas et al., 2016b) by using CFX Connect Real-Time PCR Detection System (Bio- Rad) and gene-specific primers (Supplemental Table S9).

\section{Statistical analysis}

Results are presented as the mean \pm SD. Statistical analysis were performed by two-way ANOVA followed by a Tukey post hoc test $(\mathrm{P}<0.05)$ when a significant difference was 


\section{Chapter 4}

detected (different letters denote statistical significance at $\mathrm{P}<0.05$ ). Differentially expressed transcripts were defined as those that had a fold change with an adjusted Pvalue $<0.05$ (ANOVA, and/or negative binomial Wald test followed by a BenjaminiHochberg correction). Venn diagram overlaps was subjected to hypergeometric testing using phyper ( $\mathrm{R}$ package). For relative expression analysis by qRT-PCR, statistical analyses were performed by two-tailed Student's t-test (asterisks denote statistical significance at $\mathrm{P}<0.05$ with respect to wild type).

\section{Accession numbers}

Raw and processed RNA-Seq data files were deposited in GEO (https://www.ncbi.nlm.nih.gov/geo/) under the following accession number GSE134391.

\section{Author Contributions}

D.B. and S.I.Z. performed the research; S.I.Z., R.M., F.B.F., and A.G-C. designed and supervised the research; R.M. and A.G-C. provided laboratory infrastructure and funding; S.S. and R.K.A. performed the transcriptomic bioinformatics analysis. D.B., S.I.Z. and R.M. wrote the manuscript and prepared figures; All authors read and approved the final version of the manuscript.

\section{Funding information}

This work was supported by funding from the National Science Foundation (NSF-BSF MCB-1613462, IOS-1936590, IOS-1063287, and IOS-1932639), the Bond Life Sciences Early Concept Grant, the University of Missouri, and Ministerio de Ciencia, Innovación y Universidades (Spain, AGL2016-76574-R).

\section{Acknowledgments}

We thank the University of Missouri DNA Core Facility for providing RNAseq service and the University of Missouri Electron Microscopy Core for providing electron microscopy services. Hormone measurements were carried out at the central facilities (Servei Central d'Instrumentació Científica, SCIC) of the Universitat Jaume I. D.B. was supported "Fundación Balaguer Gonel Hermanos". 


\section{References}

Allen JF, de Paula WBM, Puthiyaveetil S, Nield J (2011) A structural phylogenetic map for chloroplast photosynthesis. Trends Plant Sci 16: 645-655

Andrews S (2010) FastQC: a quality control tool for high throughput sequence data.

Baena-González E, Aro E-M (2002) Biogenesis, assembly and turnover of photosystem II units. Philos Trans R Soc L B Biol Sci 357: 1451-1459

Bailey S, Thompson E, Nixon PJ, Horton P, Mullineaux CW, Robinson C, Mann NH (2002) A critical role for the Var2 FtsH homologue of Arabidopsis thaliana in the photosystem II repair cycle in vivo. J Biol Chem 277: 2006-2011

Bechtold U, Richard O, Zamboni A, Gapper C, Geisler M, Pogson B, Karpinski S, Mullineaux PM (2008) Impact of chloroplastic- and extracellular-sourced ROS on high light-responsive gene expression in Arabidopsis. J Exp Bot 59: 121-133

Bondada BR, Syvertsen JP (2005) Concurrent changes in net CO2 assimilation and chloroplast ultrastructure in nitrogen deficient citrus leaves. Environ Exp Bot 54: 41-48

Chehab EW, Yao C, Henderson Z, Kim S, Braam J (2012) Arabidopsis Touch-Induced Morphogenesis Is Jasmonate Mediated and Protects against Pests. Curr Biol 22: 701-706 Choudhury FK, Rivero RM, Blumwald E, Mittler R (2017) Reactive oxygen species, abiotic stress and stress combination. Plant J 90: 856-867

Dar TA, Uddin M, Khan MMA, Hakeem KR, Jaleel H (2015) Jasmonates counter plant stress: A Review. Environ Exp Bot 115: 49-57

Devireddy AR, Zandalinas SI, Gómez-Cadenas A, Blumwald E, Mittler R (2018) Coordinating the overall stomatal response of plants: Rapid leaf-to-leaf communication during light stress. Sci Signal 11: 518

Dobin A, Davis CA, Schlesinger F, Drenkow J, Zaleski C, Jha S, Batut P, Chaisson M, Gingeras TR (2013) STAR: ultrafast universal RNA-seq aligner. Bioinformatics 29: 1521

Dogra V, Duan J, Lee KP, Kim C (2019) Impaired PSII proteostasis triggers a UPR-like response in the var2 mutant of Arabidopsis. J Exp Bot 70: 3075-3088 
Durgbanshi A, Arbona V, Pozo O, Miersch O, Sancho J V, Gómez-Cadenas A (2005) Simultaneous determination of multiple phytohormones in plant extracts by liquid chromatography-electrospray tandem mass spectrometry. J Agric Food Chem 53: 84378442

Edelman M, Mattoo AK (2008) D1-protein dynamics in photosystem II: the lingering enigma. Photosynth Res 98: 609-620

Farmer EE, Goossens A (2019) Jasmonates: what ALLENE OXIDE SYNTHASE does for plants. J Exp Bot 70: 3373-3378

Flexas J, Bota J, Escalona JM, Sampol B, Medrano H (2002) Effects of drought on photosynthesis in grapevines under field conditions: an evaluation of stomatal and mesophyll limitations. Funct Plant Biol 29: 461-471

Fryer MJ, Ball L, Oxborough K, Karpinski S, Mullineaux PM, Baker NR (2003) Control of Ascorbate Peroxidase 2 expression by hydrogen peroxide and leaf water status during excess light stress reveals a functional organisation of Arabidopsis leaves. Plant $\mathbf{J} 33$ : $691-705$

Gallas G, Waters ER (2015) Boechera Species Exhibit Species-Specific Responses to Combined Heat and High Light Stress. PLoS One 10: e0129041

Gasperini D, Chételat A, Acosta IF, Goossens J, Pauwels L, Goossens A, Dreos R, Alfonso E, Farmer EE (2015) Multilayered Organization of Jasmonate Signalling in the Regulation of Root Growth. PLoS Genet 11: e1005300

Hewezi T, Léger M, Gentzbittel L (2008) A comprehensive analysis of the combined effects of high light and high temperature stresses on gene expression in sunflower. Ann Bot 102: $127-140$

Hickman R, Van Verk MC, Van Dijken AJH, Mendes MP, Vroegop-Vos IA, Caarls L, Steenbergen M, Van der Nagel I, Wesselink GJ, Jironkin A, et al (2017) Architecture and dynamics of the jasmonic acid gene regulatory network. Plant Cell 29: 2086-2105

Hu Y, Jiang L, Wang F, Yu D (2013) Jasmonate regulates the INDUCER OF CBF EXPRESSION-C-REPEAT BINDING FACTOR/DRE BINDING FACTOR1 cascade and freezing tolerance in Arabidopsis. Plant Cell 25: 2907-2924 
Huang DW, Sherman BT, Lempicki RA (2009) Systematic and integrative analysis of large gene lists using DAVID bioinformatics resources. Nat Protoc 4: 44-57

Järvi S, Suorsa M, Aro E-M (2015) Photosystem II repair in plant chloroplasts Regulation, assisting proteins and shared components with photosystem II biogenesis. Biochim Biophys Acta - Bioenerg 1847: 900-909

Kazan K (2015) Diverse roles of jasmonates and ethylene in abiotic stress tolerance. Trends Plant Sci 20: 219-229

Koussevitzky S, Suzuki N, Huntington S, Armijo L, Sha W, Cortes D, Shulaev V, Mittler R (2008) Ascorbate peroxidase 1 plays a key role in the response of Arabidopsis thaliana to stress combination. J Biol Chem 283: 34197-34203

Li Z, Wakao S, Fischer BB, Niyogi KK (2009) Sensing and Responding to Excess Light. Annu Rev Plant Biol 60: 239-260

Liu J, Last RL (2017) A chloroplast thylakoid lumen protein is required for proper photosynthetic acclimation of plants under fluctuating light environments. Proc Natl Acad Sci U S A 114: 8110-8117

Love MI, Huber W, Anders S (2014) Moderated estimation of fold change and dispersion for RNA-seq data with DESeq2. Genome Biol 15: 550

Lu Y (2016) Identification and roles of Photosystem II assembly, stability, and repair factors in Arabidopsis. Front Plant Sci 7: 168

Mathur S, Agrawal D, Jajoo A (2014) Photosynthesis: Response to high temperature stress. J Photochem Photobiol B Biol 137: 116-126

Mittler R (2006) Abiotic stress, the field environment and stress combination. Trends Plant Sci 11: 15-19

Mittler R, Kim Y, Song L, Coutu J, Coutu A, Ciftci-Yilmaz S, Lee H, Stevenson B, Zhu $\mathrm{J}-\mathrm{K}$ (2006) Gain- and loss-of-function mutations in Zat10 enhance the tolerance of plants to abiotic stress. FEBS Lett 580: 6537-6542

Morgan JA (1984) Interaction of water supply and N in wheat. Plant Physiol 76: 112-117 
Morillon RL, Chrispeels MJ (2001) The role of ABA and the transpiration stream in the regulation of the osmotic water permeability of leaf cells. Proc Natl Acad Sci 98: 1413814143

Mullineaux PM, Karpinski S, Baker NR (2006) Spatial dependence for hydrogen peroxide-directed signaling in light-stressed plants. Plant Physiol 141: 346-350

Murata N, Takahashi S, Nishiyama Y, Allakhverdiev SI (2007) Photoinhibition of photosystem II under environmental stress. Biochim Biophys Acta - Bioenerg 1767: 414421

Nishiyama Y, Allakhverdiev SI, Murata N (2006) A new paradigm for the action of reactive oxygen species in the photoinhibition of photosystem II. Biochim Biophys Acta 1757: 742-749

Ort DR (2001) When there is too much light. Plant Physiol 125: 29-32

Panchuk II, Volkov RA, Schö F (2002) Heat Stress-and Heat Shock Transcription FactorDependent Expression and Activity of Ascorbate Peroxidase in Arabidopsis. Plant Physiol 129: 838-853

Park J-H, Halitschke R, Kim HB, Baldwin IT, Feldmann KA, Feyereisen R (2002) A knock-out mutation in allene oxide synthase results in male sterility and defective wound signal transduction in Arabidopsis due to a block in jasmonic acid biosynthesis. Plant $\mathbf{J}$ 31: $1-12$

Peleg Z, Blumwald E (2011) Hormone balance and abiotic stress tolerance in crop plants. Curr Opin Plant Biol 14: 290-295

Pospíšil P (2016) Production of Reactive Oxygen Species by Photosystem II as a Response to Light and Temperature Stress. Front Plant Sci 7: 1950

Rizhsky L, Liang H, Mittler R (2002) The combined effect of drought stress and heat shock on gene expression in tobacco. Plant Physiol 130: 1143-1151

Rizhsky L, Liang H, Shuman J, Shulaev V, Davletova S, Mittler R (2004) When defense pathways collide. The response of Arabidopsis to a combination of drought and heat stress. Plant Physiol 134: 1683-1696 
Rossel JB, Walter PB, Hendrickson L, Chow WS, Poole A, Mullineaux PM, Pogson BJ (2006) A mutation affecting ASCORBATE PEROXIDASE 2 gene expression reveals a link between responses to high light and drought tolerance. Plant, Cell Environ 29: 269281

Rossel JB, Wilson PB, Hussain D, Woo NS, Gordon MJ, Mewett OP, Howell KA, Whelan J, Kazan K, Pogson BJ (2007) Systemic and Intracellular Responses to Photooxidative Stress in Arabidopsis. Plant Cell 19: 4091-4110

Ruban A V. (2015) Evolution under the sun: optimizing light harvesting in photosynthesis. J Exp Bot 66: 7-23

Ruban A V (2009) Plants in light. Commun Integr Biol 2: 50

Saeed AI, Bhagabati NK, Braisted JC, Liang W, Sharov V, Howe EA, Li J, Thiagarajan M, White JA, Quackenbush J (2006) TM4 Microarray Software Suite. Methods Enzymol 411: $134-193$

Shi H, Wang X, Ye T, Chen F, Deng J, Yang P, Zhang Y, Chan Z (2014) The cysteine2/histidine2-type transcription factor ZINC FINGER OF ARABIDOPSIS THALIANA6 modulates biotic and abiotic stress responses by activating salicylic acidrelated genes and C-REPEAT-BINDING FACTOR genes in Arabidopsis. Plant Physiol 165: $1367-1379$

Spicher L, Almeida J, Gutbrod K, Pipitone R, Dörmann P, Glauser G, Rossi M, Kessler F (2017) Essential role for phytol kinase and tocopherol in tolerance to combined light and temperature stress in tomato. J Exp Bot 68: 5845-5856

Su X, Wu S, Yang L, Xue R, Li H, Wang Y, Zhao H (2014) Exogenous progesterone alleviates heat and high light stress-induced inactivation of photosystem II in wheat by enhancing antioxidant defense and D1 protein stability. Plant Growth Regul 74: 311-318

Suzuki N, Devireddy AR, Inupakutika MA, Baxter A, Miller G, Song L, Shulaev E, Azad RK, Shulaev V, Mittler R (2015) Ultra-fast alterations in mRNA levels uncover multiple players in light stress acclimation in plants. Plant J 84: 760-772

Suzuki N, Rivero RM, Shulaev V, Blumwald E, Mittler R (2014) Abiotic and biotic stress combinations. New Phytol 203: 32-43 
Szymańska R, Ślesak I, Orzechowska A, Kruk J (2017) Physiological and biochemical responses to high light and temperature stress in plants. Environ Exp Bot 139: 165-177

Takahashi S, Murata N (2008) How do environmental stresses accelerate photoinhibition? Trends Plant Sci 13: 178-182

Teskey R, Wertin T, Bauweraerts I, Ameye M, Mcguire MA, Steppe K (2015) Responses of tree species to heat waves and extreme heat events. Plant Cell Environ 38: 1699-1712 Urban J, Ingwers MW, McGuire MA, Teskey RO (2017) Increase in leaf temperature opens stomata and decouples net photosynthesis from stomatal conductance in Pinus taeda and Populus deltoides x nigra. J Exp Bot 68: 1757-1767

Wasternack C (2015) How Jasmonates earned their laurels: Past and present. J Plant Growth Regul 34: 761-794

Wasternack C, Hause B (2013) Jasmonates: biosynthesis, perception, signal transduction and action in plant stress response, growth and development. An update to the 2007 review in Annals of Botany. Ann Bot 111: 1021-1058

Yamamoto Y, Aminaka R, Yoshioka M, Khatoon M, Komayama K, Takenaka D, Yamashita A, Nijo N, Inagawa K, Morita N, et al (2008) Quality control of photosystem II: impact of light and heat stresses. Photosynth Res 98: 589-608

Zandalinas SI, Balfagón D, Arbona V, Gómez-Cadenas A, Inupakutika MA, Mittler R, Raines C (2016a) ABA is required for the accumulation of APX1 and MBF1c during a combination of water deficit and heat stress. J Exp Bot 67: 5381-5390

Zandalinas SI, Rivero RM, Martínez V, Gómez-Cadenas A, Arbona V (2016b) Tolerance of citrus plants to the combination of high temperatures and drought is associated to the increase in transpiration modulated by a reduction in abscisic acid levels. BMC Plant Biol 16: 105

Zandalinas SI, Sengupta S, Burks D, Azad RK, Mittler R (2019a) Identification and characterization of a core set of ROS wave-associated transcripts involved in the systemic acquired acclimation response of Arabidopsis to excess light. Plant J 98: 126-141

Zandalinas SI, Song L, Sengupta S, McInturf S, Grant DG, Castro-Guerrero NA, Burks D, Azad RK, Mendoza-Cozatl DG, Nechushtai R, et al (2019b) Disruption of iron-sulfur metabolism in the chloroplast impairs leaf iron sensing and homeostasis. Plant $\mathbf{J}$ subitted 


\section{Supplementary material}

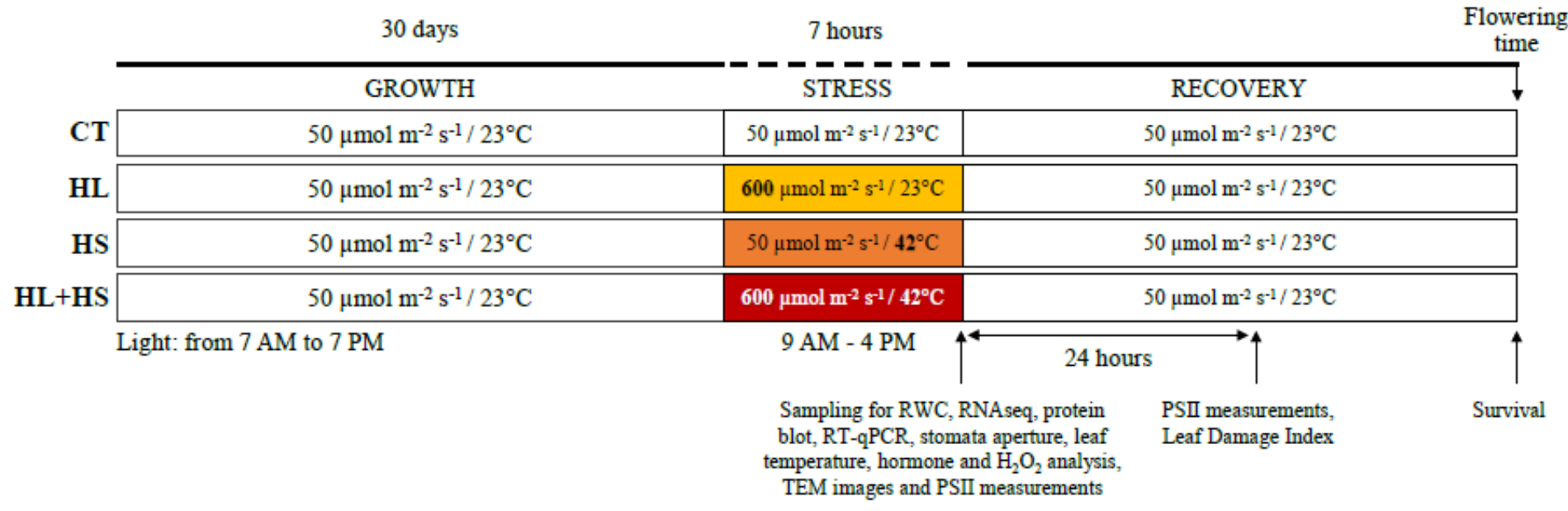

Fig. S1. The experimental design used for the study of high light (HL, yellow), heat stress (HS, orange) and a combination of high light and heat stress (HL+HS, red) using Arabidopsis plants. $\mathrm{HL}$ was applied by exposing 30-day-old plants to $600 \mu \mathrm{mol} \mathrm{m}^{-2} \mathrm{~s}^{-1}$ (Philips, F54T5/TL84/HO/ALTO) at $23^{\circ} \mathrm{C}$. HS was applied by transferring 30-day-old plants to $42^{\circ} \mathrm{C}$. $\mathrm{HL}+\mathrm{HS}$ was performed by simultaneously subjecting plants to $600 \mu \mathrm{mol} \mathrm{m}^{-2} \mathrm{~s}^{-1}$ light stress and $42^{\circ} \mathrm{C}$. Stress treatments were performed in parallel during 7 hours. Following the stress treatments, plants were divided into plants sampled for analysis (Relative water content, RNASeq, protein blot analysis, stomatal aperture, leaf temperature, hormonal and hydrogen peroxide measurements, transmission electron microscopy and PSII measurements), or plants allowed to recover under controlled conditions until flowering time to score for survival. 24 hours following the stress treatments, PSII measurements, as well as Leaf Damage Index (LDI) were also determined. All experiments were carried out at the same time of the light cycle (from 9 AM to 4 $\mathrm{PM}$ ) and were repeated at least three times using Col, aos, sid 2 and $a b a 2$ plants. RWC, relative water content; TEM, transmission electron microscopy; PSII, photosystem II. 

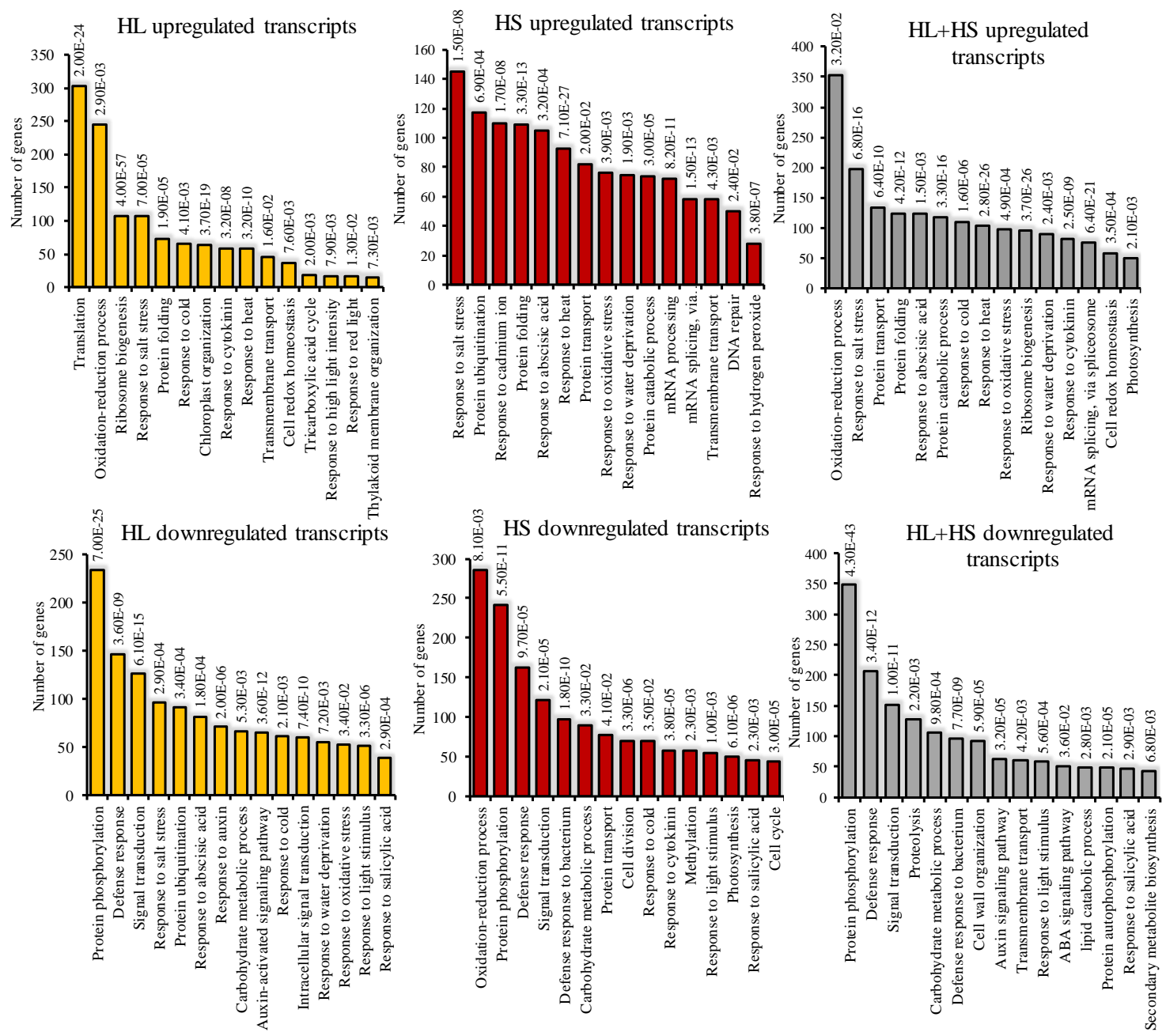

Fig. S2. Gene Ontology (GO) annotation of transcripts specifically upregulated (top) or downregulated (bottom) in leaves of Col plants subjected to high light (HL), heat stress (HS) and a combination of high light and heat stress $(\mathrm{HL}+\mathrm{HS})$. Numbers above each bar represent $\mathrm{P}$ value for statistical significance. 

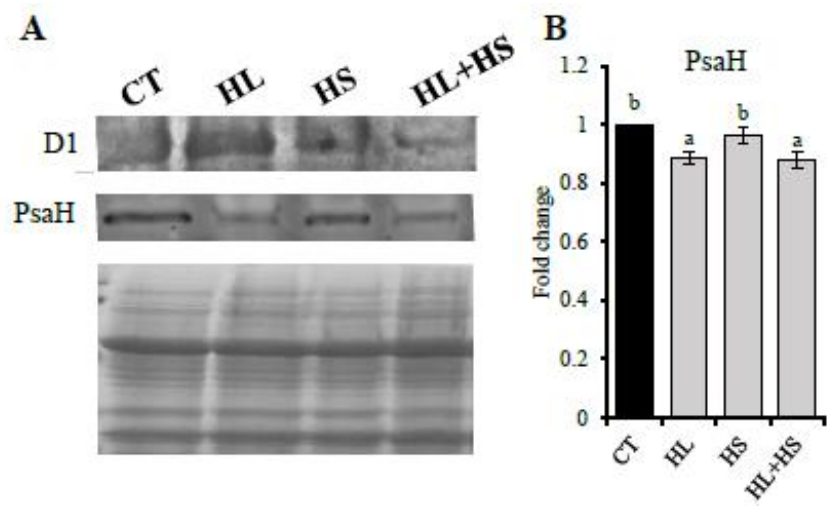

Supplemental Figure S3. Accumulation of D1 and PsaH in Col plants subjected to high light (HL), heat stress (HS), and combined high light and heat stress (HL+HS). (A) Representative images of protein blots for D1 protein (top), and PsaH (middle), as well as a loading control (Coomassie-stained gel; bottom) of Col plants subjected to the different stresses. (B) Quantification bar graph showing the accumulation of PsaH in response to the different stresses, relative to control conditions. Error bars represent SD $(\mathrm{N}=3)$. Different letters denote statistical significance at $\mathrm{P}<0.05$ (ANOVA). CT, control. 


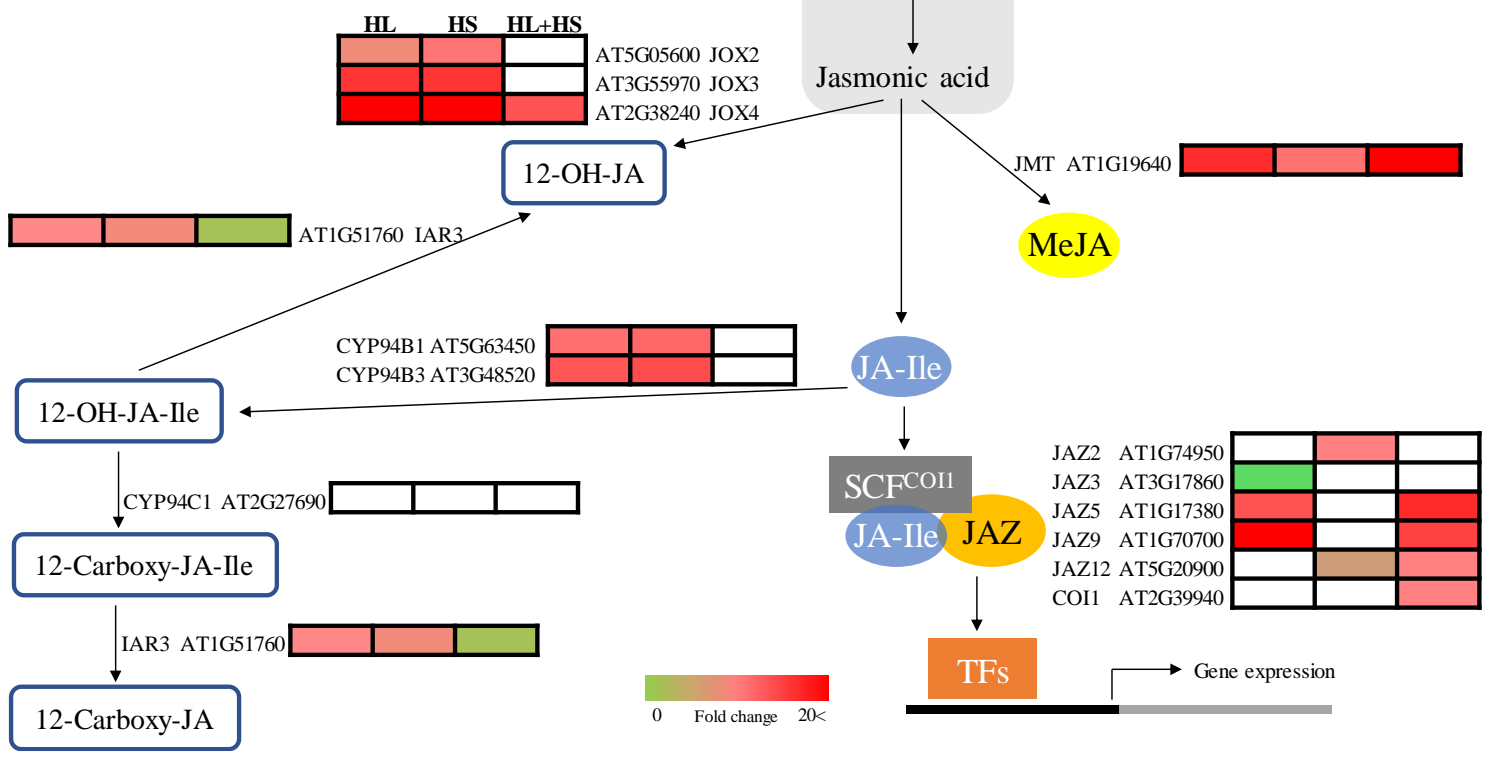

Fig. S4. Heat maps showing significantly upregulated or downregulated transcripts involved in JA biosynthesis and signaling in Col plants subjected to high light (HL), heat stress (HS) and the combination of high light and heat stress (HL+HS). 
A

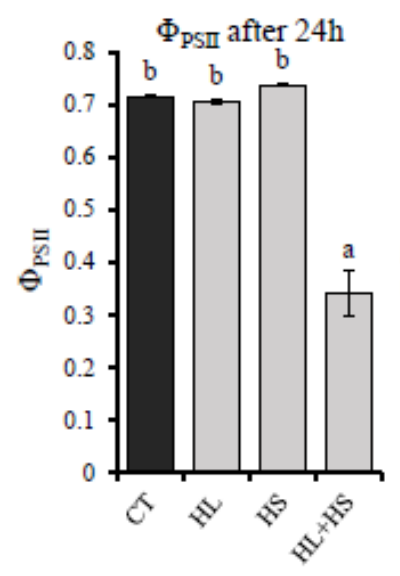

B

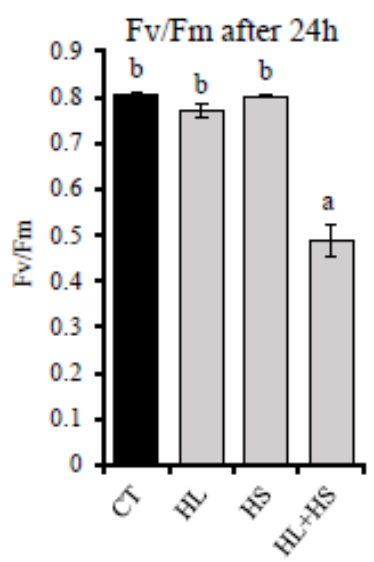

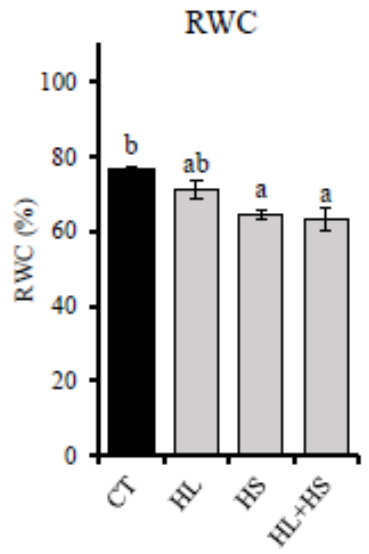

Fig. S5. PSII performance and RWC of JA-deficient aos plants subjected to high light (HL), heat stress (HS) and a combination of high light and heat stress (HL+HS). (A) Quantum yield of PSII $\left(\Phi_{\mathrm{PSII}}\right)$ and maximum efficiency of PSII (Fv/Fm) after $24 \mathrm{~h}$ of stress imposition in aos plants under control conditions. (B) Leaf RWC of aos plants subjected to the different stresses. Different letters denote statistical significance at $\mathrm{P}<0.05$. CT, control. 
A

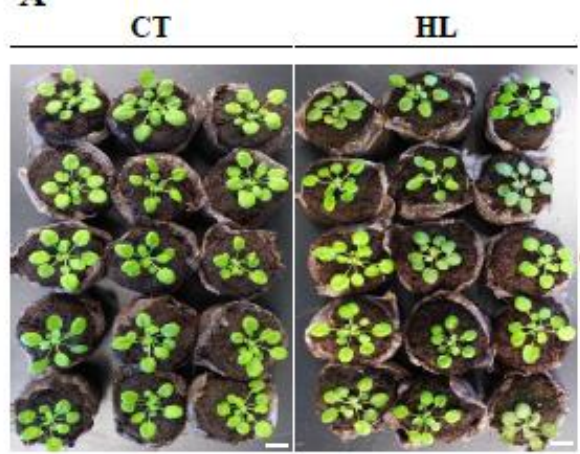

HS

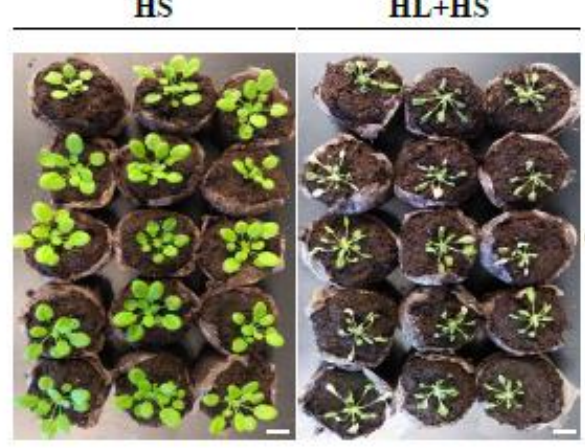

B

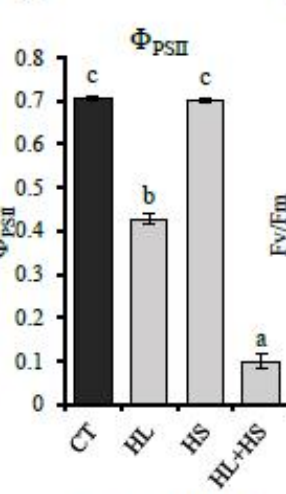

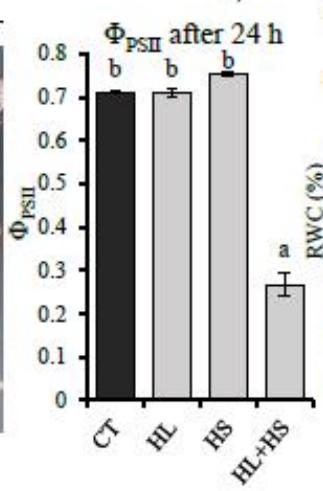

C

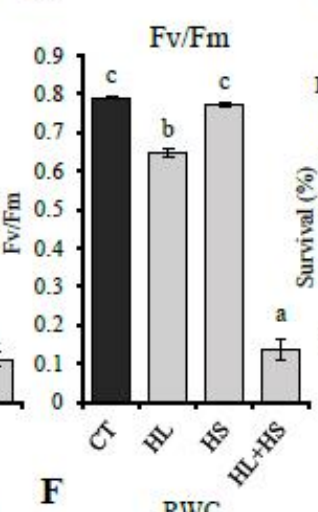

D

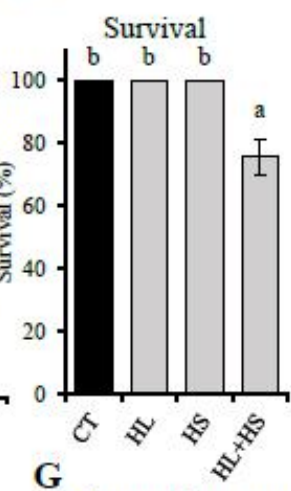

Stomatal aperture

\section{$\mathbf{E}$}

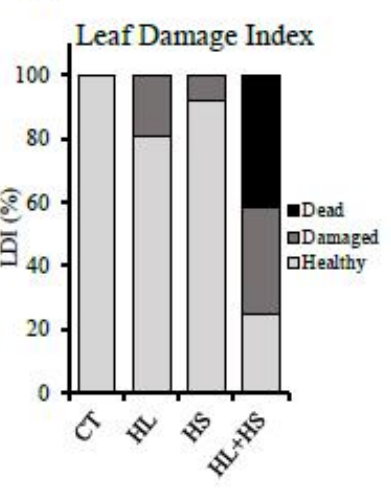

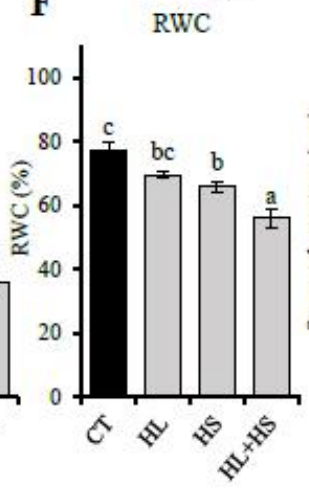

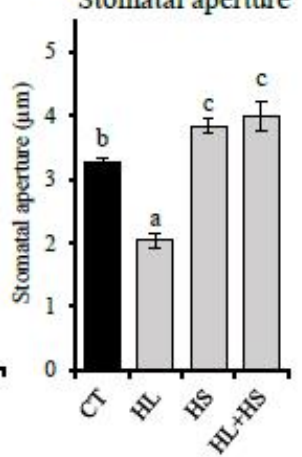

Fig. S6. PSII performance, survival rate, Leaf Damage Index, RWC and stomatal responses rate of SA-deficient sid2 plants subjected to high light (HL), heat stress (HS) and a combination of high light and heat stress (HL+HS). (A) Representative images of sid2 plants subjected to the different stresses. (B) Quantum yield of PSII ( $\left.\Phi_{\text {PSII }}\right)$ immediately after the application of each stress (top) and after $24 \mathrm{~h}$ of stress imposition in plants under control conditions (bottom). (C) Maximum efficiency of PSII (Fv/Fm) immediately after the application of each stress in sid2 plants subjected to the different stresses. (D) Survival rate of sid2 plants subjected to the different stresses. (E) Leaf Damage Index showing the appearance of sid2 plants in response to each stress. (F) Leaf RWC of sid2 plants subjected to the different stresses. (G) Stomatal aperture of sid2 plants subjected to the different stresses. Different letters denote statistical significance at $\mathrm{P}<$ 0.05. Scale bar in A indicates $1 \mathrm{~cm}$. CT, control. 

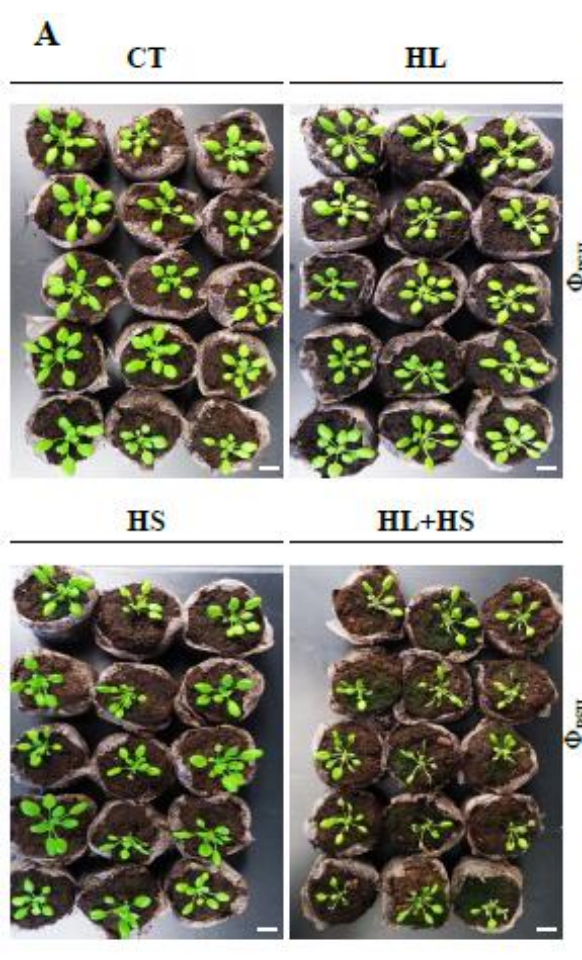
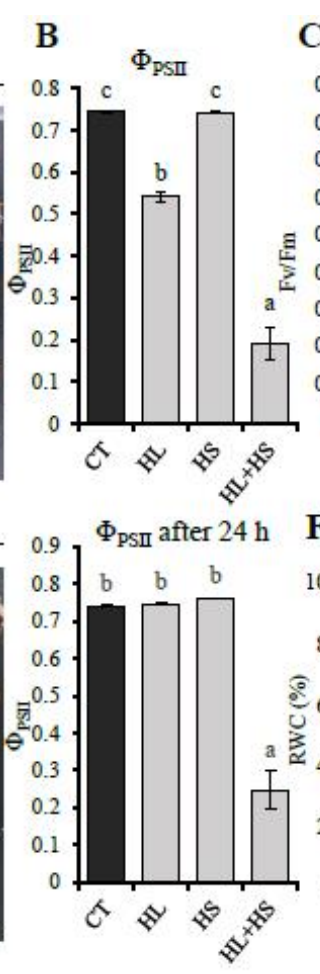
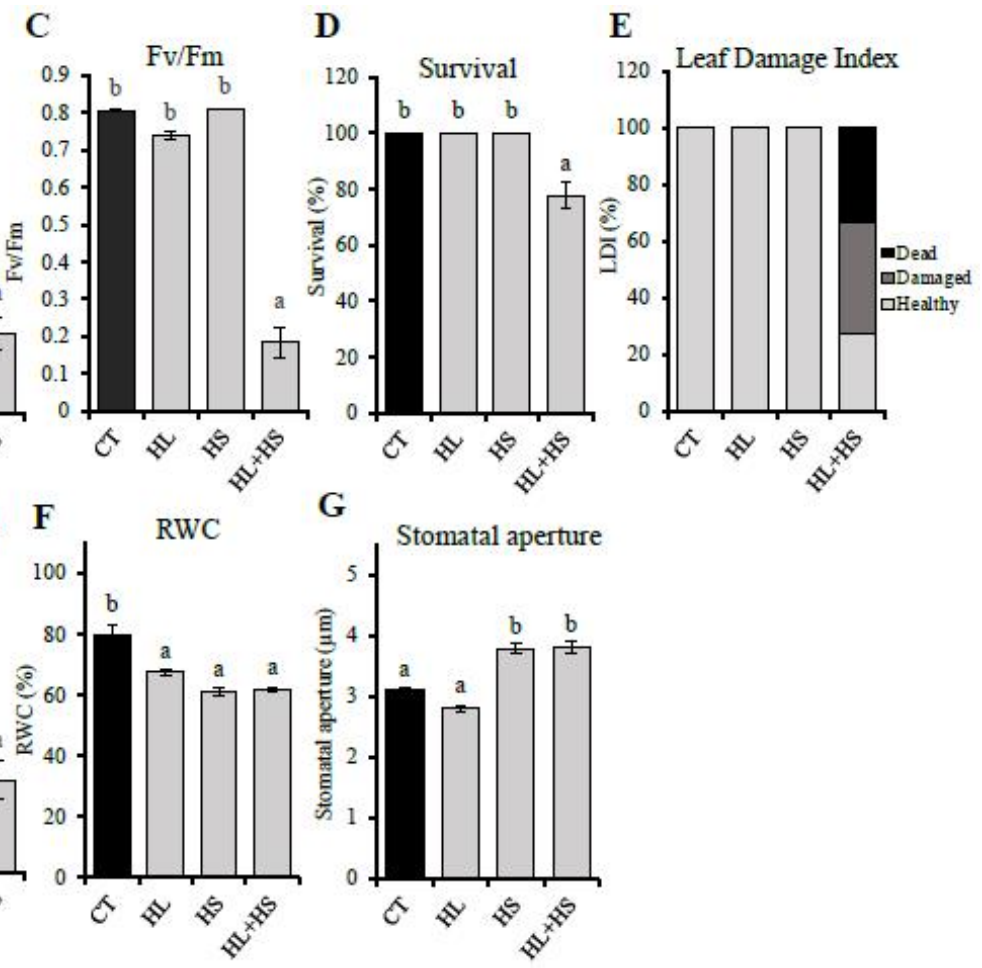

Fig. S7. PSII performance, survival rate, Leaf Damage Index, RWC and stomatal responses rate of ABA-deficient $a b a 2$ plants subjected to high light (HL), heat stress (HS) and a combination of high light and heat stress (HL+HS). (A) Representative images of $a b a 2$ plants subjected to the different stresses. (B) Quantum yield of PSII ( $\left.\Phi_{\text {PSII }}\right)$ immediately after the application of each stress (top) and after $24 \mathrm{~h}$ of stress imposition in plants under control conditions (bottom). (C) Maximum efficiency of PSII (Fv/Fm) immediately after the application of each stress in $a b a 2$ plants subjected to the different stresses. (D) Survival rate of $a b a 2$ plants subjected to the different stresses. (E) Leaf Damage Index showing the appearance of $a b a 2$ plants in response to each stress. (F) Leaf RWC of $a b a 2$ plants subjected to the different stresses. (G) Stomatal aperture of $a b a 2$ plants subjected to the different stresses. Different letters denote statistical significance at $\mathrm{P}<$ 0.05. Scale bar in A indicates $1 \mathrm{~cm}$. CT, control.

Table S1-S7. Transcripts significantly up or downregulated $(\mathrm{P}<0.05)$ in Col plants subjected to HL, HS and HL+HS. Available online:

http://www.plantphysiol.org/content/181/4/1668/tab-figures-data 
General Discussion 

Climate change and global warming are changing environmental conditions that challenge plants, animals and other organisms. Average surface temperature is rising; atmospheric $\mathrm{CO}_{2}$ concentration significantly grew up in the last two decades and was accompanied by other greenhouse gases such as methane, nitrous oxide and ozone; arable areas affected by drought are increasing and precipitation patterns are changing around the world ( $\mathrm{Li}$ et al. 2009; Zhao et al. 2017; Zandalinas et al. 2018; IPCC 2019, http://www.ipcc.ch/). Environmental conditions caused by climate change are challenging optimal development of plants and crop production is compromised. In addition, some of the environmental changes associated to the climate change impact Therefore, it is needed to develop new crops capable to face abiotic stress factors in a warmer environment and maintain their productivity when growing under stress combination conditions (Mittler and Blumwald, 2010; Suzuki et al., 2014a; Zandalinas et al., 2018). To respond to these detrimental situations, plants, as sensitive organisms, modify their gene expression, metabolism and physiology to acclimate to the new conditions. However, the acclimation process has an energetic cost that is reflected in plant growth and production (Koyro et al. 2012). When acclimation to harsh environmental conditions cannot be successfully achieved, plants may suffer important damage and even die.

Abiotic stress conditions such as drought, heat, cold or light excess are important detrimental factors that impact plant growth, productivity and survival (Calanca, 2017). In the field, these abiotic stress factors usually occur at the same time creating a new stress to plants different from the individual adverse conditions. Therefore, plant acclimation responses to stress combinations are unique and cannot be predicted by the sum of responses to the individual stresses (Mittler, 2006). In this scenario, it seems necessary to carry out research taking into consideration how two or more stresses coincident on time affect plant development. During the last years, several studies dealing with the effect of stress combination on different plant species have been published and it has been demonstrated that the effect of the stress combination on plants is different from that produced by individual stress factors (Suzuki et al., 2014b; Martinez et al., 2018; Zandalinas et al., 2018; Fábián et al., 2019; Jumrani and Bhatia, 2019; Mahalingam and Bregitzer, 2019; Zandalinas et al., 2019).

Our research conducted in Citrus and Arabidopsis is aimed to decipher the acclimation responses of plants to different stress factors applied in combination with high 
temperatures. In the first and second chapter we worked with two citrus rootstock genotypes, Carrizo citrange and Cleopatra mandarin. Previous studies have demonstrated their different tolerance to abiotic stress (López-Climent et al., 2008; Arbona et al., 2009; Argamasilla et al., 2014). Therefore, Cleopatra is more tolerant to drought and salinity due to the ability to regulate water relations by lower transpiration rate and closing stomata (López-Climent et al., 2008), whereas Carrizo is more tolerant to soil flooding due to the ability to maintain gas exchange parameters and chlorophyll fluorescence as control values (Arbona et al. 2009; Argamasilla et al. 2014). Also, it was shown that Carrizo is more tolerant to drought and heat stress combination than Cleopatra due, in part, to a better stomatal regulation that allowed the plant to keep a high transpiration rate and reduce leaf temperature (Zandalinas et al., 2016b). In the third chapter, we used Carrizo citrange genotype, with a better performance under high temperatures (Zandalinas et al., 2016b; Zandalinas et al., 2017), to study the effects of mechanical wounding and soil salinity in combination with high temperatures, two frequent stress conditions in citriculture. Finally, in chapter 4, we performed a study in Arabidopsis thaliana about plant responses to high light intensity and heat stress. Although the combination of high light intensity and high temperatures is a common phenomenon in nature, the knowledge about its impact in plants is scarce. The convenience of using a model plant such as Arabidopsis allowed us to study physiological, transcriptomic and proteomic alterations caused by high light and heat stress combination. The information obtained, therefore, could be transferred to crops in future experiments with citrus or other staple crops.

Environmental changes and stress factors can also cause metabolic imbalances in cells that induce oxidative stress because of the generation of reactive oxygen species (ROS). Despite its signaling function (Baxter et al. 2014; Mittler et al. 2016), ROS are also toxic when over accumulate, causing cellular damage and photosynthesis inhibition (Choudhury et al., 2017). Antioxidant cell machinery, including antioxidant enzymes and molecules, is in charge of ROS detoxifying to prevent damage. Superoxide dismutase (SOD) enzyme is the first level of defense against super oxide radicals. SOD catalyzes $\mathrm{O}_{2}{ }^{\bullet-}$ to form $\mathrm{H}_{2} \mathrm{O}_{2}$, which is removed by ascorbate peroxidase (APX) and catalase (CAT) activities. APX reduces $\mathrm{H}_{2} \mathrm{O}_{2}$ using AsA as the electron donor and the balance between GSH and oxidized glutathione (GSSG) is critical for maintaining a favorable redox status for the detoxification of $\mathrm{H}_{2} \mathrm{O}_{2}$. In addition, glutathione reductase (GR), the rate-limiting 
enzyme of AsA-GSH cycle, keeps the GSH/GSSG ratio favorable for ascorbate reduction (Foyer and Noctor, 2005). The ability of plants to balance ROS production and scavenging has been correlated with higher tolerance to different environmental stresses (Arbona et al., 2008; Hossain et al., 2009; Martinez et al., 2016), and specifically to stress combination (Koussevitzky et al., 2008; Suzuki et al., 2014a). According to the data collected in chapter 1 and 2, Carrizo citrange genotype is more tolerant to drought and heat stress combination than Cleopatra mandarin due to a higher efficiency of the antioxidant machinery and an increased accumulation of key proteins involved in plant acclimation to stress. Carrizo plants showed an active antioxidant system in which not only antioxidant enzymes were more active but also GSH/GSSH ratio was constant. Therefore, Carrizo plants showed a higher SOD activity than Cleopatra plants under both control and stress conditions. Furthermore, APX and Catalase activity increased in Carrizo after combination of drought and heat stress while in Cleopatra the activity remained constant or decreased under these conditions. Also, transcript analyses indicated a higher relative gene expression of CAT and APX in Carrizo respect to Cleopatra. These data correlate with the oxidative damage, estimated by MDA accumulation, observed in both genotypes under drought and heat stress combination. Although both genotypes significantly accumulated MDA under stress combination respect to control and single drought or heat stress, levels in Cleopatra plants were higher than in Carrizo ones. In addition, the specific accumulation of APX in Carrizo under stress combination indicates that the antioxidant machinery of this genotype is more activated than in Cleopatra. Other proteins can protect plants from cell damage derived from ROS accumulation and high temperatures. In this sense, HSP101 protein, a chaperone that confers thermotolerance (Queitsch et al., 2000; Wu et al., 2013), significantly accumulated in both citrus genotypes in response to high temperatures, applied alone or in combination with drought stress. However, its content in Carrizo was higher than in Cleopatra, suggesting a possible role of this protein in the higher tolerance of Carrizo plants to high temperatures. Finally, the study of molecular responses at different levels (gene expression, protein accumulation and enzymatic activity) gives us valuable information to understand the mechanism of citrus plant to cope with stress combination.

Zandalinas et al. (2016b) demonstrated that Cleopatra is sensitive to drought and heat stress combination, since plants of this genotype cultivated under stress combination suffered an important oxidative damage and a strong reduction of the photosynthesis rate. 
The higher tolerance of Carrizo was related to its ability to modulate stomatal closure and to maintain high transpiration rates (in contrast to Cleopatra). Therefore, responses such as leaf cooling by keeping open stomata and high transpiration rate, efficient activation of the antioxidant cell machinery and the accumulation of certain proteins such as HSP101 can be determinant for citrus plants to cope with drought and heat stress factors. Therefore, we conclude that Carrizo citrange is more adapted to drought and heat stress combination due to the adequate physiological and molecular responses.

In chapter 3 we evaluate the responses of Carrizo to other abiotic stress factors that could affect plants in combination with high temperatures. Stress combinations of wounding or salinity combined with heat stress changed Carrizo responses compared to the individual stresses. For example, high temperatures modified plant responses to mechanical wounding in lettuce (Saltveit, 2000). After wounding, an increase of PAL activity and a three-fold increase of phenolic compounds was observed in lettuce leaves. However, when wounding was applied at high temperatures, PAL activity and phenolic leaf content remained as control values, and other acclimation genes were upregulated, including heat shock proteins (Saltveit, 2000). Similarly, heat stress changed the metabolic responses of tomato plants to salt stress (Rivero et al., 2014). In this study, it was shown that heat stress provided protection to tomato plants from salt stress. Stress combination induced a specific accumulation of trehalose and glycine betaine that was not present under salt stress alone. The increase of these compounds was linked to the maintenance of the $\mathrm{Na}^{+} / \mathrm{K}^{+}$ratio (despite salt stress effect) and, therefore, to a better cell water status and photosynthesis compared to plants subjected only to salt stress (Rivero et al., 2014). In Carrizo citrange, after mechanical wounding, leaf JA content increased concomitantly to the upregulation of the JA-responsive gene $C s V P 2$. The biosynthesis and accumulation of Jasmonates as well as their signaling role in response to wounding has been widely studied in various species (Wasternack et al., 2006; Wasternack and Hause, 2013). However, the increase in JA levels caused by wounding was reduced at high temperatures, as well as $C s V P 2$ expression. Instead of JA, OPDA accumulated significantly in wounded plants under stress combination. Furthermore, this switch in metabolite accumulation was accompanied by a reduction in the stomatal aperture to levels lower than control. Previous studies have demonstrated that OPDA can induce stomatal closure and trigger a signal in guard cells independently from JA (Murata et al. 2015). Our results could indicate a similar role for OPDA as a regulator of stomatal aperture in citrus plants under wounding 
combined with heat stress. On the other hand, salt stress induced an over-accumulation of ABA leaf content in Carrizo plants that correlated with reductions of stomatal conductance and leaf transpiration. ABA has been demonstrated to be a key hormone for the acclimation to salt stress (Gómez-Cadenas et al., 2015). In citrus, it is known that the damage caused by salinity is due to chloride ion $\left(\mathrm{Cl}^{-}\right)$accumulation in leaves and the capability of citrus plants to tolerate salt stress is linked to the ability to exclude this ion from the leaf cells (Moya et al., 2002). $\mathrm{Cl}^{-}$absorption is produced together with the water uptake in roots; therefore, under salt stress conditions, tolerance of citrus plants depends on the resistance of roots to $\mathrm{Cl}^{-}$(Moya et al., 2003). In addition, a study in Arabidopsis plants demonstrated that $\mathrm{ABA}$ accumulation and signaling is a key response for plant acclimation to salt and heat stress combination (Suzuki et al., 2016). In that study, it was shown that in response to this stress combination, more than $10 \%$ of the up-regulated genes were ABA-dependent and, in addition, mutants impaired in ABA biosynthesis and signaling (abal and abil, respectively) were more sensitive to this stress combination (Suzuki et al., 2016). In our work, salt stress combined with heat stress caused the highest accumulation of ABA. This hormonal burst could be directed to signal stomatal closure, abnormally opened because of high temperatures, and to trigger the upregulation of genes involved in stress acclimation. Jasmonic acid and Ja-Ile also accumulated in Carrizo leaves after salt and heat stress imposition. However, under isolated salt or heat stress conditions, levels of these metabolites did not change respect to control conditions. The specific accumulation of JA under the stress combination suggests that it could be a pivotal hormone in citrus tolerance to salt and heat stress combination. In chapter 4 , we observed similar JA and JA-Ile accumulation patterns in Arabidopsis plants under high light intensity and heat stress. In this case, the stress combination caused a specific overaccumulation of JA and JA-Ile. Furthermore, aos plants, impaired in JA biosynthesis, resulted less tolerant to the stress combination showing less survival than wild type plants. JA could trigger a molecular response to the stress combination, inducing the upregulation of acclimation genes. In this sense, as transcriptomic analyses showed that 822 JA-responsive transcripts were upregulated under the stress combination. In addition, the relative expressions of the genes ZAT10, involved in light, salinity or heat tolerance (Mittler, 2006); ZAT6, proposed to positively modulate biotic and biotic stress tolerance (Suzuki et al., 2015; Hickman et al., 2017); and APX1 and APX2, involved in plant tolerance to drought, heat or light stress (Fryer et al., 2003; Rossel et al., 2007; Koussevitzky et al., 2008; Zandalinas et al., 2016a) were lower in the aos mutant under 
stress combination respect to WT plants. Thus, the specific accumulation of JA under stress combination in both Carrizo and Arabidopsis plants suggests a possible role for JA in plant acclimation to different stress combinations involving high temperatures. JA may have a role in citrus plants modulating stomatal aperture in wounded or salt stressed plants at high temperatures, acquiring a complemental role to $\mathrm{ABA}$ or other signaling molecules (Murata et al. 2015). In response to high light and heat stress combination, JA and JA-Ile could be participating in the upregulation of genes involved in plant acclimation. In the fourth chapter, moreover, we also demonstrated that under high light and heat stress combination the expression of genes encoding proteins comprising the photosynthetic apparatus (PsbA [D1], PsbD [D2], PsbC [CP43], and PsbB [CP47]) is enhanced. Under high light conditions, reaction centers of photosystems become saturated with excitation energy that can be dangerous because it can lead to irreversible damage in the reaction centers, resulting in a decrease of the efficiency and electron transported rate (Ruban, 2015). In our study, D1 protein content declined during stress combination compared to control plants, indicating that photodamage to PSII is exceeding the biosynthesis, repair and reassembly of D1 protein (most affected PSII component by HL and HS derived damage, Murata et al. 2007; Yamamoto et al. 2008; Su et al. 2014). The damage caused to the PSII and the inability to repair it could explain that plants subjected to stress combination were unable to reestablish PSII activity after $24 \mathrm{~h}$ of the stress. In contrast, plants over accumulated D1 protein under individual high light or heat stress and, in addition, light-stressed plants were capable to restore PSII activity after $24 \mathrm{~h}$.

In summary, all the results obtained in this doctoral thesis project indicate that high temperatures change the way plants face abiotic stresses. Every abiotic stress condition at high temperatures caused a different response in plants and that responses cannot be inferred by the responses to the individual stresses. We demonstrated that the high activity of the antioxidant enzymes accompanied by a higher accumulation of APX and HSP101 proteins are key responses that can important in improving growth and survival of citrus growth under combined conditions of drought and high temperatures. In this work, a different response of citrus to wounding and high salt concentrations is observed when these stresses are in combination with high temperatures. Results indicated that jasmonates acquire a different role under these conditions and may be determinant for plant survival. Finally, we demonstrated that high light intensity causes a different hormonal and transcriptomic response in Arabidopsis when is accompanied by high 
temperatures. The ability to restore PSII damage during and after stress is a key factor to guarantee plant survival. From our data is concluded that JA is a pivotal hormone in Arabidopsis plants under high light and heat stress because of its role activating a transcriptomic response that can be determinant to the plant. In addition, JA accumulation is a specific response to the stress.

This work provides valuable information for breeding programs focused on the improvement of citrus rootstocks adapted to warmer environmental conditions. The expected increase of temperatures during the next years can change the worldwide productivity of citrus plants. Therefore, it is important to develop new rootstocks and varieties capable to withstanding stress conditions co-occurring with high temperatures. In addition, our work shows some of the main responses of plants to different stress conditions and helps to unravel plant physiological and molecular acclimation mechanisms to the stress combinations.

\section{References}

Arbona V, Hossain Z, López-Climent MF, Pérez-Clemente RM, Gómez-Cadenas A (2008) Antioxidant enzymatic activity is linked to waterlogging stress tolerance in citrus. Physiol Plant 132: 452-466

Arbona V, López-Climent MF, Pérez-Clemente RM, Gómez-Cadenas A (2009) Maintenance of a high photosynthetic performance is linked to flooding tolerance in citrus. Environ Exp Bot 66: 135-142

Argamasilla R, Gómez-Cadenas A, Arbona V (2014) Metabolic and Regulatory Responses in Citrus Rootstocks in Response to Adverse Environmental Conditions. J Plant Growth Regul 33: 169-180

Baxter A, Mittler R, Suzuki N (2014) ROS as key players in plant stress signalling. J Exp Bot 65: $1229-40$

Calanca PP (2017) Effects of Abiotic Stress in Crop Production. Quantif. Clim. Var. Adapt. Mitig. Agric. Sustain. Springer International Publishing, pp 165-180

Choudhury FK, Rivero RM, Blumwald E, Mittler R (2017) Reactive oxygen species, abiotic stress and stress combination. Plant J 90: 856-867 
Fábián A, Sáfrán E, Szabó-Eitel G, Barnabás B, Jäger K (2019) Stigma functionality and fertility are reduced by heat and drought co-stress in wheat. Front Plant Sci. doi: 10.3389/fpls.2019.00244

Foyer CH, Noctor G (2005) Redox homeostasis and antioxidant signaling: A metabolic interface between stress perception and physiological responses. Plant Cell 17: 18661875

Fryer MJ, Ball L, Oxborough K, Karpinski S, Mullineaux PM, Baker NR (2003) Control of Ascorbate Peroxidase 2 expression by hydrogen peroxide and leaf water status during excess light stress reveals a functional organisation of Arabidopsis leaves. Plant J 33: $691-705$

Gómez-Cadenas A, Vives V, Zandalinas SI, Manzi M, Sánchez-Pérez AM, PérezClemente RM, Arbona V (2015) Abscisic acid: a versatile phytohormone in plant signaling and beyond. Curr Protein Pept Sci 16: 413-434

Hickman R, Van Verk MC, Van Dijken AJH, Mendes MP, Vroegop-Vos IA, Caarls L, Steenbergen M, Van der Nagel I, Wesselink GJ, Jironkin A, et al (2017) Architecture and dynamics of the jasmonic acid gene regulatory network. Plant Cell 29: 2086-2105

Hossain Z, López-Climent MF, Arbona V, Pérez-Clemente RM, Gómez-Cadenas A (2009) Modulation of the antioxidant system in citrus under waterlogging and subsequent drainage. J Plant Physiol 166: 1391-1404

Jumrani K, Bhatia VS (2019) Interactive effect of temperature and water stress on physiological and biochemical processes in soybean. Physiol Mol Biol Plants 25: 667681

Koussevitzky S, Suzuki N, Huntington S, Armijo L, Sha W, Cortes D, Shulaev V, Mittler $\mathrm{R}$ (2008) Ascorbate peroxidase 1 plays a key role in the response of Arabidopsis thaliana to stress combination. J Biol Chem 283: 34197-203

Koyro HW, Ahmad P, Geissler N (2012) Abiotic stress responses in plants: An overview. Environ. Adapt. Stress Toler. Plants Era Clim. Chang. Springer New York, pp 1-28

Li Y, Ye W, Wang M, Yan X (2009) Climate change and drought: a risk assessment of crop-yield impacts. Clim Res 39: 31-46 
López-Climent MF, Arbona V, Pérez-Clemente RM, Gómez-Cadenas A (2008) Relationship between salt tolerance and photosynthetic machinery performance in citrus. Environ Exp Bot 62: 176-184

Mahalingam R, Bregitzer P (2019) Impact on physiology and malting quality of barley exposed to heat, drought and their combination during different growth stages under controlled environment. Physiol Plant 165: 277-289

Martinez V, Mestre TC, Rubio F, Girones-Vilaplana A, Moreno DA, Mittler R, Rivero RM (2016) Accumulation of Flavonols over Hydroxycinnamic Acids Favors Oxidative Damage Protection under Abiotic Stress. Front Plant Sci 7: 838

Martinez V, Nieves-Cordones M, Lopez-Delacalle M, Rodenas R, Mestre TC, GarciaSanchez F, Rubio F, Nortes PA, Mittler R, Rivero RM (2018) Tolerance to stress combination in tomato plants: New insights in the protective role of melatonin. Molecules. doi: 10.3390/molecules23030535

Mittler R (2006) Abiotic stress, the field environment and stress combination. Trends Plant Sci 11: 15-19

Mittler R, Blumwald E (2010) Genetic engineering for modern agriculture: challenges and perspectives. Annu Rev Plant Biol 61: 443-462

Mittler R, Vanderauwera S, Gollery M, Breusegem F Van Reactive oxygen gene network of plants. doi: 10.1016/j.tplants.2004.08.009

Moya JL, Gómez-Cadenas A, Primo-Millo E, Talon M (2003) Chloride absorption in salt-sensitive Carrizo citrange and salt-tolerant Cleopatra mandarin citrus rootstocks is linked to water use. J Exp Bot 54: 825-833

Moya JL, Tadeo FR, Gómez-Cadenas A, Primo-Millo E, Talón M (2002) Transmissible salt tolerance traits identified through reciprocal grafts between sensitive Carrizo and tolerant Cleopatra citrus genotypes. J Plant Physiol 159: 991-998

Murata N, Takahashi S, Nishiyama Y, Allakhverdiev SI (2007) Photoinhibition of photosystem II under environmental stress. Biochim Biophys Acta - Bioenerg 1767: 414421 
Murata Y, Mori IC, Munemasa S (2015) Diverse stomatal signaling and the signal integration mechanism. Annu Rev Plant Biol 66: 369-392

Queitsch C, Hong SW, Vierling E, Lindquist S (2000) Heat shock protein 101 plays a crucial role in thermotolerance in Arabidopsis. Plant Cell 12: 479-92

Rivero RM, Mestre TC, Mittler R, Rubio F, Garcia-Sanchez F, Martinez V (2014) The combined effect of salinity and heat reveals a specific physiological, biochemical and molecular response in tomato plants. Plant, Cell Environ 37: 1059-1073

Rossel JB, Wilson PB, Hussain D, Woo NS, Gordon MJ, Mewett OP, Howell KA, Whelan J, Kazan K, Pogson BJ (2007) Systemic and intracellular responses to photooxidative stress in Arabidopsis. Plant Cell 19: 4091-110

Ruban A V. (2015) Evolution under the sun: optimizing light harvesting in photosynthesis. J Exp Bot 66: 7-23

Saltveit ME (2000) Wound induced changes in phenolic metabolism and tissue browning are altered by heat shock. Postharvest Biol Technol 21: 61-69

Su X, Wu S, Yang L, Xue R, Li H, Wang Y, Zhao H (2014) Exogenous progesterone alleviates heat and high light stress-induced inactivation of photosystem II in wheat by enhancing antioxidant defense and D1 protein stability. Plant Growth Regul 74: 311-318

Suzuki N, Basil E, Hamilton JS, Inupakutika, Madhuri A Zandalinas SI, Tripathy D, Yuting L, Dion E, Fukui G, Kumazaki A, Nakano R, et al (2016) ABA is required for plant acclimation to a combination of salt and heat stress. PLoS One Accepted

Suzuki N, Devireddy AR, Inupakutika MA, Baxter A, Miller G, Song L, Shulaev E, Azad RK, Shulaev V, Mittler R (2015) Ultra-fast alterations in mRNA levels uncover multiple players in light stress acclimation in plants. Plant J 84: 760-772

Suzuki N, Rivero RM, Shulaev V, Blumwald E, Mittler R (2014a) Abiotic and biotic stress combinations. New Phytol 203: 32-43

Suzuki N, Rivero RM, Shulaev V, Blumwald E, Mittler R (2014b) Abiotic and biotic stress combinations. New Phytol 203: 32-43

Wasternack C, Hause B (2013) Jasmonates: biosynthesis, perception, signal transduction and action in plant stress response, growth and development. An update to the 2007 
review in Annals of Botany. Ann Bot 111: 1021-1058

Wasternack C, Stenzel I, Hause B, Hause G, Kutter C, Maucher H, Neumerkel J, Feussner I, Miersch O (2006) The wound response in tomato - Role of jasmonic acid. J Plant Physiol 163: 297-306

Wu T, Juan Y, Hsu Y, Wu S, Liao H, Fung RWM, Charng Y (2013) Interplay between Heat Shock Proteins HSP101 and HSA32 Prolongs Heat Acclimation Memory Posttranscriptionally in Arabidopsis. Plant Physiol. 161:

Yamamoto Y, Aminaka R, Yoshioka M, Khatoon M, Komayama K, Takenaka D, Yamashita A, Nijo N, Inagawa K, Morita N, et al (2008) Quality control of photosystem II: Impact of light and heat stresses. Photosynth Res 98: 589-608

Zandalinas SI, Balfagón D, Arbona V, Gómez-Cadenas A (2017) Modulation of Antioxidant Defense System Is Associated with Combined Drought and Heat Stress Tolerance in Citrus. Front Plant Sci. doi: 10.3389/fpls.2017.00953

Zandalinas SI, Balfagón D, Arbona V, Gómez-Cadenas A, Inupakutika MA, Mittler R (2016a) ABA is required for the accumulation of APX1 and MBF1c during a combination of water deficit and heat stress. J Exp Bot 67: 5381-5390

Zandalinas SI, Fritschi FB, Mittler R (2019) Signal transduction networks during stress combination. J Exp Bot. doi: 10.1093/jxb/erz486

Zandalinas SI, Mittler R, Balfagón D, Arbona V, Gómez-Cadenas A (2018) Plant adaptations to the combination of drought and high temperatures. Physiol Plant 162: 212

Zandalinas SI, Rivero RM, Martínez V, Gómez-Cadenas A, Arbona V (2016b) Tolerance of citrus plants to the combination of high temperatures and drought is associated to the increase in transpiration modulated by a reduction in abscisic acid levels. BMC Plant Biol 16: 105

Zhao C, Liu B, Piao S, Wang X, Lobell DB, Huang Y, Huang M, Yao Y, Bassu S, Ciais $\mathrm{P}$, et al (2017) Temperature increase reduces global yields of major crops in four independent estimates. Proc Natl Acad Sci U S A 114: 9326-9331 
Conclusions 

1. High temperatures change the effect of individual abiotic stresses (drought, salinity, wounding and high light intensity) on plants. Therefore, physiological, hormonal, proteomic and transcriptomic plant responses to abiotic stress are modified in warm environments.

2. Carrizo citrange is more tolerant than Cleopatra mandarin to drought and heat stress combination. This is, at least in part, due to a higher efficiency of the antioxidant machinery that prevents oxidative damage, a higher accumulation of HSP101 that confers thermotolerance and a better stomatal modulation that allows high transpiration rate and leaf cooling.

3. The change in Jasmonate accumulation in Carrizo citrange plants under wounding at high temperatures (with a reduction of JA accumulation and an increase of OPDA content with respect to wounded plants to low temperatures) indicate a switch in hormonal regulation under combined stress conditions and suggests a role to OPDA, independent from JA, to modulate acclimation responses.

4. The harmful effect of salt stress on Carrizo citrange is aggravated in combination with high temperatures due to a higher leaf chloride accumulation caused by the increase in the transpiration rate. $\mathrm{ABA}$ accumulation under salt and heat stress combination is directed to regulate stomatal closure and, in consequence, reduce transpiration. Specific JA accumulation, together with ABA, under this stress combination may be important to trigger a molecular acclimation response to salt and heat stress combination.

5. Damage produced to PSII during high light and heat stress can be fatal to plant survival. This is supported by the fact that under high light and heat stress combination, PSII efficiency is more affected and plants cannot restore it after the recovery period. In addition, degradation of D1 protein is higher at stress combination which indicates that repair and reassembly of PSII components, particularly D1 protein, are key process in Arabidopsis plants to tolerate this stress combination. 
6. Jasmonic acid plays an important role in the acclimation of Arabidopsis thaliana to a combination of high light and heat stress. This hormone triggers a specific response of genes involved in light, heat and oxidative stress acclimation. This conclusion is also supported by the behavior of the aos mutant, impaired in JA biosynthesis, which is more sensitive to light and heat stress combination and has diminished upregulation of important genes in light and heat stress acclimation. 
1. Las altas temperaturas cambian el efecto que los estreses abióticos individuales (sequía, salinidad, herida y alta intensidad de luz) causan sobre las plantas. Por lo tanto, la respuesta fisiológica, hormonal, proteómica, y transcriptómica de las plantas al estrés abiótico es modificada en situaciones de altas temperaturas.

2. Carrizo citrange es más tolerante que Cleopatra mandarin a la combinación de sequía y altas temperaturas. Esto es debido, en parte, a una mayor eficiencia del sistema antioxidante que previene el daño oxidativo, a una mayor acumulación de la proteína HSP101 que confiere termotolerancia y a una modulación estomática más adecuada que permite aumentar la transpiración y enfriar la hoja.

3. El cambio en la acumulación de jasmonatos en las plantas de Carrizo citrange sometidas a herida y altas temperaturas (reducción de JA y aumento de OPDA con respecto a las plantas heridas a temperatura control) indica un cambio en la regulación hormonal de las plantas bajo combinación de estrés y sugiere un rol del OPDA, independiente del JA, en la activación de respuestas de aclimatación.

4. El efecto dañino del estrés salino en Carrizo citrange es agravado en combinación con el estrés por calor debido a una mayor acumulación foliar de cloruros causada por el incremento de la transpiración. La acumulación de ABA bajo combinación de estrés salino y calor está dirigida a regular el cierre estomático y, en consecuencia, reducir la transpiración. La acumulación de JA, junto con el ABA, en condiciones de estrés combinado podría ser clave en la señalización de respuestas moleculares de aclimatación al estrés combinado de salinidad y calor.

5. El daño producido en el PSII durante el estrés por alta intensidad de luz y altas temperaturas puede ser fatal para la supervivencia de las plantas. Esta idea se sustenta en el hecho de que, bajo la combinación de los dos estreses, la eficiencia del PSII se ve más afectada y las plantas no pueden retomar los valores iniciales de eficiencia después de un periodo de recuperación. Además, la degradación de la proteína D1 es mayor en las plantas sometidas al estrés combinado, lo que indica que la reparación y reposición de los componentes del PSII, 
particularmente la proteína D1, son procesos clave en las plantas de Arabidopsis para tolerar esta combinación de estrés.

6. El ácido jasmónico tiene un rol importante en la aclimatación de Arabidopsis thaliana a la combinación de estrés por luz y calor. Esta hormona desencadena una respuesta genética específica a la aclimatación de luz, calor y estrés oxidativo. Además, el mutante defectivo en la síntesis de JA aos es más sensible a la combinación de estrés por luz y calor, y la activación de genes implicados en la aclimatación a estos estreses se ve disminuida en este mutante. 
1. Les altes temperatures canvien l'efecte que els estressos abiòtics individuals (sequera, salinitat, ferida i alta intensitat de llum) causen en les plantes. Per tant, la resposta fisiològica, hormonal, proteòmica i transcriptòmica de les plantes a l'estrès abiòtic és modificada en situacions d'altes temperatures.

2. Carrizo citrange és més tolerant que Cleopatra mandarin a la combinació de sequera i altes temperatures. Això es degut, en part, a un major eficiència del sistema antioxidant que preveu el dany oxidatiu, a una major acumulació de la proteïna HSP101 que confereix termotolerancia i a una modulació estomàtica més adequada que permet augmentar la transpiració y refredar la fulla.

3. El canvi en la acumulació de jasmonats en les plantes de Carrizo citrange sotmeses a ferida i altes temperatures (reducció d'JA i augment d'OPDA amb comparació a les plantes ferides a temperatura control) indica un canvi en la regulació hormonal de les plantes sotmeses a la combinació d'estrès i suggereix un rol de l'OPDA, independent de l'JA, en l'activació de respostes d'aclimatació.

4. L'efecte nociu de l'estrès salí en Carrizo citrange es engreujat en combinació amb l'estrès per calor degut a una major acumulació foliar de clorurs causada per l'increment de la transpiració. L'acumulació d'ABA en situacions de combinació d'estrès salí y calor està dirigida a regular el tancament estomàtic $i$, en consequiència, reduir la transpiració. L'acumulació d'JA, junt amb el ABA, en condicions d'estrès combinat podria ser clau en la senyalització de respostes moleculars d'aclimatació a l'estrès combinat de salinitat i calor.

5. El dany ocasionat en el PSII durant l'estrès per alta intensitat de llum i altes temperatures pot ser fatal per a la supervivència de les plantes. Aquesta idea es sustenta en el fet de que, baix la combinació dels dos estressos, l'eficiència del PSII es veu més afectada i les plantes no poden reprendre els valor inicials d'eficiència després d'un període de recuperació. A més, la degradació de la proteïna D1 es major en les plantes sotmeses a l'estrès combinat, el que indica que la reparació i reposició del components del PSII, particularment la proteïna D1, son processos clau en les plants d'Arabidopsis per tolerar aquesta combinació d'estrès. 
6. L'àcid jasmònic té un rol important en l'aclimatació d'Arabidopsis thaliana a la combinació d'estrès per llum y calor. Aquesta hormona desencadena una resposta genètica específica a l'aclimatació de llum, calor i estrès oxidatiu. A més, el mutant defectiu en la síntesis d'JA aos és més sensible a la combinació d'estrès per llum i calor, i l'activació de gens implicats en l'aclimatació a aquests estressos es veu disminuïda en aquest mutant. 
ADDENDIX 



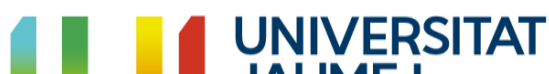 \\ JAUME I}

Escola de Doctorat · ED

Aurelio Gómez Cadenas, como coautor/ coautora doy mi autorización a Damián Balfagón Sanmartín para la presentación de las siguientes publicaciones como parte de su tesis doctoral.

Relación de publicaciones:

Zandalinas SI, Balfagón D, Arbona V, Gómez-Cadenas A. 2017. Modulation of Antioxidant Defense System Is Associated with Combined Drought and Heat Stress Tolerance in Citrus. Frontiers in Plant Science 8: 953.

Balfagón D, Zandalinas SI, Baliño P, Muriach M, Gómez-Cadenas A. 2018. Involvement of ascorbate peroxidase and heat shock proteins on citrus tolerance to combined conditions of drought and high temperatures. Plant Physiology and Biochemistry 127: 194-199.

Balfagón D, Zandalinas SI, Gómez-Cadenas A (2019) High temperatures change the perspective: Integrating hormonal responses in citrus plants under co-occurring abiotic stress conditions. Physiologia Plantarum 165: 183-197.

Balfagón D, Sengupta S, Gómez-Cadenas A, Fritschi FB, Azad R, Mittler R, Zandalinas SI. 2019. Jasmonic acid is required for plant acclimation to a combination of high light and heat stress. Plant Physiology 181: 1668-1682.

Balfagón D, Zandalinas SI, Mittler R, Gómez-Cadenas A. 2020. High temperatures modify plant responses to abiotic stress conditions. Physiologia Plantarum Submitted

Asimismo, renuncio a poder utilizar estas publicaciones como parte de otra tesis doctoral.

Y para que conste firmo el presente documento,

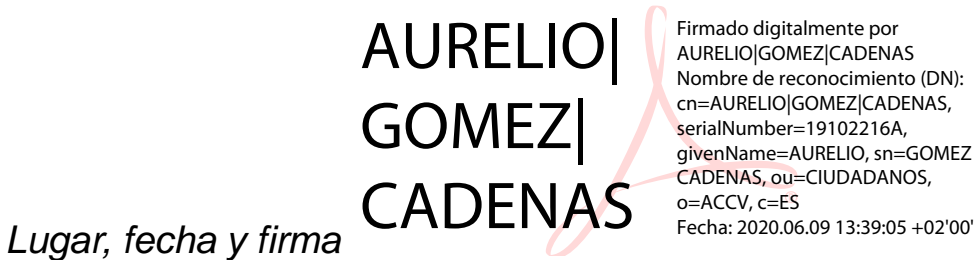

Todo ello, atendiendo al artículo 23 de la Normativa de los Estudios de Doctorado, regulados por el RD 99/2011, en la Universitat Jaume I (Aprobada por el Consejo de Gobierno núm. 19 de 26 de Enero de 2012, modificada por el Consejo de Gobierno núm. 29 de 27 de Noviembre de 2012 y con posterior modificación por el Consejo de Gobierno núm. 37 de 25 de Julio de 2013):

$$
\text { “(...) }
$$

"Aquellas tesis doctorales que opten por la incorporación de artículos (compendio de publicaciones) deben de ajustarse, en la medida de lo posible, a la siguiente estructura: -Introducción/objetivos - Un capítulo por artículo incorporado - Discusión general de los resultados - Conclusiones. -Aceptación de los coautores de que el doctorando presente el trabajo como tesis y renuncia expresa de estos a presentarlo como parte de otra tesis doctoral." 


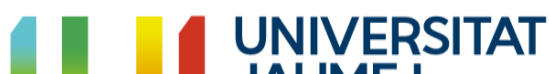 \\ JAUME I}

Escola de Doctorat · ED

Sara Izquierdo Zandalinas, como coautor/ coautora doy mi autorización a Damián Balfagón Sanmartín para la presentación de las siguientes publicaciones como parte de su tesis doctoral.

Relación de publicaciones:

Zandalinas SI, Balfagón D, Arbona V, Gómez-Cadenas A. 2017. Modulation of Antioxidant Defense System Is Associated with Combined Drought and Heat Stress Tolerance in Citrus. Frontiers in Plant Science 8: 953.

Balfagón D, Zandalinas SI, Baliño P, Muriach M, Gómez-Cadenas A. 2018. Involvement of ascorbate peroxidase and heat shock proteins on citrus tolerance to combined conditions of drought and high temperatures. Plant Physiology and Biochemistry 127: 194-199.

Balfagón D, Zandalinas SI, Gómez-Cadenas A (2019) High temperatures change the perspective: Integrating hormonal responses in citrus plants under co-occurring abiotic stress conditions. Physiologia Plantarum 165: 183-197.

Balfagón D, Sengupta S, Gómez-Cadenas A, Fritschi FB, Azad R, Mittler R, Zandalinas SI. 2019. Jasmonic acid is required for plant acclimation to a combination of high light and heat stress. Plant Physiology 181: 1668-1682.

Balfagón D, Zandalinas SI, Mittler R, Gómez-Cadenas A. 2020. High temperatures modify plant responses to abiotic stress conditions. Physiologia Plantarum Submitted

Asimismo, renuncio a poder utilizar estas publicaciones como parte de otra tesis doctoral.

Y para que conste firmo el presente documento,

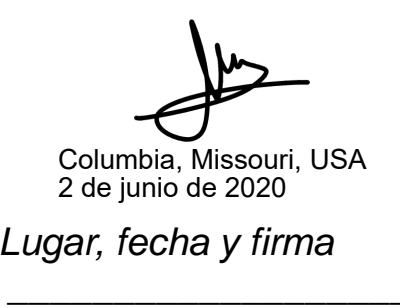

Todo ello, atendiendo al artículo 23 de la Normativa de los Estudios de Doctorado, regulados por el RD 99/2011, en la Universitat Jaume I (Aprobada por el Consejo de Gobierno núm. 19 de 26 de Enero de 2012, modificada por el Consejo de Gobierno núm. 29 de 27 de Noviembre de 2012 y con posterior modificación por el Consejo de Gobierno núm. 37 de 25 de Julio de 2013):

$$
\text { “(...) }
$$

"Aquellas tesis doctorales que opten por la incorporación de artículos (compendio de publicaciones) deben de ajustarse, en la medida de lo posible, a la siguiente estructura: -Introducción/objetivos - Un capítulo por artículo incorporado - Discusión general de los resultados - Conclusiones. -Aceptación de los coautores de que el doctorando presente el trabajo como tesis y renuncia expresa de estos a presentarlo como parte de otra tesis doctoral." 


\section{UNIVERSITAT \\ JAUME I}

Escola de Doctorat · ED

Vicent Arbona, como coautor doy mi autorización a Damián Balfagón Sanmartín para la presentación de las siguientes publicaciones como parte de su tesis doctoral.

Relación de publicaciones:

Zandalinas SI, Balfagón D, Arbona V, Gómez-Cadenas A. 2017. Modulation of Antioxidant Defense System Is Associated with Combined Drought and Heat Stress Tolerance in Citrus. Frontiers in Plant Science 8: 953.

Asimismo, renuncio a poder utilizar estas publicaciones como parte de otra tesis doctoral.

Y para que conste firmo el presente documento,

Castelló de la Plana, 1 de Juny de 2020

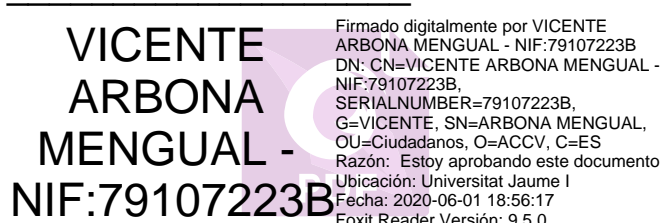

Todo ello, atendiendo al artículo 23 de la Normativa de los Estudios de Doctorado, regulados por el RD 99/2011, en la Universitat Jaume I (Aprobada por el Consejo de Gobierno núm. 19 de 26 de Enero de 2012, modificada por el Consejo de Gobierno núm. 29 de 27 de Noviembre de 2012 y con posterior modificación por el Consejo de Gobierno núm. 37 de 25 de Julio de 2013):

$$
\text { "(...) }
$$

"Aquellas tesis doctorales que opten por la incorporación de artículos (compendio de publicaciones) deben de ajustarse, en la medida de lo posible, a la siguiente estructura: -Introducción/objetivos - Un capítulo por artículo incorporado - Discusión general de los resultados - Conclusiones. -Aceptación de los coautores de que el doctorando presente el trabajo como tesis y renuncia expresa de estos a presentarlo como parte de otra tesis doctoral." 


\section{UNIVERSITAT \\ JAUME I}

Escola de Doctorat · ED

María Muriach Sauri, como coautor/ coautora doy mi autorización a Damián Balfagón Sanmartín para la presentación de las siguientes publicaciones como parte de su tesis doctoral.

Relación de publicaciones:

Balfagón D, Zandalinas SI, Baliño P, Muriach M, Gómez-Cadenas A. 2018. Involvement of ascorbate peroxidase and heat shock proteins on citrus tolerance to combined conditions of drought and high temperatures. Plant Physiology and Biochemistry 127: 194-199.

Asimismo, renuncio a poder utilizar estas publicaciones como parte de otra tesis doctoral.

Y para que conste firmo el presente documento,

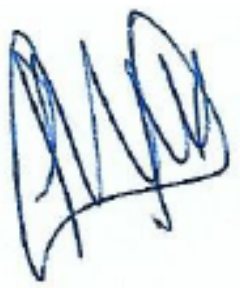

Castellón, 1 de Junio de 2020

Lugar, fecha y firma

Todo ello, atendiendo al artículo 23 de la Normativa de los Estudios de Doctorado, regulados por el RD 99/2011, en la Universitat Jaume I (Aprobada por el Consejo de Gobierno núm. 19 de 26 de Enero de 2012, modificada por el Consejo de Gobierno núm. 29 de 27 de Noviembre de 2012 y con posterior modificación por el Consejo de Gobierno núm. 37 de 25 de Julio de 2013):

$$
\text { “(...) }
$$

"Aquellas tesis doctorales que opten por la incorporación de artículos (compendio de publicaciones) deben de ajustarse, en la medida de lo posible, a la siguiente estructura: -Introducción/objetivos - Un capítulo por artículo incorporado - Discusión general de los resultados - Conclusiones. -Aceptación de los coautores de que el doctorando presente el trabajo como tesis y renuncia expresa de estos a presentarlo como parte de otra tesis doctoral." 


\section{UNIVERSITAT \\ JAUME I}

Escola de Doctorat · ED

Pablo Baliño Remiro como coautor doy mi autorización a Damián Balfagón Sanmartín para la presentación de las siguientes publicaciones como parte de su tesis doctoral.

Relación de publicaciones:

Balfagón D, Zandalinas SI, Baliño P, Muriach M, Gómez-Cadenas A. 2018. Involvement of ascorbate peroxidase and heat shock proteins on citrus tolerance to combined conditions of drought and high temperatures. Plant Physiology and Biochemistry 127: 194-199.

Asimismo, renuncio a poder utilizar estas publicaciones como parte de otra tesis doctoral.

Y para que conste firmo el presente documento,

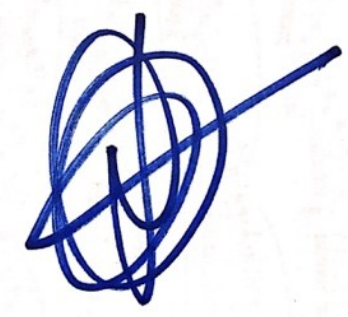

Lugar, fecha y firma

Todo ello, atendiendo al artículo 23 de la Normativa de los Estudios de Doctorado, regulados por el RD 99/2011, en la Universitat Jaume I (Aprobada por el Consejo de Gobierno núm. 19 de 26 de Enero de 2012, modificada por el Consejo de Gobierno núm. 29 de 27 de Noviembre de 2012 y con posterior modificación por el Consejo de Gobierno núm. 37 de 25 de Julio de 2013):

$$
\text { “(...) }
$$

"Aquellas tesis doctorales que opten por la incorporación de artículos (compendio de publicaciones) deben de ajustarse, en la medida de lo posible, a la siguiente estructura: -Introducción/objetivos - Un capítulo por artículo incorporado - Discusión general de los resultados - Conclusiones. -Aceptación de los coautores de que el doctorando presente el trabajo como tesis y renuncia expresa de estos a presentarlo como parte de otra tesis doctoral." 
I, Ron Mittler, hereby authorise Damián Balfagón Sanmartín to include the publications listed below in his doctoral thesis. In addition, I waive the right to use those articles as part of any other doctoral thesis.

List of articles:

Balfagón D, Sengupta S, Gómez-Cadenas A, Fritschi FB, Azad R, Mittler R, Zandalinas SI. 2019. Jasmonic acid is required for plant acclimation to a combination of high light and heat stress. Plant Physiology 181: 1668-1682.

Balfagón D, Zandalinas SI, Mittler R, Gómez-Cadenas A. 2020. High temperatures modify plant responses to abiotic stress conditions. Physiologia Plantarum Accepted

Signed,

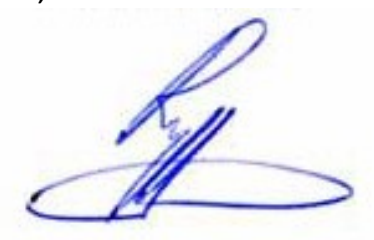

In accordance with article 23 of the Regulation of Doctoral Studies, regulated by RD 99/2011, at the Universitat Jaume I (Approved by the Governing Council No. 19 of January 26, 2012, modified by the Governing Council no. 29 of November 27, 2012 and subsequent amendment by the Governing Council No. 37 of July 25, 2013):"(...) "Those doctoral theses that opt for the incorporation of articles (compendium of publications) must include the acceptance of the co-authors of the publications that have waived the right to present them as a part of another PhD thesis" 
I, Felix B. Fritschi, hereby authorise Damián Balfagón Sanmartín to include the publications listed below in his doctoral thesis. In addition, I waive the right to use those articles as part of any other doctoral thesis.

List of articles:

Balfagón D, Sengupta S, Gómez-Cadenas A, Fritschi FB, Azad R, Mittler R, Zandalinas SI. $2019 \mathrm{~b}$. Jasmonic acid is required for plant acclimation to a combination of high light and heat stress. Plant Physiology 181: 1668-1682.

Signed,

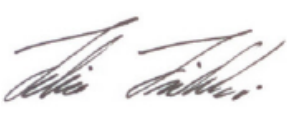

\author{
Dr. Felix B Fritschi \\ C. Alice Donaldson Professor \\ University of Missouri \\ Division of Plant Sciences
}

In accordance with article 23 of the Regulation of Doctoral Studies, regulated by RD 99/2011, at the Universitat Jaume I (Approved by the Governing Council No. 19 of January 26, 2012, modified by the Governing Council no. 29 of November 27, 2012 and subsequent amendment by the Governing Council No. 37 of July 25, 2013):"(...) "Those doctoral theses that opt for the incorporation of articles (compendium of publications) must include the acceptance of the co-authors of the publications that have waived the right to present them as a part of another PhD thesis" 
I, Soham Sengupta, hereby authorise Damián Balfagón Sanmartín to include the publications listed below in his/her doctoral thesis. In addition, I waive the right to use those articles as part of any other doctoral thesis.

List of articles:

Balfagón D, Sengupta S, Gómez-Cadenas A, Fritschi FB, Azad R, Mittler R, Zandalinas SI. 2019b. Jasmonic acid is required for plant acclimation to a combination of high light and heat stress. Plant Physiology 181: 1668-1682.

Signed,

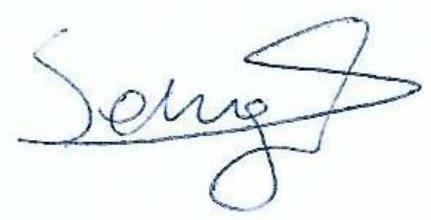

In accordance with article 23 of the Regulation of Doctoral Studies, regulated by RD 99/2011, at the Universitat Jaume I (Approved by the Governing Council No. 19 of January 26, 2012, modified by the Governing Council no. 29 of November 27, 2012 and subsequent amendment by the Governing Council No. 37 of July 25, 2013):"(...) "Those doctoral theses that opt for the incorporation of articles (compendium of publications) must include the acceptance of the co-authors of the publications that have waived the right to present them as a part of another PhD thesis" 


\section{UNIVERSITAT}

Escola de Doctorat · ED

June 7, 2020

I, Rajeev K Azad, as a co-author of the following publication with Damián Balfagón Sanmartín, allow Damián to include this publication in his doctoral thesis, indicating his contributions in this research article. In addition, I waive the right to use this article as part of any other doctoral thesis.

Publication:

Balfagón D, Sengupta S, Gómez-Cadenas A, Fritschi FB, Azad R, Mittler R, Zandalinas SI. $2019 \mathrm{~b}$. Jasmonic acid is required for plant acclimation to a combination of high light and heat stress. Plant Physiology 181: 1668-1682.

Sincerely,

Rajeev K. Azad, Ph.D. Associate Professor

Department of Biological Sciences Department of Mathematics University of North Texas

1155 Union Cir, Denton, TX 76203

940-369-5078

rajeev.azad@unt.edu 



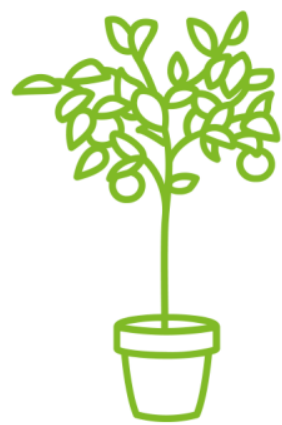

U UNIVERSITAT

1 JAUME.I 